DEPARTAMENTO DE ECONOMÍA AGRARIA, ESTADÍSTICA Y GESTIÓN DE EMPRESAS

UNIVERSIDAD POLITÉCNICA DE MADRID

ESCUELA TÉCNICA SUPERIOR DE INGENIEROS AGRÓNOMOS

\title{
LAS PATENTES Y LOS NUEVOS PRODUCTOS EN LA INDUSTRIA AGROALIMENTARIA ESPAÑOLA
}

\section{Luís González Polonio}

Ingeniero Agrónomo

$$
\text { Director }
$$

D. Silverio Alarcón Lorenzo

Doctor Ingeniero Agrónomo

2016 



\title{
A PILAR
}

\begin{abstract}
Sentí tu mano en la mía, tu mano de compañera tu voz de niña en mi oído como una campana nueva, como una campana virgen de un alba de primavera.
\end{abstract}

A. Machado

A la memoria de mi padre, Luis González Hazañas, ejemplo siempre al que echo tanto de menos 



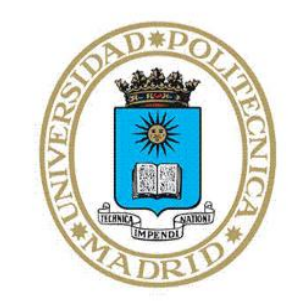

\title{
UNIVERSIDAD POLITÉCNICA DE MADRID
}

Tribunal nombrado por el Magnífico y Excelentísimo Sr. Rector de la Universidad Politécnica de Madrid, el día 14 de julio de 2016.

Presidente: D. Pedro Arias Martín. Profesor titular de universidad. ETSI Agrónomos Universidad Politécnica de Madrid (UPM)

Vocal: D. Rodolfo Bernabéu Cañete. Profesor titular de universidad. ETSI Agrónomos y de Montes de Albacete - Universidad de Castilla - La Mancha (UCLM)

Vocal: Dạ Mạ Ramona Barrena Figueroa. Profesora contratada Doctora. ETSI Agrónomos - Universidad Pública de navarra (UPNA)

Vocal: Dạ Amparo Baviera Puig. Profesora contratada Doctor. Facultad de Administración y Dirección de Empresas - Universidad Politécnica de Valencia (UPV)

Secretario: D. Arturo Serrano Bermejo. Profesor titular de universidad. ETSI Agrónomos - Universidad Politécnica de Madrid (UPM)

Suplente: Dạ Mạ Mercedes Sánchez García. Profesora titular de universidad. ETSI Agrónomos - Universidad Pública de Navarra (UPNA)

Suplente: D. José Mạ García Álvarez-Coque. Catedrático de universidad. ETS de Ingeniería Agronómica y del Medio Natural -Universidad Politécnica de Valencia (UPV)

Realizado el acto de defensa y lectura de la Tesis el día 20 de julio de 2016 en la Escuela Técnica Superior de Ingenieros Agrónomos de Madrid.

EL PRESIDENTE

LOS VOCALES

\author{
EL SECRETARIO
}





\section{PRÓLOGO}

La innovación en los sistemas productivos se considera un factor con una alta capacidad para mejorar la posición en el mercado de las empresas según las teorías dedicadas al crecimiento económico. Teorías que han ido evolucionando a lo largo de la historia adaptándose a diferentes situaciones tanto políticas como sociales o tecnológicas. El sector industrial es en mayor medida el responsable de trasladar a la sociedad los avances tecnológicos que la ciencia le proporciona.

La innovación en el sistema agroalimentario español precisa de análisis por parte de los investigadores en aras de un mejor conocimiento del tejido que conforma dentro del sector industrial español. Resulta difícil encontrar estudios que analicen el sector agroindustrial español desde el enfoque que en este trabajo se realiza. Sin embargo la producción literaria relacionada con otros aspectos, como por ejemplo la seguridad alimentaria, sí ha sido bastante desarrollada.

La aparición en las últimas décadas de bases de datos que posibilitan estos estudios ha permitido que de manera conjunta o incluso en sectores concretos se hayan llevado a cabo análisis de la estructura y comportamiento de las empresas industriales. Estas bases dan a conocer datos que son fundamentales para el esclarecimiento de las estrategias empresariales. Por otro lado, las innovaciones en los recursos que se emplean en la actualidad para el tratamiento de datos y la evolución de la econometría favorecen también el desarrollo de este tipo de trabajos aportando rapidez y precisión a la hora de trabajar con una gran cantidad de datos.

En este contexto, el sector agroindustrial debe participar en el mantenimiento de un sistema de innovación que proporcione a medio y largo plazo un beneficio que redunde en la sociedad, innovando en productos que permitan mejorar la calidad de vida; en procesos que mejoren la calidad ambiental atendiendo al correcto uso de los recursos naturales y la reducción de costes; y en la organización empresarial mejorando las relaciones, los servicios, la comercialización y la distribución.

Lograr un mejor funcionamiento del sector agroindustrial implica una actuación de la administración pública, dotándolo de normativas que por un lado impulsen 
eficientemente el sistema de innovación, y por otro lado, que corrija los fallos de mercado que se ocasionan cuando el origen de la innovación es un bien intangible como es el conocimiento, que se considera el paso previo a la innovación llevada a cabo por la industria.

La protección de la innovación como recurso legal pretende motivar a través de su apropiación a las empresas que la realizan y a su vez corregir el fallo de mercado al que nos referíamos en el párrafo anterior.

Las Tecnologías de la Información y la Comunicación (TICs) han variado el marco que se ha descrito hasta hace no poco tiempo. Las posibilidades que ofrecen han permitido que las relaciones comerciales se hayan globalizado de tal manera que han trastocado las relaciones tradicionales ampliando un mercado que era en realidad un mercado de potenciales clientes a otro, el actual, en el que han pasado a ser clientes reales o al menos con una mayor posibilidad de captación.

No se debe olvidar uno de los mayores problemas con el que nos enfrentamos en la actualidad, la afectación del medioambiente por parte de los sectores industriales que desafortunadamente hasta ahora es uno de los mayores contribuyentes.

No quiero terminar este prólogo sin dejar constancia de mi agradecimiento personal a las personas que de alguna manera me han ayudado y animado a llevar a cabo este proyecto.

En primer lugar al Profesor D. Silverio Alarcón Lorenzo, director de esta Tesis, gracias por el apoyo y la confianza que me ha demostrado a lo largo de este periodo. La realización de este tipo de trabajos lleva a sufrir pero también a momentos muy satisfactorios y enriquecedores.

A mi amigo Luis Miguel Juárez, gracias por haberme escuchado durante todo este tiempo, haber confiado y animado.

A todos aquellos que han sido mis profesores y compañeros de estudios, en especial a Mariano García Briones y a Nacho Valdés Paniagua, gracias porque de 
alguna manera habéis contribuido a la realización de la Tesis Doctoral. A todos los recuerdo de una manera muy grata.

A mi familia, mi madre "Ange" y mis hermanos, Salvador, Keka, Marta (a su memoria), Jose y Ana. A mis cuñados, Marta de Paula y David Fernández y a una interminable lista de sobrinos, Raúl, Lucas, Sara, Lucía, Luís, Clara, Elena, Estér, Marta, Leo, Vega y Aitor.

A Pilar y a mis hijos Nicolás y Candela, a partir de ahora seré más vuestro, perdonad si os habéis sentido en cierto modo abandonados en algún momento.

Gracias a todos. 

ÍNDICE Y LISTAS 

Tabla de contenido

PRÓLOGO VII

TABLAS XVII

GRÁFICOS XXI

DIAGRAMAS $X X V$

ACRÓNIMOS XXVII

ABSTRACT XXIX

1. INTRODUCCIÓN 3

1.1. Objeto de estudio: La inNovación 3

1.2. OBJETIVOS DE LA INVESTIGACIÓN Y PREGUNTAS 6

1.3. Relevancia de la inVestigación 8

1.4. AlCANCE de LA INVESTigación 9

1.5. PUblicACIONES Y PRESENTACIONES A CONGRESOS 11

1.6. ESTRUCTURA DE LA TESIS 12

2. MARCO TEÓRICO 17

2.1. CONCEPTO DE INNOVACIÓN 17

2.2. CLASIFICACIÓN DE LA INNOVACIÓN 23

2.3. LA IMPORTANCIA DE LA INNOVACIÓN 26

2.3.1. EL MERCADO DEL CONOCIMIENTO 29

2.4. TEORÍAS ECONÓMICAS RELACIONADAS CON LA INNOVACIÓN EMPRESARIAL 33

2.4.1. Teoría del Crecimiento económico: de los Clásicos a la Teoría del CRECIMIENTO ENDÓGENO 38

2.4.2. TEORía de los RECURSOS y CAPACIDADES 40 
2.4.3. TEORÍA DE LA ORGANIZACIÓN INDUSTRIAL 42

2.5. MAPA CONCEPTUAL DE LA INNOVACIÓN EMPRESARIAL 45

2.5.1. EL SUBMODELO DE LA ESTRUCTURA EMPRESARIAL 47

2.5.2. EL SUBMODELO DE LA ESTRATEGIA EMPRESARIAL 47

2.5.3. EL SUBMODELO DE LA APROPIACIÓN DE LA INNOVACIÓN 48

2.6. INVESTIGACIÓN EMPÍRICA GENERAL 49

2.7. INVESTIGACIÓN EMPÍRICA EN EL SECTOR AGROINDUSTRIAL 54

2.8. HiPÓTESIS DE INVESTIGACIÓN 58

2.8.1. LA RELACIÓN DEL GASTO EN I+D CON EL REGISTRO DE PATENTES. 60

2.8.2. LA RELACIÓN DE LA COOPERACIÓN TECNOLÓGICA CON EL REGISTRO DE PATENTES. 61

2.8.3. LA RELACIÓN DE OTROS ACTIVOS COMPLEMENTARIOS CON LA PROPENSIÓN A PATENTAR 63

2.8.4. RESUMEN DE HIPÓTESIS 64

3. MODELOS ECONOMÉTRICOS DE CONTEO 69

3.1. MÉTOdO DE REGRESIÓN LINEAL 70

3.2. REVISIÓN DE MODELOS ECONOMÉTRICOS PARA DATOS DE CONTEO 72

3.2.1. EL MODELO DE REGRESIÓN DE POISSON 73

3.2.2. El MODELO DE REGRESIÓN BINOMIAL NEGATIVA 74

3.2.3. EL MODELO CERO INFLADO 75

3.2.4. El MODELO DE REGRESIÓN HURDLE 76

3.2.5. DATOS DE PANEL 77

4. FUENTES DE INFORMACIÓN 83

4.1. EnCUESTA SObre EStrategias EMPRESARIALES (ESEE) 84

4.1.1. CARACTERÍSTICAS DE LA ENCUESTA 89

4.1.2. ESTRUCTURA DE LA ENCUESTA 91

4.1.3. DATOS DE LA ENCUESTA 92

4.2. Panel de InNovación TeCnológica (PITEC) 101

4.2.1. CARACTERÍSTICAS DE LA ENCUESTA 104

4.2.2. ESTRUCTURA DE LA ENCUESTA 105

4.2.3. DATOS DE LA ENCUESTA 107 
5.1. Planteamiento técnico del problema 123

5.2. VARIABLES 124

5.3. ESPECIFICACIÓN ECONOMÉTRICA DE LOS MODELOS 130

5.3.1. ESPECIFICACIÓN DEL MODELO ECONOMÉTRICO (CASO EMPíRICO 1) 130

5.3.2. ESPECIFICACIÓN DEL MODELO ECONOMÉTRICO (CASO EMPÍRICO 2) 132

5.3.3. ESPECIFICACIÓN DEL MODELO ECONOMÉTRICO (CASO EMPÍRICO 3) 134

6. RESULTADOS 137

6.1. Resultados del CASO 1. Variable explicada: Número de Patentes 137

6.2. ResUltados del CASO 2. VAR. EXPLICADA: № DE INNOVACIONES EN PRODUCTO. 147

6.3. RESULTADOS DEL CASO 3: VARIABLE EXPLICADA: NÚMERO DE PATENTES, MODELOS DE UTILIDAD Y MARCAS DE FÁBRICA 152

7. CONCLUSIONES 161

7.1. LIMITACIONES DE LA INVESTIGACIÓN 166

7.2. SUGERENCIAS PARA FUTURAS INVESTIGACIONES 166

BIBLIOGRAFÍA 171

APÉNDICE 1: Estrategia ESPAÑola de CIENCIA Y TECNOLOGía Y dE INNOVACIÓN 2013-2020 183

APÉNDICE 2: DEFINICIONES 185

APÉNDICE 3: ANÁLISIS ESTADÍSTICO (ESEE) 189

APÉNDICE 4: ANÁLISIS ESTADístico (PITEC) 191

APÉNDICE 5: SALIDAS DEL PROGRAMA ESTADíSTICO R. CASO EMPÍRICO 2 198 APÉNDICE 6: SALIDAS DEL PROGRAMA ESTADístico R. CASO EMPÍRICO 3. 207 



\section{TABLAS}

Tabla 1: No de Tesis Doctorales leídas en España con diferentes palabras

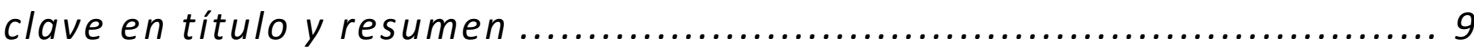

Tabla 2: Definiciones del concepto de innovación ..........................20

Tabla 3: Definiciones de innovación según investigadores .................21

Tabla 4: Clasificación de la innovación .....................................23

Tabla 5: Clasificación de los fallos sistémicos del Sistema de Innovación 30

Tabla 6: Clasificación fallos de mercado del Sistema de Innovación......31

Tabla 7: Clasificación del conocimiento y de las patentes como bienes

Tabla 8: Objetivos de los tratados de libre comercio (TLC) ................. 35

Tabla 9: Principales etapas, autores y sus aportaciones ................... 36

Tabla 10: Teorías clásicas de crecimiento económico ......................40

Tabla 11: Escenarios de análisis de la cadena de valor ......................44

Tabla 12: Resumen de Trabajos revisados................................ 50

Tabla 13: Efectos esperados para cada una de las hipótesis planteadas.

Tabla 14: Modelos econométricos para datos de conteo 70

Tabla 15: Fuentes de información industrial en España 84 
Tabla 16: Participación en la encuesta ESEE .86

Tabla 17: Empresas que participan en la encuesta. (1.998-2.008) 88

Tabla 18: Ficha técnica de la Encuesta Sobre Estrategias Empresariales

Españolas .89

Tabla 19: Clasificación Sectorial. Correspondencia entre CNAE-93 Y

CNAE-2009 90

Tabla 20: Participación en la encuesta del PITEC. 103

Tabla 21: Ficha técnica del panel de innovación tecnológico (PITEC) .. 105

Tabla 22: Resumen de las variables explicativas de los modelos.... 129

Tabla 23: Coeficiente de correlación (Spearman) 138

Tabla 24: Resultado del modelo 2. Variables explicativas GEID y GIID.

Variable explicada: PAT

Tabla 25: Resultado del modelo 3. Variable explicativa: Cooperación.

Variable explicada: PAT

Tabla 26: Resultado de la estimación del modelo quasipoisson de efectos fijos (variable dependiente: número de patentes) 143

Tabla 27: Resultado de la estimación del modelo quasipoisson de efectos aleatorios (variable dependiente: número de patentes) 144

Tabla28: Estimación de la regresión binomial negativa. Variable explicada: no de innovaciones en producto (IPR) 148 
Tabla29: Estimación de la regresión binomial negativa. Variable

explicada: $n$ o de innovaciones en product (IP) Por subsectores 150

Tabla30: Estimación de la regresión binomial negativa. Variable

explicada: $n$ o de innovaciones en product (IP) (B2B) Por subsectores. 151

Tabla 31: Coeficiente de correlación (Spearman)

Tabla 32: Resultado de la estimación del modelo binomial (Logit) Efectos fijos (TODAS).

Tabla 33: Resultado de la estimación del modelo binomial (Logit) Efectos aleatorios (TODAS) 157

Tabla 34: Objetivos generales y específicos de la estrategia española de ciencia tecnología y de innovación 184

Tabla 35: Número de empresas de la muestra 189

Tabla 36: Gastos externos en I+D en Ia IAA 189

Tabla 37: Gastos internos en I+D en Ia IAA 190

Tabla 38: Número de empresas que innovan en producto (IP) y en proceso (IPR) en Ia IAA.... 190

Tabla 39: Número de empresas del Panel 191

Tabla 40: Número de empresas totales del Panel 191

Tabla 41: Número de empresas con gastos internos en I+D y Media de los gastos en $1+D$

Tabla 42: Cooperación en IAA 192 
Tabla 43: Cooperación en RESTO de empresas 193

Tabla 44: Cooperacion en sector agrario 193

Tabla 45: Tabla de datos de innovación en producto en IAA 194

Tabla 46: Tabla de datos de innovación en producto en RESTO de empresas 194

Tabla 47: Tabla de datos de innovación en producto en Agricultura ... 195

Tabla 48: Tabla de datos de innovación en proceso en IAA 195

Tabla 49: Tabla de datos de innovación en producto en RESTO de empresas 196

Tabla 50: Tabla de datos de innovación en producto en Agricultura ... 196

Tabla 51: Tabla de datos de protecciones en IAA, RESTO y Agricultura 197 


\section{GRÁFICOS}

Gráfico 1: Porcentaje del PIB en gastos en I+D en la Unión Europea (2014).

Gráfico 2: Gastos en innovación en el sector agroalimentario español.

“2002-2009"

Gráfico 3: Evolución de empresas que participan en la encuesta 85

Gráfico 4: Relación entre el no de empresas y el no de años de participación en la encuesta ESEE

Gráfico 5: Número de empresas de la muestra

Gráfico 6: Número de patentes en España (PATESP) y en el extranjero

(PATEXT) en el período 1998-2008. Sector agroindustrial

Gráfico 7: Número de patentes en el período 1998-2008 en el Sector

Manufacturero.

Gráfico 8: Gastos Internos y Externos en I+D/ no empresa en sector agroalimentario 94

Gráfico 9: Evolución del número de empresas que realizan gastos internos y externos en $1+D$ en la muestra del sector agroalimentario....95 Gráfico 10: Evolución del no de empresas que llevan a cabo algún tipo de colaboración (Sector agroindustrial) ................................... 96

Gráfico 11: Evolución del número de innovaciones en producto (IP) y en proceso (IPR) en la muestra del sector agroalimentario español 96 
Gráfico 12: Porcentajes de empresas con dominio propio en Internet (PYMES)

Gráfico 13: Porcentaje de empresas con dominio propio en Internet (Grandes) 98

Gráfico 14: Evolución de las TIC en PYMES. 100

Gráfico 15: Evolución de las TIC en empresas grandes 100

Gráfico 16: Evolución del número de empresas del PITEC.... 102

Gráfico 17: Evolución del número de empresas de la muestra en el sector agrario (AGRO), la industria agroalimentaria (IAA) y del resto de los sectores (RESTO) 107

Gráfico 18: Evolución del uso de protecciones en empresas agroalimentarias 108 Gráfico 19: Evolución del uso de protecciones en el resto del sector... 109 Gráfico 20: Evolución de los diferentes tipos de patentes en las empresas agroalimentarias 111

Gráfico 21: Evolución de los diferentes tipos de patentes en el resto de empresas

Gráfico 22: Evolución del número de empresas que realizan gastos en actividades de $1+D$ internas y externas en las empresas agroalimentarias.

Gráfico 23: Evolución del número de empresas que realizan gastos en actividades de $1+D$ internas y externas en el resto de empresas. 
Gráfico 24: Evolución de los gastos en actividades de I+D internas y externas en empresas agroalimentarias

Gráfico 25: Evolución de los gastos en actividades de I+D internas y externas en el resto de empresas.

Gráfico 26: Evolución del número de empresas que realizan cooperación para actividades de $1+D$

Gráfico 27: Evolución del no innovaciones en producto en las empresas agroalimentarias.

Gráfico 28: Evolución del no innovaciones en producto en el resto de empresas.

Gráfico 29: Evolución del no innovaciones en proceso en las empresas agroalimentarias.

Gráfico 30: Evolución del no innovaciones en proceso en el resto de empresas.

Gráfico 31: Evolución de las actividades innovadora en curso o no exitosas.

Gráfico 32: Número de patentes en España y en el extranjero

Gráfico 33: Porcentaje de empresas con I+D o cooperación tecnológica 

DIAGRAMAS

Diagrama 1: Estructura del documento 14

Diagrama 2: Objetivos principales de cada tipo de innovación. 25

Diagrama 3: Evolución de las teorías relacionadas con la innovación ...38

Diagrama 4: Mapa Conceptual de la Innovación Empresarial 46

Diagrama 5: Diagrama de Ishikawa (causa-efecto).... 130

Diagrama 6: Diagramas de correlación entre las variables 155 

ACRÓNIMOS

\begin{tabular}{|c|c|}
\hline CNAE - & Clasificación Nacional de Actividades Económicas \\
\hline EUROSTAT - & Oficina de Estadística de la Unión Europea \\
\hline ESEE - & Encuesta Sobre Estrategias Empresariales \\
\hline $\mathrm{FCIA}-$ & Fichero Coordinado de Industrias Agroalimentarias \\
\hline FECYT - & Fundación Española para la Ciencia y la Tecnología \\
\hline FIAB - & Federación Española de Industrias Alimentarias y Bebidas \\
\hline$I+D+i-$ & Investigación, Desarrollo e innovación \\
\hline INE - & Instituto Nacional de Estadística \\
\hline MEA - & Modelo Efectps Aleatorios \\
\hline MEF - & Modelo Efectps Sijos \\
\hline MLG - & Modelo Lineal Generalizado \\
\hline OCDE - & Organización de Cooperación y Desarrollo Económico \\
\hline PIB - & Producto Interior Bruto \\
\hline PITEC - & Panel de Innovación Tecnológica \\
\hline PYMES - & Pequeñas y medianas empresas \\
\hline RBV - & Resource-Based View \\
\hline SEPI - & Sociedad Estatal de Participación Industrial \\
\hline TIC - & Tecnologías de la Información y la Comunicación \\
\hline
\end{tabular}



ABSTRACT

To understand the agro-food production sector is necessary among other things the study of innovation through output innovation indicators. This research analyzes the evolution over the years 1998 and 2012 of two indicators such as patents and the launch of new products on the food market.

This Thesis presents the results of three empirical studies whose overall objective is to identify statistically significant factors related to these output innovation indicators.

The methodological approach adopted is based on the specification and estimation of econometric models that use count explicative variables. The characterization of innovation in the agrofood sector has been obtained from PITEC the ESEE surveys.

The results show the significant contribution of technological cooperation in the production of new products and demand for patents and other forms of protection. This contribution is higher in SMEs than in large enterprises. The results also suggest the relevant role of both $R \& D$ internal and external. 



\section{RESUMEN}

Para entender el sector productivo agroalimentario es necesario entre otros aspectos estudiar su innovación a través de indicadores de resultados de la innovación (outputs). Esta investigación analiza la evolución, entre los años 1998 y 2012, de dos indicadores como son las patentes y la aparición de nuevos productos en el mercado de alimentos.

Esta Tesis presenta los resultados de tres estudios empíricos cuyo objetivo general es identificar estadísticamente los factores relacionados de manera significativa con estos indicadores de output de la innovación.

El enfoque metodológico que se ha adoptado se basa en la especificación y estimación de modelos econométricos que utilizan variables explicadas de conteo. La caracterización de la innovación del sector agroalimentario se ha obtenido de las bases de datos ESEE y PITEC.

Los resultados muestran la significativa contribución de la cooperación tecnológica a la producción de nuevos productos y la demanda de patentes y otras formas de protección. Dicha contribución es mayor en las pymes que en las grandes empresas. Los resultados también apuntan al papel relevante de ambas $I+D$, tanto interna como externa. 

Capítulo 1

INTRODUCCIÓN 



\section{INTRODUCCIÓN}

En los siguientes apartados se presentan el objeto de estudio y los objetivos de la investigación, así como su relevancia a partir de la cual se pretende justificar su realización su alcance y la estructura del documento.

\subsection{Objeto de estudio: la innovación}

La preocupación de los investigadores por el crecimiento económico de los países a nivel macro y de las empresas a nivel microeconómico ha generado una cantidad enorme de literatura empírica.

En este sentido, los análisis tratan de diagnosticar los problemas del sector industrial analizando el comportamiento de las empresas y en particular, el de los factores relacionados con sus estrategias competitivas.

Asociar crecimiento económico con industrialización tiene sentido si tenemos en cuenta que es el sector industrial el que introduce un mayor número de progresos técnicos de los que la economía se beneficia. La bajada de costes de producción, disminución de mano de obra para su producción serían algunos de los efectos de la innovación.

En este tipo de trabajos científicos sobre innovación se utilizan indicadores relacionados con diversos ámbitos de la estructura empresarial - contable, técnicos, humanos, etc.- para valorar la influencia de diferentes factores empresariales sobre los procesos innovadores. Esto proporciona una evidencia empírica que permite identificar los factores internos y externos que son relevantes a la hora de llevar a cabo estrategias empresariales. 
En este trabajo se pretenden analizar dichas estrategias en el sector agroindustrial español para lo cual es importante que se aborde desde una perspectiva que considere la particularidad de este sector e incluir todos aquellos factores que han demostrado ser relevantes en otros sectores puesto que el objetivo final en cualquier sector económico es obtener una rentabilidad económica superior a la que se obtiene antes de llevar a cabo la innovación.

La importancia del sector agroindustrial como productor de bienes y servicios es innegable. Bienes necesarios de primer orden para la alimentación humana y animal y servicios tanto medioambientales también necesarios de primer orden-que permitan la sostenibilidad del planeta, así como sociales relacionados con el empleo que permite el crecimiento económico y el desarrollo de las zonas rurales.

Dentro del ámbito de la economía de la empresa, no tanto en el sector agroindustrial, se ha producido un intenso trabajo por parte de los investigadores que ha posibilitado el debate sobre cómo la innovación empresarial afecta a la productividad de las empresas y al desarrollo económico y social.

El gasto en I+D ha experimentado, a lo largo de las últimas décadas, un aumento que ha llevado a esta partida a ser una de las más importantes en empresas de un determinado tamaño. Conocer el valor que los distintos factores que conforman una empresa confieren al resultado final del proceso, calculado como valor añadido, a la larga redundará en las empresas aportando argumentos para el desarrollo e instrumentalización de políticas gubernamentales destinadas a impulsar la innovación dentro del sector industrial.

El sector agroindustrial está considerado, tanto en España como en la Unión Europea, como un sector estratégico. Su aportación al producto interior bruto (PIB) y el alto porcentaje de población que 
están empleadas en el sector y en sectores auxiliares directamente relacionados con este avalan esta consideración.

Aunando ambos aspectos, brevemente descritos en los dos párrafos anteriores, y teniendo en cuenta la falta de estudios que relacionan la innovación y el sector agroindustrial se ha considerado interesante la incorporación al estado de la materia actual esta aportación que se presenta.

La metodología empleada en la investigación empírica ha consistido en la elaboración de un marco teórico de estudio a través de una revisión bibliográfica que incluye el planteamiento de las hipótesis. Un segundo análisis también realizado a partir de una revisión de los métodos econométricos susceptibles de ser usados para el tipo de datos con los que se va a trabajar. Una vez llevados a cabo ambos análisis se exponen las aplicaciones prácticas fruto de la investigación que han sido publicadas.

Este trabajo está enfocado en aspectos muy concretos relacionados con la innovación como son, por un lado la innovación en proceso y producto y por otro lado, las diversas formas de apropiación de las innovaciones. Para este propósito se establece un marco general que nos permitirá tener una visión global de las empresas y en particular de todos aquellos factores de que dispone la empresa, tanto internos como externos, que entrarían a formar parte del conjunto de variables explicativas que, en mayor o menor medida, determinarían el hecho de llevar a cabo o no innovación en procesos o en productos y más adelante la protección de las innovaciones llevadas a cabo por las empresas.

Un aspecto llamativo de este debate es la importancia que los distintos gobiernos, independientemente de su signo político, atribuyen a la innovación. La mayoría de los países, tanto desarrollados como en vías de desarrollo, otorgan a la Investigación, el Desarrollo y la 
innovación $(I+D+i)$ una gran relevancia al introducir en sus políticas estrategias y planes para mejorar la competitividad. En el caso español, es relevante la Estrategia para la Economía Sostenible aprobada en noviembre de 2009, que entre otras incluye la Ley de la Ciencia, la Tecnología y la Innovación. Además, también se ha desarrollado la Estrategia Estatal de Innovación, estrategia que aborda el problema aunando a todos los actores y recursos participantes en los procesos de innovación.

En conclusión, y dada la preocupación que genera la sostenibilidad económica y el crecimiento económico, este trabajo pretende analizar la situación del sector agroindustrial español a partir de un indicador como es la innovación que es clave para garantizar tanto el crecimiento como la sostenibilidad económica. En concreto se estudian los recursos que disponen las empresas para fomentar y proteger el fruto obtenido gracias a la inversión dedicada a la investigación, el desarrollo y la innovación.

\subsection{Objetivos de la investigación y preguntas}

El objetivo último de la presente investigación es identificar y cuantificar aquellos factores que están relacionados con la culminación de los procesos innovadores en las empresas agroindustriales españolas en los últimos años.

El desarrollo de la investigación se realiza desde una perspectiva integrada, que incluye un análisis de la problemática objeto del trabajo y de los métodos y técnicas econométricas necesarias para dicho análisis. 
Por lo tanto, se ofrece un marco para el análisis que va a permitir determinar la especificación de los modelos econométricos al objeto de valorar la significatividad de los factores.

Los objetivos intermedios que se consideran para tratar de alcanzar el objetivo general son los siguientes:

(1) Realizar una revisión de la innovación en el sector agroalimentario español que permita:

(2) Llevar a cabo la elaboración del marco teórico

(3) Identificar los factores relacionado con los procesos innovadores.

(4) Realizar una revisión de los modelos econométricos de conteo que nos permita conocer el nivel en el que se encuentran el estado de la ciencia en cuestiones econométricas.

A la hora de plantear el problema de investigación se considera esencial delimitar claramente los objetivos de la misma, las preguntas que se pretenden contestar y por último justificar la investigación.

El objeto de la investigación ha sido ya introducido en el apartado anterior y las preguntas que se derivan directamente de ellos y a las que la presente investigación pretende responder son las siguientes:

¿Qué factores están relacionados con la decisión de las empresas agroalimentarias para llevar a cabo procesos de innovación tanto de proceso como de producto?

Y, una vez que la empresa ha tomado la decisión de llevar a cabo dichos procesos innovadores, ¿Con qué factores se relaciona la decisión empresarial de proteger dichas innovaciones? 


\subsection{Relevancia de la investigación}

La justificación de la investigación se basa en la necesidad de realizar análisis dentro del sector agroindustrial español que puedan aportar un grado de conocimiento superior permitiendo mejorar el tejido industrial agrario. El conocimiento del comportamiento del sector es fundamental a la hora de elaborar políticas de mejora de la competitividad empresarial.

Por otra parte, y no menos importante, la constante evolución a nivel mundial de un sector que como ya se ha comentado es estratégico tanto en la economía española como en la europea y que además incide en importantes aspectos como el social y el medioambiental, hace necesaria la actuación del Estado. Esta evolución es fruto de la actuación de la Unión Europea que toma cartas en el asunto para ordenar los subsectores industriales y potenciar la competitividad de las empresas europeas para no perder posiciones en mercados internos y externos a causa de la globalización de la economía.

Por otro lado, en el ámbito de tesis doctorales, podemos justificar el presente trabajo una vez consultada la base de datos TESEO donde se pueden clasificar las Tesis Doctorales leídas en España consideradas aptas desde el año 1976.

Mediante la búsqueda avanzada en la aplicación del Ministerio de Educación, Cultura y Deporte, introduciendo diferentes palabras que puedan estar incluidas en el título y en el resumen de la tesis se ha elaborado la Tabla 1 que refleja el número de tesis doctorales leídas en España. La fecha en la que se ha consultado la base de datos es febrero de 2016. 
Tabla 1: № de Tesis Doctorales leídas en España con diferentes palabras clave en título y resumen

\begin{tabular}{|l|c|c|}
\hline \multicolumn{2}{|c|}{ Palabras incluidas en título y resumen } & $\begin{array}{c}\text { No de tesis } \\
\text { encontradas }\end{array}$ \\
\hline Innovación & Innovación & 1479 \\
\hline Innovación & Sector Agroalimentario & 254 \\
\hline & Patentes & 27 \\
\hline \multicolumn{2}{|c|}{ Modelos de utilidad } & 1 \\
\hline
\end{tabular}

El cuadro anterior nos da idea de la escasez de investigación que se ha llevado a cabo a nivel de doctorado en el sector agroalimentario español. Tan sólo 5 tesis doctorales aparecen cuando se incluyen las palabras innovación y sector agroalimentario. En conclusión, el cuadro indica el carácter novedoso del tema dentro del área considerada.

Para terminar de justificar el trabajo, el preámbulo de la Ley de 20 de marzo de 1986, Número 11/1986 de patentes de invención y modelos de utilidad (B.O.E. de 26 de marzo de 1986) considera necesario el impulso de la innovación tecnológica que permita elevar el nivel de competitividad de la industria española. Esta ley nace con el propósito de proteger eficazmente los resultados de las investigaciones constituyendo por otro lado un elemento necesario de la política española de fomento de la investigación y el desarrollo tecnológico.

\subsection{Alcance de la investigación}

El alcance de esta investigación se puede considerar triple si tenemos en cuenta lo ya expuesto con anterioridad. 
Primero, consideramos el alcance exploratorio de la investigación. Aunque el tema ha sido estudiado para el conjunto de sectores que conforman el espectro industrial español, no lo ha sido tanto en cuanto al estudio de los subsectores y en concreto al agroindustrial español que es el que nos ocupa.

Segundo, un alcance descriptivo. Gracias a las bases de datos, se hace posible la especificación de las propiedades de las empresas que participan en la encuesta y el uso de la estadística descriptiva nos permite medir las variables estudiadas en la investigación.

Tercero, el alcance correlacional. Dicho alcance nos permite obtener las conclusiones una vez determinada la influencia de las variables explicativas (causas hipotéticas) sobre las variables explicadas (efectos).

Por último, un cuarto alcance que se podría considerar en esta investigación, pero que no se hace, sería el alcance explicativo donde se buscan las causas de los efectos producidos que se han obtenido tras el estudio correlacional.

El alcance de la investigación en términos de localización geográfica se circunscribe a España y temporalmente al periodo 19982012.

Los tres enfoques que abarca el trabajo de investigación responden a tres periodos distintos:

Un primer periodo, 1998-2008, en el que se identifican los factores asociados a la innovación en la industria agroalimentaria española tomando el registro de patentes como un indicador de innovación. 
En un segundo periodo, 2000-2008, en el que se identifican los recursos y estrategias asociadas con la introducción de nuevos productos en la industria agroalimentaria española.

Y un tercer y último periodo, 2003-2012, en el que se modelizan las opciones más empleadas para proteger las innovaciones en función de los esfuerzos en I+D de las empresas agroalimentarias.

\subsection{Publicaciones y presentaciones a congresos}

A lo largo del periodo de investigación que ha dado como resultado el presente documento se han publicado un artículo en una revista científica y el capítulo de un libro, ambos con su respectiva revisión externa por parte de investigadores independientes.

En cuanto a los congresos a los que se han presentado las comunicaciones, estos son tres realizados en diferentes lugares entre España, Portugal y Chile. A continuación se enumeran cada uno de ellos distinguiendo entre publicaciones y presentaciones a congresos.

\section{Publicaciones}

Alarcón, S., González-Polonio, L.; (2014) Patents, research \& development and technological cooperation in the Spanish agri-food industry. New Medit, Mediterranean Journal of Economics, Agriculture and Environement. Vol. XIII, n3/2014 (Índice de impacto JCR en 2014 0,377 (Q3) en la categoría AGRICULTURE, MULTIDISCIPLINARY).

Alarcón, S., González-Polonio, L. Sánchez, M.; (2014) E-Innovation for Sustainable Development of Rural Resources During Global Economic Crisis. Chapter 14: Strategies for the Development of New Products in the Spanish Agri-Food Industry. IGI Global 


\section{Presentaciones a congresos}

Alarcón, S. González-Polonio, L.; (2011) Factores explicativos del uso de patentes en el sector agroalimentario español. III Congreso Regional de Economía Agraria, Valdivia, Chile, 9-11 de noviembre 2011

Alarcón, S., González Polonio, L.; (2012) Estrategias para el desarrollo de nuevos productos en la industria agroalimentaria. IX Coloquio Ibérico de Estudios Rurales. Lisboa, Portugal. 27-29 de julio 2012.

Alarcón, S. González-Polonio, L.; (2015). La protección de las innovaciones en la industria agroalimentaria española. X Congreso de Economía Agraria. Córdoba, España, 9-11 de Septiembre 2015.

\subsection{Estructura de la tesis}

Al objeto de alcanzar los objetivos propuestos y una vez introducido el presente trabajo, el resto del documento se estructura de la siguiente manera:

En el capítulo 2, se expone el marco teórico a partir de la revisión bibliográfica que nos permite conocer el estado de la cuestión y poder de esta manera justificar el enfoque metodológico seguido para el análisis de las estrategias empresariales. En primer lugar se exponen aspectos generales del tema como el concepto, la clasificación y la importancia de la innovación. En segundo lugar, se incluyen referencias a las teorías económicas relacionadas con la innovación y además se expone la investigación empírica. La tercera parte del capítulo plantea las hipótesis de partida que serán contrastadas para la obtención de los resultados empíricos. 
El capítulo 3, se establece el marco instrumental en el que se apoya la investigación. Se presentan las técnicas empleadas para el análisis de los datos tras una revisión de los modelos econométricos de conteo (Count Data Model) que más se han utilizado para este tipo de análisis. En esta sección se abordan los modelos econométricos aplicables en los casos en los que la variable explicada de los modelos son de tipo conteo, Poisson, Binomial negativa, Hurdle.

En el capítulo 4 se exponen las fuentes de información empleadas en la investigación conteniendo un análisis de las variables utilizadas en la misma. En particular, se hace referencia a las dos Bases de Datos elaboradas en España, la Encuesta Sobre Estrategias Empresariales (ESEE) y el Panel de Innovación Tecnológica (PITEC). La naturaleza de los datos de ambas fuentes nos permite realizar el seguimiento del desarrollo de las actividades tecnológicas de las empresas españolas disponiendo de paneles de datos a nivel nacional y una frecuencia anual. Además, se realiza una descripción de la muestra examinando las principales características relacionadas con la innovación.

A continuación, el capitulo 5 , en el que en primer lugar se describen las variables seleccionadas en base a la teoría económica y a los trabajos revisados. $Y$, en segundo lugar, se construyen los modelos de estrategias a partir de especificaciones de modelos econométricos para los tres casos empíricos llevados a cabo a lo largo del periodo doctoral.

En el capítulo 6 se exponen los resultados obtenidos del ajuste de los modelos econométricos propuestos. Entre estos, podemos resaltar la importancia de los gastos internos y externos en I+D y la cooperación tecnológica según sea el tamaño de la empresa.

El capítulo 7, expone las conclusiones más relevantes que se derivan de la presente investigación extraídas de las aplicaciones 
empíricas. Además se incluyen las limitaciones y la propuesta de investigación futura.

Por último se recogen la bibliografía y los apéndices del trabajo de investigación.

Diagrama 1: Estructura del documento

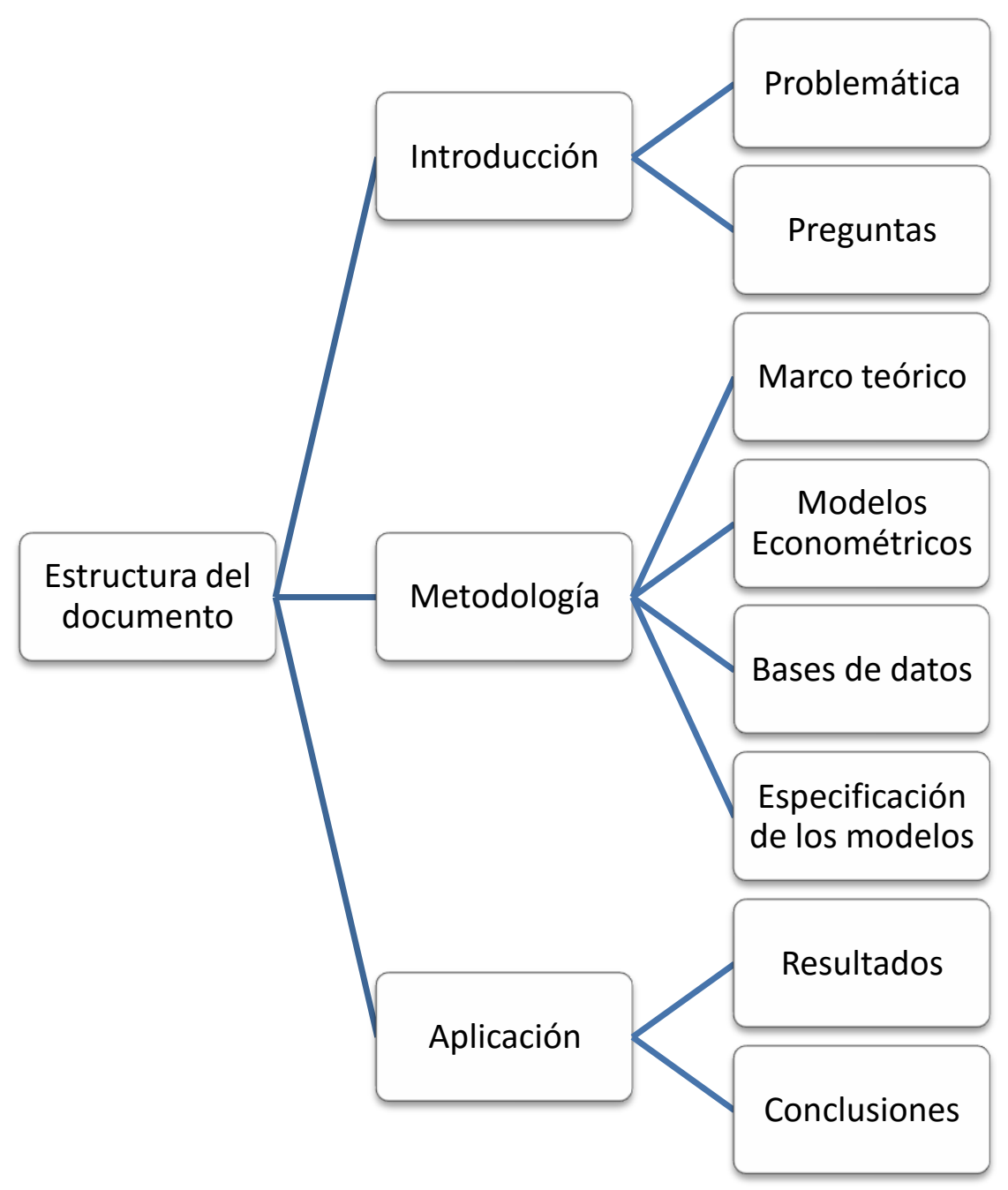

Fuente: Elaboración propia 
Capítulo 2

Marco TEÓRICO 



\section{MARCO TEÓRICO}

El objetivo de este capítulo es configurar un marco teórico que sustente la investigación llevada a cabo.

Para ello se ha hecho una revisión bibliográfica de artículos en revistas de impacto y libros que están relacionados con la innovación empresarial. A continuación, en el siguiente apartado, se hace una breve revisión cronológica del concepto de innovación y una clasificación de los tipos de innovaciones. A continuación se abordan los diferentes enfoques teóricos más importantes que son aplicables al análisis de la innovación. Con todo ello, lo que se pretende es justificar la elección de la hipótesis que son desarrolladas en el siguiente apartado. Por último, se presenta el mapa conceptual propuesto como modelo empresarial.

Para concluir, cabe señalar que la extensión de este capítulo, tanto en tiempo como en espacio, daría para otro trabajo independiente. La proliferación de teorías a lo largo del tiempo rebasa con creces la ambición de este trabajo.

\subsection{Concepto de innovación}

La supervivencia de las empresas dado el clima de alta competitividad que existe en los mercados hace necesario que las empresas aborden estrategias que respondan a las exigencias de los consumidores. Por otro lado e íntimamente ligado, la internacionalización empresarial que se ha impuesto en el entramado comercial global hace que las estrategias empresariales enfocadas hacía la innovación sean todavía más necesarias. Es por esto que las empresas se ven obligadas a innovar. 
La I+D+i dentro del marco europeo forma parte de uno de los objetivos para el año 2020, la creación del Espacio Europeo de Investigación (EEI) dentro de la Unión de la Innovación. En el Gráfico 1 se puede observar el porcentaje del PIB en gasto en I+D de los países de la Unión Europea. La media de la Unión alcanza el 2.03 \% y, tan sólo tres de los Estados miembros, Finlandia (3.78 \%), Suecia (3.37\%) y Dinamarca (3.09\%), alcanzan el objetivo. Muy próximo a la objetivo se encuentran Austria (2.99\%) y Alemania (2.87 \%). Nueve países se encuentran por debajo del $1,00 \%$ entre los que destacan Chipre y Rumanía con menos del $0.50 \%$.

Gráfico 1: Porcentaje del PIB en gastos en I+D en la Unión Europea (2014)

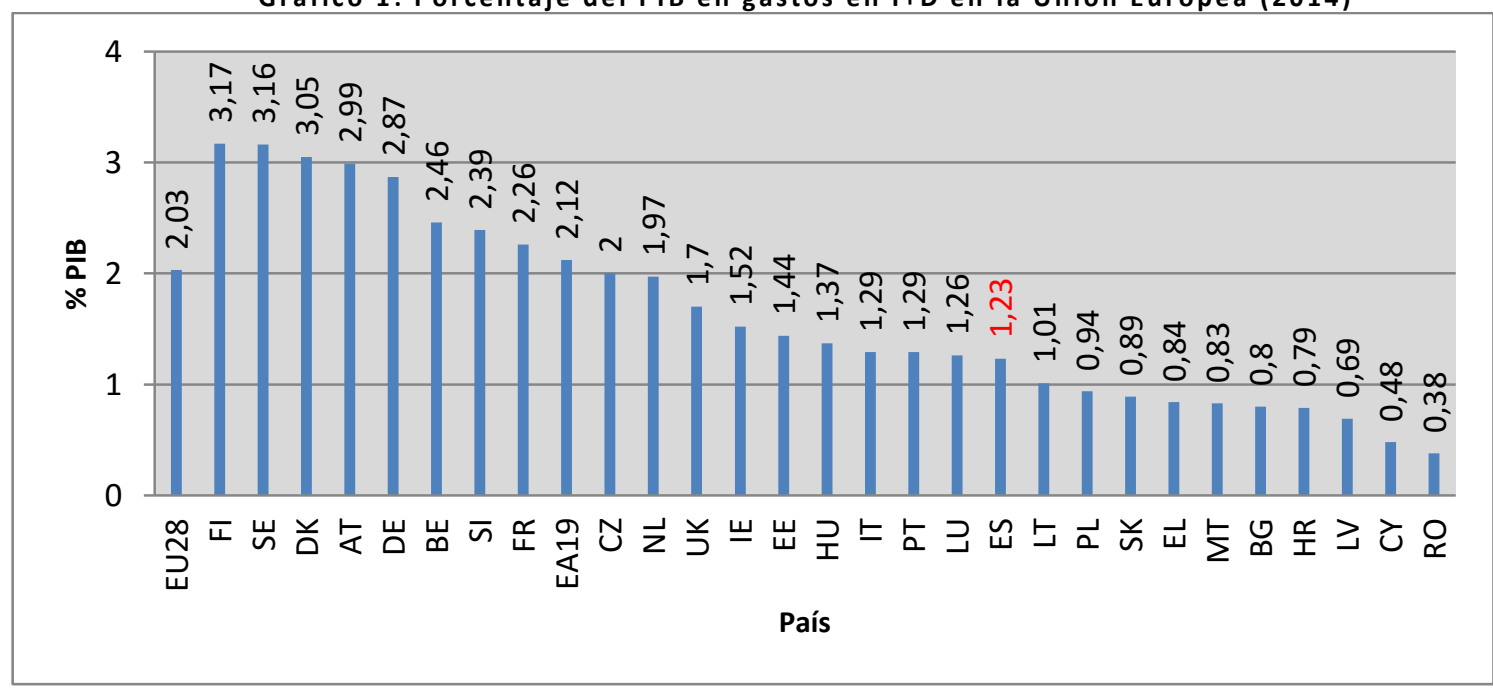

Fuente: Eurostat

En el caso de España (1.23\%), el porcentaje se sitúa 0.80 puntos por debajo de la media de la Unión Europea. En este contexto, la UE se ha planteado como objetivo dentro de la estrategia Europa 2020 alcanzar el 3 \% del PIB en I+D. A través del programa Horizonte 20142020 en el que se proponen las medidas que la Comisión Europea y con una dotación de 80 billones de euros está previsto que el objetivo se cumpla en el año 2020. Se cuenta con la creación de un mercado único del conocimiento, la investigación y la innovación.

La Unión Europea prevé que si se alcanza para el año 2020 el objetivo de que se invierta el 3 \% del PIB en cada país de la UE en I+D, 
cuando se alcance el año 2025 el número de empleos que se generará será de o 3.7 millones.

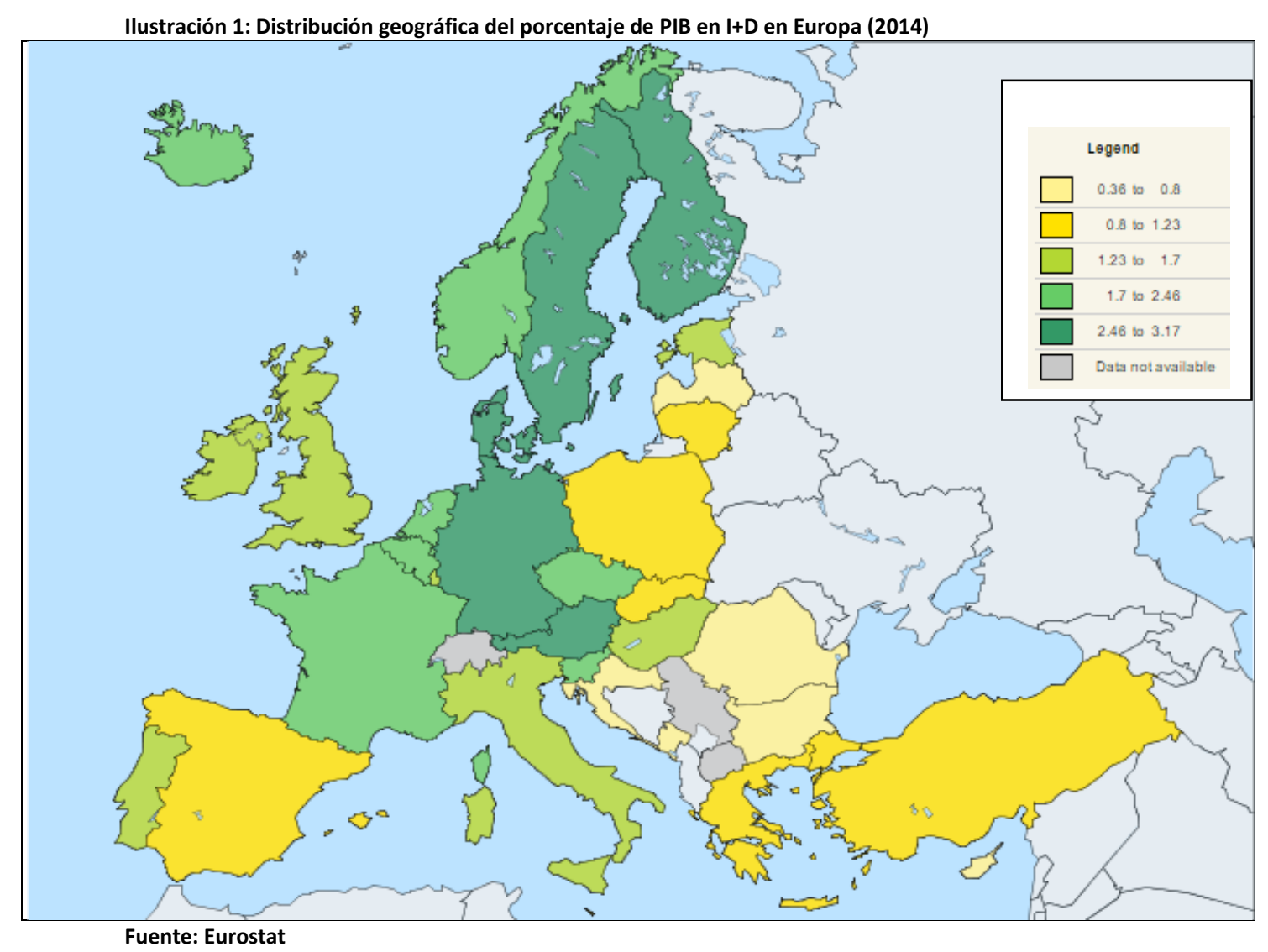

De forma general, la innovación empresarial consiste en la introducción de alguna novedad. Llevar a cabo algún tipo de innovación es, ante todo, una manera de diferenciarse del resto de actores que participan en la producción de un mismo bien o servicio. Esta diferenciación puede ser incorporada tanto al proceso de producción como al propio producto e incluso a la organización de las propias empresas.

En la Tabla 2 que se presenta a continuación se pueden observar las diferentes definiciones de innovación que han sido propuestas por diferentes instituciones u organismos desde el año 1992 hasta el año 2006. 
Tabla 2: Definiciones del concepto de innovación

\begin{tabular}{|c|c|c|}
\hline Organismo & Año & Definición de innovación \\
\hline R.A.E. & 1.992 & $\begin{array}{l}\text { Creación o modificación de un producto, y su } \\
\text { introducción en un mercado. }\end{array}$ \\
\hline $\begin{array}{c}\text { Libro blanco de } \\
\text { CE }\end{array}$ & 1.993 & $\begin{array}{l}\text { Innovación es sinónimo de producir, asimilar y explotar } \\
\text { con éxito una novedad, en las esferas económica y social, } \\
\text { de forma que aporte soluciones inéditas a los problemas y } \\
\text { permita así responder a las necesidades de las personas y } \\
\text { de la sociedad }\end{array}$ \\
\hline $\begin{array}{l}\text { Unión Europea } \\
\text { (Libro Verde de } \\
\text { Innovación) }\end{array}$ & 1.995 & $\begin{array}{l}\text { Renovación y ampliación de la gama de productos y } \\
\text { servicios, y de los mercados asociados; la instauración de } \\
\text { nuevos métodos de producción, suministro y distribución; } \\
\text { la introducción de cambios en la gestión, la organización } \\
\text { del trabajo, así como en las condiciones de trabajo y las } \\
\text { calificaciones de los trabajadores }\end{array}$ \\
\hline $\begin{array}{l}\text { O.C.D.E. (1 a } \\
\text { Edición del } \\
\text { Manual de } \\
\text { Oslo) }\end{array}$ & $19 \varsigma$ & $\begin{array}{l}\text { Innovar es utilizar el conocimiento, y generarlo si es } \\
\text { necesario, para crear productos, servicios o procesos, que } \\
\text { son nuevos para la empresa, o mejorar los ya existentes, } \\
\text { consiguiendo con ello tener éxito en el mercado }\end{array}$ \\
\hline $\begin{array}{l}\text { O.C.D.E. (3a } \\
\text { Edición del } \\
\text { Manual de } \\
\text { Oslo) }\end{array}$ & 2.005 & $\begin{array}{l}\text { Innovación es la implementación de un producto (bien o } \\
\text { servicio) o proceso nuevo o con un alto grado de mejora, } \\
\text { o un método de comercialización u organización nuevo } \\
\text { aplicado a las prácticas de negocio, al lugar de trabajo o a } \\
\text { las relaciones externas. }\end{array}$ \\
\hline $\begin{array}{l}\text { AENOR (UNE } \\
166.000)\end{array}$ & 2.006 & $\begin{array}{l}\text { Actividad que tiene como resultado la obtención de } \\
\text { nuevos productos o procesos, o mejoras sustancialmente } \\
\text { significativas de los ya existentes. }\end{array}$ \\
\hline
\end{tabular}

Fuente: "La innovación: factor clave del sector empresarial" (Gómez y Calvo: 2010)

A lo largo del periodo comprendido entre el año 1992 y 2006 la definición de innovación ha ido completándose incluyendo además del ámbito empresarial el social. 
Por otro lado, atendiendo a los diferentes autores que a lo largo del tiempo han investigado la innovación empresarial podemos elaborar otra tabla (Tabla 3), esta con las definiciones de innovación en la que cada uno pone el énfasis en un aspecto concreto. La extensión de esta lista real, si contuviese todas las posibles definiciones que se pueden encontrar en la literatura existente al respecto sería interminable.

Tabla 3: Definiciones de innovación según investigadores

\begin{tabular}{|c|c|c|}
\hline Investigador & año & definición \\
\hline $\begin{array}{l}\text { Michael A. West y } \\
\text { James L. Farr. }\end{array}$ & 1990 & $\begin{array}{l}\text { Innovación es la secuencia de actividades por las } \\
\text { cuales un nuevo elemento es introducido en una } \\
\text { unidad social con la intención de beneficiar la } \\
\text { unidad, una parte de ella o a la sociedad en su } \\
\text { conjunto. El elemento no necesita ser } \\
\text { enteramente nuevo o desconocido a los } \\
\text { miembros de la unidad, pero debe implicar algún } \\
\text { cambio discernible o reto en el status quo. }\end{array}$ \\
\hline Nystrom & 1990 & $\begin{array}{l}\text { Conocimiento que se traduce en nuevos } \\
\text { productos, nuevos procesos y servicios para } \\
\text { mejorar la ventaja competitiva y satisfacer las } \\
\text { necesidades de los clientes }\end{array}$ \\
\hline Rogers & 1990 & $\begin{array}{l}\text { Idea, práctica u objeto percibido como nuevo } \\
\text { por un individuo u otra unidad de adopción. }\end{array}$ \\
\hline Bello & 1992 & $\begin{array}{l}\text { Conjunto de actividades que llevan a la } \\
\text { introducción con éxito en el mercado de una } \\
\text { idea, en forma de nuevos o mejorados } \\
\text { productos, procesos, servicios o técnicas de } \\
\text { gestión yorganización. }\end{array}$ \\
\hline Carnegie y Butlin & 1993 & $\begin{array}{l}\text { Es algo nuevo o mejorado realizado por una } \\
\text { empresa con el fin de crear valor añadido de } \\
\text { manera significativa ya sea directamente para la } \\
\text { empresa o directamente para sus clientes. }\end{array}$ \\
\hline
\end{tabular}




\begin{tabular}{|c|c|c|}
\hline Crawford y Voss & 1994 & $\begin{array}{l}\text { La innovación en producto implica una } \\
\text { innovación en proceso. }\end{array}$ \\
\hline Kuczmarski & 1996 & $\begin{array}{l}\text { Es un valor empresarial, una actitud permanente } \\
\text { y modo de pensar y actuar de las empresas que } \\
\text { va más allá del momento presente, creando así } \\
\text { una visión de organización orientada al futuro. }\end{array}$ \\
\hline Drucker & 1998 & $\begin{array}{l}\text { Es el esfuerzo de crear un cambio útil centrado } \\
\text { en el potencial económico social de la empresa. }\end{array}$ \\
\hline Livingstone el al. & 1998 & $\begin{array}{l}\text { Son aquellos productos o procesos nuevos que } \\
\text { generan valor incluyendo desde las patentes } \\
\text { hasta aquellos productos de nuevo desarrollo } \\
\text { que generan un uso creativo de la información y } \\
\text { mejora de la gestión de los recursos humanos. }\end{array}$ \\
\hline $\begin{array}{l}\text { Abramson y } \\
\text { Littman }\end{array}$ & 2002 & $\begin{array}{l}\text { Aquello que representa algo nuevo y provoca } \\
\text { cambios en la forma en que una organización o } \\
\text { parte de ella opera y entrega sus productos al } \\
\text { mercado. }\end{array}$ \\
\hline $\begin{array}{l}\text { Munuera y } \\
\text { Rodríguez }\end{array}$ & 2002 & $\begin{array}{l}\text { La innovación en producto como la creación de } \\
\text { un producto o servicio original que se introduce } \\
\text { en el mercado con la finalidad de satisfacer una } \\
\text { necesidad. En proceso es la que evoca la } \\
\text { novedad en los procesos o sistemas de } \\
\text { fabricación, gestión, organización } \\
\text { comercialización de un producto o servicio. }\end{array}$ \\
\hline
\end{tabular}

Fuente: Elaborado a partir de Sánchez Pérez, Galera Quiles et al. (2007)

La innovación, desde una serie de disciplinas académicas, se ha planteado como un elemento clave en la consecución del desarrollo económico (Méndez, 2002). Desde el campo de la economía, la historia, la sociología, la empresa se ha estudiado el rol que en cada uno de ellos representa. 


\subsection{Clasificación de la innovación}

La clasificación elegida se muestra en la Tabla 4 y se ha elaborado a partir de la tercera edición del Manual de Oslo. En este se dividen en cuatro los tipos de innovación que se llevan a cabo en la empresa: innovaciones en producto, innovaciones en proceso, innovaciones organizativas y por último innovaciones en mercadotecnia.

Tabla 4: Clasificación de la innovación

Desarrollo productos Nuevos bienes o servicios

Procesos

Métodos de producción

Distribución

Prácticas empresariales

Innovaciones organizativas

Organización de la empresa

Organización de las relaciones externas

Diseño o envasado de producto

Método de asignación de precios

Innovaciones de mercadotecnia

Colocación del producto

Promoción

Fuente: Libro blanco de la UE

La innovación en producto se considera a aquella que incorpora un producto nuevo o un producto mejorado de manera significativa tanto técnica como funcionalmente. Se incluyen además las innovaciones en nuevos servicios y sus mejoras significativas como ocurre con los productos.

La innovación en proceso, al igual que en el caso de la innovación en producto, abarca tanto los nuevos procesos como las mejoras significativas de los procesos. 
Se considera que una empresa lleva a cabo una innovación en la organización cuando realiza cambios en los métodos organizativos en cuanto a las prácticas propias de la empresa y sus relaciones exteriores.

Por último, las innovaciones relacionadas con la mercadotecnia basada en la introducción de nuevos métodos de comercialización. Incluye aspectos como el diseño y la promoción entre otros.

En el Diagrama 2 que a continuación se representa se establecen los principales objetivos de cada uno de los cuatro tipos de innovación que se han considerado anteriormente. 
Diagrama 2: Objetivos principales de cada tipo de innovación.

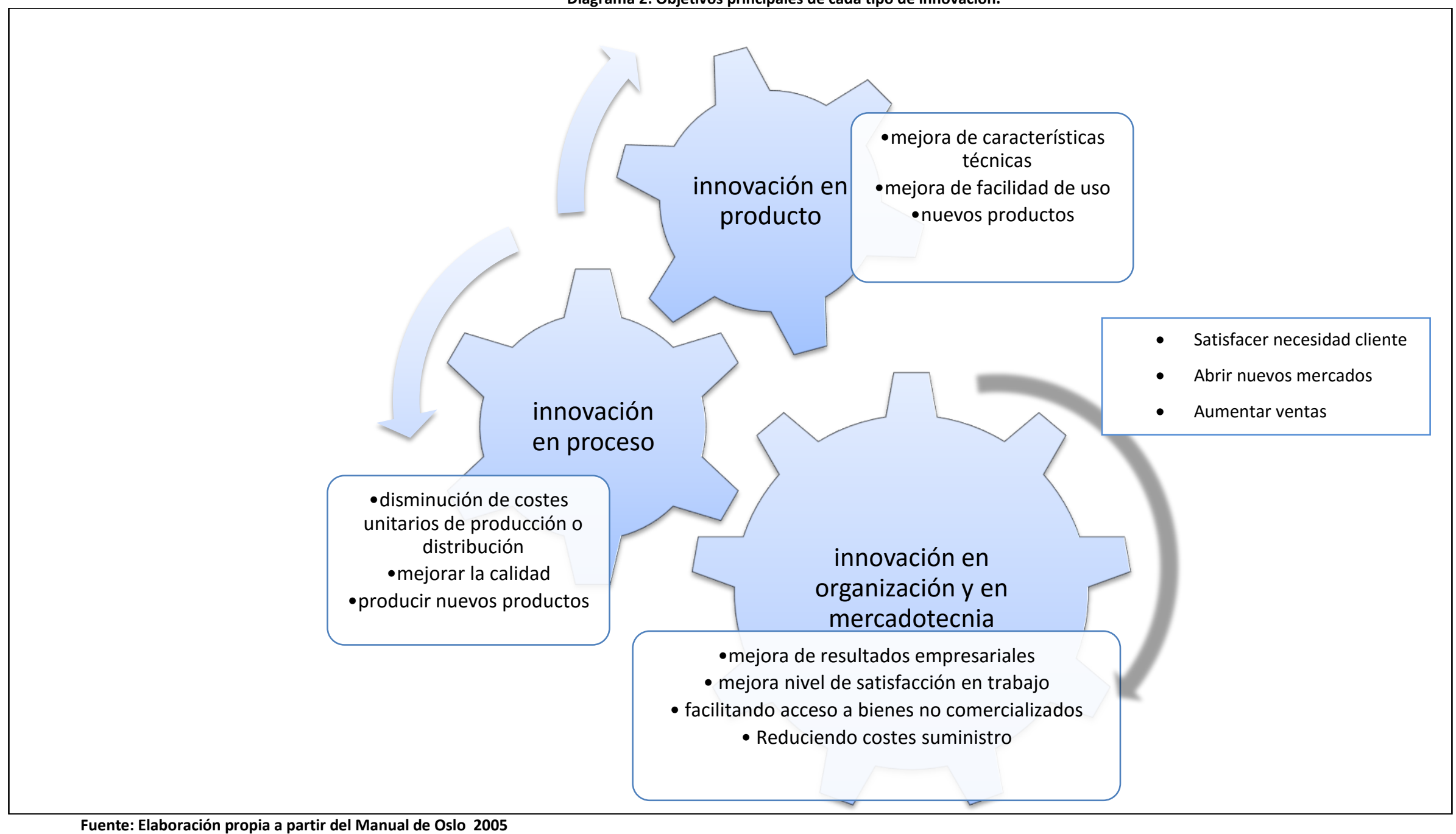

Fuente: Elaboración propia a partir del Manual de Oslo 2005 


\subsection{La importancia de la innovación}

La importancia de la innovación como factor que condiciona el crecimiento de la economía de los países y la repercusión sobre la sociedad, tanto en términos de empleo como de mejora de la calidad de vida, es un hecho de sobra conocido y repetido. La globalización provoca que la innovación refuerce su influencia en cómo se organiza la economía con las nuevas herramientas con las que se dispone en la actualidad. Esto ha permitido que la dedicación investigadora siga aún vigente e incorpore los nuevos factores producto de la evolución de la sociedad del conocimiento.

En palabras de Schumpeter (1955), "En la naturaleza de las innovaciones está implícito el vértigo de emprender grandes cambios para poder dar grandes saltos. El mejor camino para que una nación se proyecte mejor en el futuro es que definitivamente asuma que sólo innovando podrá alcanzar a los países más prósperos"

En el campo del pensamiento, los autores clásicos introdujeron sus teorías sobre el crecimiento económico y el papel que la innovación juega en su desarrollo. De esta manera, Adam Smith (1776), considerado el primer economista moderno, ya apuntó que la innovación se promovía gracias a la división del trabajo que a su vez lo hacía con la propia riqueza de las naciones. Esta idea, ya evolucionada, ha permanecido hasta el día de hoy en la ingente cantidad de investigaciones que se han generado buscando aquellos factores que determinan o condicionan el crecimiento económico.

Otros economistas más modernos, dedicados al campo de la innovación como Robert M. Solow (1957) en su contribución a la Teoría 
del Crecimiento reconocen el papel decisivo de la innovación tecnológica como determinante del crecimiento económico.

Otros, continuando con la línea de los anteriores, de la década de los 90 como Romer (1990) establecen en sus aportaciones a la derivación de la Teoría del Crecimiento hacía el crecimiento endógeno donde se otorga a la innovación un papel intrínseco y no el de factor determinante del crecimiento económico.

La innovación actualmente está considerada un elemento imprescindible de las políticas de Investigación y Desarrollo. Importantes instituciones, tanto europeas como mundiales elaboran informes sobre innovación en los que se realizan seguimientos de la actividad innovadora (OCDE, Comisión Europea,...).

Según los datos ofrecidos por el Ministerio de Agricultura, Alimentación y Medio Ambiente (MAGRAMA), la industria agroalimentaria española aportó en 2015 un 20.5 \% del total de las ventas netas de la industria española. Aporta el $16.8 \%$ del Valor Añadido Bruto (V.A.B.) de la industria. Representa por otro lado un $8 \%$ del PIB del país, lo que indica que la industria agroalimentaria forma parte de los sectores estratégicos del país. Aporta además, el $15 \%$ del total de las exportaciones españolas a la balanza comercial y se prevé que estas cifras continúen aumentando durante los próximos años.

La importancia del sector se hace mayor cuando se analiza la aportación que hace al mantenimiento de la población rural en zonas desfavorecidas del territorio español proporcionando actividad económica, y por tanto, demandando mano de obra, que permite el desarrollo de estas zonas rurales.

Es por tanto fundamental que las empresas agroalimentarias aumenten su competitividad en aras de seguir contribuyendo y favoreciendo el crecimiento económico del país. 
La evolución de los gastos en I+D (INE, 2011) en la industria agroalimentaria española, como podemos ver en el Gráfico 2, ha aumentado a lo largo de los últimos años. Hay que destacar el descenso del año 2009 como consecuencia de la situación económica que padecen todos los sectores de la economía en España y en otros muchos países de su entorno.

Gráfico 2: Gastos en innovación en el sector agroalimentario español. "2002-2009"

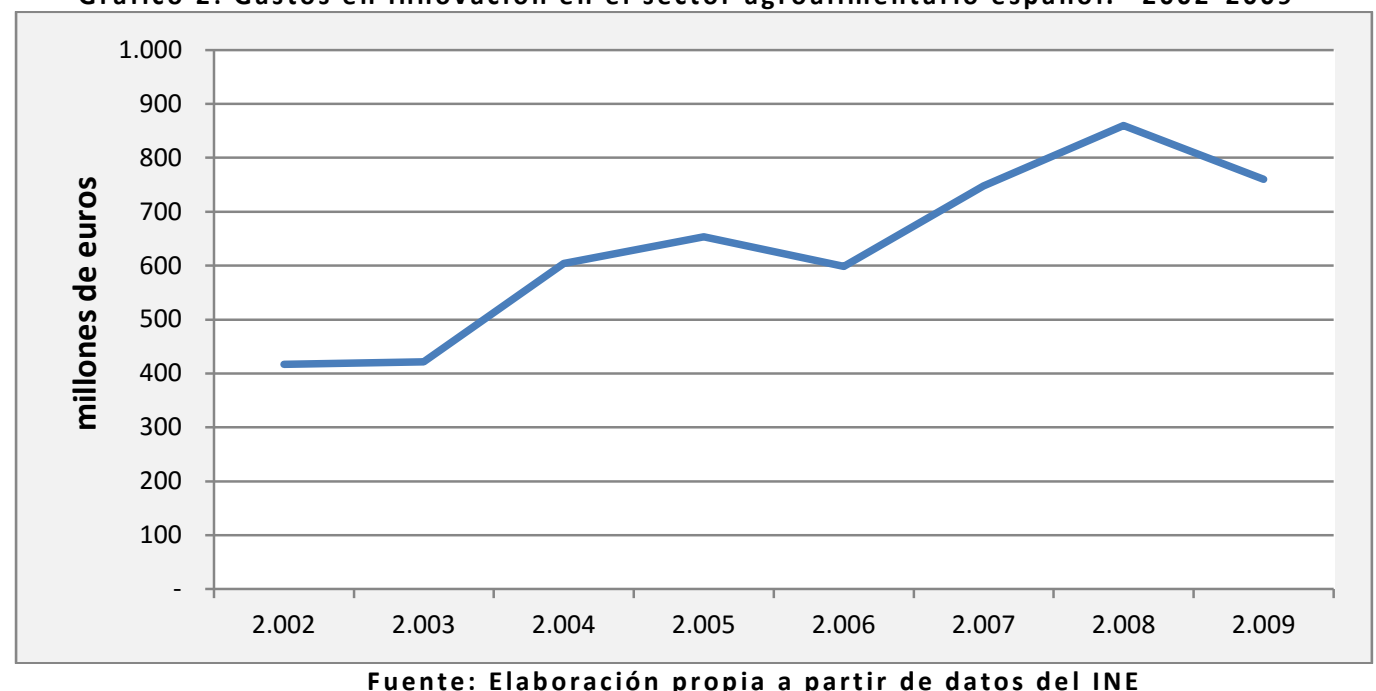

La expansión del sector depende del esfuerzo que las empresas dedican a mejorar sus recursos y capacidades. El hecho de ser un sector estratégico para la economía del país le obliga a estar en permanente evolución adaptándose a las nuevas tecnologías que le puedan proporcionar nuevos métodos de gestión de la producción, es decir, de mejorar los procesos productivos y por ende los productos y servicios finales. En definitiva, la industria agroalimentaria precisa seguir avanzando en competitividad y para ello necesita invertir en la obtención de innovaciones que le permitan ser más competitiva tanto dentro como fuera del mercado español. Para conseguir este objetivo las empresas agroalimentarias españolas debido a la estructura atomizada del sector necesitan la colaboración con otras empresas, del mismo o de diferentes sectores, para poder innovar y aprovechar económicamente la situación de auge del sector. A esta colaboración 
entre empresas $y / u$ organismos públicos es a lo que se llama cooperación tecnológica.

Sin embargo, las estrategias de innovación pueden ser diversas, es decir, se pueden desarrollar y/o combinar diferentes inputs de innovación y se puede planificar la obtención de varios outputs de innovación. Así, dentro de los inputs destacan la diferencia entre realizar I+D dentro de la empresa (invertir en bienes de equipo, contratar personal de I+D, utilizar TICs, etc.) o recurrir a la I+D empleando recursos externos de la organización (cooperación con diferentes agentes, subcontratación con agentes tecnológicos, etc.) (Brewin et al., 2009 y Barge-Gill, 2010). Entre los outputs de innovación se pueden obtener innovaciones en productos, en procesos, mejoras en la gestión, proteger las innovaciones con patentes, etc. Profundizar en estas cuestiones es fundamental para realizar recomendaciones a las empresas que no innovan y para mejorar las estrategias de las que sí lo hacen.

\subsubsection{El mercado del conocimiento}

La apropiabilidad del conocimiento en general, así como de los derechos de propiedad en particular, implica una serie de problemas que es necesario solventar para que no afecten a los derechos de propiedad de los individuos ni a los de la colectividad.

Un sistema de derechos de propiedad es imprescindible para el buen funcionamiento de la economía. En este punto las innovaciones como caso particular de bien susceptible de apropiabilidad precisan de un sistema de regulación como un sistema de patentes en el que se describan con precisión las limitaciones del uso del derecho.

El tratamiento que se da a los bienes derivados de la I+D repercute a la hora de tomar decisiones económicas por parte de la empresa. En el sistema económico en el que vivimos (de mercado) nos 
encontramos con que es necesario resolver lo que se ha dado por llamar un "fallo de mercado", es decir, como se asigna un recurso clasificado como intangible como es el conocimiento que tiene como objetivo el avance tecnológico y por tanto económico de una sociedad.

A estos efectos, en Heijs (2012) se identifican y analizan los fallos de mercado enmarcados dentro del marco teórico de los sistemas de innovación. El autor señala la ineficiencia de la política de $I+D+i$ echando por tierra el esfuerzo financiero realizado con el objetivo de obtener resultados útiles en el sistema productivo. Separa los fallos en "fallos sistémicos" (Tabla 5) y en "fallos de mercado" (Tabla 6). Estos últimos los considera inherentes al propio proceso de innovación.

Tabla 5: Clasificación de los fallos sistémicos del Sistema de Innovación

Fallos de las capacidades individuales y colectivas

Fallos institucionales formales e informales

Fallos de interacción, coordinación y redes.

Fallos infraestructurales respecto a la ciencia

Fallos sistémicos y la tecnología.

Fallos de relevancia y acoplamiento.

Fallos contextuales

Fuente: Elaborado a partir de Heijs (2012)

Los fallos de mercado que se relacionan a continuación están motivados por la imperfección del mercado. Esta imperfección repercute de forma negativa sobre el bienestar de los consumidores y una pérdida de eficiencia sobre el sistema de producción. 
Tabla 6: Clasificación fallos de mercado del Sistema de Innovación.

Ventajas de escala e indivisibilidad.

Bienes públicos.

Fallos de mercado Externalidades.

Apropiabilidad.

Información imperfecta

Incertidumbre.

Fuente: elaborado a partir de Heijs (2012)

El problema de la generación de conocimiento es que este se considera un bien público puro, es decir, un bien "no rival" que una vez producido el coste marginal de que un consumidor lo consuma es cero, y "no exclusivo" al no poder excluir de su uso al que no paga por el bien.

\begin{tabular}{|c|c|c|}
\hline & Excluible & No excluible \\
\hline Rival & $\begin{array}{l}\text { Bienes } \\
\text { privados: } \\
\text { Patentes }\end{array}$ & Bienes públicos \\
\hline $\begin{array}{l}\text { No } \\
\text { rival }\end{array}$ & Bienes club & $\begin{array}{c}\text { Bienes públicos } \\
\text { puros: } \\
\text { Conocimiento }\end{array}$ \\
\hline
\end{tabular}

La solución a este problema (fallo de mercado) de funcionamiento pasa por la participación de las instituciones legislando para que el conocimiento pueda ser asignado de manera eficiente, quiere esto decir, para que dichos recursos (conocimientos) puedan ser apropiados o intercambiados por los intervinientes en los procesos productivos. Entran en juego aquí los mecanismos de apropiación privada de la investigación como las patentes, las marcas de fábrica y los modelos de utilidad que aportan un estímulo a la generación de conocimiento. La creación de un mercado regulado de derechos de propiedad corrige de 
alguna manera la ineficiencia del sistema permitiendo el monopolio temporal de la innovación como recompensa por su aportación al avance económico en términos de conocimiento. En definitiva, la incorporación al proceso productivo de las innovaciones se constituye como una fuente de crecimiento económico a medio o largo plazo, cuando se extingue el derecho y los resultados de la innovación pueden ser utilizados por los competidores.

El modelo endógeno de crecimiento, en contraposición al exógeno, que se desarrolla a partir de los años 80 , confiere a las políticas un importante papel para obtener unas organizaciones empresariales capaces de favorecer el crecimiento económico. La innovación se considera una necesidad intrínseca a las empresas dado el ámbito global de la economía en la que actualmente actúan estas. Por este motivo los distintos gobiernos a lo largo de las últimas décadas han elaborado diferentes herramientas que buscan motivar e incentivar a las empresas para que su permanencia en los mercados sea sostenible y puedan adecuarse a los incesantes cambios que se producen en los mercados y responder a sus exigencias. Es decir, las empresas persiguen estrategias ajustando su estructura a cada momento en concreto en relación al ámbito en el cual desarrollan su actividad. Aquellas empresas que sean capaces de adaptarse conseguirán mantener su posición dentro del mercado. Para ello los gobiernos favorecen con sus políticas la inversión en educación, formación, investigación y desarrollo.

Siguiendo a Heijs, Buesa y Baumet (2007), se concibe el Sistema Nacional de Innovación como el entramado de instituciones y empresas que dentro de un país, orientan su actividad, total o parcialmente, al despliegue del conocimiento con la finalidad o bien de hacer progresar la ciencia o bien de incrementar el elenco de las tecnologías sobre las que se soportan las innovaciones que se encuentran en la base del desarrollo económico. 
La intervención del Estado queda legalmente justificada en el artículo 149.15 de la Constitución española de 1978: “El Estado tiene competencia exclusiva sobre el fomento y la coordinación general de la investigación científica y técnica". El desarrollo del artículo se llevó a cabo con la Ley13/1986 de 14 de abril, de Fomento, Coordinación General de la Investigación científica y técnica

Actualmente las competencias en materia de investigación científica y técnica, desarrollo e innovación las asume dentro del Ministerio de Economía y Competitividad, la Secretaría de Estado de Investigación, Desarrollo e Innovación. Desde esta Secretaría se propone y ejecuta la política del Gobierno, coordina los organismos públicos de investigación y coordina el fomento de la I+D+i. (ver anexo)

- Programa Marco de la Unión Europea "HORIZONTE 2020"

- Estrategia Española de Ciencia y Tecnología y de Innovación

- Ley para la Ciencia, la Tecnología y la Innovación (4/2011)

\subsection{Teorías económicas relacionadas con la innovación empresarial}

A la hora de analizar el impacto de la innovación sobre el crecimiento económico hemos de considerar los diversos enfoques que han surgido a lo largo de la historia. Durante los últimos dos siglos y lo que ha transcurrido del presente, se ha desarrollado dentro de la teoría económica una parcela dedicada al análisis de los efectos de la innovación entendida como un tipo de acumulación de capital que permite el ahorro y por tanto la inversión que lleva al crecimiento económico en primer lugar de las empresas y más tarde en los países donde residen.

"La teoría económica es un conjunto de proposiciones que establecen una relación entre los hechos económicos. A diferencia de la 
política económica, el objeto de la teoría económica no es intentar influir sobre los acontecimientos económicos, sino dedicarse exclusivamente a su observación, al estudio de las interacciones entre los agentes, a su contrastación empírica y a la formulación de leyes que sirvan para su predicción. En función de su ámbito de aplicación se puede dividir en macroeconomía y microeconomía." (La gran Enciclopedia de la economía)

Las teorías económicas tratan de explicar el comportamiento de las economías desde dos puntos de vista, el micro y el macroeconómico. Las teorías clásicas por lo general se han desarrollado desde el enfoque macroeconómico mientras que, las teorías modernas se desarrollan desde un enfoque microeconómico.

Estas teorías están orientadas a determinar cuáles son y en qué sentido los factores, bajo los que las empresas llevan a cabo sus estrategias, influyen en su desarrollo.

El análisis de modelos teóricos, en los que se aborda el estudio del comportamiento de las empresas para conseguir las ventajas competitivas que le permiten permanecer en el mercado, ha sido objeto de estudio durante las últimas décadas y aún lo es debido a los cambios en el comportamiento empresarial provocados por la globalización de los mercados. Una de las consecuencias que ha provocado dicha globalización es la proliferación de tratados de libre comercio (TLC) entre países y a su vez entre bloques de países. Entre los objetivos de los TLC, se encuentra proporcionar una protección adecuada a los derechos de propiedad intelectual. El resto de objetivos se presentan a continuación en el siguiente cuadro: 
Eliminar barreras que afecten o mermen el comercio entre las zonas que firman el tratado.

Promover las condiciones para una competencia justa.

Incrementar las oportunidades de inversión.

Establecer procesos efectivos para la estimulación de la producción nacional y la sana competencia.

Fomentar la cooperación entre países miembros.

Ofrecer una solución a controversias.

Fuente: http://www.sice.oas.org/trade/nafta_s/CAP01.asp\#Cap.I

Desde que la economía aparece como ciencia se han desarrollado toda una serie de teorías que muestran la preocupación por el crecimiento de las economías y su indudable repercusión en el desarrollo de los países, tanto económico como social y cultural.

Autores como Adam Smith, considerado el pionero, David Ricardo, Max Weber, Walras y otros muchos considerados economistas clásicos han contribuido con sus aportaciones a la elaboración de numerosas teorías cuyo germen se encuentra en estos autores.

Siguiendo el trabajo de Sala i Martín (1994), se dividen en cinco grupos a lo largo del tiempo las tendencias, los modelos o las teorías que se han ido elaborando.

En la Tabla 9 siguiente se puede ver el desarrollo histórico de la Teoría del Crecimiento que se expone a continuación. Se incluye la época, la corriente a la que pertenecen y su principal aportación. 
Tabla 9: Principales etapas, autores y sus aportaciones

\begin{tabular}{|c|c|c|c|}
\hline & & Autores & Aportaciones \\
\hline \multirow{2}{*}{$\frac{n}{0}$} & S. XVIII - XIX & $\begin{array}{l}\text { Adam Smith } \\
\text { David } \\
\text { Ricardo } \\
\text { Thomas } \\
\text { Malthus }\end{array}$ & $\begin{array}{l}\text { Ley de los rendimientos decrecientes y su } \\
\text { relación con la acumulación de capital físico o } \\
\text { humano. } \\
\text { La relación entre progreso tecnológico y } \\
\text { especialización del trabajo }\end{array}$ \\
\hline & 1 mitad S.XX & $\begin{array}{l}\text { Frank } \\
\text { Ramsey } \\
\text { Alling Young } \\
\text { Frank Knight } \\
\text { Joseph } \\
\text { Schumpeter }\end{array}$ & $\begin{array}{l}\text { Primeras contribuciones en la búsqueda de } \\
\text { determinantes de la tasa de crecimiento y del } \\
\text { progreso tecnológico } \\
\text { Modelo de Ramsey (Análisis del comportamiento } \\
\text { óptimo de los consumidores) } \\
\text { Teoría del empresario innovador }\end{array}$ \\
\hline 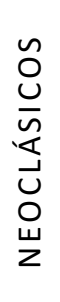 & 2 a mitad S.XX & $\begin{array}{l}\text { Solow } \\
\text { Swan } \\
\text { Cass } \\
\text { Koopsmans }\end{array}$ & $\begin{array}{l}\text { Modelos de desarrollo exógeno } \\
\text { Establecen el crecimiento tecnológico exógeno } \\
\text { como motor último del crecimiento a largo plazo. }\end{array}$ \\
\hline \multirow{2}{*}{$\begin{array}{l}\sim \\
0 \\
\sum \\
\sim \\
u \\
0 \\
0 \\
\Sigma\end{array}$} & \multirow{2}{*}{$\begin{array}{l}\text { Última } \\
\text { década del } \\
\text { S.XX }\end{array}$} & $\begin{array}{l}\text { Romer } \\
\text { Lucas } \\
\text { Rebelo } \\
\text { Barro }\end{array}$ & $\begin{array}{l}\text { Primeros modelos de desarrollo endógeno. La } \\
\text { tecnología deja de considerarse una variable } \\
\text { exógena. Entran en juego la externalidades o la } \\
\text { introducción de capital humano para generar } \\
\text { tasas positivas de crecimiento. }\end{array}$ \\
\hline & & $\begin{array}{l}\text { Romer } \\
\text { Aghion } \\
\text { Grossaam }\end{array}$ & $\begin{array}{l}\text { Introducción del entorno de competencia } \\
\text { imperfecta en el desarrollo de modelos. }\end{array}$ \\
\hline
\end{tabular}

Fuente: elaboración propia a partir de Sala i Martín (1994)

El primer grupo, llamado de los clásicos, desarrollan su teoría en base a la ley de los rendimientos decrecientes.

Un segundo grupo, los clásicos de la primera mitad del siglo XX, cuyo enfoque está centrado en los determinantes de la tasa de crecimiento y del progreso tecnológico. 
El tercer grupo, los neoclásicos de la segunda mitad del siglo XX, que introducen el crecimiento tecnológico exógeno considerándolo el motor del crecimiento a largo plazo.

El último grupo que en realidad podría dividirse en dos, basan sus investigaciones en primer lugar y haciendo referencia a un primer grupo, en considerar, al contrario que los anteriores, que la tasa de crecimiento a largo plazo venía determinada por factores endógenos, entre ellos la tecnología. Y en segundo lugar, la incorporación al análisis de la competencia imperfecta generada por la apropiación de la innovaciones.

Concluyendo esta sección, las teorías que se han ido desarrollando a lo largo de la historia han intentado explicar qué factores determinan la evolución empresarial y por ende la evolución técnica. El campo de estudio, según la revisión realizada, está dominado por los modelos o paradigmas que se enuncian a continuación.

De la Teoría del Crecimiento Económico basada fundamentalmente en los avances tecnológicos, surge la Teoría de los Recursos y Capacidades basada en los activos y las capacidades organizacionales (Diagrama 3)

Como extensión de la anterior surge la Teoría de la gestión del conocimiento que se fundamenta en el capital humano o más específicamente en el capital intelectual. Otras teorías se exponen como complemento a las anteriores, como la Teoría de la Organización Industrial fundamentada en las características estructurales de la industria, la conducta de las empresas y los resultados obtenidos por las empresas.

En este trabajo nos basamos principalmente en el enfoque dado por la teoría de los Recursos y Capacidades y la teoría de la 
organización industrial, a partir de los trabajos que analizan el ámbito interno de la empresa.

Diagrama 3: Evolución de las teorías relacionadas con la innovación

Teoría del Crecimiento Económico

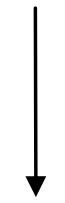

Teoría de la Organización Industrial

Estructura-conducta-

resultado

(Mason, 1939)

Teoría de los Recursos y Capacidades (80`s)

Gestión del Conocimiento (90’s) Modelo de las 5 fuerzas (Porter,1982)

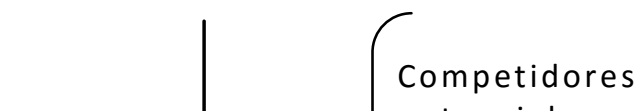
potenciales Productos sustitutos

Factores externos Proveedores Compradores Competidores en la industria

Fuente: elaboración propia

\subsubsection{Teoría del Crecimiento económico: de los clásicos a la Teoría} del crecimiento endógeno

La relación que existe entre el crecimiento económico y el progreso tecnológico se estudian desde el origen del pensamiento económico con Adam Smith y David Ricardo. Ambos autores dedicaron parte de su esfuerzo a determinar cuáles eran los factores que provocaban el crecimiento económico. Asimismo, Solow (1957) ya en el siglo XX y a través del modelo de crecimiento neoclásico, afirmaba que 
el progreso técnico es el factor clave para alcanzar el crecimiento económico junto con la inversión en mano de obra y de capital. Con este modelo, Solow estimó que cuatro quintas partes del crecimiento norteamericano eran atribuibles al progreso técnico. El análisis de Solow muestra que en los países avanzados la innovación tecnológica contrarresta los rendimientos decrecientes, obteniendo más producción, aún con la misma cantidad de capital y trabajo. Sin embargo, hay una amplia variedad de factores que influyen sobre la difusión y adopción de innovaciones (Nelson, 1981), y diversos autores han aportado teorías y evidencias sobre ellos.

Las teorías han ido evolucionando desde la época de la Teorías económicas clásicas hasta la época actual con la Teoría de Crecimiento Endógeno. A lo largo de este período de tiempo ha variado la percepción del concepto capital como uno de los factores de producción. La teoría clásica limita a la tierra, el trabajo y el capital, los factores que forman parte de la función de producción. A partir de aquí se han ido perfilando los papeles que cada uno de los factores juega en la función. Es el capital el factor que a lo largo de la historia se ha ido desglosando para conformar una función de producción en la que entra en juego el capital humano y el tecnológico.

La disponibilidad de los factores de producción se consideraba un factor que hacía detener el crecimiento en cuanto estos estuvieran empleados en su totalidad. La mera incorporación de factores de producción no siempre aseguraba un aumento de la producción debido a la ley de los rendimientos decrecientes,

La mayoría de los autores llegan a la conclusión de que las economías desembocan en el llamado "estado estacionario". La pregunta que se planteaban era como salir de este estado provocando el crecimiento económico. En la Tabla 10 se resumen las respuestas a las preguntas que en su momento se hacían los teóricos económicos. La 
preocupación que se tenía en aquel contexto histórico en el que se desarrollaba esta teoría era determinar qué factores permitían salir del estado estacionario al cual estaba abocado el sistema económico.

Tabla 10: Teorías clásicas de crecimiento económico

\begin{tabular}{lll}
\hline Autor (fecha) & $\begin{array}{l}\text { ¿Por qué aumenta la tasa de } \\
\text { crecimiento? }\end{array}$ & $\begin{array}{l}\text { ¿Qué lleva a salir del } \\
\text { estado estacionario? }\end{array}$ \\
\hline Adam Smith (1776) & Especialización del trabajo & Innovación y apertura \\
\hline T.R. Malthus (1799) & Aumento de la oferta & Reducción de población \\
\hline D. Ricardo (1877) & Rendimientos decrecientes & Innovación Tecnológica y \\
\hline K. Marx (1867) & Acumulación del capital & La ganancia del capital \\
\hline J.A. Schumpeter (1911) & La innovación & La competencia \\
\hline Keynes (1936) & La inversión & La exportación
\end{tabular}

\subsubsection{Teoría de los Recursos y Capacidades}

Dentro del ámbito de la Estrategia Empresarial (Corporate Strategy) se desarrollan dos líneas o enfoques basados en aspectos internos y externos a la empresa. En los primeros, es decir, la organización como tal, está basada la Teoría de los Recursos y Capacidades (Resource-based view, RBV) (Penrose, 1959; Wernerfelt, 1984; Barney, 1991; entre otros)

La Teoría de Recursos y Capacidades profundiza sobre cómo las empresas alcanzan ventajas competitivas mediante estrategias que promueven el desarrollo de recursos y capacidades, y se contrapone a la visión más tradicional de analizar las debilidades y fortalezas de los productos ofrecidos por la empresa. Estos recursos engloban activos, capacidades, atributos, información, conocimientos, organización de 
procesos, etc. que permiten que la empresa formule e implemente sus estrategias. Estos recursos, además, deben reunir ciertas características para evitar que sean copiados por los competidores. Es decir, deben ser valiosos, escasos, inimitables y no sustituibles. Las repercusiones de los recursos de las empresas sobre sus resultados dependen de la intensidad de estas características.

Entre las distintas categorías de recursos considerados están, evidentemente, los relacionados con la innovación y con los gastos en investigación y desarrollo, pero no de forma aislada e independiente de otros recursos de la empresa. Christensen (1995) ofrece una visión integradora al considerar que la innovación tecnológica está determinada por la conjunción e interrelación de activos de innovación y activos complementarios (marketing, distribución, apoyo postventa, etc.).

Si se contemplan exclusivamente los recursos de I+D se puede estar infravalorando o ignorando una parte importante del esfuerzo tecnológico que realizan las empresas. Los activos de innovación incluyen la investigación científica, el desarrollo de procesos (maquinaria, sistemas de producción, organización, logística, calidad, etc.) y productos (ingeniería de producto, materiales, componentes, etc.), así como recursos destinados al diseño estético (tanto producto como embalaje). Este autor considera que la investigación científica y el diseño estético dependen más de la creatividad $y$, por consiguiente, originan resultados más inciertos y sorprendentes que los generados por el desarrollo de productos y procesos. Por su parte, el desarrollo de procesos y productos se podría realizar internamente mediante gastos en desarrollo pero también mediante inversiones en tecnologías desarrolladas externamente o a través de colaboraciones tecnológicas con otras empresas. Los activos complementarios también son críticos para tener éxito en la innovación como muestra Teece (1986) con muchos ejemplos de empresas que no supieron capturar los beneficios 
de sus innovaciones porque otras empresas imitadoras eran fuertes en los activos complementarios de esas innovaciones.

La innovación tecnológica se entiende mejor desde esta visión más amplia de combinaciones de activos de innovación y complementarios que usando exclusivamente la intensidad de la I+D. El interés de la investigación empírica estaría en identificar las combinaciones de activos que conforman las estrategias y perfiles de innovación de las empresas en diferentes sectores y situaciones. A partir de estas ideas, Christensen (1995) reflexiona sobre los perfiles de innovación en los diferentes sectores.

Así, indica que la industria alimentaria, como otros sectores de productos de consumidor, estaría más focalizada en desarrollo de productos y diseño estético; sin embargo también existe la posibilidad de innovación en procesos para la producción a escala intensiva; e incluso innovación basada directamente en investigación científica mediante el uso de la biotecnología.

\subsubsection{Teoría de la organización industrial}

Siguiendo al profesor Caldentey (1998), se entiende por industria al entramado de empresas manufactureras que compiten entre sí para hacerse con la máxima cuota de mercado entendido como el lugar donde se forman los precios a través de la oferta y la demanda de los productos. Esto le confiere a la industria categoría de ente económico al ser capaz de afectar a las condiciones del mercado dependiendo de las estrategias empresariales adoptadas.

En el origen de la teoría de la organización industrial (Mason, 1938) cuantificó para su análisis las variables que explicaban el comportamiento, los resultados y la estructura del mercado. Considerando no válido para analizar el mercado los fundamentos de la competencia perfecta. 
El paradigma que fundamenta la teoría de la organización industrial es el llamado paradigma E-C-R (Estructura-ConductaResultados) (Bain, 1958). Resumiendo, lo que viene a decir o a plantear el paradigma ECR no es más que en función de la estructura o de las características de la industria esta tendrá una conducta hacía el mercado aplicando una u otra estrategia según le convenga. A su vez esta relación entre la estructura y el comportamiento influye sobre el resultado.

Al analizar el comportamiento empresarial y siguiendo a Sanz (2000) los análisis realizados en las investigaciones que sobre el Sistema agroalimentario se han realizado en los últimos años enfocados en la teoría de la organización industrial se centran en las relaciones interempresariales, la organización interna de las empresas y la estructura del tejido empresarial. (Boehlje, 1995, Cotteril (1993), Ménard (2000)).

La versión más moderna referida al sistema agroalimentario en el cual se incluye el sector agroindustrial, es la seguida por los profesores Briz y De Felipe (2012). Los autores consideran el método global de la cadena de valor adapatada a la ya comentada trilogía de estructuraconducta-funcionamiento derivada de la Teoría de Organización Industrial.

Empleado como método de análisis en el sector agroalimentario, trata de explicar los fenómenos y problemas de un sector. Se basa en la optimización de los recursos de forma que satisfaga los deseos de los consumidores y la búsqueda de la mayor eficiencia en los flujos de bienes y servicios teniendo en cuenta a todos los agentes de la cadena. Los autores en su trabajo especifican las dimensiones de evaluación de cada uno de los tres componentes del paradigma de la cadena de valor. Estas se exponen en la Tabla 11 donde se resumen los tres escenarios que se emplean para el análisis. 
Tabla 11: Escenarios de análisis de la cadena de valor

Escenario estructuralista

\begin{tabular}{l|l}
\hline \multicolumn{1}{c|}{ Sistema organizativo } & Nivel en que se sitúa \\
\hline \multirow{2}{*}{ Interconexión entre agentes socioeconómicos } & Procesos que desarrollan \\
\cline { 2 - 2 } & Planicación \\
\cline { 2 - 2 } & Control \\
\hline \hline
\end{tabular}

Escenario relacional

\begin{tabular}{c|l}
\hline \hline Comportamientos & TIC (e-comercio) \\
\hline Actitudes & Regulaciones administrativas \\
\hline Respuestas & Cambios de hábitos de consumo \\
\hline \hline
\end{tabular}

Escenario Funcional

\begin{tabular}{l|l} 
& Relación coste-beneficio \\
\cline { 2 - 2 } Resultados finales & $\begin{array}{l}\text { Dinámica empresarial } \\
\text { (innovaciones, competitividad) }\end{array}$ \\
\cline { 2 - 2 } & Gobernanza
\end{tabular}

Fuente: Elaboración propia a partir de De Felipe, I., Briz, J. y Briz T. (2012) 


\subsection{Mapa conceptual de la innovación empresarial}

De manera general se propone un modelo empresarial donde se establecen las relaciones entre la diversas actuaciones que se acomenten por parte de los responsables en cada uno de los ámbitos del ciclo de vida de la producción, es decir, desde la toma de decisión de gestión hasta el tratamiento que se da a los resultados en aras de mejorar los resultados empresariales.

$$
\text { En el }
$$

Diagrama 4 que se presenta a continuación se representa de manera visual el mapa conceptual integrado por los tres submodelos en los cuales influyen las decisiones de gestión:

- Submodelo de la estructura empresarial

- Submodelo de estrategias empresariales

- Submodelo de apropiación de la innovación

En cada uno de los submodelos se incluyen las variables que los definen y se señalan los indicadores de causalidad mediante los cuales se interrelacionan unas variables con otras y cada submodelo con los demás. 


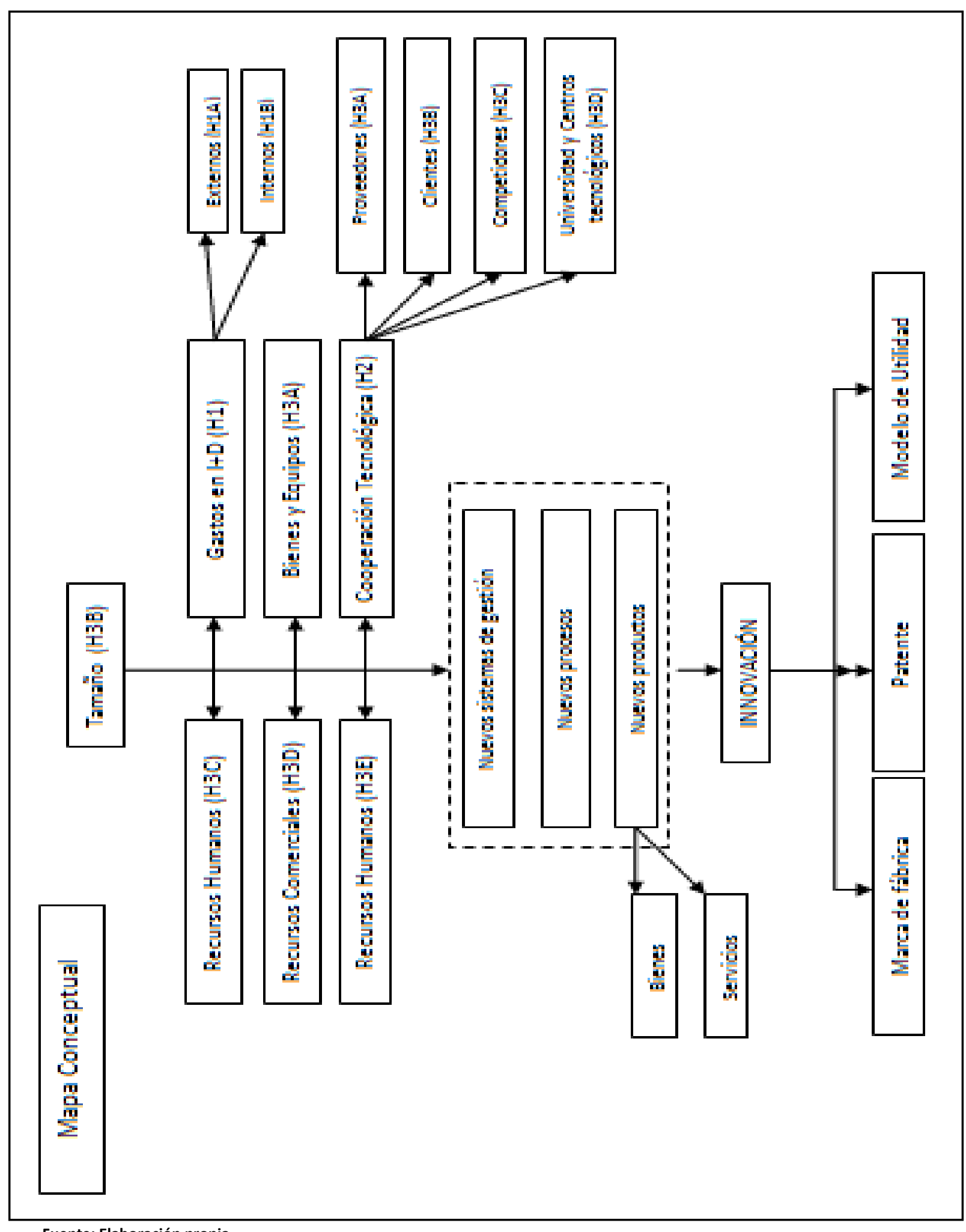

Fuente: Elaboración propia 


\subsubsection{El submodelo de la estructura empresarial}

La gestión de un proceso innovador se inicia adaptando la estructura de la empresa a esa nueva situación. La necesidad de recursos que se precisan para llevar a cabo un proceso innovador obliga a la empresa a generar un ámbiente propicio en el que todos los actores sean conscientes de la necesidad de apoyar la decision de innovar. Recursos humanos y físicos tienen que ser los apropiados. En conclusión, la existencia de una cultura innovadora es fundamental. Es preciso una dirección que sea capaz de dirigir el proyecto innovador facilitando su consecución.

Se incluyen en este submodelo aquellos factores que se han considerado más influyentes en el proceso de innovación empresarial tras el análisis de la literatura revisada. Desde el tamaño de la empresa hasta la interacción con agentes externos que proporcionan colaboración investigadora y pasando por la conformación de los diversos departamentos de la empresa. El proceso innovador se ve afectado por cómo están dirigidos los recursos humanos disponibles, los recursos tecnológicos al servicio de la empresa, los gastos que se dedican a I+D, tanto externa como interna, y por la cooperación tecnológica establecida entre los diferentes agentes que participan en la cadena productiva, los clientes, los proveedores, los competidores y por último los centro tecnológicos y la universidades.

\subsubsection{El submodelo de la estrategia empresarial}

En lo relativo a la estrategia empresarial la decisión de llevar a cabo alguno de los diferentes tipos de innovación tiene una repercusión directa sobre los resultados empresariales. Las diferentes estrategias empresariales que se incluyen en el modelo de innovación empresarial se dividen en tres, establecer nuevos procesos organizativos, nuevos procesos de producción y nuevos productos. 
La esencia de la innovación conlleva en realidad las tres estrategias. Cuando se avanza en el proceso organizativo donde se incluye el marketing y la comercialización, se proponen nuevos productos que precisan de cambios en los procesos productivos. En realidad la casuistica con la que nos podríamos encontrar incluye a cada una de las innovaciones de manera independiente y serían consideradas de alguna manera innovaciones.

\subsubsection{El submodelo de la apropiación de la innovación}

Por último, la incorporación al modelo de innovación de los factores que permiten apropiarse a la empresa del fruto del proceso innovador. Tres son en este caso los factores, el registro de patentes, la marca de fábrica y el modelo de utilidad.

La Ley de Patentes de 1986, al amparo de la cual se pueden proteger las invenciones, considera patentables las invenciones nuevas que implican una actividad inventiva y sean susceptibles de aplicación industrial. En la ley se diferencia entre patente y modelo de utilidad (art.143). En el caso de los modelos de utilidad, estos se emplean para invenciones que consisten en dar a un objeto una configuración, estructura o constitución de la que resulta alguna ventaja prácticamente apreciable para su uso o fabricación. La consideración de nueva hace referencia a que la invención no esté comprendida en el estado de la técnica (art. 6.1). La propia ley indica que dicho estado está constituido por todo lo que antes de la fecha de presentación de la solicitud de patente se ha hecho accesible al público en España o en el extranjero por una descripción escrita u oral, por una utilización o por cualquier otro medio.

En cuanto a la actividad inventiva, está estipulado (art. 8.1) para actividades que no resulten del estado de la técnica de una manera evidente para un experto en la materia. 
Por último, para terminar con los términos incluidos en la definición de invenciones patentables, se considera que una invención es susceptible de aplicación industrial (art. 6.2) cuando su objeto puede ser fabricado en cualquier tipo de industria, incluida la agrícola.

\subsection{Investigación empírica general}

A la hora de demostrar lo que la Teoría Económica establece en cuanto a la innovación y su efecto sobre el crecimiento económico realizaremos un análisis de la investigación empírica realizada por economistas e investigadores en general.

La importancia del tema es de tal magnitud que se han involucrado en estos análisis muchas disciplinas, economistas, industriales de todos los sectores, educación, sociólogos, etc. Como consecuencia existe una amplia literatura empírica.

En la Tabla 12 se revisa a través de la literatura empírica de los últimos años las aportaciones más relevantes de aquellos autores que analizan los distintos recursos empresariales que caracterizan a una empresa innovadora, y su relación con la capacidad de innovación de la misma, entendida esta como la obtención de algún tipo de ventaja comparativa.

Entre las aportaciones más relevantes, cabe destacar por orden cronológico las siguientes: 
Tabla 12: Resumen de Trabajos revisados

Autor

Scherer (1965) Variable explicada

Patentes
Variables explicativas

Sector

Tamaño

Poder de monopolio

Diversificación

Concentración

Nivel de sindicalización Intensidad

de capital

Acs y Audretsch (1988)

No de innovaciones
$\mathrm{N}$ o de patentes

Tamaño

Diferenciación

Capital humano

Gastos en I+D

Gastos en I+D

Número de patentes
Gambardella (1992)

Galende y Suárez (1999)
Gastos I+D

No publicaciones científicas

Localización

Concentración

Oportunidad tecnológica

Recursos financieros

Deuda

Tamaño

Intensidad del factor capital

Capital humano

Recursos comerciales

Experiencia acumulada

Tamaño

Deuda

Gastos I+D

Recursos humanos

Galende, J. y de Ia Fuente, J.M., 2003

Cooperación I+D

Recursos comerciales

Innovaciones

Recursos organizativos

Diversificación

Internacionalización

Tamaño

Grupo

financiación pública

Miotti y Sachwald (2003)

Patentes

Cooperación I+D
Gastos en I+D

Nivel tecnológico

Tipo de cooperación tec.

Cuota de mercado

Patentes

Tamaño

Estructura de propiedad 


\begin{tabular}{|c|c|c|}
\hline & & $\begin{array}{l}\text { Capacidades organizativas } \\
\text { Estructura de capital } \\
\text { Spillovers } \\
\text { Diversificación }\end{array}$ \\
\hline Johansson y Lööf (2006) & & $\begin{array}{l}\text { Región } \\
\text { Estructura corporativa } \\
\text { Nivel I+D } \\
\text { Recursos financieros } \\
\text { Marcas registradas } \\
\text { Recursos permanentes I+D } \\
\text { Tamaño }\end{array}$ \\
\hline Surroca y Santamaría (2007) & $\begin{array}{l}\text { Resultados innovadores } \\
\text { Resultados empresariales }\end{array}$ & $\begin{array}{l}\text { Cooperación tecnológica } \\
\text { Innovación en producto } \\
\text { Innovación en proceso } \\
\text { Resultados innovadores } \\
\text { Exportaciones } \\
\text { Tamaño } \\
\text { Networks }\end{array}$ \\
\hline
\end{tabular}

Fuente: Elaboración propia

Los primeros trabajos que se realizan dentro del ámbito de las patentes para la determinación de los factores explicativos de los procesos innovadores son los de Scherer (1965). Realizado sobre una muestra de 448 empresas de la industria de EE.UU en la década de los 50. Incluye como variables explicativas del número de patentes, el tamaño de la firma, el poder de mercado y la diversificación de los productos. Sus principales resultados fueron que el tamaño de la empresa y la diversificación de productos tenían efectos positivos sobre el número de patentes de la empresa.

En el trabajo de (ACs y Audretsch, 1988), los autores presentan un modelo que sugiere que la producción innovadora se ve influida por el gasto en $I+D$ y las características del mercado. Mediante un modelo de regresión de sección transversal estiman el número total de innovaciones en la pequeña y gran empresa. Como resultado, encuentran que el número total de innovaciones se relaciona 
negativamente con la concentración y la sindicalización, y positivamente con los gastos en I+ D y la mano de obra cualificada.

Galende y Suárez (1999) investigan, mediante la evaluación de los factores internos y organizativos de las empresas, cuales son los que determinan las decisiones de la empresas para llevar a cabo actividades de I+D. Afirman que, en función de los recursos disponibles logrados en el pasado y de su estructura de recursos se puede explicar la actividad innovadora de las empresas. Por ello, incorporan en el modelo los recursos financieros, los recursos físicos y los recursos intangibles. La muestra formada por 100 empresas, está localizada íntegramente en la Comunidad Autónoma de Castilla y León. Lo que además nos ofrece una idea de cómo responden las empresas en zonas menos industrializadas de España. En cuanto al modelo propuesto, se emplea un modelo de regresión logística en el que la variable dependiente es dicotómica y cualitativa, es decir, se estima la probabilidad de que las empresas Ileven a cabo actividades de I+D. Como consecuencia de los resultados obtenidos, los autores concluyen que los factores intangibles son los principales determinantes de la probabilidad que una empresa lleve a cabo actividades de I+D.

Los sectores más avanzados tecnológicamente son los que presentan una mayor propensión al registro de patentes (Arundel y Kabla, 1998). En esta línea, el trabajo de (Cuello de Oro \& López-Cózar, 2005) en la misma línea de los trabajos anteriores pone en valor las característica internas de las empresas y la estrategia de diversificación que cada una lleva a cabo. El trabajo está centrado en la industria farmacéutica, en concreto, la muestra está formada por 27 laboratorios. En este trabajo el modelo se ha estimado mediante el método de mínimos cuadrados ordinarios. La variable dependiente es una variable de conteo, es decir, discreta hubiera sido más correcto haber empleado un modelo lineal generalizado $(M L G)$ en el que se considere la distribución de dicha variable una distribución de Poisson 
Miotti y Sachwald (2003) examinan los determinantes de la elección de socio para llevar a cabo la cooperación en I+D. La muestra empleada es de 4.215 empresas francesas con más de 10 empleados realizada por el Ministerio de Industria francés entre los años 1994 y 1996. El perfil de empresa innovadora que tratan de encontrar a través de la cooperación tecnológica lo desarrollan a partir de doce características internas de las mismas. Estas características son: el tamaño, la pertenencia o no a un grupo empresarial, la financiación pública con la que cuenta la empresa, la existencia o no de una estructura permanente dedicada a I $+D$, la pertenencia o no a sectores con alta y media tecnología, la ciencia, la cuota de mercado, los riesgos y los costes de innovación, la falta de información del mercado y tecnológica que sufren las empresas.

El trabajo de Surroca y Santamaría (2007) abunda en la importancia de los recursos intangibles generados por la estructura empresarial. De este modo, se estudia el impacto de la cooperación tecnológica, considerada un generador de recursos intangibles, sobre los resultados innovadores de las empresas y sobre los resultados empresariales de las mismas. Una de sus aportaciones consiste en identificar los diferentes efectos diferenciales que ejerce cada uno de los principales tipos de colaboración que se establecen entre los distintos actores de la cadena productiva. En cuanto al modelo especificado en este trabajo, se ha estimado mediante una regresión Logit con datos de panel. Al igual que el trabajo de Miotti y Sachwald (2003) la variable dependiente mediante la cual se aproxima el resultado innovador es una variable dicotómica y cualitativa pero, en este caso, responde a si la empresa innova o no en producto y/o en proceso. La muestra procede de la Encuesta sobre Estrategias Empresariales (ESEE) durante el período 1998-2002 con 6.500 empresas de todos los sectores industriales. Como conclusión principal, de 
acuerdo con los resultados, la cooperación tecnológica incrementa la probabilidad de obtención de innovaciones en producto y/o proceso.

Por último, el más reciente de todos los trabajos, el de Karantininis et al (2010) en el que se resalta el poder de mercado como un factor potencial para la innovación. Los autores, sobre la base de las condiciones de la industria agroalimentaria danesa, sugieren que aquellas que tienen relación con proveedores y clientes tienen una mayor propensión a introducir más innovaciones. En particular la integración vertical y la existencia de redes de colaboración establecidos a través de acuerdos contractuales mejoran significativamente la tasa de desarrollo de la innovación. En términos de tamaño, las empresas de tamaño medio y grande tienen más recursos financieros y humanos para resistir los riesgos asociados a la innovación que las pequeñas empresas. Las organizaciones más grandes también pueden apoyar las actividades de pre y post-comercialización necesarios para el lanzamiento de productos exitosos. Las empresas con orientación hacia las exportaciones tienden a innovar más.

\subsection{Investigación empírica en el sector agroindustrial}

Es importante en este punto hacer notar que investigar los determinantes de la innovación sin hacer distinción de la actividad productiva que realizan las empresas analizadas conduce a no detectar los efectos de la innovación (de Jong y Vermeulen, 2006). La especificidad de cada sector es importante porque cada uno de ellos afronta la innovación con ritmos y fuentes tecnológicas diferentes (Pavitt, 1984) y también porque la capacidad de apropiación de las rentas generadas por la innovación es función de factores dependientes de la estructura productiva, de la naturaleza de la tecnología y del régimen de protección (Teece, 1986, 2006). Profundizar en los patrones 
de comportamiento de cada industria permite mejorarlas políticas de fomento de innovaciones y la competitividad de las empresas.

En este apartado se revisa la literatura empírica de los últimos años, en concreto, las aportaciones más relevantes que analizan los recursos empresariales que caracterizan la capacidad de innovación de la empresa agroalimentaria. La mayoría de los trabajos se concentran en Europa (Alemania -Weiss y Wittkopp; 2005; Hartl y Herrmann, 2006-; Dinamarca -Karantininis et al., 2010-; España -Rama, 1996; García y Burns, 1999-; Francia -Huiban y Bouhsina, 1998-; Holanda -Batternik et al., 2006- ) o Norteamérica (Canadá -Brewin et al., 2009-; Estados Unidos -Gopinath y Vasavada, 1999; Röder et al. ,2000-). Fuera de estos dos zonas geográficas, se ha encontrado un estudio sobre empresas agroalimentarias brasileñas (Cabral y Traill, 2001) y otro sobre multinacionales agroalimentarias (Alfranca et al., 2004).

Una cuestión de interés, tanto teórica como práctica, sobre la que no existe consenso es cómo medir la innovación de las empresas. En buena parte de la literatura revisada sobre innovación en empresas agroalimentarias las aproximaciones se hacen a partir de las innovaciones tanto en producto como en proceso hechas por las empresas (García y Burns, 1999; Huiban y Bouhsina, 1999; Karantininis et al, 2010: Röder et al., 2000; Cabral y Traill, 2001; Brewin et al. 2009). Una opción próxima a esta es emplear el número de innovaciones en producto introducidas por las empresas (Weiss y Wittkopp, 2005; Hartl y Herrmann, 2006 y Cruz-Casares et al, 2010). En ambos casos, estas variables suelen ser las repuestas que dan las propias empresas en encuestas sobre estrategias de innovación. Esto lleva a que se puedan computar como innovación aspectos que no implican un cambio real en la tecnología y que no aportan una verdadera ventaja comparativa dentro del sector. Existen también trabajos (Avermaete et al., 2004, entre otros) que clasifican las empresas en varias categorías de 
propensión a la innovación en función de si innovan o no en proceso y/o en producto y en función de si invierten o no en I+D.

Otra alternativa para medir la innovación es el empleo del número de patentes (Rama, 1996; Gopinath y Vasavada, 1999; Alfranca et al., 2004) que para algunos autores es una opción demasiado restrictiva, sobre todo en la industria alimentaria donde la velocidad con la que aparecen nuevos productos es elevada (Brewin et al. 2009). Esta alternativa es más objetiva y recoge la parte de la innovación que más contribuye a la competitividad y a la generación de valor añadido y rentabilidad en las empresas.

Entre las variables utilizadas para explicar la innovación en las empresas destacan la inversión en tecnología (Rama, 1996; García y Burns, 1999; Huiban y Bouhsina, 1998; Cabral y Traill, 2001) y los gastos en I+D (Gopinath y Vasavada, 1999; Cabral y Traill, 2001; Traill y Muelenber, 2002; Batternik et al., 2006).

Complementando los efectos de la I+D, hay trabajos empíricos que introducen variables relacionadas con cooperación tecnológica (Cabral y Traill, 2001; Batternik et al., 2006; Karantininis et al, 2010) y cualificación del trabajo (Avermaete et al., 2004; Huiban y Bouhsina, 1998).

Desde el punto de vista de las características de la empresa, son frecuentes los trabajos que toman en consideración el efecto del tamaño de la empresa (Alfranca et al., 2004; Cabral y Traill, 2001; Hartl y Herrmann, 2006; Huiban y Bouhsina, 1998; Karantininis et al., 2010; Furtan and Sauer, 2008).

Otros trabajos tienen en cuenta factores relacionados con la posición competitiva de la empresa y las conexiones desarrolladas con proveedores, clientes y competidores. Así se han encontrado estudios que incluyen variables que miden los siguientes aspectos: orientación al 
mercado (Batternik et al., 2006; Cabral y Traill, 2001), poder de mercado de productores (Gopinath y Vasavada, 1999; Hartl y Herrmann, 2006; Weiss y Wittkopp, 2005), poder de mercado de minoristas (Weiss y Wittkopp, 2005), el tamaño de mercado (Röder et al., 2000), presión de empresas competidoras (Brewin et al., 2009), integración vertical (Karantininis et al., 2010).

Otros estudios incorporan variables relacionadas con decisiones de comercialización como diversificación de productos (Hartl y Herrmann, 2006; Röder et al., 2000), marketing (Avermaete et al., 2004), exportación (Karantininis et al., 2010), y nuevas vías de financiación (Batternik et al., 2006).

Por último, en relación a las TICs, no es abundante la literatura que estudia la relación entre TICs, innovación y sector agroindustrial. Cabe destacar los efectos positivos que diferentes autores atribuyen a esta revolución tecnológica. Así, Beurskens (2003) estudia las potencialidades de e-commerce e indica que puede afectar a las tendencias de las grandes empresas del sector agroindustrial. Chisenga (2008) por su parte presenta el potencial de e-agriculture en diferentes países. Koellinger (2008) demuestra como la utilización de internet o no afecta al crecimiento de la empresa, aunque otro tipo de innovaciones (producto o proceso) lo hacen en mayor medida. Xuemei et al., (2010) indican que la existencia de "Internet of Things" (IOT) reduce la asimetría de información existente entre productores y consumidores. Cho and Park (2012) han testado en Korea incluso la influencia de las redes sociales (Twitter) en la innovación desde el Ministry for Food, Agriculture, Forestry and Fisheries.

Apoyándonos en estas todas estas referencias, se considera en este trabajo que la innovación en producto en las empresas agroalimentarias españolas es función, en menor o mayor medida, de las siguientes estrategias: 
- Inversión en bienes de equipo e innovación en procesos productivos.

- Cooperación tecnológica con proveedores, clientes, competidores y universidades y centros de investigación.

- Gastos de I+D tanto internos como externos.

- Inversión y uso de tecnologías de la información y comunicación.

Además existe interés en estudiar si las PYMEs y las grandes empresas siguen estrategias de innovación diferentes y por ello se contrastan por separado estas ideas en estas dos clases de empresas. Esta posible diferencia de actuación por dimensión empresarial recibe resultados contradictorios en la literatura, por ejemplo García and Burns (1999) muestra como las grandes empresas son menos dependientes tecnológicamente en términos de productos tecnológicos que las PYMEs, mientras que en términos de procesos tecnológicos las empresas medianas muestran un alto nivel de autonomía tecnológica. En la misma línea de estos argumentos hay un pequeño núcleo de empresas que patentan que contribuyen alrededor del $80 \%$ del número total de patentes en el sector agroindustrial internacional (Alfranca et al., 2004), y estos no son especialmente grandes empresas. Por otro lado, Furtan and Sauer (2008) no aprecian diferencias en la actividad innovadora debidas a la dimensión de la empresa para el caso del sector agroalimentario Danés.

\subsection{Hipótesis de investigación}

El objetivo fundamental de los procesos innovadores es, como ya se ha indicado en anteriores apartados, adquirir por parte de las empresas la ventaja competitiva que permita mejorar los resultados económicos. Es primordial por otro lado proteger estas invenciones de 
ser usadas por empresas competidoras que se puedan aprovechar de ellas sin haber realizado ningún tipo de inversión para lograr las mejoras que redunden en unos mejores resultados económicos.

Por un lado, los consumidores de bienes y servicios en general requieren cada vez más que estos satisfagan sus gustos y cumplan con aspectos relacionados con la calidad. En particular, la industria agroalimentaria ha diversificado de manera muy notable los productos de consumo, tan sólo hay que fijarse en los puntos de distribución de productos alimentarios para darse cuenta de la cantidad de variedades que existen de un mismo producto. En este contexto, hay que hacer notar que el proceso innovador no se produce de manera homogénea en cualquier tipo de industria y este es el caso de la industria agroalimentaria, que está considerada, según la teoría, un subsector industrial de baja tecnología y baja innovación.

Las hipótesis que se proponen en la presente investigación pretenden evaluar cómo influyen los factores a los que llamamos causas hipotéticas a los efectos que se persiguen a lo largo de la cadena empresarial.

Dada la consabida baja tendencia de la industria agroalimentaria al uso de los diferentes sistemas de protección de los resultados derivados de la innovación las hipótesis se plantean en tres etapas. Una primera etapa en la que se evalúa la influencia de diferentes factores sobre el hecho de llevar a cabo la protección de la innovación mediante el uso de patentes. En una segunda etapa en la que es la innovación en producto lo que se evalúa. Y una tercera y última etapa en la que se analiza, dando un paso más, como influyen estos factores sobre el hecho de proteger las innovaciones añadiendo otros tipos de protección de innovaciones como son los modelos de utilidad y las marcas de fábrica. 


\subsubsection{La relación del gasto en I+D con el registro de patentes.}

Los gastos en I+D es uno de los factores internos de las empresas que más se ha estudiado como indicador de la innovación empresarial (Galende y Suárez (1999) y Surroca y Santamaría (2007). Además se ha discutido mucho sobre el efecto de la patentes en la competitividad de la economía pues no hay un traspaso directo del conocimiento sino que se genera un monopolio temporal que por otro lado se corresponde con el incentivo que dicho desarrollo recibe y por el que se compensan los gastos destinados al proceso de investigación y desarrollo de la invención o la innovación. Szabolcs y Escribano (2010).

El gasto en I+D debería ser el principal factor relacionado con las patentes. Las empresas pueden realizar su I+D internamente o pueden adquirirla de otras empresas. Existe un interés en averiguar el papel que ambos tipos de I+D desempeñan en la industria agroalimentaria (Alarcón y Sánchez, 2013). En esta línea se formula la siguiente hipótesis:

Hipótesis 1: Los gastos en I+D están relacionados
positivamente con el registro de patentes en la industria
agroalimentaria española.

Dado que las bases de datos distinguen entre ambos tipos se han formulado las hipótesis por separado:

\footnotetext{
Hipótesis 1A: La I+D externa está relacionada positivamente con el registro de patentes en la industria agroalimentaria española.

Hipótesis 1B: La I+D interna está relacionada positivamente con el registro de patentes en la industria agroalimentaria española.
} 


\subsubsection{La relación de la cooperación tecnológica con el registro de patentes.}

Se entiende por cooperación las relaciones que se establecen entre empresas que se encuentran al mismo nivel de la cadena (cooperación tecnológica con competidores, СTCO), entre la empresa y los proveedores (CTPR), con los clientes (CTCL) y con centros tecnológicos y universidades (CUCT).

La cooperación tecnológica permite que las empresas que tienen menos posibilidad de innovar en su proceso productivo, culminen este con una solicitud de patente. Los análisis más recientes sobre el impacto de la cooperación tecnológica sobre los resultados innovadores los encontramos en los trabajos de Miotti y Sachwald (2.003) y de Surroca y Santamaría, (2.007). Ambos trabajos se enmarcan en la Teoría de Recursos y Capacidades en la que se pone de manifiesto que son las estrategias empresariales diseñadas para generar capacidad de innovación las que proporcionan ventajas comparativas y colocarse en los primeros puestos del ranking de empresas innovadoras. En nuestro caso damos un paso más en el proceso estableciendo el registro de patentes como un indicador output de la actividad innovadora. Esto nos va a permitir estudiar de qué manera la colaboración tecnológica entre distintas empresas afecta al registro de patentes. Entendemos por cooperación las relaciones que se establecen entre empresas que se encuentran al mismo nivel de la cadena comercial, en este caso hablamos de cooperación tecnológica con competidores (CTCO). Además también se entiende que existe cooperación tecnológica cuando esta se establece entre la empresa y los proveedores (CTPR), con los clientes (CTCL) y con centros tecnológicos y universidades (CUCT).

La cooperación tecnológica adquiere especial relevancia en las empresas con una baja capacidad de inversión en I+D. Su situación económica constituye la principal barrera para alcanzar niveles de inversión en I+D que garanticen su futuro y mejoren su competitividad, 
por lo que se ven avocadas a depender de otras empresas para el desarrollo de su actividad innovadora.

En concordancia con la literatura revisada y en el ámbito de las empresas agroalimentarias españolas, el signo esperado por tanto es positivo para la cooperación tecnológica entre la empresa y los clientes y los proveedores. En cambio con los competidores el signo que se ha de esperar será negativo.

Por lo tanto, establecemos la primera hipótesis general:

Hipótesis 2: La cooperación tecnológica está relacionada
positivamente con el registro de patentes en la industria
agroalimentaria española.

Las hipótesis particulares que hacen referencia a cada uno de los tipos de colaboración que se pueden llevar a cabo y de los cuales tenemos datos en la encuesta son:

Hipótesis 2A: La cooperación con proveedores está
relacionada positivamente con el registro de patentes en industria
agroalimentaria española.
Hipótesis 2B: La cooperación con clientes está relacionada
positivamente con el registro de patentes en industria
agroalimentaria española.
Hipótesis 2C: La cooperación con competidores está
relacionada negativamente con el registro de patentes en la
industria agroalimentaria española.
Hipótesis 2D: La colaboración con las Universidades y
registro de patentes en la industria agroalimentaria española.




\subsubsection{La relación de otros activos complementarios con la propensión a patentar}

En la revisión anterior se ha visto cómo la inversión en nuevos equipos puede ser una vía de innovación. La inversión en maquinaria y en equipos probablemente sea una condición necesaria, aunque no suficiente, para que la empresa tenga cierto nivel tecnológico que le permita patentar. Se espera, por tanto, una contribución positiva:

Hipótesis 3A: La inversión en bienes de equipo está relacionada positivamente con el registro de patentes en la industria agroalimentaria española

Schumpeter (1934), fue el primero en incluir el tamaño de la empresa como factor explicativo afirmando que un mayor tamaño de empresa incrementaba la probabilidad de que la empresa lleve cabo actividades de innovación. El principal aspecto que se pone de relieve para afirmar que las empresas grandes tienen una mayor propensión a patentar como instrumento de protección de la actividad innovadora es su capacidad financiera para llevarla a cabo. Sin embargo, otros autores han argumentado en sentido contrario, es decir, las empresas grandes son más rígidas que las pequeñas que tienen una mejor capacidad para adaptarse al entorno en el que actúan. Por tanto, sí cabe esperar una relación entre tamaño y capacidad de patentar. Y una posibilidad plausible sería que dependiera de cierto tamaño óptimo, de forma que existiera una relación positiva hasta alcanzar este óptimo y fuera negativa tras superarlo. En cualquier caso, la hipótesis se formula en términos más generales:

Hipótesis 3B: El tamaño de la empresa tiene una relación significativa con el registro de patentes en la industria agroalimentaria española.

El tamaño en sí puede verse como una forma de medir la calidad de los activos complementarios de la empresa, pues es de esperar que 
un mayor volumen de facturación y plantilla de trabajadores se correspondan con una mejor organización de la empresa y con mayor calidad de los recursos humanos, comerciales y financieros. No obstante, se han incluido hipótesis adicionales para estos tres tipos de recursos y se espera de ellos una relación positiva con la capacidad de patentar:

Hipótesis 3C: La calidad de los recursos humanos está relacionada positivamente con el registro de patentes en las empresas agroalimentarias españolas.

Hipótesis 3D: La calidad de los recursos comerciales está relacionada positivamente con el registro de patentes en las empresas agroalimentarias españolas.

Hipótesis 3E: La calidad de los recursos financieros está relacionada positivamente con el registro de patentes en las empresas agroalimentarias españolas.

\subsubsection{Resumen de hipótesis}

En la Tabla 13 se resumen las hipótesis planteadas en los apartados anteriores con el signo estimado que se espera encontrar para cada una de ellas de acuerdo con la literatura revisada al respecto. Se define a qué variable dentro del modelo está referida cada hipótesis así como el factor de la empresa en el que se incluye. Las hipótesis se plantean sobre aquellos factores que nos parecen más relevantes en el proceso de innovación empresarial. 
Tabla 13: Efectos esperados para cada una de las hipótesis planteadas.

\begin{tabular}{|c|c|c|c|}
\hline Hipótesis & Factor & Variable & Signo estimado \\
\hline $1 \mathrm{~A}$ & Recurso estratégico & Gastos I+D externa & + \\
\hline $1 B$ & “ & Gastos I+D interna & + \\
\hline $2 \mathrm{~A}$ & “ & CTPR & + \\
\hline $2 \mathrm{~B}$ & “ & CTCL & + \\
\hline $2 \mathrm{C}$ & “ & СТСO & - \\
\hline 2D & “ & CUCT & + \\
\hline $3 \mathrm{~A}$ & Recurso tecnológico & INBEA & + \\
\hline $3 B$ & Recurso organizativos & PTP (Tamaño) & $+/-$ \\
\hline $3 C$ & Recursos Humanos & CPSP & + \\
\hline $3 D$ & Recursos comerciales & $\mathrm{PX}$ & + \\
\hline \multirow{3}{*}{$3 E$} & \multirow{3}{*}{ Recursos Financieros } & FMV & + \\
\hline & & & \\
\hline & & DEUDA & + \\
\hline
\end{tabular}

Fuente: Elaboración propia

Como podemos ver, se espera que tengan efectos positivos sobre el número de patentes, en base a la literatura empírica revisada, todos salvo la cooperación con empresas competidoras (rivales). En el caso del tamaño como ya hemos señalado no podemos predecir un signo a priori.

En el

Diagrama 4 de la página 46, se muestra la relación de las hipótesis de investigación con el mapa conceptual planteado para el trabajo. 



\section{Capítulo 3}

Modelos

ECONOMÉTRICOS DE

CONTEO 



\section{MODELOS ECONOMÉTRICOS DE CONTEO}

El uso de la regresión estadística ha permitido realizar análisis de datos en el ámbito de las ciencias sociales. La econometría se define como "El campo de la economía que tiene que ver con la aplicación de la estadística matemática y las herramientas de inferencia estadística, a las mediciones empíricas de relaciones postuladas por la economía teórica" (Greene, 2006). A este autor le debemos uno de los libros más influyentes en el análisis econométrico.

El objetivo de este apartado de la investigación es la descripción de los modelos de regresión que se han encontrado en la literatura econométrica y que son empleados cuando lo que se pretende es analizar modelos en los que la variable explicada es lo que llamamos una variable de conteo. Es decir, cuando dicha variable es el resultado de un recuento del número de veces que ocurre un hecho en un intervalo de tiempo determinado. Estos son el modelo de Poisson, el modelo de regresión binomial negativo, el modelo de Poisson ceroinflado (Zero-inflated) y el modelo de regresión Hurdle (valla).

En el ámbito específico de la innovación podemos mencionar el número de patentes solicitadas por las empresas y el número de innovaciones (en producto y en proceso) llevadas a cabo por las empresas como ejemplos en los que se emplean variables de conteo como variable respuesta.

Los siguientes modelos que se presentan de forma ordenada atienden a la evolución que han desarrollado diferentes autores. Cada uno de ellos resuelve limitaciones de modelos anteriores o tiene en cuenta aspectos que no consideraban. 
Tabla 14: Modelos econométricos para datos de conteo

\begin{tabular}{|c|c|c|}
\hline \multirow{2}{*}{ Modelo } & Autor & $\begin{array}{c}\text { Limitación que resuelve cada método respecto } \\
\text { al anterior }\end{array}$ \\
\hline Poisson & $\begin{array}{c}\text { Poisson, } \\
1837\end{array}$ & Distribución de los datos \\
\hline Quasipoisson & $\begin{array}{c}\text { Wedderbum, } \\
1974\end{array}$ & Sobredispersión de los datos \\
\hline Binomial Negativa & Cameron, & Heterogeneidad de los datos \\
\hline Cero inflado & 1987 & Eambert, \\
Lurdle & 1992 & Exceso de ceros \\
\hline
\end{tabular}

Fuente: Elaboración propia

\subsection{Método de regresión lineal}

La técnica utilizada en esta investigación ha consistido en el empleo de métodos de regresión. Se pueden encontrar ejemplos de su aplicación en la búsqueda de factores explicativos en múltiples trabajos y múltiples ámbitos. En el ámbito industrial, Voces Rodríguez (2011) analiza, en el sector de la industria forestal, la importancia de la innovación y la sostenibilidad en la industria.

No es objeto de este trabajo una exposición rigurosa sobre el método de regresión lineal, por ello nos limitamos en este caso a hacer una breve recopilación que se describe en los magníficos manuales de Novales (1996) y Greene (2008). Ambos recogen ampliamente las técnicas para la realización de análisis de datos.

El fundamento del método de regresión se basa en la consideración que supone la existencia de una relación entre diferentes 
variables que caracterizan a los individuos analizados, sea este una persona, una empresa, o cualquier otra entidad. La posibilidad de hallar una función de relación entre las variables nos permite establecer los perfiles de conducta de dichas variables.

Si tenemos en cuenta la dificultad que en la mayoría de los casos supone observar todas las variables que tienen efecto sobre una variable determinada, la función buscada siempre estará incompleta. En el caso de que esta función sea completa o exacta tendría una expresión del tipo 1 para el caso de una única variable independiente $X$. La función es determinista en este caso.

$$
y_{i}=\beta_{0}+\beta_{1} x_{i}
$$

Donde y es la variable explicada (respuesta) y $x$ es la variable explicada (factores). Los coeficientes de la regresión $\beta_{0}$ y $\beta_{1}$ se corresponden con la ordenada en el origen y con la pendiente de la recta del modelo respectivamente.

La función 1 se complica debido a diferentes causas, entre ellas:

-La necesidad de tener en cuenta más de una variable explicativa, dando lugar a un modelo de regresión múltiple.

$$
y_{i}=\beta_{0}+\sum \beta_{i} x_{i} \quad \mathrm{i}=1,2, \ldots, \mathrm{n}
$$

En este caso $x_{i}$ representa a un conjunto de variables explicativas.

-Imposibilidad de contar con más de una variable explicativa, dando lugar a un modelo de regresión de carácter estocástico.

$$
y_{i}=\beta_{0}+\sum \beta_{i} x_{i}+e_{i} \quad \mathrm{i}=1,2, \ldots, \mathrm{n}
$$

En este modelo la $e_{i}$ es el residuo o error cometido en la especificación del modelo de tal manera que recoge la parte del modelo que no somos capaces de incluir ya sea porque se desconozca su efecto, 
se omita por razones económicas o sea difícil técnicamente su obtención.

A partir de este punto en el que se ha incluido el término de error entran en juego los tipos de distribución asociadas al término de error y por tanto a la distribución de la variable explicada o endógena, al ser esta aleatoria y depender del término de error. Es por tanto necesario observar conceptos importantes como la heterocedasticidad, la autocorrelación y la multicolinealidad. En caso de que exista alguno de estos fenómenos la estimación de los parámetros por el método de mínimos cuadrados ordinario ya no es posible. El método que se emplea en estos casos es el de estimación de mínimos cuadrados generalizados. Este consiste en la transformación del modelo que permita emplear el método de mínimos cuadrados ordinario

En este contexto, cuando la distribución de los errores no siempre sigue una distribución normal, se necesita emplear distribuciones de la familia exponencial y por tanto el empleo de modelos que tienen en cuenta esta consideración.

\subsection{Revisión de modelos econométricos para datos de conteo}

Un concepto fundamental para el desarrollo de estos modelos es el concepto de familia exponencial que nos permite dar un paso más y obtener modelos que se ajustan más a la realidad. Básicamente se trata de obtener resultados apropiados cuando la variable sólo puede tomar valores específicos. En particular, en el caso del recuento del número de patentes el resultado no podrá ser ni un valor negativo ni un valor no entero, es decir, tan sólo los valores enteros positivos serán válidos. En general, los modelos para datos de conteo forman parte de un tipo de modelos cuyos valores de la variable dependiente o explicada están limitados de alguna forma. Entre estos modelos encontramos los de 
variable de elección binaria, es decir, toman dos posibles valores (0 y 1), los modelos de elección discreta (números enteros) y los modelos con datos de recuento (números enteros no negativos). Son estos últimos los que se emplean para modelizar fenómenos como el número de invenciones que una empresa patenta en un año.

Lo habitual en estos casos es trabajar con un tipo de distribución que describa lo más parecido posible la realidad de los datos. En nuestro caso, al tomar el número de patentes de una empresa o el número de innovaciones en producto o proceso como variable dependiente se observa que no sigue una distribución Normal sino que se distribuye según una distribución de Poisson.

En la gráfica vemos cómo se distribuyen los datos para el caso de las innovaciones en producto (IP) obtenida de la Encuesta sobre Estrategias empresariales.

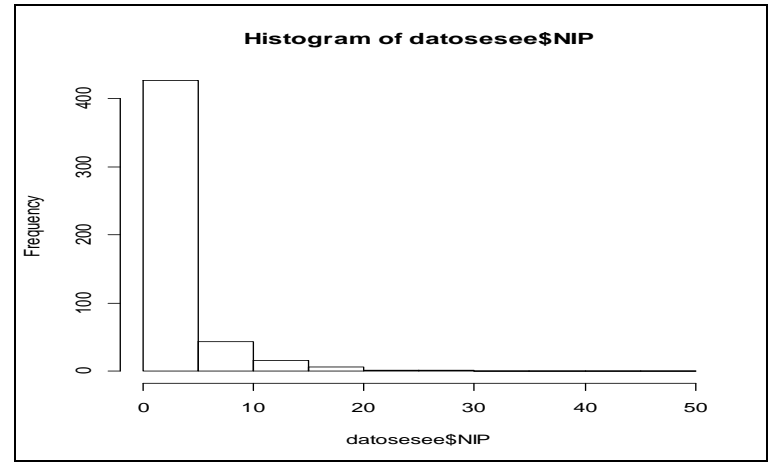

\subsubsection{El modelo de Regresión de Poisson}

En este modelo la variable explicada tiene una distribución de Poisson que se corresponde con el número de veces que un hecho ocurre en un intervalo determinado pudiendo este ser temporal o espacial. La ocurrencia de esta variable es aleatoria, independiente en el tiempo y en el espacio y con una tasa de ocurrencia constante. 
El parámetro que caracteriza a la distribución de Poisson es la media $(\lambda)$. El subíndice i hace referencia a cada individuo de la muestra, $X$ a las variables explicativas e $Y$ a la variable explicada.

De esta manera el modelo queda especificado según:

$$
P\left(Y_{i=1} y_{i} / x_{i}\right)=\frac{e^{-\lambda_{i}} \lambda_{i}^{y_{i}}}{y_{i}} \quad y_{i=0,1,2, \ldots}
$$

Donde el parámetro $\lambda_{i}$ se formula como:

$$
\ln \lambda_{i}=\beta^{\prime} x_{i}
$$

Y la esperanza condicionada resulta:

$$
E\left[y_{i} \mid x_{i}\right]=\lambda_{i}
$$

Cuatro son las críticas que se hacen al modelo de Poisson. En primer lugar, la propiedad de equidispersión de los datos (media igual a la varianza) que presenta este modelo es una propiedad muy restrictiva y no es realista con la naturaleza de los datos analizados dentro del ámbito de las ciencias sociales y económicas. En segundo lugar, la frecuencia de ceros resulta ser inconsistente con el modelo de Poisson. En tercer lugar, la independencia de los sucesos es una condición que tampoco se cumple y por último, en cuarto lugar y relacionado con la especificación del parámetro de la distribución, en el caso del modelo de Poisson no permite la existencia de la posible heterogeneidad no observable.

\subsubsection{El modelo de regresión binomial negativa}

Este modelo resuelve el problema que presenta el modelo de Poisson relacionado con la heterogeneidad de las observaciones. En las mayoría de los casos que se estudian cuando los datos son de conteo no se produce una igualdad entre la media y la varianza (equidispersión) como presupone el modelo de regresión de Poisson. La heterogeneidad 
de los datos en muchas ocasiones tiene un efecto en la propiedad de dispersión de estos, en concreto se presenta una sobredispersión de los datos (varianza superior a la esperada).

Este inconveniente se resuelve con la introducción de un efecto individual no observado $u_{i}$ en la media condicional en el modelo de Poisson (Lambert, 1992; Welsh et al. 1996; Böhning et al., 1999)

$$
\begin{gathered}
\log \mu_{i}=\beta^{\prime} x+\epsilon_{i}=\log \lambda_{i}+\log u_{i} \\
f\left(y_{i} \mid x_{i}, u_{i}\right)=\frac{e^{-\lambda_{i} u_{i}}\left(\lambda_{i} u_{i}\right)^{y_{i}}}{y_{i} !}
\end{gathered}
$$

La función de densidad de $y_{i}$ queda de la siguiente manera, con el parámetro de dispersión $\theta$ que si es igual a cero tenemos el modelo de Poisson pues la media y la varianza se igualan.

$$
f\left(y_{i} \mid x_{i}\right)=\frac{\Gamma\left(\theta+y_{i}\right)}{\Gamma\left(y_{i}+1\right) \Gamma(\theta)} r_{i}^{y_{i}}(1-r)^{\theta}, \quad \operatorname{con} r_{i}=\frac{\lambda_{i}}{\lambda_{i}+\theta}
$$

\subsubsection{El modelo cero inflado}

El exceso de un determinado valor como ocurre con el cero en el conjunto de datos es una característica que es posible considerar a la hora de plantear el tipo de distribución de dichos datos. Dicho exceso deriva de la heterogeneidad no observada. En este caso dicho valor presentará una ocurrencia que precisa de una distribución diferente a la de Poisson o la Binomial Negativa. Se recurre en este caso a diferenciar las distribuciones de los datos considerando una diferente según el origen de este valor. Este primer modelo y el que a continuación se expone tienen en cuenta esta última consideración diferenciando el origen de los ceros a través de procesos generadores de datos distintos. 
En este primer modelo, denominado en la literatura como Modelo CeroInflado, Zero-Inflated Model, Poisson o Binomial Negativo Cero-Inflado, se distinguen lo que se ha llamado los ceros estructurales, es decir, aquellos que son siempre cero y los ceros muestrales que comparten el mismo proceso generador que los demás valores. Los ceros estructurales responden en nuestro caso particular a los de aquellas empresas que por su idiosincrasia no patentan nunca. En cambio los ceros estructurales corresponden a aquellas empresas que en el intervalo de tiempo considerado unas veces patentan (valores positivos) y otras no (cero).

La especificación de este modelo se expresa de la siguiente forma si se considera de Poisson la distribución de los valores positivos:

$$
\begin{gathered}
P\left(Y_{i}=0\right)=q_{i}+\left(1-q_{i}\right) e^{-\lambda_{i}} \\
P\left(Y_{i}=y_{i}>0\right)=\left(1-q_{i}\right) \frac{e^{-\lambda_{i}} \lambda_{i}^{y_{i}}}{y_{i} !} \quad \operatorname{con} \lambda_{i}=e^{x_{i} \beta}
\end{gathered}
$$

De tal manera que si $q_{i}=0$, obtenemos el modelo de Poisson.

En el caso del modelo binomial negativo, la especificación será la mostrada a continuación:

$$
\begin{gathered}
P\left(Y_{i}=0\right)=q_{i}+\left(1-q_{i}\right)\left(\frac{v}{v+\lambda_{i}}\right)^{v} \\
P\left(Y=y_{i}>0\right)=\left(1-q_{i}\right) \frac{\Gamma\left(y_{i}+v\right)}{\Gamma\left(y_{i}+1\right) \Gamma(v)}\left(\frac{v}{v+\lambda_{i}}\right)^{v}\left(\frac{\lambda_{i}}{v+\lambda_{i}}\right)^{\lambda_{i}}
\end{gathered}
$$

En este caso, si $q_{i}=0$, obtenemos el modelo binomial negativo.

\subsubsection{El modelo de regresión Hurdle}

Este modelo precisa de la combinación de dos modelizaciones. Una primera en la que se distingue entre valores cero y valores positivos a través de un modelo binario, y una segunda que se ha dado 
en llamar modelo truncado en cero para aquellos valores que son mayores que cero. Particularizando, la primera parte del modelo distingue entre aquellas empresas que patentan sus invenciones en el período de tiempo correspondiente al análisis y las que no lo hacen, y la segunda parte que distingue el número de veces que a lo largo del periodo ha patentado siempre que lo haya hecho una vez al menos.

Una especificación del modelo la encontramos en SalinasRodríguez (2009), la mezcla de las dos distribuciones queda de la siguiente forma:

$$
\begin{gathered}
P(y=0)=f_{1}(0) \\
P(y=j)=\frac{1-f_{1}(0)}{1-f_{2}(0)} f_{2}(y)
\end{gathered}
$$

En el caso de que $f_{1}()=.f_{2}($.$) estaríamos en un modelo de Poisson$ al no reconocer la igualdad de los procesos generadores de ceros y números positivos.

\subsubsection{Datos de panel}

Los datos disponibles en las bases de datos empleadas en esta tesis conforman un panel de datos en los que se combina la información de los mismos individuos (corte transversal) durante distintos periodos de tiempo (corte temporal). De esta manera, siguiendo el modelo descrito en Novales (1996), la relación que se establece entre la variable explicada y las explicativas están referidas a cada uno de los individuos de la muestra $(i=1,2, \ldots, N)$ a lo largo de varios periodos de tiempo $(t=1,2, \ldots, T)$ y se representa a través del modelo de regresión:

$$
y_{i t}=\beta_{0}+\beta_{1} x_{i t}+u_{i t}
$$

En el caso que nos compete la i está referida a cada una de las empresas del panel y la $t$ al momento concreto para el que se toma un valor determinado. 
Entre las bases de datos de las que se disponen en España que contienen información relacionada con la actividad innovadora que realizan las empresas encontramos dos que serán comentadas en el capítulo siguiente y que se caracterizan por tener una estructura de panel. La Encuesta sobre estrategias empresariales (ESEE) y el Panel de innovación tecnológico (PITEC). En el caso de la primera además de datos de la actividad innovadora se encuentran también datos relacionados con otros aspectos como los referidos a datos contables, financieros, de comercio exterior y otros. En el caso del segundo panel, este sí que está dedicado en exclusiva a la actividad innovadora de las empresas.

Siguiendo a Baltagi (2001), las ventajas del empleo de datos con estructura de panel son:

- El control de la heterogeneidad de los individuos

- Los datos de panel proporcionan más información, más variabilidad, menos colinealidad entre las variables, más grados de libertad y más eficiencia en las estimaciones econométricas.

- Son capaces de identificar y medir efectos que no son detectables fácilmente cuando los datos son series temporales (time-series data) o transversales (cross-section data).

- Construir modelos de comportamiento complejos.

- Estudiar las dinámicas de ajuste.

Y en relación a las desventajas que implican el uso de los datos de panel:

- La propia elaboración del panel de datos.

- Los errores en las respuestas dadas por los individuos debidos a la no comprensión de las preguntas. 
El modelo que se plantea viene definido por la expresión:

$$
\mathrm{y}_{\mathrm{it}}=\alpha_{i}+\beta \mathrm{x}_{\mathrm{it}}+\mathrm{u}_{\mathrm{it}} \quad \text { con } \quad \mathrm{u}_{\mathrm{it}}=\mu_{\mathrm{i}}+v_{\mathrm{it}}
$$

Donde $x_{i t}$ es un vector fila con $k$ variables que llamamos explicativas o endógenas, $\beta$ son los parámetros que se pretenden estimar $y u_{i t}$ es el término de error dividido en dos componentes. El primero, $\mu_{i}$, de los dos componentes del error señala factores que no son observables y que son diferentes para cada individuo (efecto individual) aunque no en el tiempo y la segunda componente, $v_{i t}$, representa al error aleatorio que es particular para un individuo en un determinado periodo.

Esta dualidad del componente de error del modelo nos permite utilizar de forma alternativa modelos que llamaremos de efectos fijos (Fixed Effects Model) y de efectos aleatorios (Ramdon Effects Model).

La diferencia entre ambos modelos es la consideración que cada uno de ellos hace de los efectos individuales. El modelo de efectos fijos (MEF) considera el término constante $\mu_{\mathrm{i}}$ distinto entre todos los individuos y que son independientes entre sí. Por el contrario en el caso del modelo de efectos aleatorios (MEA) considera que dichos efectos individuales $\mu_{\mathrm{i}}$ no son independientes entre sí y están distribuidos aleatoriamente.

En el MEF la estimación se realiza considerando las desviaciones de las medias del grupo:

$$
y_{i t}-\bar{y}_{i}=\beta\left(x_{i t}-\bar{x}_{i}\right)+\left(u_{i t}-\bar{u}_{i}\right)
$$

Mientras en el MEA se realiza la estimación considerando las desviaciones parciales:

$$
y_{i t}-\lambda_{i} \bar{y}_{i}=\beta\left(x_{i t}-\lambda_{i} \bar{x}_{i}\right)+\left(u_{i t}-\lambda_{i} \bar{u}_{i}\right) \quad \operatorname{con} \lambda_{i}=1-\sqrt{\frac{\sigma_{v}^{2}}{T_{i} \sigma_{\mu}^{2}+\sigma_{v}^{2}}}
$$





\section{CApítulo 4}

\section{Fuentes de Información}





\section{FUENTES DE INFORMACIÓN}

Previamente a la especificación del modelo econométrico se exponen las fuentes de información que se emplean en el análisis de la actividad innovadora de las empresas. A través de ellas se llevará a cabo la caracterización de las diferentes variables empleadas en los estudios empíricos.

Para el análisis desarrollado en la Tesis se ha recurrido a dos fuentes de información estadísticas que resultan de evidente interés para los objetivos planteados y que nos permite aproximar las características de las empresas del sector agroindustrial.

Las fuentes de información con la que se ha contado en la presente investigación son fruto del interés suscitado por parte de las administraciones públicas.

La Administración pública española, a través de diversos ministerios y a lo largo de las tres últimas décadas viene realizando una serie de bases de datos donde queda recogida la información económico-financiera y de diferentes ámbitos entre el que se encuentra la actividad innovadora de las empresas que pertenecen al sector industrial español. En concreto y dada la relevancia dada por la administración pública al fomento de las inversiones empresariales en $I+D+i$, se puso en marcha desde el año 1990 la elaboración de una herramienta con el objeto de que los investigadores pudieran caracterizar el tejido industrial español por un lado y por otro lado con el objeto de proporcionar la información necesaria para poder implementar políticas de $I+D+i$.

Las principales fuentes de información son la Encuesta Sobre Estrategias Empresariales (ESEE) y el Panel de Innovación Tecnológica (PITEC). Ambos instrumentos estadísticos son analizados en este capítulo. 
En la Tabla 15 siguiente se relacionan las principales fuentes que se encuentran en España y que permiten el análisis del sector industrial.

\begin{tabular}{|c|c|c|c|}
\hline Encuesta & Organismo/Institución & Carácter & $\begin{array}{l}\text { Año de } \\
\text { inicio }\end{array}$ \\
\hline $\begin{array}{l}\text { Encuesta } \\
\text { Industrial }\end{array}$ & I.N.E. & Estructural & 1993 \\
\hline $\begin{array}{l}\text { Central de } \\
\text { Balances }\end{array}$ & Banco de España & Financiera & 1991 \\
\hline E.S.E.E. & $\begin{array}{l}\text { SEPI/Ministerio de } \\
\text { Industria }\end{array}$ & Económico/Innovación & 1990 \\
\hline P.I.TEC. & FECYT/I.N.E. & Innovación & 2004 \\
\hline
\end{tabular}

Fuente: Elaboración propia

\subsection{Encuesta Sobre Estrategias Empresariales (ESEE)}

El periodo que abarca la encuesta es de 23 años, desde el 1990 hasta el 2013, y el período que se ha utilizado para la realización del estudio se ha fijado atendiendo a la naturaleza de la encuesta entre los años 1998 y 2008. El inicio del período se fija en el año 1998 ya que es en este año cuando se comienza a reflejar en la encuesta las preguntas relacionadas a la cooperación tecnológica que realizan las empresas manufactureras españolas y son variables que aparecen incorporadas al modelo econométrico.

La encuesta ha sido elaborada por la Sociedad Estatal de Participaciones Industriales (SEPI). Su diseño está pensado para generar información microeconómica de panel adaptada a la especificación y contraste de modelos econométricos derivados de la teoría económica. 
Desde sus comienzos se han encuestado una media anual aproximada de 1800 empresas, a partir de un cuestionario de 107 preguntas, con más de 500 campos. Incorpora además información sobre sus cuentas de resultados y balances contables. Gracias a esto podemos aproximar en los modelos que especificamos a continuación aquellas variables que no tienen una traducción directa en la encuesta.

El análisis se realiza con los datos que facilitan las empresas que voluntariamente acceden a cumplimentar la encuesta tras haber sido seleccionada mediante la combinación de criterios de exhaustividad y de muestreo aleatorio. El número de empresas que han participado en algún momento del periodo en la encuesta son un total de 4.629 empresas.

Como se aprecia en la Gráfico 3, en términos absolutos, el número de empresas que han participado en la encuesta aumentó en el periodo 1998-2008. La media anual de empresas del conjunto de sectores industriales españoles que han participado en la encuesta es 1.777 empresas. Si nos fijamos en las empresas del sector de la industria agroalimentaria (IAA) la media anual es de 256 empresas y de 1.530 en el resto de sectores.

Gráfico 3: Evolución de empresas que participan en la encuesta

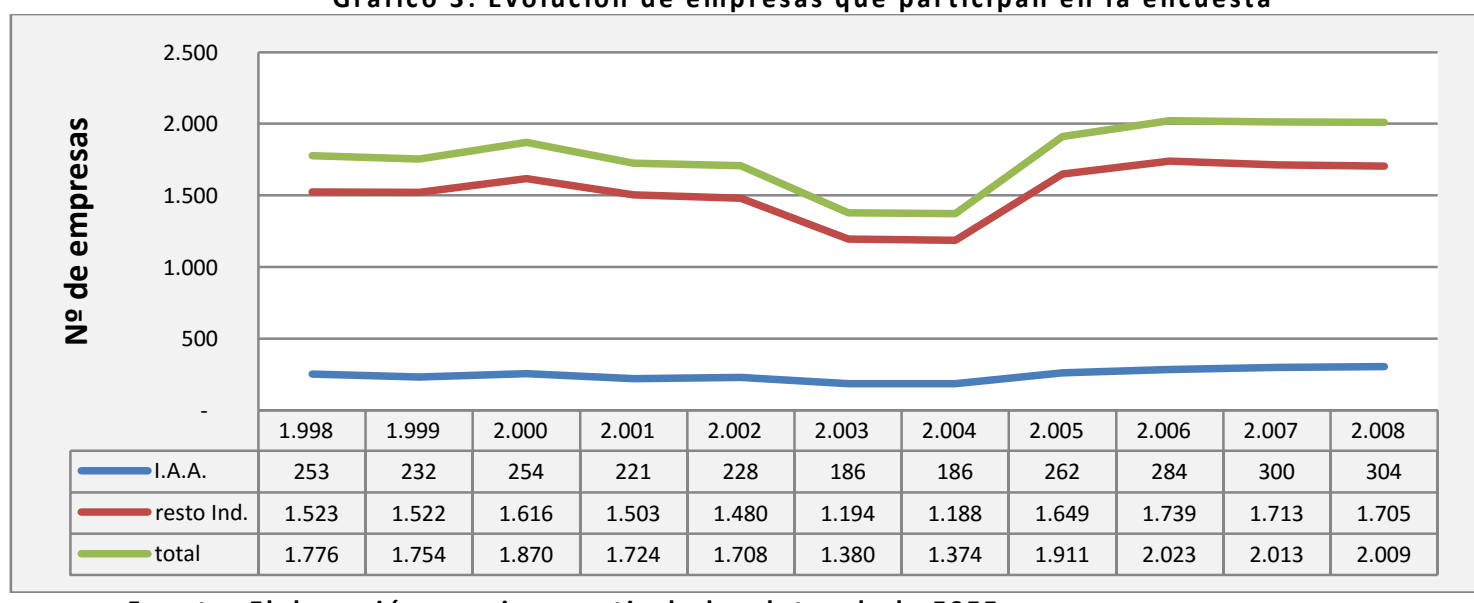

Fuente: Elaboración propia a partir de los datos de la ESEE

En la Tabla 16 se observa toda la casuística de la participación de las empresas en la encuesta en el periodo 1998-2008. 
Tabla 16: Participación en la encuesta ESEE

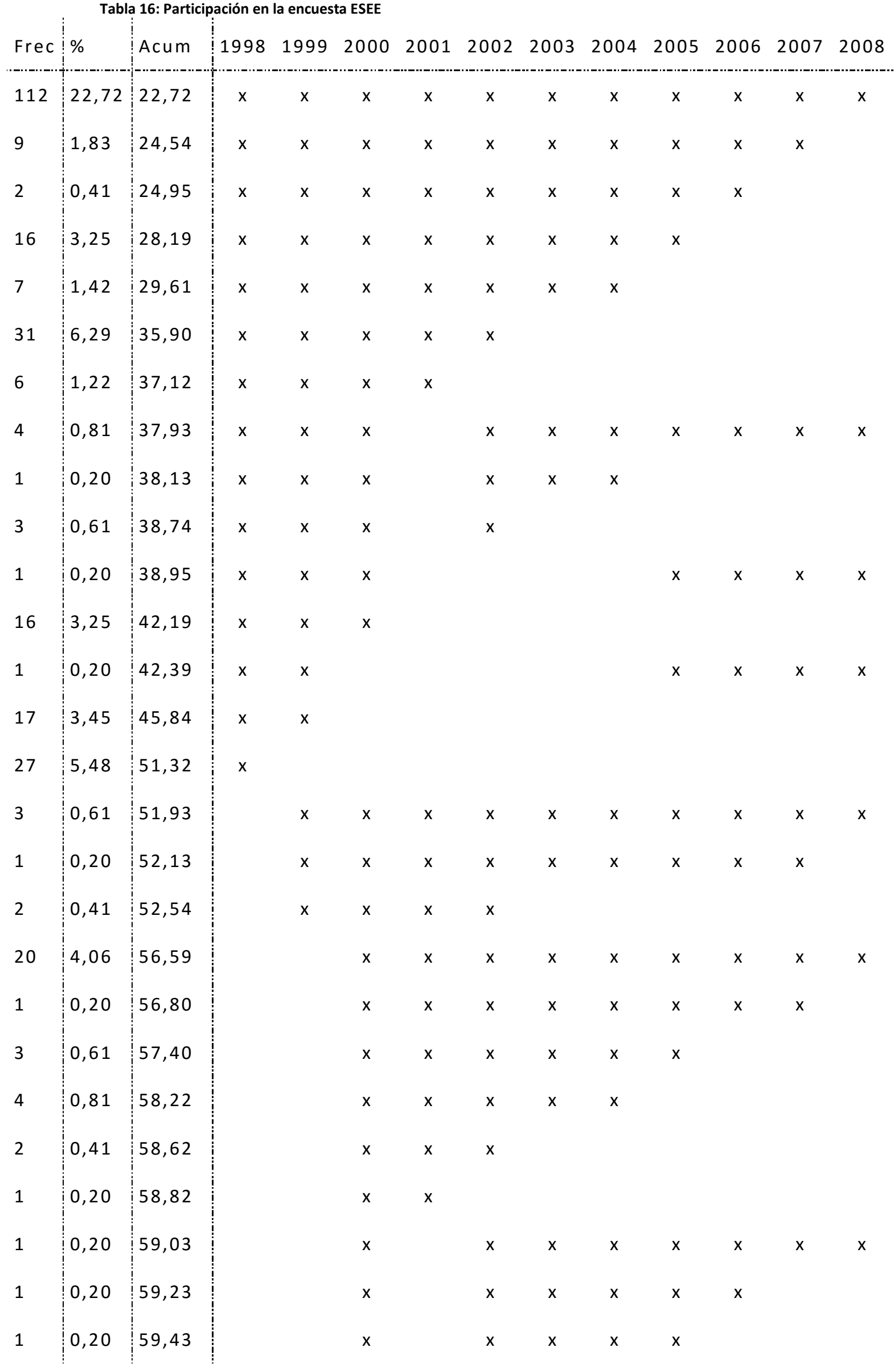




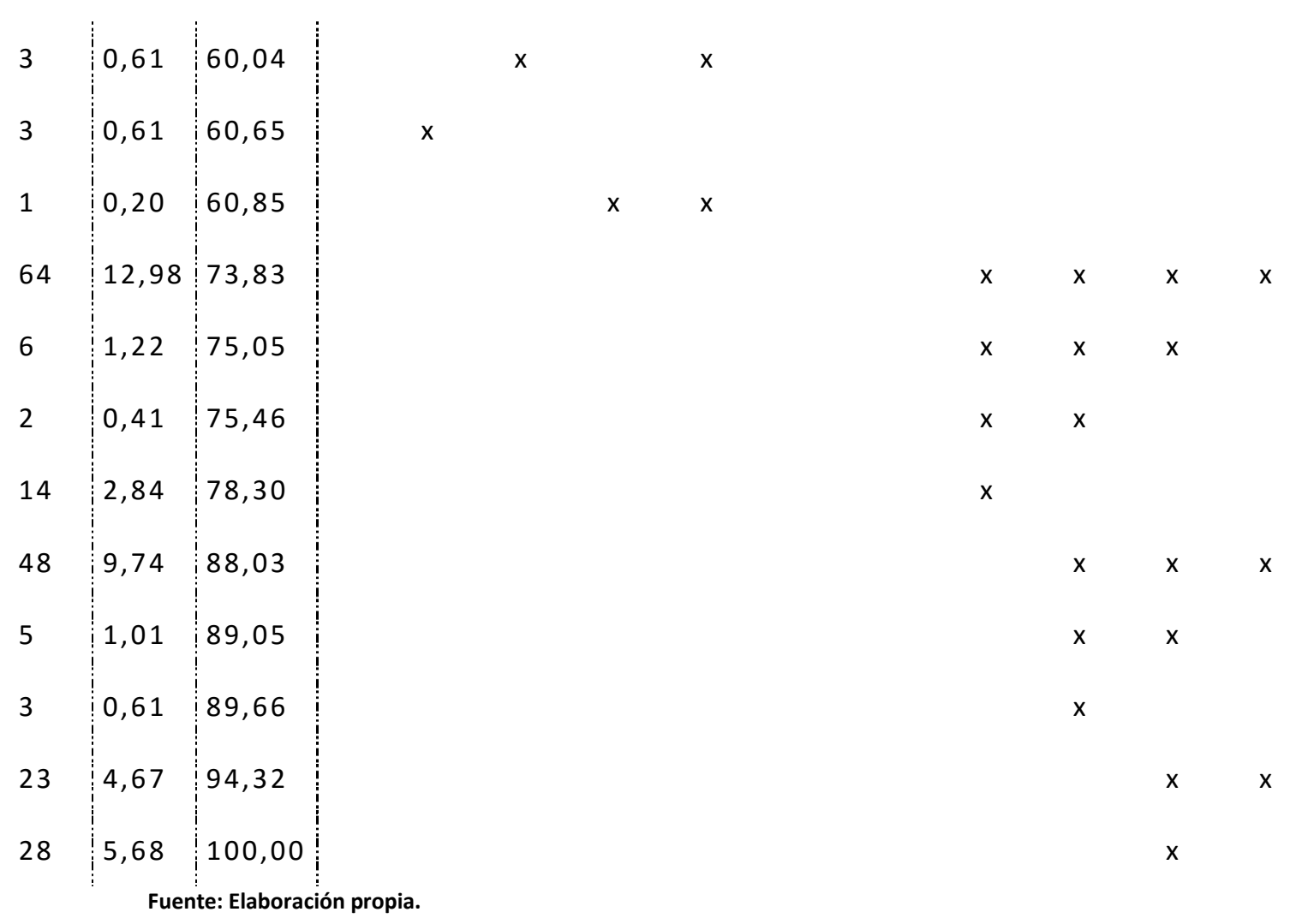

Durante el periodo analizado, aproximadamente la cuarta parte de las empresas $(22,7 \%)$ de la muestra del sector agroindustrial ha participado todos los años. Esto se corresponde con un total de 112 empresas. En el Gráfico 4 recoge el número de empresas que participan en la encuesta en relación con el número de años que lo hacen en el período de análisis.

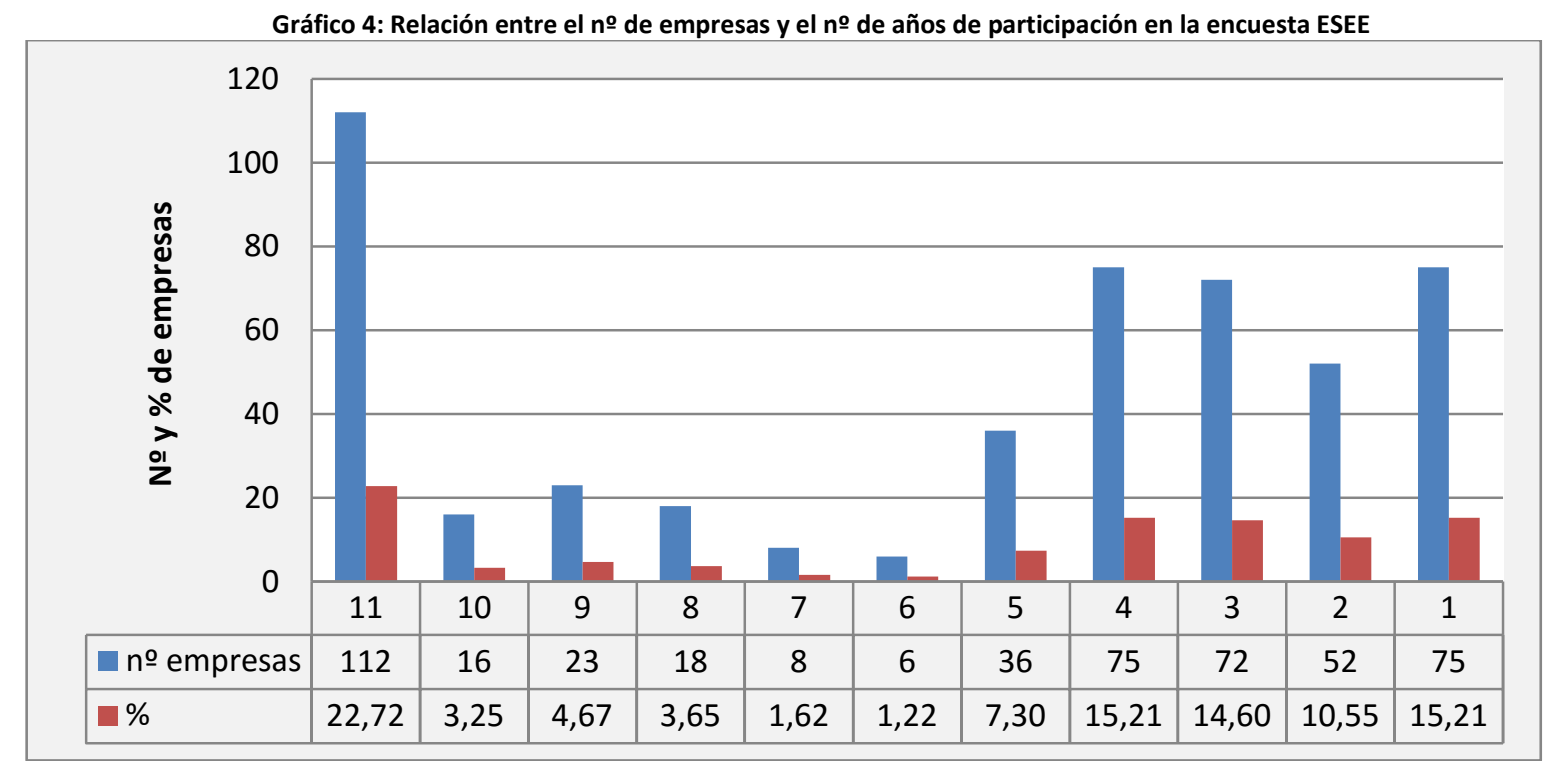

Fuente: Elaboración propia a partir de datos de la ESEE 
Entre ambos, Gráfico 3 y Gráfico 4, podemos tener una idea del comportamiento de las empresas agroindustriales a la hora de participar en la encuesta.

En la Tabla 17 se muestra el número de empresas que han participado en la encuesta distinguiendo el sector de actividad al que pertenece. Las tres primeras son las que conforman la muestra del sector agroindustrial.

Tabla 17: Empresas que participan en la encuesta. (1.998-2.008)

\begin{tabular}{|c|c|c|c|}
\hline & SECTOR & No EMPRESAS & $\%$ \\
\hline 1 & Industria cárnica & 110 & 3,10 \\
\hline 2 & Productos alimenticios y tabaco & 319 & 9,00 \\
\hline 3 & Bebidas & 69 & 1,95 \\
\hline 4 & Textiles y vestidos. & 290 & 8,18 \\
\hline 5 & Cuero y calzado & 114 & 3,21 \\
\hline 6 & Industria de la madera. & 124 & 3,50 \\
\hline 7 & Industria del papel. & 103 & 2,90 \\
\hline 8 & Edición y artes gráficas. & 183 & 5,16 \\
\hline 9 & Productos químicos. & 219 & 6,18 \\
\hline 10 & Productos de caucho y plástico. & 189 & 5,33 \\
\hline 11 & Productos minerales no metálicos. & 257 & 7,25 \\
\hline 12 & Metales férreos y no férreos. & 103 & 12,90 \\
\hline 13 & Productos metálicos. & 434 & 12,24 \\
\hline 14 & Máquinas agrícolas e industriales. & 262 & 7,39 \\
\hline 15 & Máquinas de oficina, proceso de datos, etc. & 60 & 1,69 \\
\hline 16 & Maquinaria y material eléctrico. & 214 & 6,03 \\
\hline 17 & Vehículos a motor. & 171 & 4,82 \\
\hline 18 & Otro material de transporte. & 78 & 2,20 \\
\hline 19 & Industria del mueble. & 174 & 4,91 \\
\hline \multirow[t]{2}{*}{20} & Otras industrias manufactureras. & 73 & 2,06 \\
\hline & TOTAL & 3.546 & 100 \\
\hline
\end{tabular}

Fuente: Elaboración propia a partir de los datos de la ESEE 
En total en la IAA participan 498 empresas de las cuales el 64\% pertenecen al sector de productos alimenticios y tabaco, el $22 \%$ al sector cárnico y el $14 \%$ al sector de bebidas. En cuanto al resto de sectores, el que presenta un mayor porcentaje de empresas en la encuesta es el sector de metales férreos y no férreos con un $12,90 \%$ seguido del sector de productos metálicos con un $12,24 \%$. Y los que menos porcentaje presenta son el sector de las máquinas de oficina, proceso de datos, etc. con un $1,69 \%$ del total de empresas.

El panel de datos empleado en el trabajo se ha obtenido a través de encuestas realizadas a un número representativo de empresas de todos los sectores manufactureros,

\subsubsection{Características de la encuesta}

En la ficha técnica de la encuesta que se presenta en el cuadro siguiente se pueden observar las características técnicas de la encuesta:

Tabla 18: Ficha técnica de la Encuesta Sobre Estrategias Empresariales Españolas

\begin{tabular}{|l|l|}
\hline \multicolumn{1}{|c|}{ Universo } & \multicolumn{1}{|c|}{ Empresas manufactureras españolas } \\
\hline Población & Empresas manufactureras con 10 o más trabajadores \\
\hline Ámbito & España \\
\hline Tamaño muestral & 1700 \\
\hline Tipo de muestreo & $\begin{array}{l}\text { Aleatorio estratificado y censal según tamaño de la empresa y } \\
\text { sector de pertenencia }\end{array}$ \\
\hline $\begin{array}{l}\text { Fechade } \\
\text { realización }\end{array}$ & $1990-2013$ \\
\hline
\end{tabular}

Fuente: Elaboración propia

La principal característica de la encuesta es que con los datos se permite construir un panel de datos. Las encuestas son contestadas por las mismas empresas cada año. Otra característica, no menos 
importante es la representatividad de la muestra que se mantiene a lo largo de toda la serie.

El diseño de la encuesta se realiza diferenciando aquellas en las que hay más de 200 trabajadores y las de 200 o menos trabajadores. Para estas últimos el tipo de muestreo es aleatorio estratificado y en el caso de las de más de 200 es de tipo de selección censal.

La clasificación sectorial corresponde a la CNAE-2009 que es la última clasificación que se ha adoptado en el marco de la Unión Europea.

Tabla 19: Clasificación Sectorial. Correspondencia entre CNAE-93 Y CNAE-2009

\begin{tabular}{|c|c|c|c|}
\hline Sector & Denominación & CNAE-93 & CNAE-2009 \\
\hline 1 & Industria cárnica & 151 & 101 \\
\hline 2 & Productos alimenticios y tabaco & 152 a $158+160$ & 102 a 109,120 \\
\hline 3 & Bebidas & 159 & 110 \\
\hline 4 & Textiles y confección & 171 a 177 y 181 & 131 a $133,139,141$ \\
\hline 5 & Cuero y calzado & 191 a 193 & $151+152$ \\
\hline 6 & Industria de la madera & 201 a 205 & $161+162$ \\
\hline 7 & Industria del papel & $211+212$ & $171+172$ \\
\hline 8 & Artes gráficas & 221 a 223 & $181+182$ \\
\hline 9 & Industria química y productos & 241 a 247 & 201 a $206,211+$ \\
\hline 10 & Productos de caucho y plástico & 251 a 252 & $221+222$ \\
\hline 11 & Productos minerales no metálicos & 261 a 268 & 231 a 237,239 \\
\hline 12 & Metales férreos y no férreos & 271 a 275 & 241 a 245 \\
\hline 13 & Productos metálicos & 281 a 287 & 251 a 257,259 \\
\hline 14 & Máquinas agrícolas e industriales & 291 a 297 & 281 a 284,289 \\
\hline 15 & Productos informáticos, & $300+(331$ a 335$)$ & 261 a 268 \\
\hline 16 & Maquinaria y material eléctrico & 311 a 316 y 321 & 271 a 275,279 \\
\hline 17 & Vehículos de motor & 341 a 343 & 291 a 293 \\
\hline 18 & Otro material de transporte & 351 a 355 & 301 a 304, 309 \\
\hline 19 & Industria del mueble & 361 & 310 \\
\hline 20 & Otras industrias manufactureras & 362 a 366,371 a & 321 a 325,329 \\
\hline
\end{tabular}

Fuente: Instituto Nacional de Estadística 


\subsubsection{Estructura de la encuesta}

El contenido de la encuesta está formado por 8 bloques de preguntas que atienden a diversos epígrafes.

El primer bloque está dedicado a la actividad, a los productos y a los procesos de fabricación. Da información de su localización, la forma jurídica con la que opera, los distintos tipos de participaciones,

En cuanto a las actividades tecnológicas, nos informa sobre las actividades de $I+D$, los gastos tanto internos como externo en $I+D$, los servicios de información científica y técnica, los estudios de mercado y marketing, patentes, modelos de utilidad, innovaciones en producto y proceso, cooperación con diversos actores y personal cualificado.

La relación con los clientes y los proveedores viene recogida en la encuesta atendiendo al tipo de clientes, al destino final de la producción y sus canales de distribución y aspectos comerciales.

El contenido del cuestionario aporta también datos sobre los precios que se pagan por la empresa y su política de precios a la venta.

En relación al comercio exterior se incluyen datos sobre exportación e importación y la distribución dividida por áreas geográficas y vías.

Por último, otros datos que se pueden encontrar en la encuesta hacen relación a datos contables, empleo y mercados servidos por la empresa. 


\subsubsection{Datos de la encuesta}

\subsubsection{Patentes registradas en España y en el extranjero}

En primer lugar vamos a analizar los datos referidos a las patentes que se han concedido en España y en el extranjero. En la Gráfico 5 observamos que durante el período 1998-2008 el porcentaje medio de empresas del sector agroalimentario sobre la muestra total es de aproximadamente un 14\%. Aún eliminando los dos años peores, el 2003 y el 2004 , la media se mantiene en ese $14 \%$. Observamos también que tanto en el sector agroindustrial como en el conjunto de la industria manufacturera la tendencia es descendente en cuanto al número de empresas de la muestra. Aún así el número de empresas es significativo.

Gráfico 5: Número de empresas de la muestra

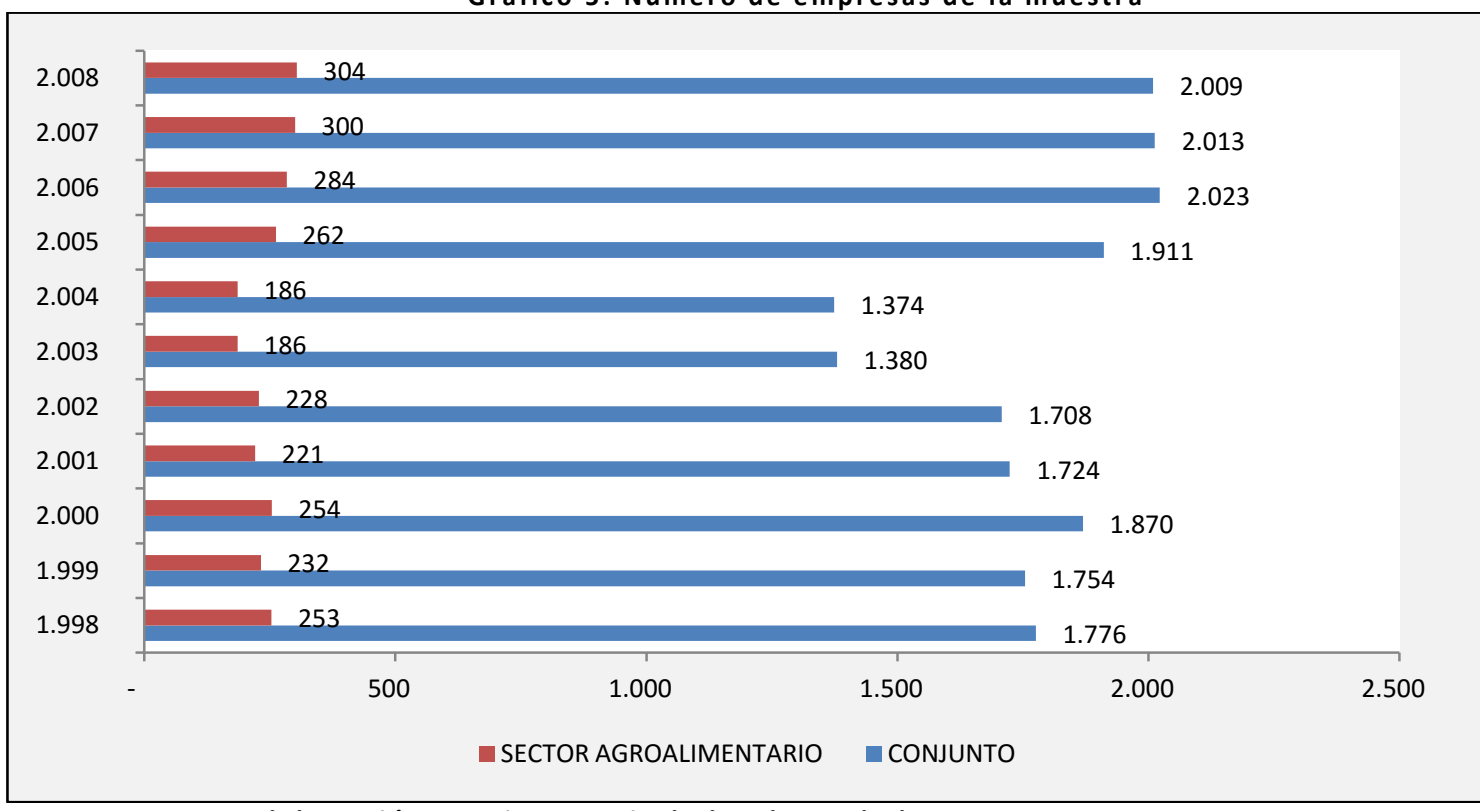

Fuente: Elaboración propia a partir de los datos de la ESEE

En la Gráfico 6 se representan las evoluciones durante el período analizado del número de patentes que se han presentado tanto en España como en el extranjero. La encuesta no especifica en qué país en concreto han sido presentadas las patentes. En términos porcentuales y en el sector agroalimentario español, las patentes registradas en España durante el periodo de los once años de estudio representan el $70 \%$ del total, frente al $30 \%$ de las que se registran en el extranjero. Tan sólo 
hay un año, el 2001, en el que el porcentaje de patentes registradas en el extranjero es superior al de las registradas en España. Por lo general, podemos afirmar que las tendencias son paralelas en ambos casos.

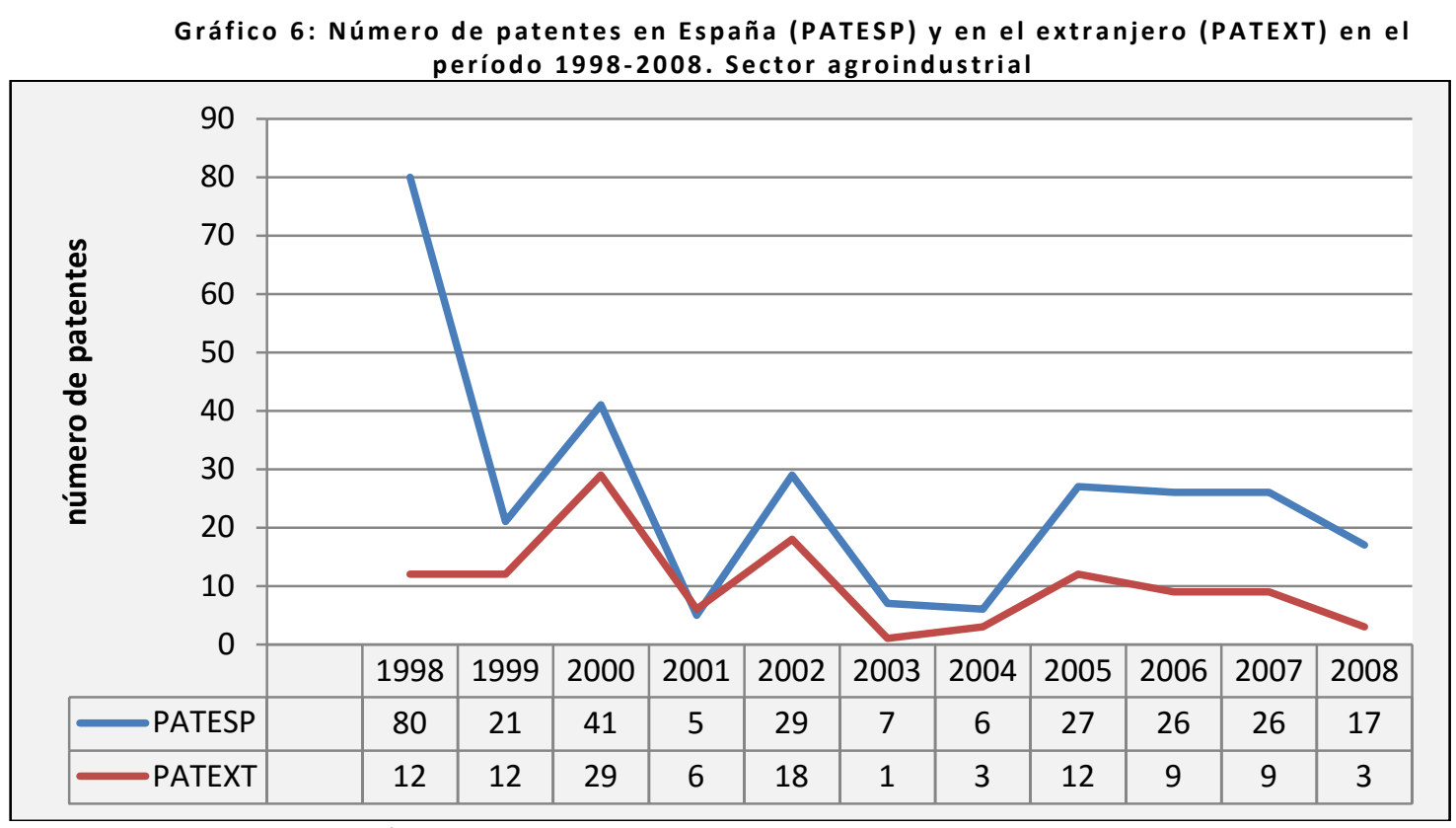

Fuente: Elaboración propia a partir de los datos de la ESEE

En la Gráfico 7 podemos ver la evolución del número de patentes durante el periodo 1998-2008.

La tendencia de la evolución es ascendente para el caso de las patentes registradas en el extranjero. En el caso de las registradas en España, la evolución es descendente para el mismo periodo.

Gráfico 7: Número de patentes en el período 1998-2008 en el Sector Manufacturero.

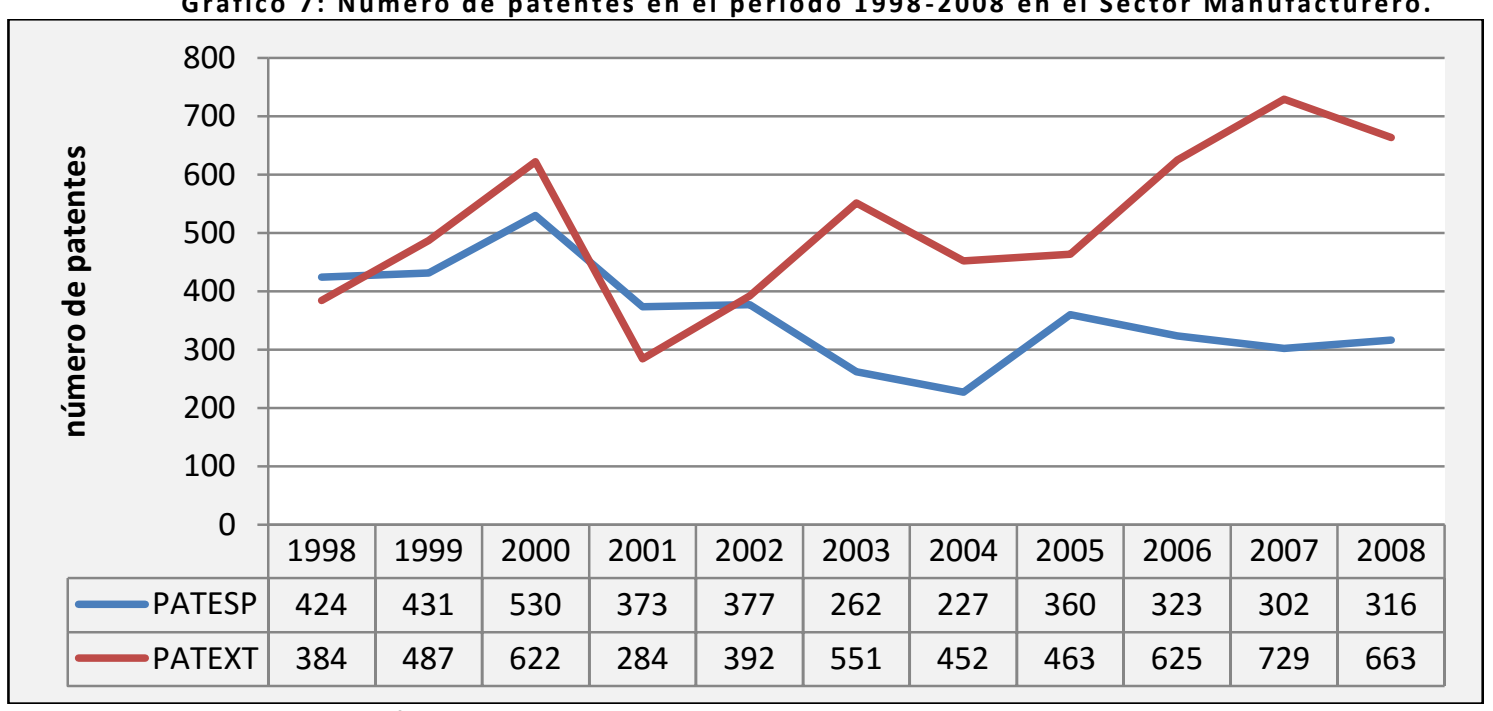

Fuente: Elaboración propia a partir de los datos de la ESEE 


\subsubsection{Gastos en I+D}

Para el análisis de los gastos en I+D hemos calculado el ratio que nos indica los gastos en I+D por empresa. En la Gráfico 8 podemos ver cómo es su evolución durante el período 1998-2008 en el sector agroalimentario.

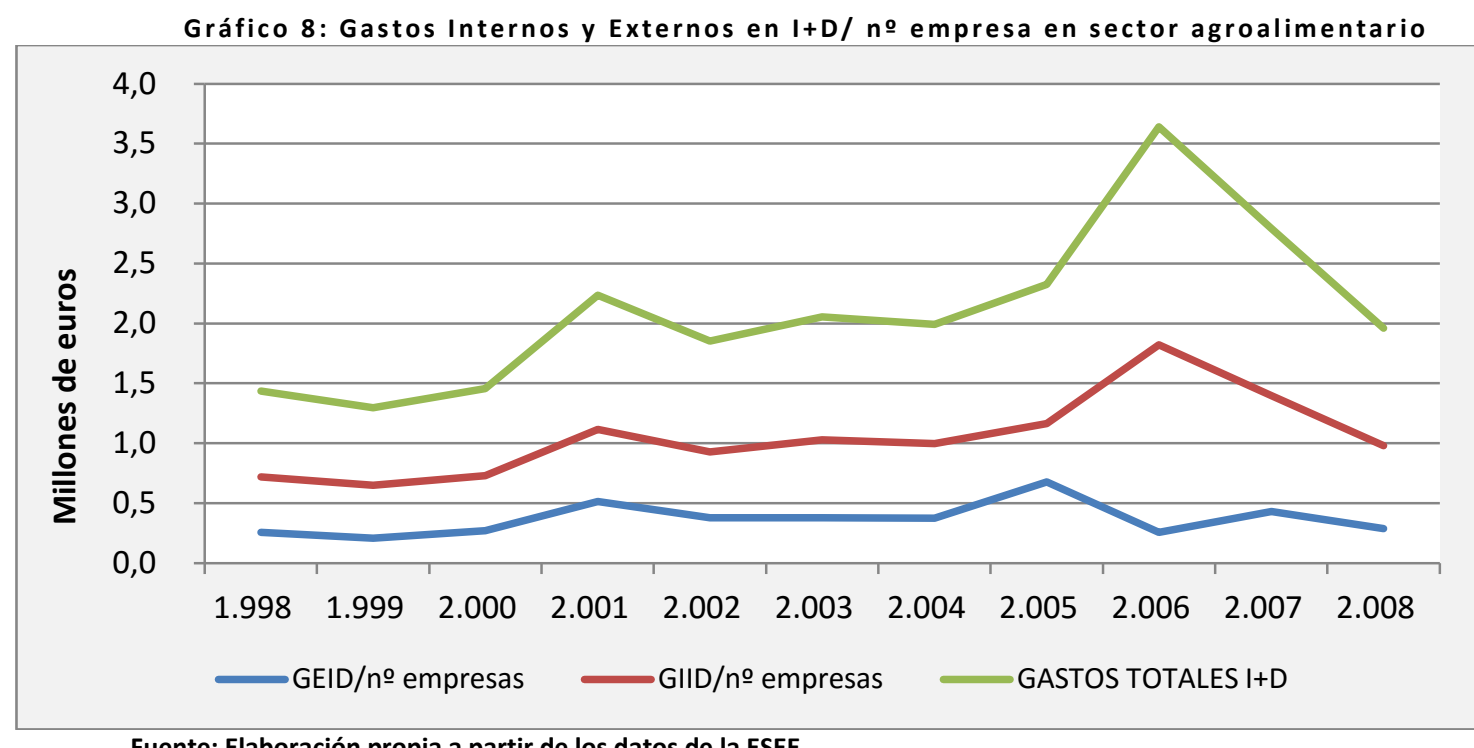

Fuente: Elaboración propia a partir de los datos de la ESEE

Tanto los gastos internos como los externos siguen tendencia ascendente desde el año 1998 hasta el año 2006 que comienza a descender y lo hace en mayor medida para los gastos internos e I+D. En términos absolutos se puede apreciar un aumento entre el primer año y el último. La media de los gastos en I+D por empresa es de 366.541€ para los gastos externos y $680.764 €$ para los gastos internos.

En cuanto al número de empresas que incurren en gastos en $I+D$, vemos en el Gráfico 9 que es mayor el número de empresas con gastos internos en I+D que las que tienen gastos externos. La media de las empresas que llevan a cabo gastos en $1+D$ es de $46 \%$ para los gastos externos y un $67 \%$ para los gastos internos en I+D. 
Gráfico 9: Evolución del número de empresas que realizan gastos internos y externos en I+D en la muestra del sector agroalimentario

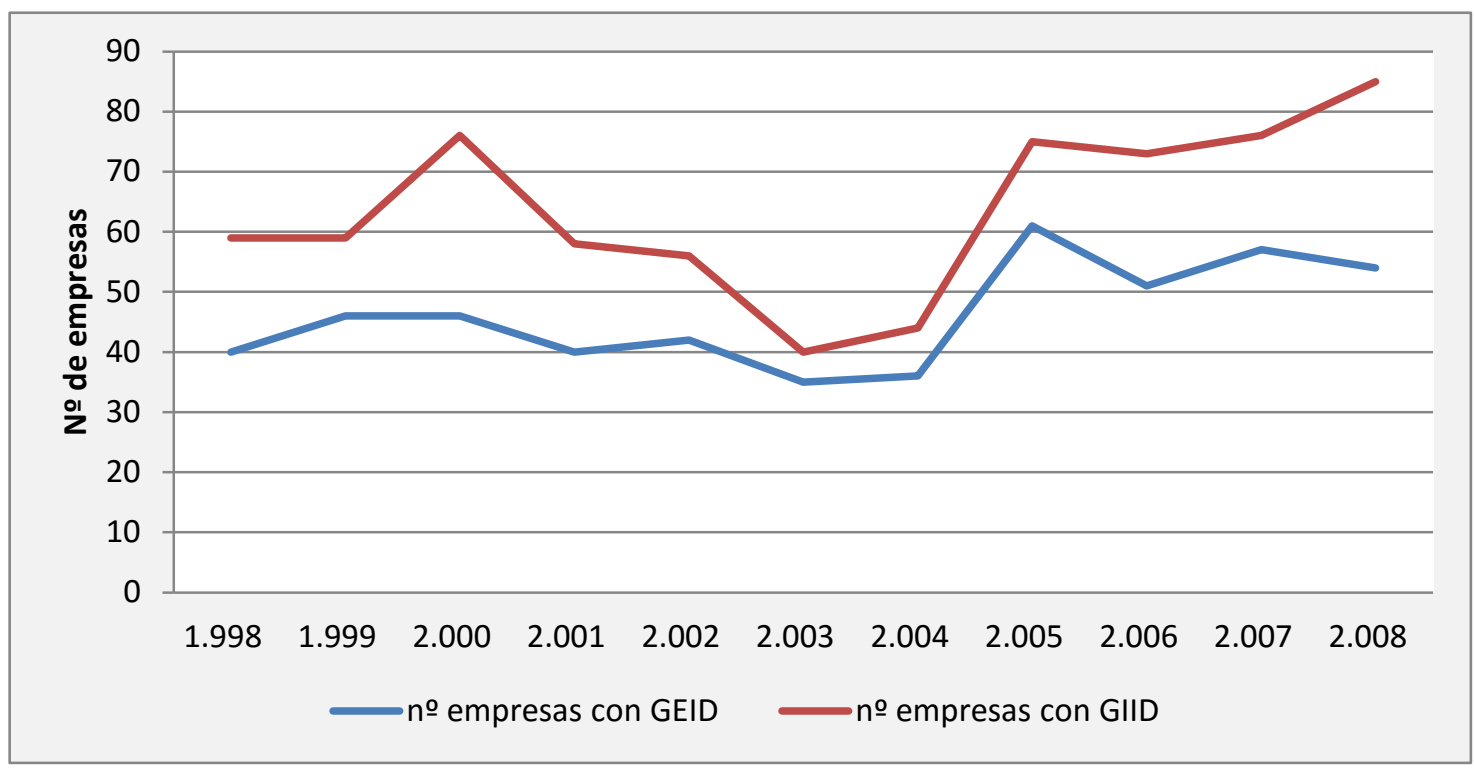

Fuente: Elaboración propia a partir de los datos de la ESEE

\subsubsection{Cooperación tecnológica}

La evolución del número de empresas que siguen las diferentes estrategias que vamos a analizar en el presente trabajo se puede ver en el Gráfico 10. La opción con un mayor número de empresas es la colaboración con las Universidades y los centros tecnológicos. Esta opción ha experimentado un repunte durante los últimos tres años del periodo analizado. La segunda opción más seguida es la cooperación tecnológica con los proveedores. En este caso vemos que ha sufrido un descenso durante los mismos tres últimos años del periodo analizado. Y por último, claramente inferiores en número, encontramos la cooperación tecnológica con clientes y con empresas rivales. 
Gráfico 10: Evolución del no de empresas que llevan a cabo algún tipo de colaboración (Sector agroindustrial)

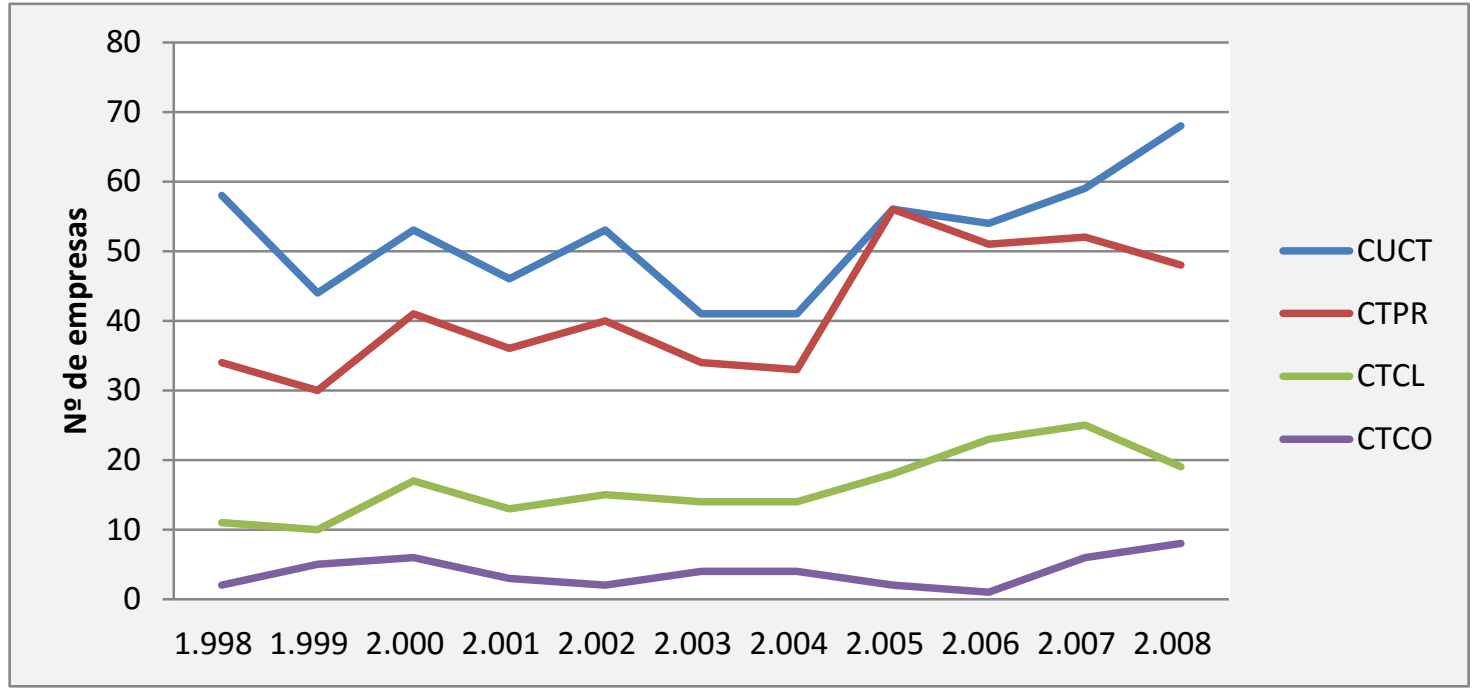

Fuente: Elaboración propia a partir de los datos de la ESEE

\subsubsection{Innovaciones en producto y en proceso}

En la Gráfico 11 podemos ver como las innovaciones que se realizan en los procesos son muy superiores a las que se realizan en los productos. A partir del año 2005 , la diferencia se hace cada año mayor en el conjunto de empresas de la muestra que se ha analizado. En el año 2008 esta diferencia es más del doble en el caso de las innovaciones realizadas en procesos que las realizadas en los productos.

Gráfico 11: Evolución del número de innovaciones en producto (IP) y en proceso (IPR) en la muestra del sector agroalimentario español

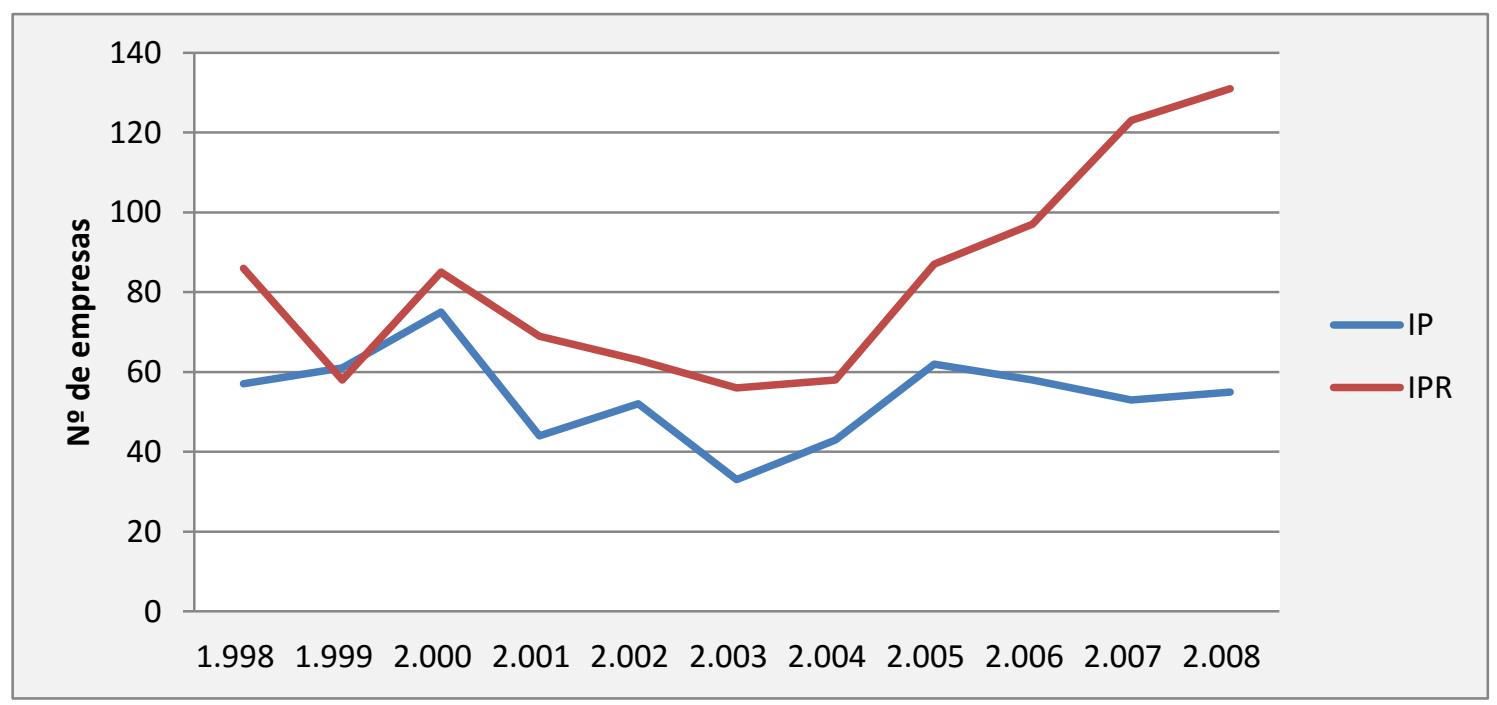

Fuente: Elaboración propia a partir de los datos de la ESEE 


\subsubsection{Actividades TICs}

Además de analizar el esfuerzo interno y externo que realizan las empresas en el ámbito de la innovación, este trabajo pretende estudiar su relación con las actividades de TICs. Las variables que van a ser utilizadas para medir este comportamiento empresarial son: número de empresas que poseen un dominio propio en Internet y número de empresas que emplean TICs en sus compras y ventas, diferenciando entre PYMES y grandes. Para España, la evolución de la importancia relativa de la e-innovación en el sector agroalimentario sobre el sector manufacturero total se refleja en los gráficos que a continuación se representan, comparando el subsector de industria cárnica, el de productos alimenticios y tabaco y el de bebidas con el total del sector manufacturero.

Comenzando por la presencia de 'dominio en internet', la evolución de la proporción de empresas con dicho dominio se recoge en Gráfico 12.

Gráfico 12: Porcentajes de empresas con dominio propio en Internet (PYMES)

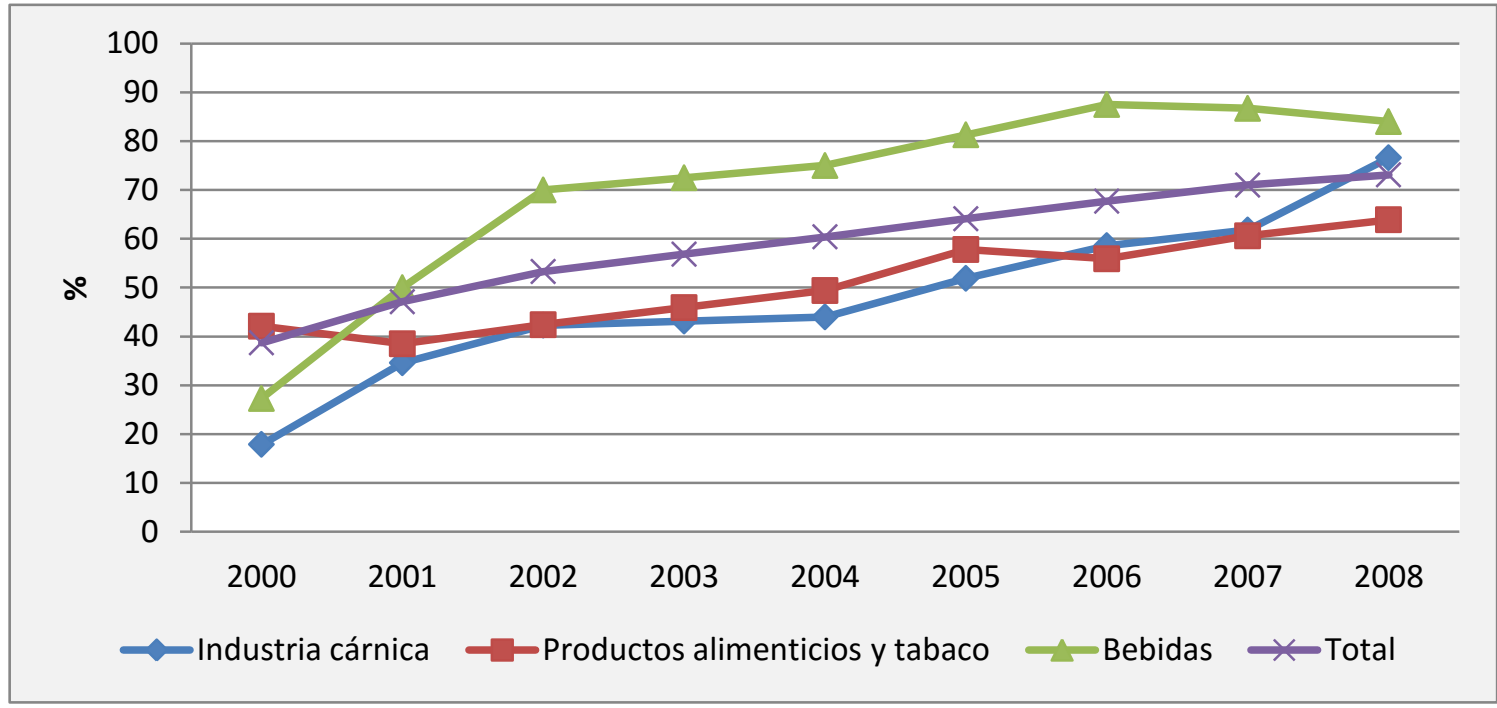

Fuente: elaborado a partir de los datos de la ESEE

La proporción en el año 2000 para las empresas con 200 y menos empleados estaba situada para los sectores de la industria cárnica $(17,9 \%)$ y bebidas $(27,3)$ por 
debajo de la de la industria total manufacturera $(38,7 \%)$, mientras que para el sector de productos alimenticios y tabaco $(42,10 \%)$ se situaba por encima de la misma. Al final del periodo se puede observar cómo las proporciones se invierten pasando a estar por encima de la del total del sector manufacturero $(73,1 \%)$ los sectores de la industria cárnica $(76,6 \%)$ y bebidas $(84 \%)$. Los aumentos de empresas con dominio propio en internet por sectores son considerables. Así, en la industria cárnica, dicho aumento es del $58,70 \%$, Productos alimenticios y tabaco, $21,8 \%$ y bebidas, $56,70 \%$. La variación en el total del sector manufacturero es del 34,4\%.

Respecto de las empresas grandes (Gráfico 13), las proporciones son bastante superiores y situándose el subsector de bebidas $(81,8 \%)$ por encima del sector manufacturero total $(74,7 \%)$ al principio del período analizado (año 2000). En cuanto a los otros dos subsectores se situaban en el $60 \%$ la industria cárnica y con un $72,1 \%$ el subsector de productos alimenticios y tabacos.

Gráfico 13: Porcentaje de empresas con dominio propio en Internet (Grandes)

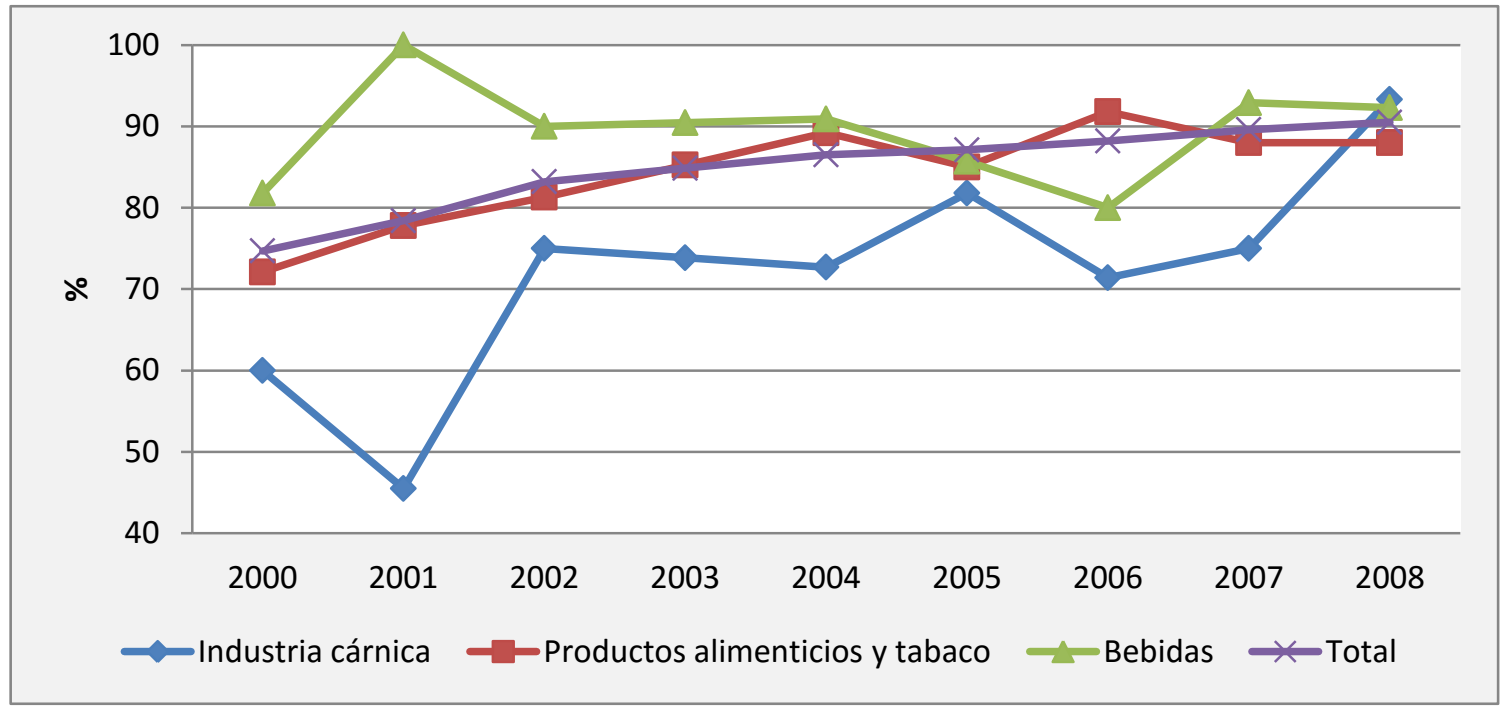

Fuente: elaborado a partir de la ESEE

Para las PYMES al final del período considerado los subsectores de la industria cárnica $(93,3 \%)$ y el de bebidas $(92,3 \%)$ se sitúan por encima del sector manufacturero total $(90,5 \%)$ y el subsector de productos alimenticios y tabacos $(88 \%)$ continua por debajo. 
En el caso de las industrias de mayor tamaño las variaciones de las proporciones de empresas con Dominio propio en Internet son menores en relación con los aumentos de las PYMES. Así, para los sectores de la industria cárnica, productos alimenticios y bebidas son del $33,3 \%, 15,90 \%$ y $10,50 \%$, respectivamente. Para el total del sector manufacturero esta variación es del 15,80\%.

En definitiva, el sector agroalimentario presenta proporciones de empresas con dominio en internet similar a las de otros sectores industriales. Las proporciones en el grupo de grandes empresas son considerablemente mayores, por encima del 90\%, que las del grupo de PYMES, entre 60 y $80 \%$. Sin embargo el esfuerzo realizado por estas últimas, entre 2000 y 2008, por adquirir dominio en internet ha sido enorme, como se puede ver al comparar las pendientes de Gráfico 12 (PYMES) con Gráfico 13 (grandes).

En relación a la proporción de empresas usuarias de TICs, la ESEE proporciona información de uso de TICs mediante los cuatro indicadores siguientes:

Pagina web en servidores de la empresa: indica que su página Web está alojada en servidores de su empresa.

Compras a proveedores por internet: indica la realización de compras de bienes o servicios (proveedores) por Internet.

Ventas a consumidores finales por internet: indica la disposición de un sistema de ventas a consumidores finales por Internet.

Ventas a empresas por internet: indica la disposición de un sistema de ventas a otras empresas por Internet.

Los Gráficos 14 y 15 muestran las proporciones de empresas usuarias de estas variables dentro de PYMES y grandes empresas, respectivamente. Comparando ambos gráficos, se aprecia cómo las PYMES agroalimentarias han hecho un esfuerzo importante entre 2000 y 2008 para adquirir sistemas de compras y ventas por internet, así como en alojar sus páginas web en servidores de la empresa. A pesar de estos esfuerzos, sin embargo, el uso de TICs es menor en PYMES que en grandes empresas. 
Gráfico 14: Evolución de las TIC en PYMES

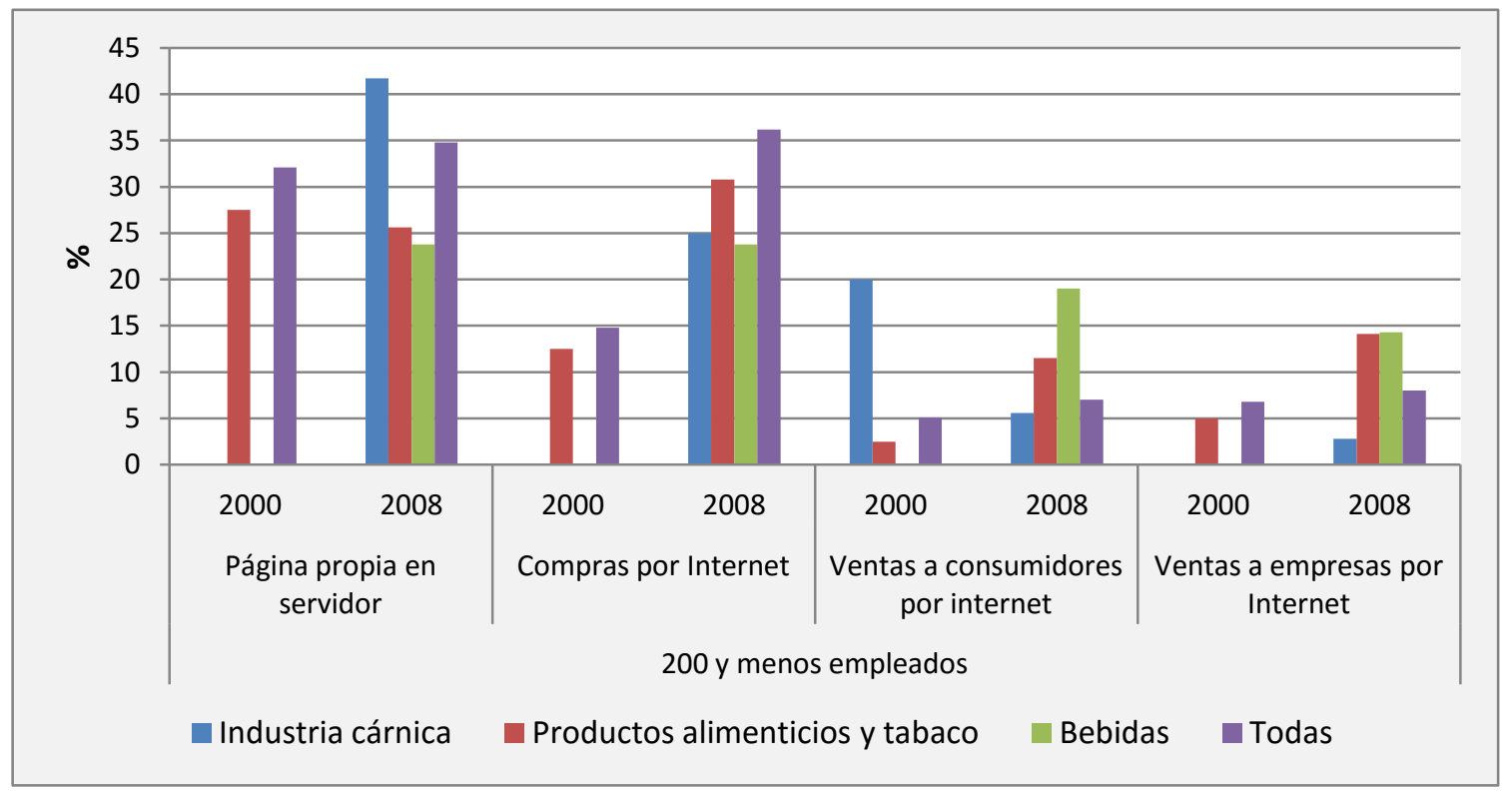

Fuente: elaborado a partir de la ESEE

Gráfico 15: Evolución de las TIC en empresas grandes

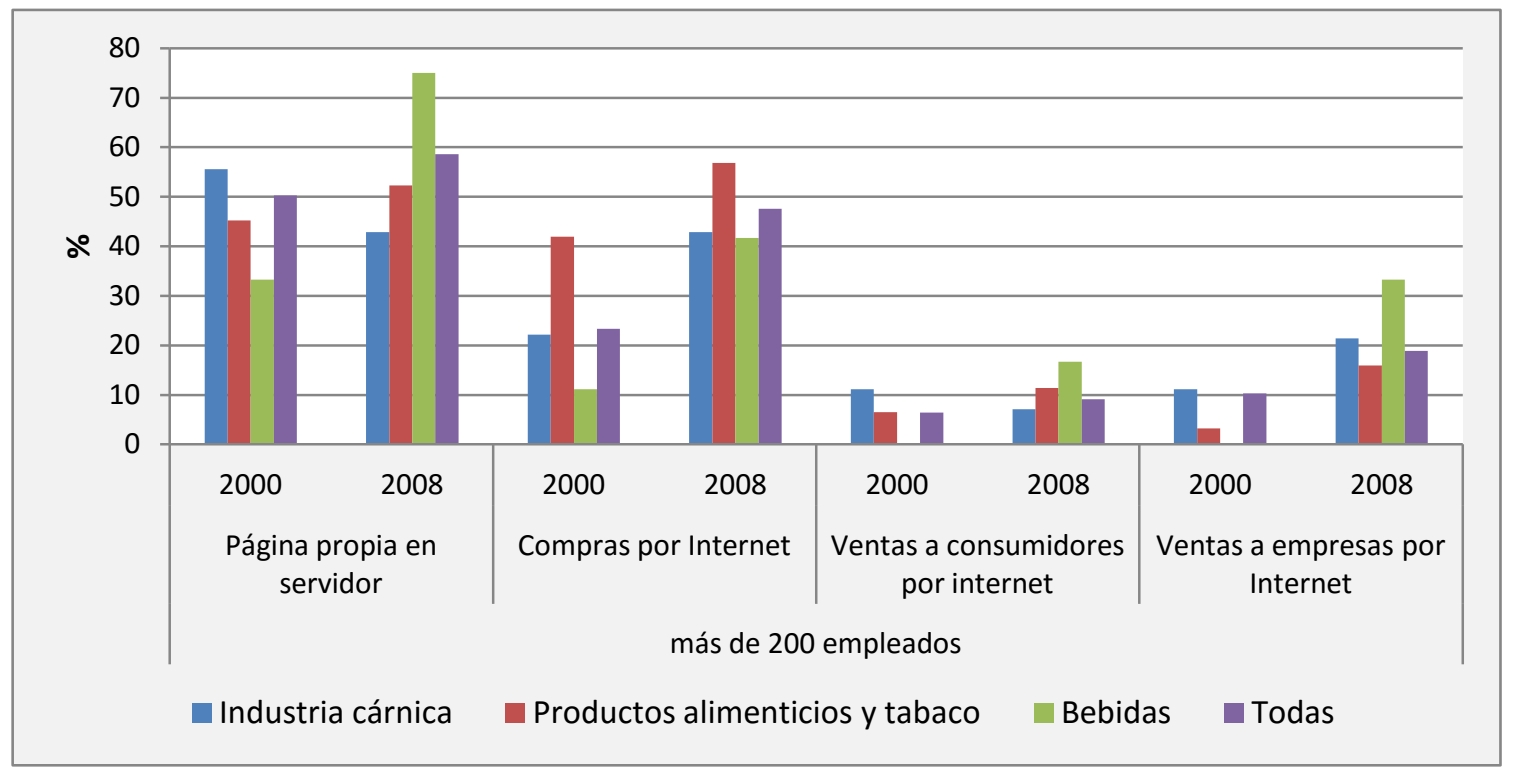

Fuente: elaborado a partir de la ESEE

En compras a proveedores por internet de unas proporciones nulas o bajas en 2000 (0\% Industria cárnica, 12.5\% Productos alimenticios y tabaco, 0\% Bebidas) se ha pasado a unas proporciones en el entorno del 25\% en 2008 (25.0\% Industria cárnica, 
30,8\% Productos alimenticios y tabaco, 23.8\% Bebidas). Las grandes empresas presentaban en 2000 una situación considerablemente mejor (22.2\% Industria cárnica, 41.9\% Productos alimenticios y tabaco, 11.1\% Bebidas) y en 2008 se sitúan por encima del 40\% (42.9\% Industria cárnica, 56.8\% Productos alimenticios y tabaco, $41.7 \%$ Bebidas).

El uso de internet para vender no es tan elevado como para realizar compras. Sin embargo la brecha entre PYMES y grandes es menor. Por ejemplo, en 2008, en la Industria cárnica vendían a consumidores finales el $5.6 \%$ y a otras empresas el $2.8 \%$ en las PYMES, frente a $7.1 \%$ y $21.4 \%$ en grandes empresas; en Productos alimenticios y tabaco el $11.5 \%$ vendían a consumidores y el $14.1 \%$ a empresas dentro de PYMES, y 11.4\% y $15.9 \%$ en grandes; en Bebidas, dentro de PYMES, el 19.0\% vendían a consumidores y el $14.3 \%$ a empresas, frente a $16.7 \%$ y $33.3 \%$ en grandes.

\subsection{Panel de Innovación Tecnológica (PITEC)}

El objetivo al que apunta directamente la encuesta es el seguimiento de las actividades de innovación tecnológicas y no tecnológicas llevadas a cabo por las empresas manufactureras españolas. De esta manera se contribuye a una mejora de la información estadística sobre el tejido empresarial español. Inicia su andadura el año 2004. Es elaborada por el Instituto Nacional de Estadística (INE) y patrocinada por la Fundación Española de Ciencia y Tecnología (FECYT) y la Subdirección de Planificación y Seguimiento de la Secretaría de Estado de I+D+i del Ministerio de Economía y Competitividad.

El panel lo forman dos grupos de empresas, empresas con 200 o más trabajadores que hacen o no actividades de I+D y empresas Grandes y PYMES con gasto en I+D interna.

A esto cabe añadir la advertencia de que la muestra empleada no es representativa de la empresas españolas del sector agroalimentario, 
tan sólo lo es de las empresas del sector agroalimentario que dedican parte de su capital a la investigación y el desarrollo.

En el Gráfico 16 puede verse la evolución del número de empresas que han participado en la encuesta. El motivo por el cual la encuesta muestra un gran salto entre el año 2004 y 2005 es la incorporación de dos muestras que se corresponden con las PYMES sin gastos en innovación y PYMES que hacen I+D externa y la incorporación de más PYMES con I+D interna. (Informe PITEC, 2010). A partir de ese año la muestra se mantiene constante con una media anual de 12814 empresas)

Gráfico 16: Evolución del número de empresas del PITEC

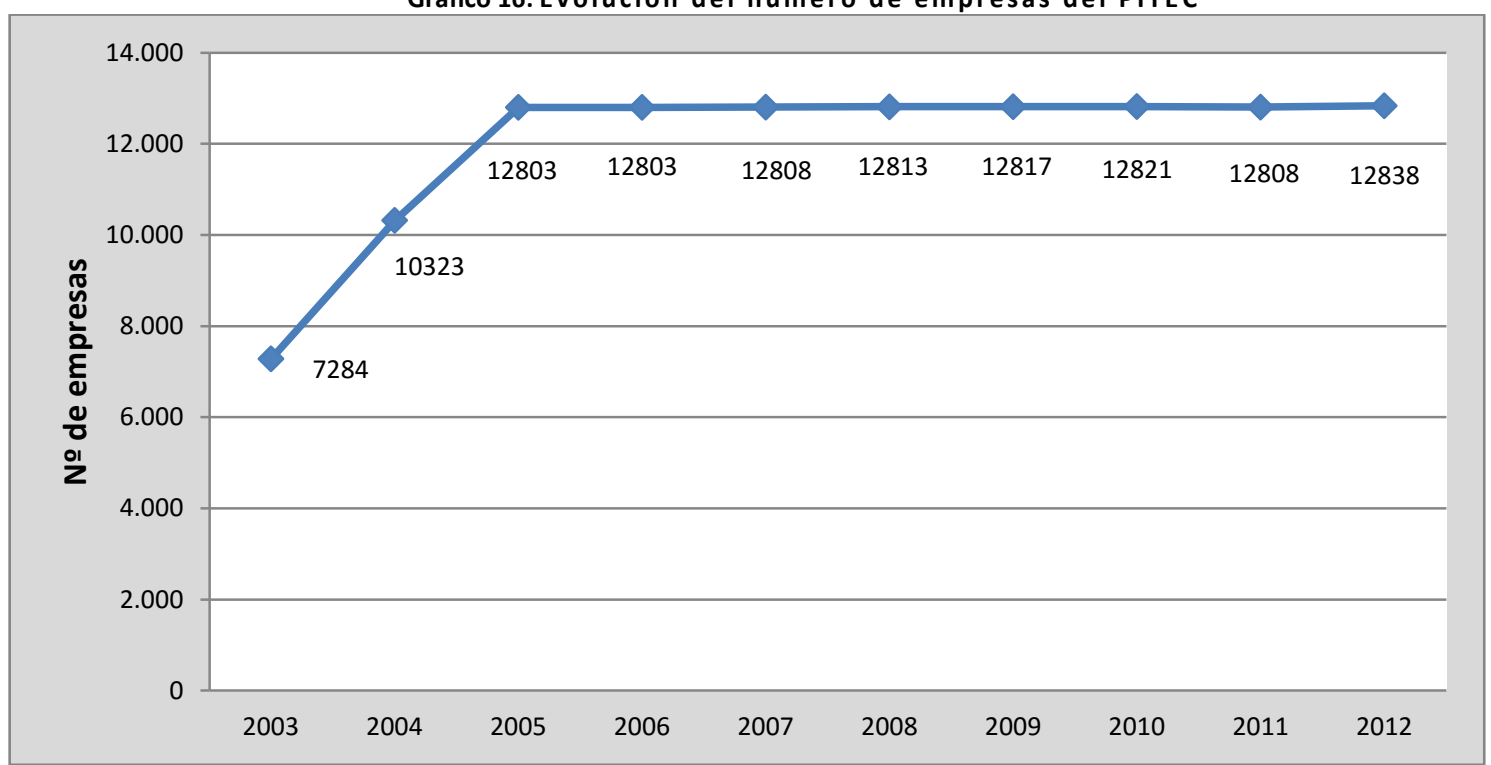

Fuente: Elaborada a partir de los datos del panel de innovación tecnológica.

En la tabla 20, al igual que en la encuesta ESEE, se ve toda la casuística que se ha presentado a lo largo del periodo 2004-2012 del comportamiento de las empresas en el seguimiento de la realización de la encuesta.

Se observa como mas de la mitad de las empresas han participado a lo largo de todo el período estudiado. Un $14 \%$ de las empresas lo han hecho todos los años menos el primero. El resto de las empresas se 
reparten en el resto de posibles casos que como se puede apreciar en la tabla y que se corresponden con porcentajes bastante bajos, entre $2,43 \%$ y $0,12 \%$.

La encuesta permite realizar análisis de la evolución de la actividades de las empresas del panel, entre otras, el empleo, las ventas, los gastos en I+D internos y externos y las solicitudes de patentes presentadas por las empresas.

\begin{tabular}{|c|c|c|c|c|c|c|c|c|c|c|c|}
\hline & & & & $20:$ & ipaci & la & ta & & & & \\
\hline Frec & $\%$ & Acum & 2004 & 2005 & 2006 & 2007 & 2008 & 2009 & 2010 & 2011 & 2012 \\
\hline 473 & 54,68 & 54,68 & $x$ & $x$ & $x$ & $x$ & $x$ & $x$ & $x$ & $x$ & $x$ \\
\hline 20 & 2,31 & 56,99 & $x$ & $x$ & $x$ & $x$ & $x$ & $x$ & $x$ & $x$ & \\
\hline 21 & 2,43 & 59,42 & $x$ & $\mathbf{x}$ & $\mathbf{x}$ & $x$ & $x$ & $x$ & $\mathbf{x}$ & & \\
\hline 3 & 0,35 & 59,77 & $x$ & $x$ & $\mathbf{x}$ & $x$ & $\mathbf{x}$ & $x$ & & $\mathbf{x}$ & $x$ \\
\hline 11 & 1,27 & 61,04 & $\mathbf{x}$ & $\mathbf{x}$ & $\mathbf{x}$ & $\mathbf{x}$ & $\mathbf{x}$ & $\mathbf{x}$ & & & \\
\hline 2 & 0,23 & 61,27 & $x$ & $x$ & $x$ & $x$ & $x$ & & $x$ & $x$ & $x$ \\
\hline 1 & 0,12 & 61,39 & $\mathbf{x}$ & $\mathbf{x}$ & $\mathbf{x}$ & $\mathbf{x}$ & $\mathbf{x}$ & & $\mathbf{x}$ & $\mathbf{x}$ & \\
\hline 2 & 0,23 & 61,62 & $x$ & $x$ & $x$ & $x$ & $x$ & & $x$ & & \\
\hline 2 & 0,23 & 61,85 & $\mathbf{x}$ & $\mathbf{x}$ & $x$ & $\mathbf{x}$ & $\mathbf{x}$ & & & $x$ & $\mathbf{x}$ \\
\hline 15 & 1,73 & 63,58 & $x$ & $x$ & $x$ & $x$ & $x$ & & & & \\
\hline 3 & 0,35 & 63,93 & $\mathbf{x}$ & $\mathbf{x}$ & $\mathbf{x}$ & $\mathbf{x}$ & & $\mathbf{x}$ & $\mathbf{x}$ & $\mathbf{x}$ & $\mathbf{x}$ \\
\hline 2 & 0,23 & 64,16 & $x$ & $x$ & $x$ & $x$ & & $x$ & $x$ & $x$ & \\
\hline 1 & 0,12 & 64,28 & $x$ & $x$ & $x$ & $x$ & & & $x$ & $x$ & \\
\hline 1 & 0,12 & 64,39 & $x$ & $x$ & $x$ & $x$ & & & & $x$ & \\
\hline 15 & 1,73 & 66,13 & $\mathbf{x}$ & $\mathbf{x}$ & $x$ & $\mathbf{x}$ & & & & & \\
\hline 5 & 0,58 & 66,71 & $x$ & $x$ & $x$ & & $\mathbf{x}$ & $\mathbf{x}$ & $\mathbf{x}$ & $x$ & $\mathbf{x}$ \\
\hline 2 & 0,23 & 66,94 & $\mathbf{x}$ & $\mathbf{x}$ & $x$ & & $\mathbf{x}$ & $\mathbf{x}$ & $\mathbf{x}$ & $x$ & \\
\hline 1 & 0,12 & 67,05 & $\mathbf{x}$ & $\mathbf{x}$ & $\mathbf{x}$ & & & $\mathbf{x}$ & $\mathbf{x}$ & $\mathbf{x}$ & $\mathbf{x}$ \\
\hline 1 & 0,12 & 67,17 & $x$ & $x$ & $x$ & & & & & $x$ & \\
\hline 16 & 1,85 & 69,02 & $\mathbf{x}$ & $\mathbf{x}$ & $\mathbf{x}$ & & & & & & \\
\hline 2 & 0,23 & 69,25 & $x$ & $x$ & & $\mathbf{x}$ & $\mathbf{x}$ & $x$ & $x$ & $x$ & $\mathbf{x}$ \\
\hline 1 & 0,12 & 69,36 & $\mathbf{x}$ & $\mathbf{x}$ & & $\mathbf{x}$ & $\mathbf{x}$ & $\mathbf{x}$ & & & \\
\hline 1 & 0,12 & 69,48 & $\mathbf{x}$ & $\mathbf{x}$ & & $\mathbf{x}$ & $\mathbf{x}$ & & & & \\
\hline 1 & 0,12 & 69,60 & $x$ & $x$ & & & $\mathbf{x}$ & $\mathbf{x}$ & $x$ & $x$ & $\mathbf{x}$ \\
\hline 16 & 1,85 & 71,45 & $x$ & $x$ & & & & & & & \\
\hline 6 & 0,69 & 72,14 & $\mathbf{x}$ & & $\mathbf{x}$ & $\mathbf{x}$ & $\mathbf{x}$ & $\mathbf{x}$ & $\mathbf{x}$ & $\mathbf{x}$ & $\mathbf{x}$ \\
\hline 4 & 0,46 & 72,60 & $x$ & & $x$ & $x$ & $x$ & $x$ & $x$ & $x$ & \\
\hline 2 & 0,23 & 72,83 & $\mathbf{x}$ & & & $\mathbf{x}$ & $\mathbf{x}$ & $\mathbf{x}$ & $\mathbf{x}$ & $\mathbf{x}$ & $\mathbf{x}$ \\
\hline 1 & 0,12 & 72,95 & $x$ & & & $x$ & $x$ & & & & \\
\hline 1 & 0,12 & 73,06 & $x$ & & & $x$ & & & & & \\
\hline 1 & 0,12 & 73,18 & $x$ & & & & & & $\mathbf{x}$ & $\mathbf{x}$ & $\mathbf{x}$ \\
\hline 16 & 1,85 & 75,03 & $x$ & & & & & & & & \\
\hline 123 & 14,22 & 89,25 & & $\mathbf{x}$ & $\mathbf{x}$ & $x$ & $x$ & $\mathbf{x}$ & $\mathbf{x}$ & $\mathbf{x}$ & $\mathbf{x}$ \\
\hline
\end{tabular}




\begin{tabular}{|c|c|c|c|c|c|c|c|c|c|c|}
\hline 6 & 0,69 & 89,94 & $\mathbf{x}$ & $\mathbf{x}$ & $\mathbf{x}$ & $\mathbf{x}$ & $\mathbf{x}$ & $x$ & $\mathbf{x}$ & \\
\hline 7 & 0,81 & 90,75 & $x$ & $\mathbf{x}$ & $\mathbf{x}$ & $\mathbf{x}$ & $x$ & $x$ & & \\
\hline 1 & 0,12 & 90,87 & $\mathbf{x}$ & $\mathbf{x}$ & $\mathbf{x}$ & $\mathbf{x}$ & $\mathbf{x}$ & & $\mathrm{x}$ & $x$ \\
\hline 1 & 0,12 & 90,98 & $x$ & $x$ & $x$ & $x$ & $x$ & & & $x$ \\
\hline 4 & 0,46 & 91,45 & $\mathbf{x}$ & $\mathbf{x}$ & $\mathbf{x}$ & $\mathbf{x}$ & $x$ & & & \\
\hline 3 & 0,35 & 91,79 & $x$ & $x$ & $x$ & $x$ & & & & \\
\hline 1 & 0,12 & 91,91 & $\mathbf{x}$ & $\mathbf{x}$ & $\mathbf{x}$ & & $x$ & $x$ & $x$ & $x$ \\
\hline 1 & 0,12 & 92,02 & $x$ & $x$ & $x$ & & $x$ & $x$ & $x$ & \\
\hline 1 & 0,12 & 92,14 & $x$ & $x$ & $x$ & & & & $x$ & $x$ \\
\hline 4 & 0,46 & 92,60 & $x$ & $x$ & $x$ & & & & & \\
\hline 4 & 0,46 & 93,06 & $x$ & $x$ & & $x$ & $x$ & $x$ & $x$ & $x$ \\
\hline 2 & 0,23 & 93,29 & $\mathbf{x}$ & $x$ & & & $x$ & & & $x$ \\
\hline 3 & 0,35 & 93,64 & $x$ & $x$ & & & & & & \\
\hline 1 & 0,12 & 93,76 & $\mathbf{x}$ & & $\mathbf{x}$ & $\mathbf{x}$ & $\mathbf{x}$ & $\mathbf{x}$ & $\mathbf{x}$ & $\mathbf{x}$ \\
\hline 1 & 0,12 & 93,87 & $x$ & & & $x$ & $x$ & $x$ & $x$ & $x$ \\
\hline 1 & 0,12 & 93,99 & $x$ & & & & & $\mathbf{x}$ & $x$ & \\
\hline 9 & 1,04 & 95,03 & $x$ & & & & & & & \\
\hline 5 & 0,58 & 95,61 & & $x$ & $x$ & $x$ & $x$ & $x$ & $x$ & $x$ \\
\hline 2 & 0,23 & 95,84 & & $\mathbf{x}$ & $\mathbf{x}$ & $\mathbf{x}$ & $\mathbf{x}$ & & & \\
\hline 2 & 0,23 & 96,07 & & $x$ & $x$ & & & & & \\
\hline 2 & 0,23 & 96,30 & & $x$ & & & & & & \\
\hline 3 & 0,35 & 96,65 & & & $x$ & $x$ & $x$ & $x$ & $x$ & $\mathbf{x}$ \\
\hline 1 & 0,12 & 96,76 & & & $x$ & & & & & \\
\hline 9 & 1,04 & 97,80 & & & & $x$ & $\mathbf{x}$ & $\mathbf{x}$ & $x$ & $x$ \\
\hline 2 & 0,23 & 98,03 & & & & $x$ & & & & \\
\hline 4 & 0,46 & 98,50 & & & & & $x$ & $x$ & $x$ & $x$ \\
\hline 1 & 0,12 & 98,61 & & & & & $\mathbf{x}$ & $x$ & $x$ & \\
\hline 1 & 0,12 & 98,73 & & & & & & $x$ & $x$ & $x$ \\
\hline 1 & 0,12 & 98,84 & & & & & & $x$ & $x$ & \\
\hline 1 & 0,12 & 98,96 & & & & & & $x$ & & \\
\hline 3 & 0,35 & 99,31 & & & & & & & $\mathbf{x}$ & $\mathbf{x}$ \\
\hline 6 & 0,69 & 100,00 & & & & & & & $\mathbf{x}$ & \\
\hline
\end{tabular}

865

Fuente: Elaboración propia a partir de los datos del PITEC

\subsubsection{Características de la encuesta}

Una descripción exhaustiva de la encuesta se puede encontrar en la página web http://icono.fecyt.es/. A continuación se exponen las características principales de la encuesta.

En la ficha técnica de la encuesta que se presenta en la Tabla 20 se pueden observar las características técnicas de la encuesta: 
Tabla 21: Ficha técnica del panel de innovación tecnológico (PITEC)

\begin{tabular}{|c|c|}
\hline Universo & Empresas manufactureras y de servicios españolas \\
\hline Población & Empresas que realizan I+D \\
\hline Ámbito & España \\
\hline Tamaño muestral & 12.179 (año 2005) \\
\hline Diseño de la muestra & Panel balanceado \\
\hline Fecha de realización & $2004-2016$ \\
\hline
\end{tabular}

Fuente: Elaboración propia

La repetición de las empresas año tras año permite elaborar una base de datos con estructura de panel que permite aprovechar las características de este tipo de bases de datos.

La encuesta responde a más de 460 variables de cerca de 12.000 empresas. Es una encuesta dinámica que se corrige año tras año cuando el cuestionario sufre alguna modificación.

Otra importante característica de la encuesta es que incluye empresas manufactureras y empresas de servicio. Esto permite realizar análisis sectoriales y comparar sus resultados.

\subsubsection{Estructura de la encuesta}

Un primer apartado sobre datos generales de la empresa incluye la actividad de la empresa, su clase, el año de creación y forma, la ubicación, los resultados económicos, el número medio de empleados y mercados en los que actúa.

Un segundo apartado proporciona información sobre las actividades de I+D interna incluyendo datos sobre la organización de la I+D interna de la empresa, el personal dedicado actividades de I+D interna tanto por ocupación como por titulación. Los gastos en I+D 
interna, las becas de investigación, la distribución del gasto y la financiación de los mismos.

En relación a la compra de servicios de $I+D$, se incorporan los importes efectuados por la adquisición de servicios de I+D fuera de la empresa en el territorio nacional y en el extranjero.

Todo lo relacionado con las actividades para la innovación tecnológica realizadas por las empresas se encuentra distribuido en aspectos como la distribución de gastos en I+D por comunidades autónomas, de la financiación por administraciones y el uso o no de software libre.

En cuanto a la Innovación de productos y de procesos la encuesta nos ofrece información sobre si se introdujeron o no innovaciones, quién la realizó, su descripción, e impacto sobre la cifra de negocios de la empresa tanto de las innovaciones en producto como en proceso. Además incluye aspectos como las fuentes de información para la realización de las innovaciones tecnológicas, la cooperación para la realización de actividades de las mismas. Por último en este grupo de cuestiones se solicita el objetivo que ha promovido la innovación.

En el siguiente apartado son los factores que dificultan las actividades de innovación o incluso impiden su realización.

A continuación en la encuesta se hace referencia a los derechos de propiedad intelectual e industria; patentes y otros métodos de protección de las invenciones como el modelo industrial, las marcas de fábrica o los derechos de autor.

Las encuesta se completa con los siguientes epígrafes: Ingresos y pagos por tecnología desincorporada, las innovaciones organizativas, las innovaciones de comercialización, las deducciones fiscales para I+D e innovación tecnológica. 


\subsubsection{Datos de la encuesta}

Los datos que ofrece la encuesta permiten llevar a cabo una caracterización de la actividad innovadora de las empresas agroalimentarias. A continuación se presentan en los siguientes apartados un resumen de los valores medios correspondientes a las protecciones de la innovaciones en tres versiones - patentes, modelos de utilidad y marcas de fábrica-, los gastos realizados por las empresas en I+D, la cooperación tecnológica y las innovaciones en producto y procesos realizadas.

En primer lugar, antes de pasar a la caracterización innovadora propiamente dicha, se expone en el Gráfico 17 el número de empresas del sector agroalimentario español que a lo largo del periodo 2003-2012 participaron en la encuesta conjuntamente con la evolución del número de empresas del sector agrario y del resto de los sectores. La media anual a partir de los datos es de 657 empresas para las empresas agroalimentarias, 136 para el sector agrario y de 11.177 empresas en el resto de empresas.

Gráfico 17: Evolución del número de empresas de la muestra en el sector agrario (AGRO), la industria agroalimentaria (IAA) y del resto de los sectores (RESTO)

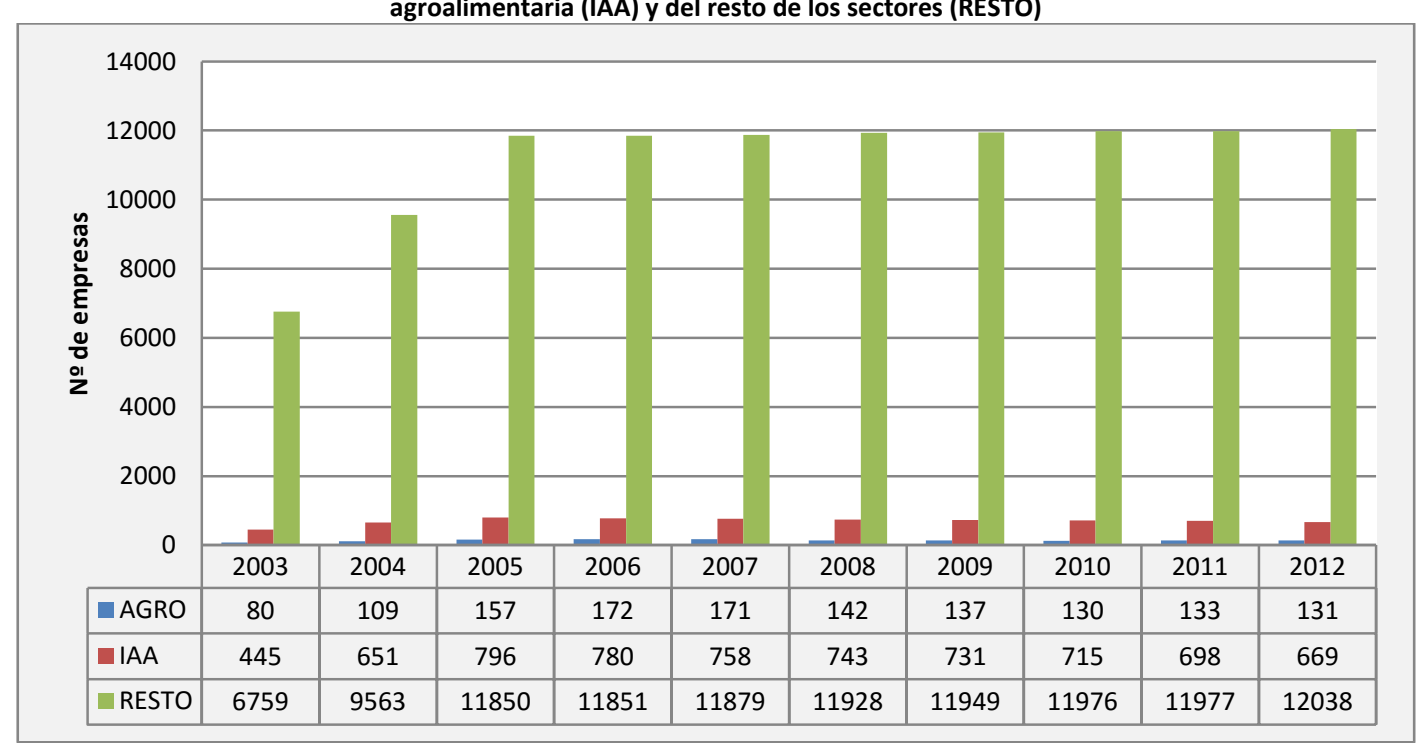

Fuente: elaborado con los datos de PITEC 


\subsubsection{Protecciones de las innovaciones}

En el Gráfico 18 está representada la evolución a lo largo del periodo 2003-2012 del número de cada una de las opciones para proteger las invenciones. Lo primero que llama la atención es que a partir de 2004 se produce un importante incremento del uso de las protecciones tanto en las empresas agroalimentarias como en el resto de empresas. Este salto tan significativo es causa de la evolución de la propia muestra. Aún así, la tendencia continúa siendo descendente como venía siendo con anterioridad a la subida del año 2004. Entre las causas que se barajan para dar una explicación a este descenso es el momento económico analizado que se corresponde con el período de crisis global en el que los indicadores económicos sufrieron importantes descensos.

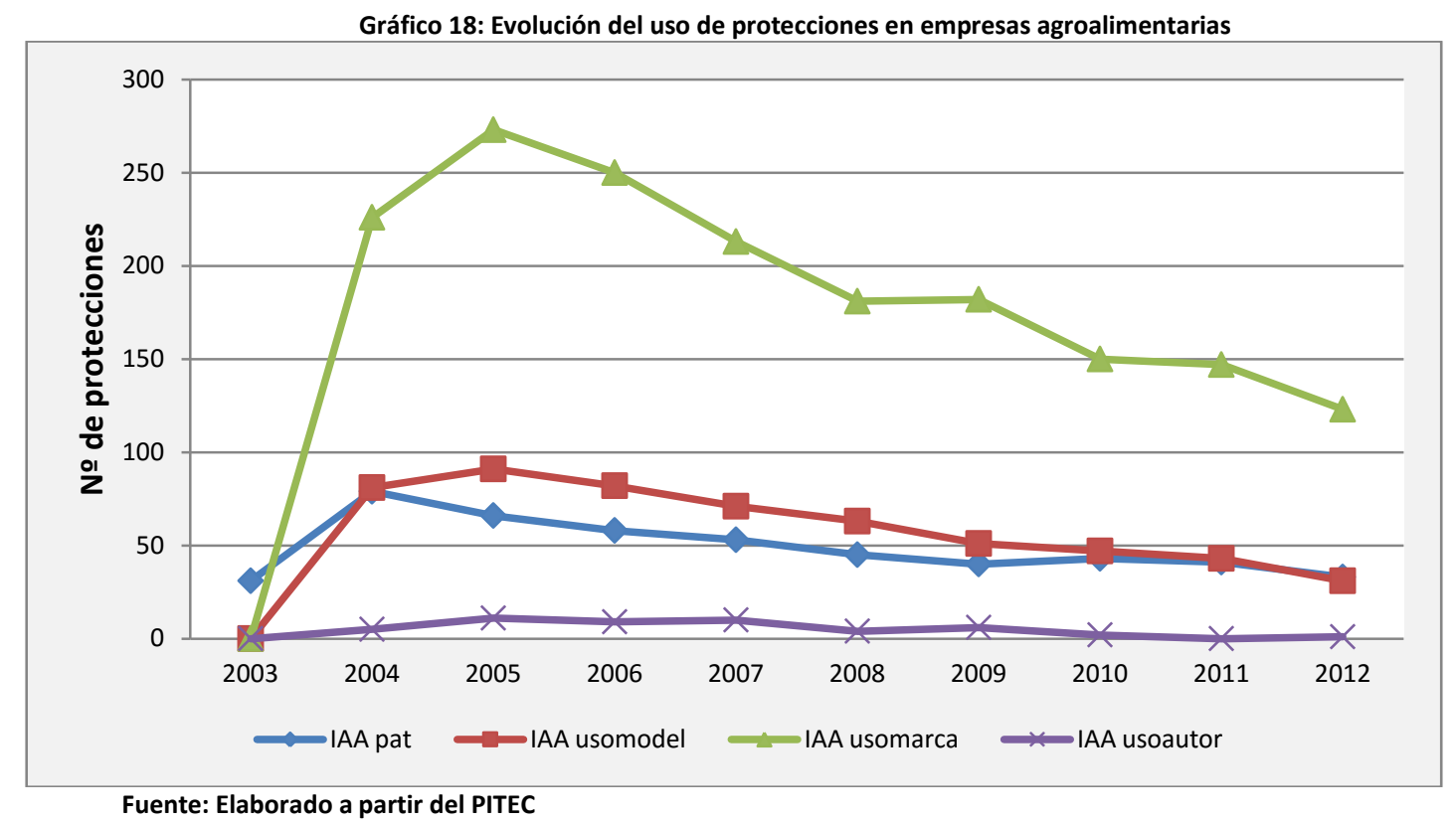

En la Gráfico 18 se distinguen cuatro tipos diferentes de usos de protección que en la encuesta son especificados. Estos son las patentes, los modelos de utilidad, las marcas de fábrica y los derechos de autor.

Respecto a la industria agroalimentaria el uso de protección que más se emplea es la marca de fábrica, bastante inferior es el uso de patentes y de modelos de utilidad. En el caso de los derechos de autor 
estos son escasamente empleados por las empresas agroalimentarias. Gráficamente podemos observar como la evolución de los tres primeros usos de protección es aproximadamente paralela mientras que en el caso de los derechos de autor la evolución es prácticamente estable.

En el mismo gráfico se aprecia un descenso en cada uno de los tres tipos que se consideran en la presente investigación. En este sentido, se observa como el descenso más acentuado se produce en la solicitud de patente.

Respecto al número de protecciones (Gráfico 19) en el resto de empresas en el que no se consideran ni las empresas agrarias ni las agroalimentarias las evoluciones de cada una de ellas sigue las mismas pautas que en el caso de las empresas agroalimentarias. La diferencia entre ambos grupos es que el uso de patentes es superior al de modelos de utilidad en el caso del grupo formado por el resto de empresas.

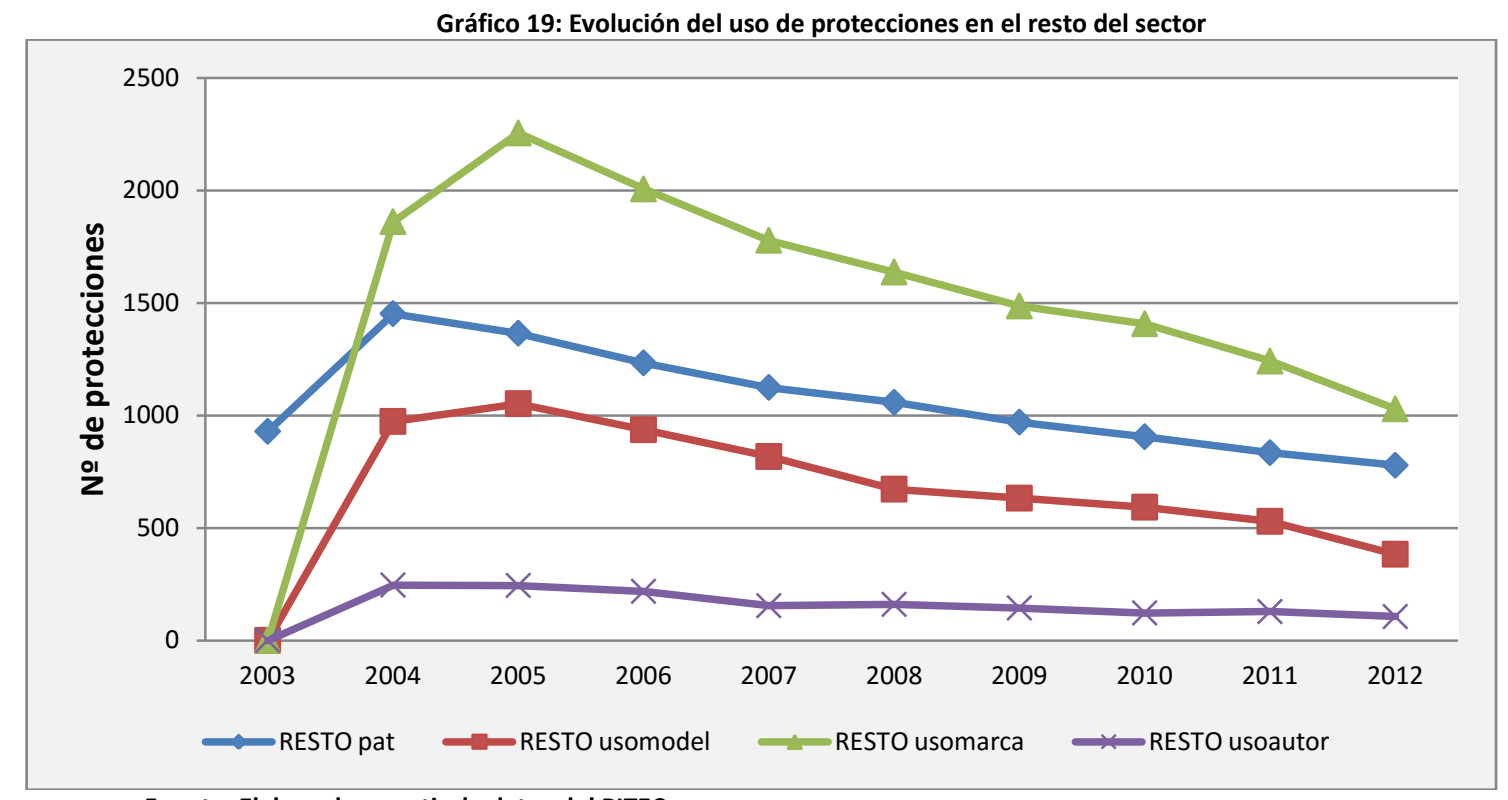

Fuente: Elaborado a partir de datos del PITEC

$\begin{array}{ll}\text { pat } & \text { Solicitud de patentes } \\ \text { usomodel } & \text { Registros de modelo de utilidad } \\ \text { usomarca } & \text { Marcas de fábrica } \\ \text { usoautor } & \text { Derechos de autor }\end{array}$


La conclusión que resulta de la comparación de los grupos de empresas es que los patrones de comportamiento en cuanto al uso de protecciones de las innovaciones son similares en el caso de las marcas de fábrica y de los derechos de autor mientras que en el caso de las patentes están son empleadas en un porcentaje menor en las empresas agroalimentarias.

En el caso particular de las patentes, la encuesta nos ofrece además de forma disgregada cuatro tipos de patentes atendiendo a la oficina donde estas se presentan. Se distinguen entre las oficinas española, europea y americana a la hora de presentar la patente y el Tratado de cooperación de patentes.

Su evolución a lo largo del período analizado se puede observar en el Gráfico 20 en el cual llama la atención un punto de inflexión para el año 2004. Dicha inflexión en las líneas de evolución se deben a la ausencia de datos para estas variables en la base de datos del panel.

Conjuntamente en el gráfico se observa cómo el número de patentes ha disminuido durante el periodo 2003-2012 y cómo han sido las patentes presentadas en la Oficina Española de Patentes y Marcas las que han disminuido en prácticamente el 70\% en el año 2012 comparado con el año 2005 pasando de 144 a 46.

Contrasta el resultado anterior con el que se observa cuando se analizan el número de patentes que se presentan en la oficina europea y en la americana o a través del Tratado de cooperación de patentes. Sus evoluciones en estos casos son prácticamente constantes con pequeñas variaciones a lo largo del periodo. 


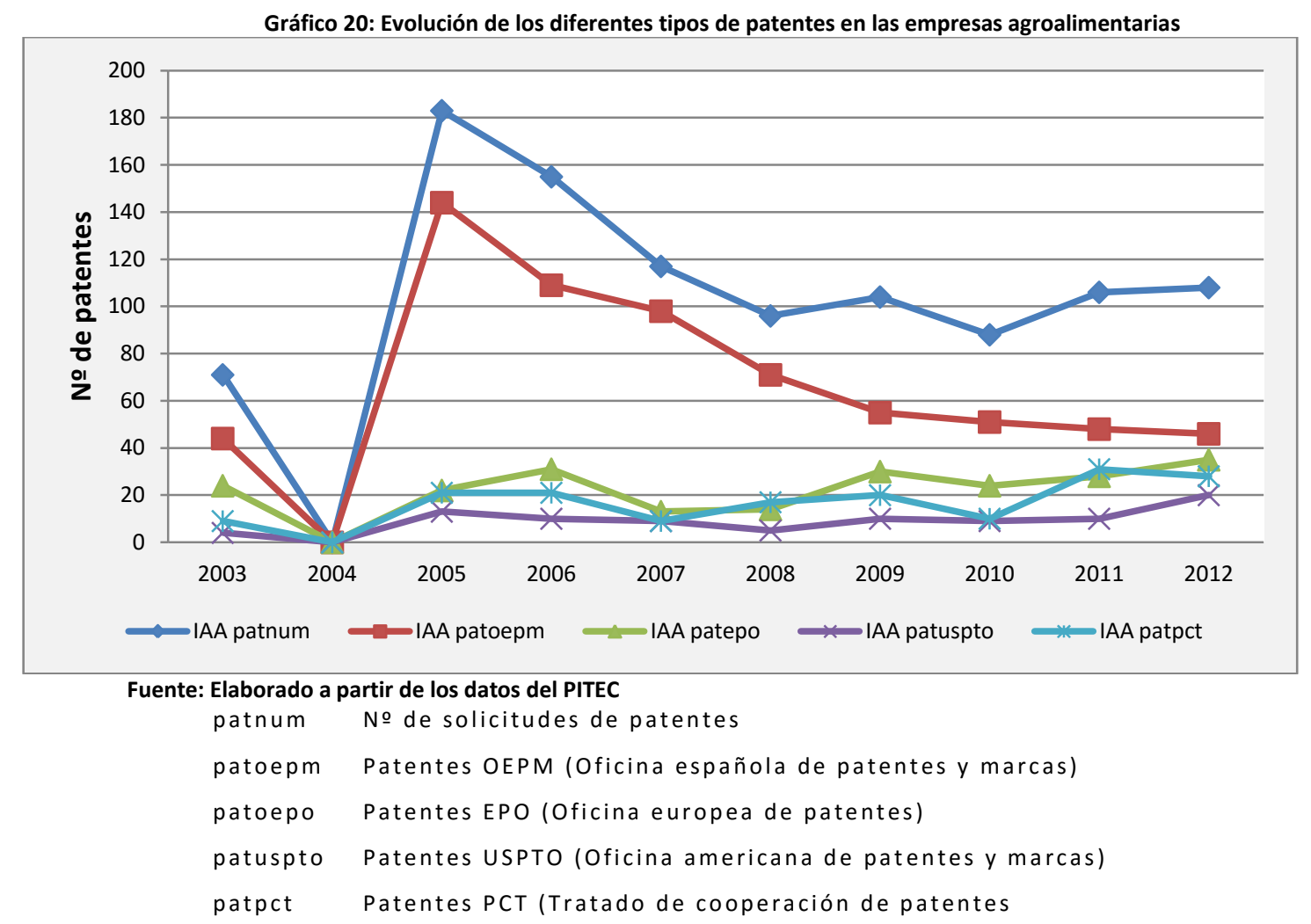

Algo similar al grupo de empresas agroalimentarias ocurre con el grupo del resto de empresas. Según se observa en el Gráfico 21 las evoluciones a lo largo del periodo 2003-2012 de los distintos tipos de patentes que ofrece la muestra indican tendencias similares al del grupo de empresas agroalimentarias

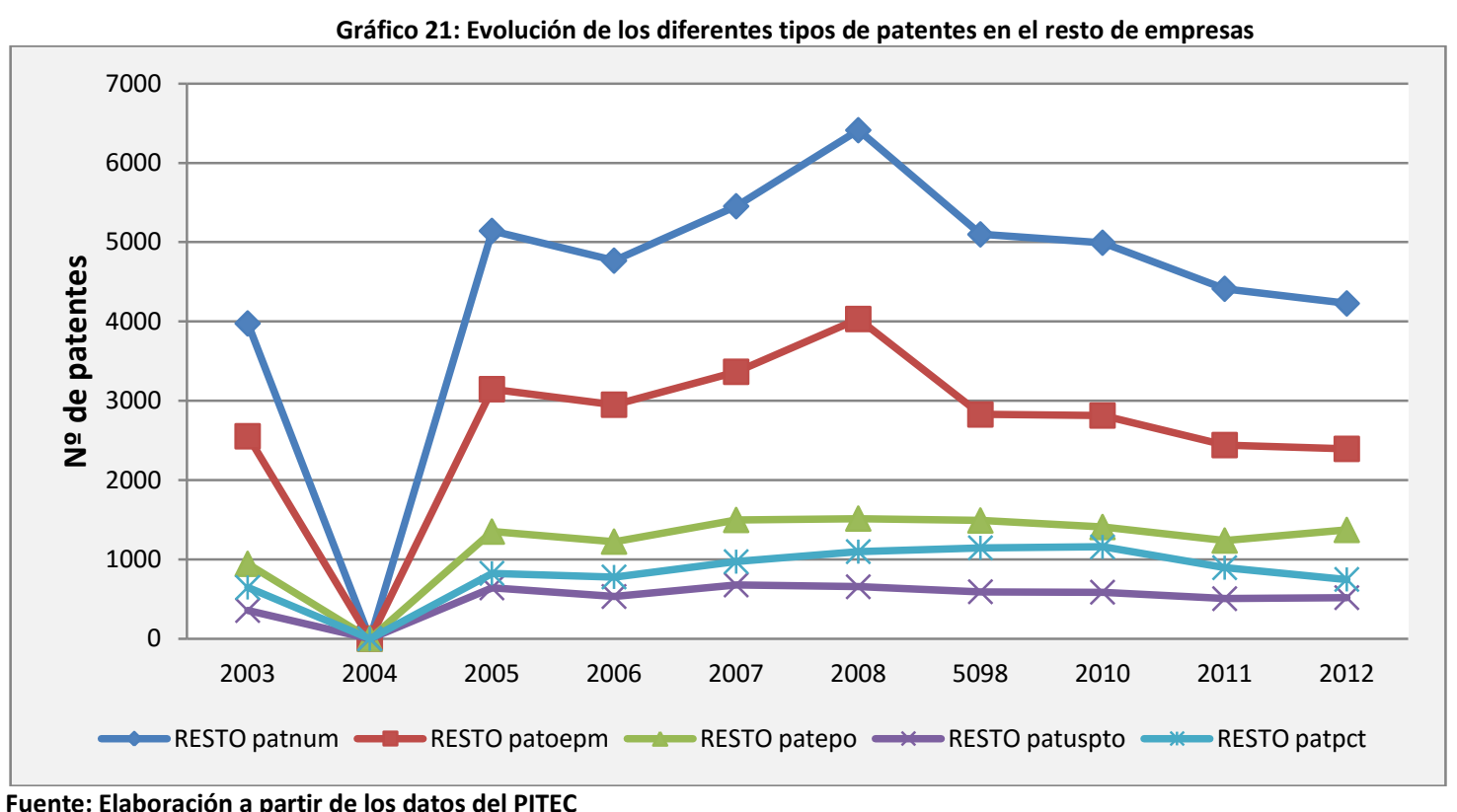




\subsubsection{Gastos en I+D}

En la encuesta de PITEC se define actividad interna de I+D como aquellos trabajos creativos llevados a cabo dentro de la empresa, que se emprenden de modo sistemático con el fin de aumentar el volumen de conocimientos para concebir nuevas aplicaciones, como productos y procesos nuevos o sensiblemente mejorados.

En el periodo 2003-2012, como se puede observar en el Gráfico 22, el número de empresas agroalimentarias que dedicaban parte de su capital a gastos en actividades de I+D internas (idin) experimentó una brusca caída de cerca del 55\% pasando de 509 empresas en el año 2005 a 275 empresas en el año 2012.

Las actividades de I+D externa se reflejan en la encuesta como la adquisición de servicios de I+D fuera de la empresa mediante contrato o convenio principalmente y siempre que no signifiquen una compra directa de I+D.

A su vez la encuesta distingue entre la compra de servicios de I+D en España y en el extranjero y en cada uno de estos casos con que entidades los contrata: empresas del mismo grupo, otras empresas, asociaciones de investigación o centros tecnológicos, organismos de la Administración Pública, Universidades e Instituciones privadas sin fines de lucro.

En el caso el número de empresas que llevan a cabo actividades de I+D externa (idex) la caída es menor, un 37,5\% pasando de 237 empresas en 2005 a 148 en 2012.

El Gráfico 22 pone de manifiesto la preferencia de las empresas agroalimentarias a la hora de realizar actividades de I+D de manera interna frente a la externa. 
Gráfico 22: Evolución del número de empresas que realizan gastos en actividades de I+D internas y externas en las empresas agroalimentarias.

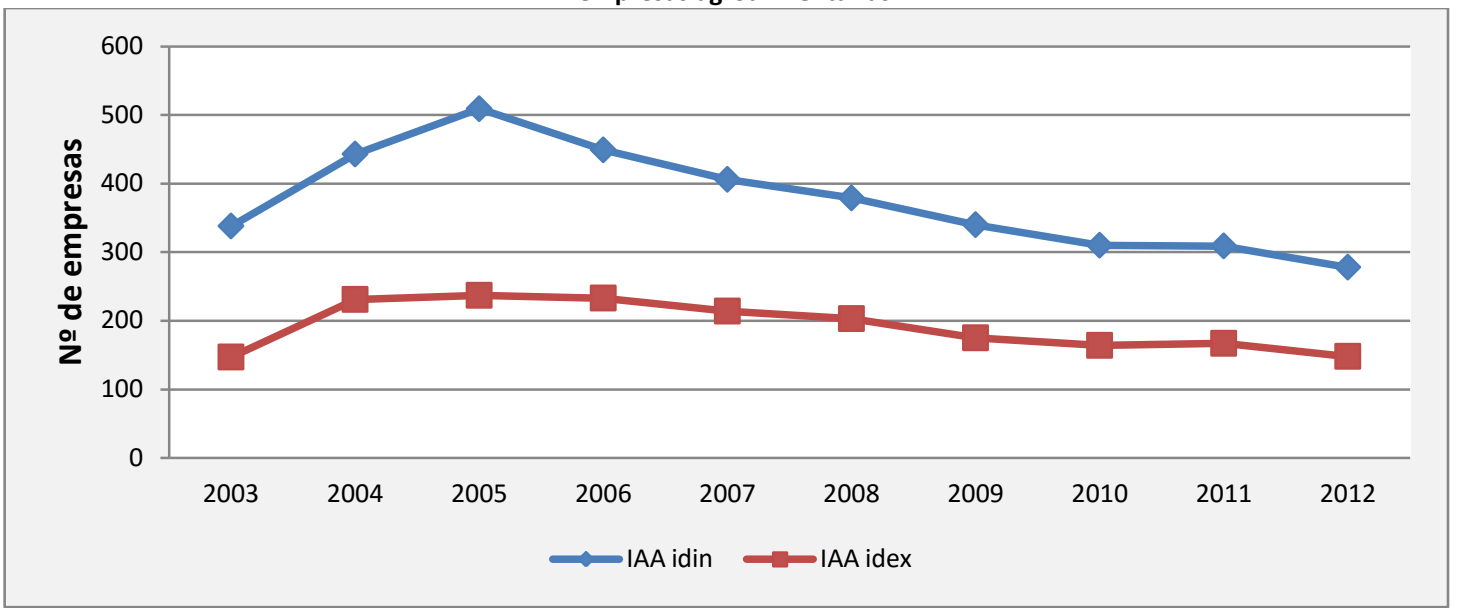

Fuente: Elaborado a partir de datos del PITEC

La situación en el caso del resto de las empresas de la muestra es similar a la que se produce en las empresas agroalimentarias. En ambos casos, la tendencia del número de actividades en I+D internas y externas es descendente como se aprecia en el Gráfico 23.

Gráfico 23: Evolución del número de empresas que realizan gastos en actividades de I+D internas y externas en el resto de empresas.

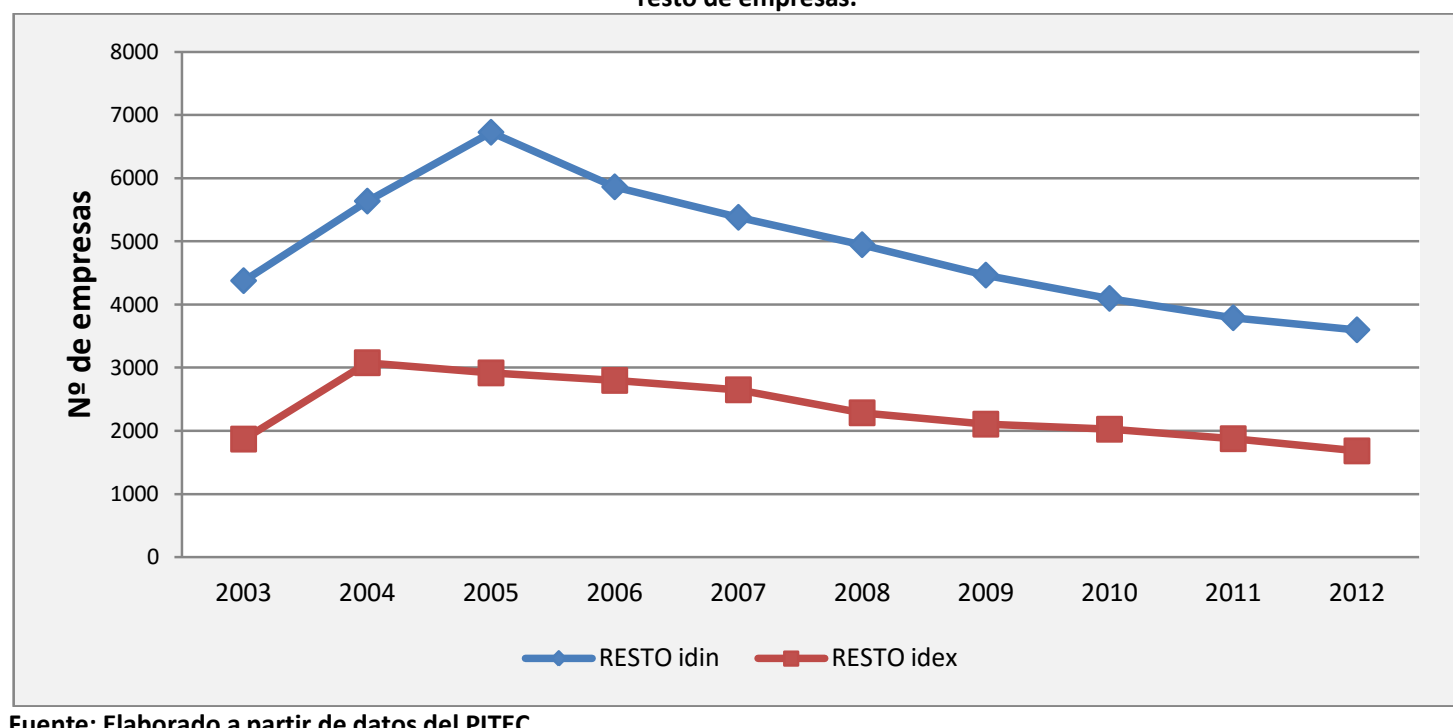

Una vez analizado el patrón de comportamiento de las empresas españolas procedemos a analizar la evolución de los gastos en actividades de I+D internas y externas.

Se consideran gastos en actividades de I+D interna los correspondientes al coste empresarial de los investigadores, de los técnicos y de los auxiliares como gastos corrientes en I+D y los equipos 
e instrumentos, los terrenos y los edificios y la adquisición de software específico para I+D como gastos de capital en I+D.

Los datos para las empresas agroalimentarias se recogen en el Gráfico 24. En consonancia con la evolución descendente del número de empresas que desarrollan actividades de I+D, los gastos dedicados a las actividades de I+D internas sufren una importante caída. De igual manera los gastos en actividades de I+D externas están muy por debajo de los dedicados a las actividades de I+D internas.

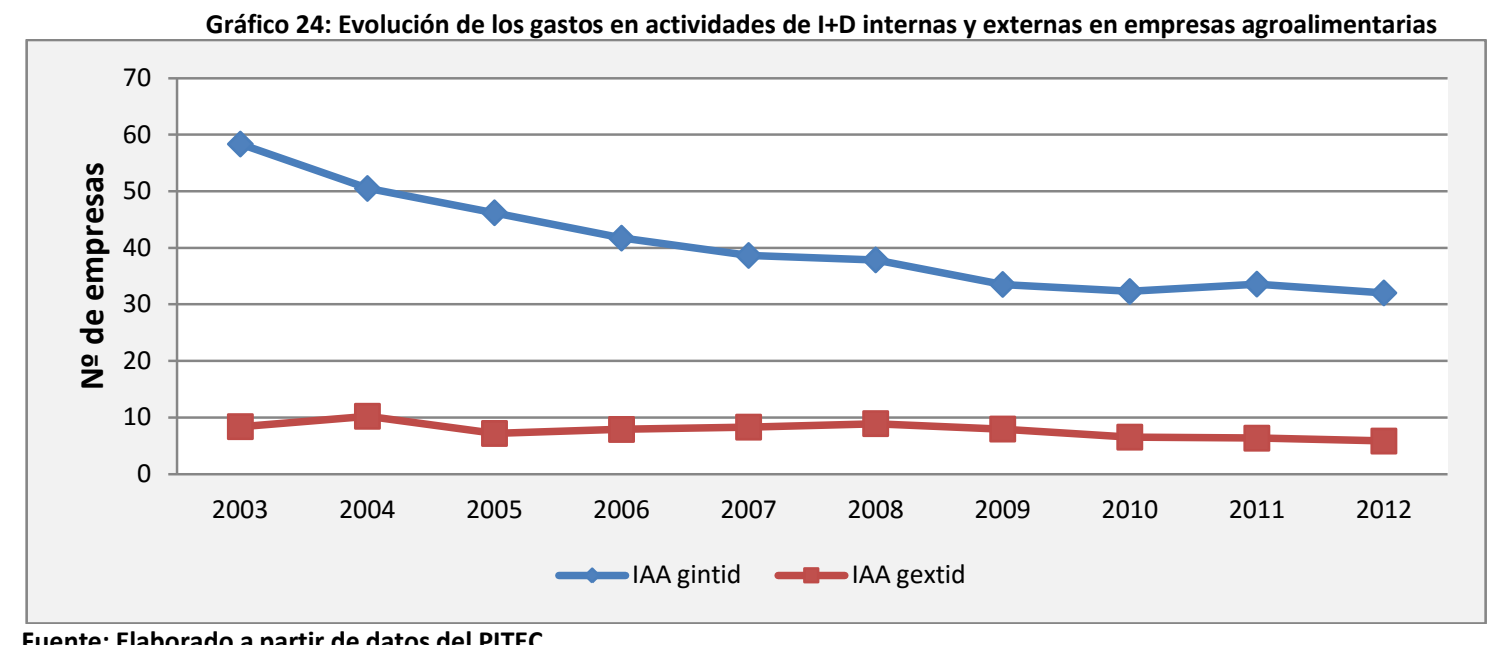

Fuente: Elaborado a partir de datos del PITEC

En cuanto al resto de empresas de la muestra en el Gráfico 25 se aprecia el mismo comportamiento que en las empresas agroalimentarias, un descenso bastante significativo de los gastos y preferencia a las actividades de I+D interna sobre las externas.

Gráfico 25: Evolución de los gastos en actividades de I+D internas y externas en el resto de empresas.

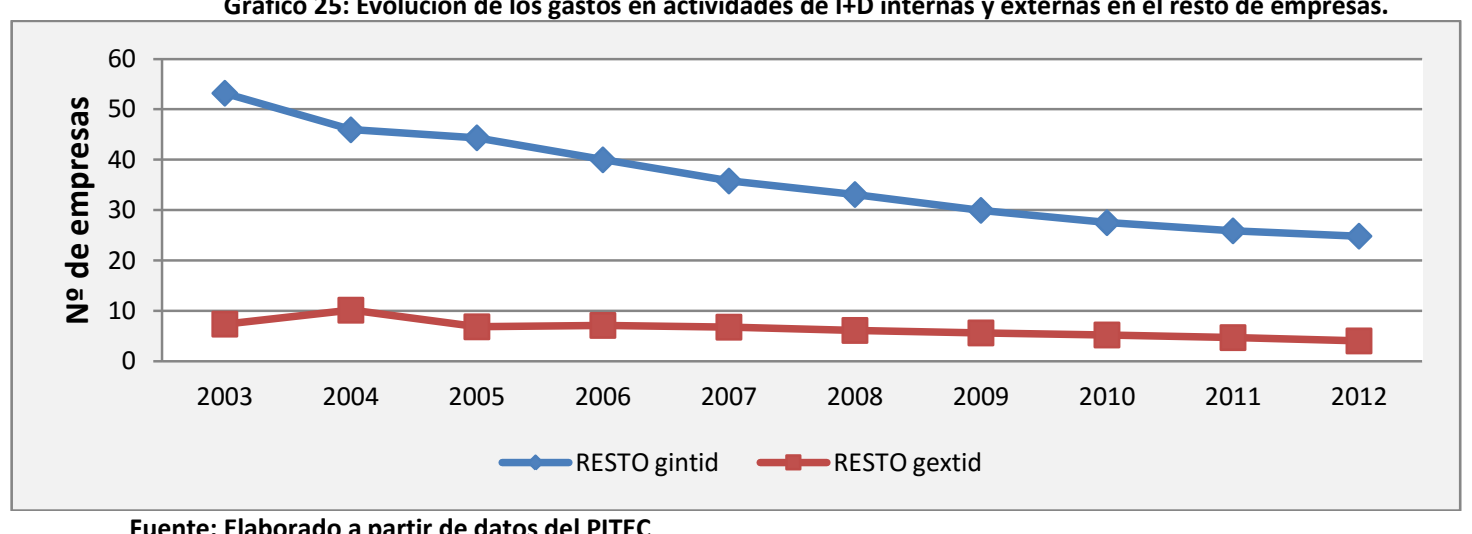

Fuente: Elaborado a partir de datos del PITEC 


\subsubsection{Cooperación tecnológica}

Ocho son las opciones de cooperación tecnológica que la encuesta propone a las empresas. Cooperación con otras empresas, con proveedores de equipos, material, componentes o software, con clientes del sector público y privado, con competidores, con consultores - laboratorios comerciales, con universidades u otros centros de enseñanza superior y con centros de investigación públicos o privados.

La cooperación para actividades de innovación tecnológica consiste según la encuesta en la participación activa con otras empresas o entidades no comerciales en actividades de innovación sin que sea necesario que ambas partes obtengan un beneficio comercial y excluyendo la subcontratación de trabajos sin cooperación activa.

En el Gráfico 26 se observa la diferencia entre el sector agroalimentario y el resto de empresas, en las primeras se aprecia estabilidad en la evolución del número de empresas que cooperan y en cambio en las segundas hay un descenso notable entre los años 2005 y 2012

Gráfico 26: Evolución del número de empresas que realizan cooperación para actividades de I+D

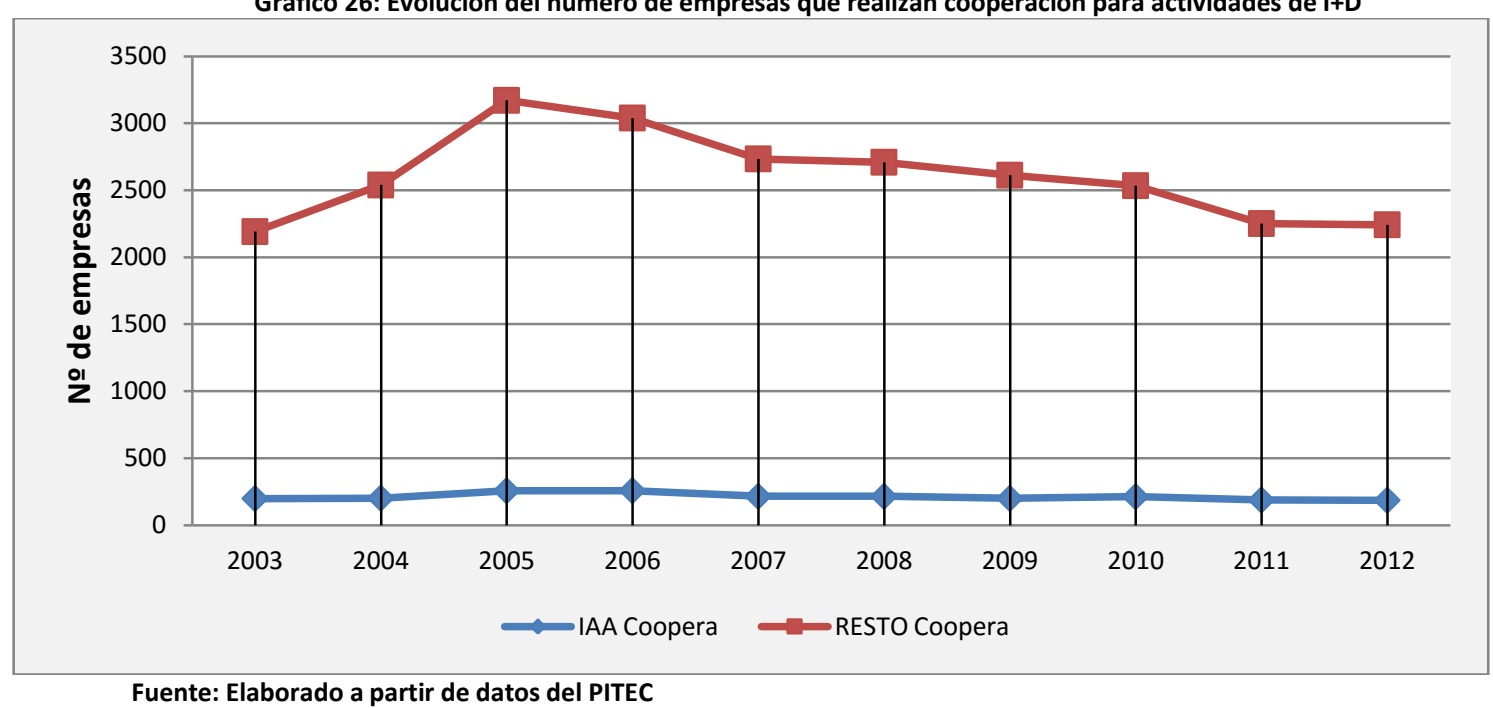

Fuente: Elaborado a partir de datos del PITEC 


\subsubsection{Innovaciones en producto y en proceso}

Por último, para terminar con el análisis de los datos de la encuesta, se analiza la evolución a lo largo del periodo 2003-2012 de las innovaciones en productos y servicios de las empresas españolas de la muestra.

La innovación en producto, según la encuesta es la introducción en el mercado de bienes o servicios nuevos o mejorados de manera significativa con respecto a características básicas, especificaciones técnicas, software incorporado $u$ otros componentes intangibles, finalidades deseadas o prestaciones. No se tienen en cuenta los cambios de naturaleza meramente estética ni la venta de innovaciones completamente producidas y desarrolladas por otras empresas. Además la innovación debe serlo para la empresa aunque no necesariamente para su sector o mercado. Tampoco importa en el caso de que la innovación se desarrolle inicialmente por la empresa o no lo haya hecho desde el inicio.

Se incorpora en el análisis las diferentes opciones que son ofrecidas por la encuesta: innovación en producto (innprod), innovación en bienes (innobien) e innovación en servicios (innoserv).

Observando el Gráfico 27 se observa un descenso en el número de empresas que lleva cabo innovaciones en producto. En el caso de las empresas agroalimentarias es bastante significativa la diferencia que se aprecia entre las innovaciones en bienes y las innovaciones en servicios.

A la luz de los datos podemos concluir que es importante el número de empresas que realizan a la vez innovaciones en bienes y servicios. Estos últimos incluyen servicios relacionados con la Web y el comercio electrónico. 


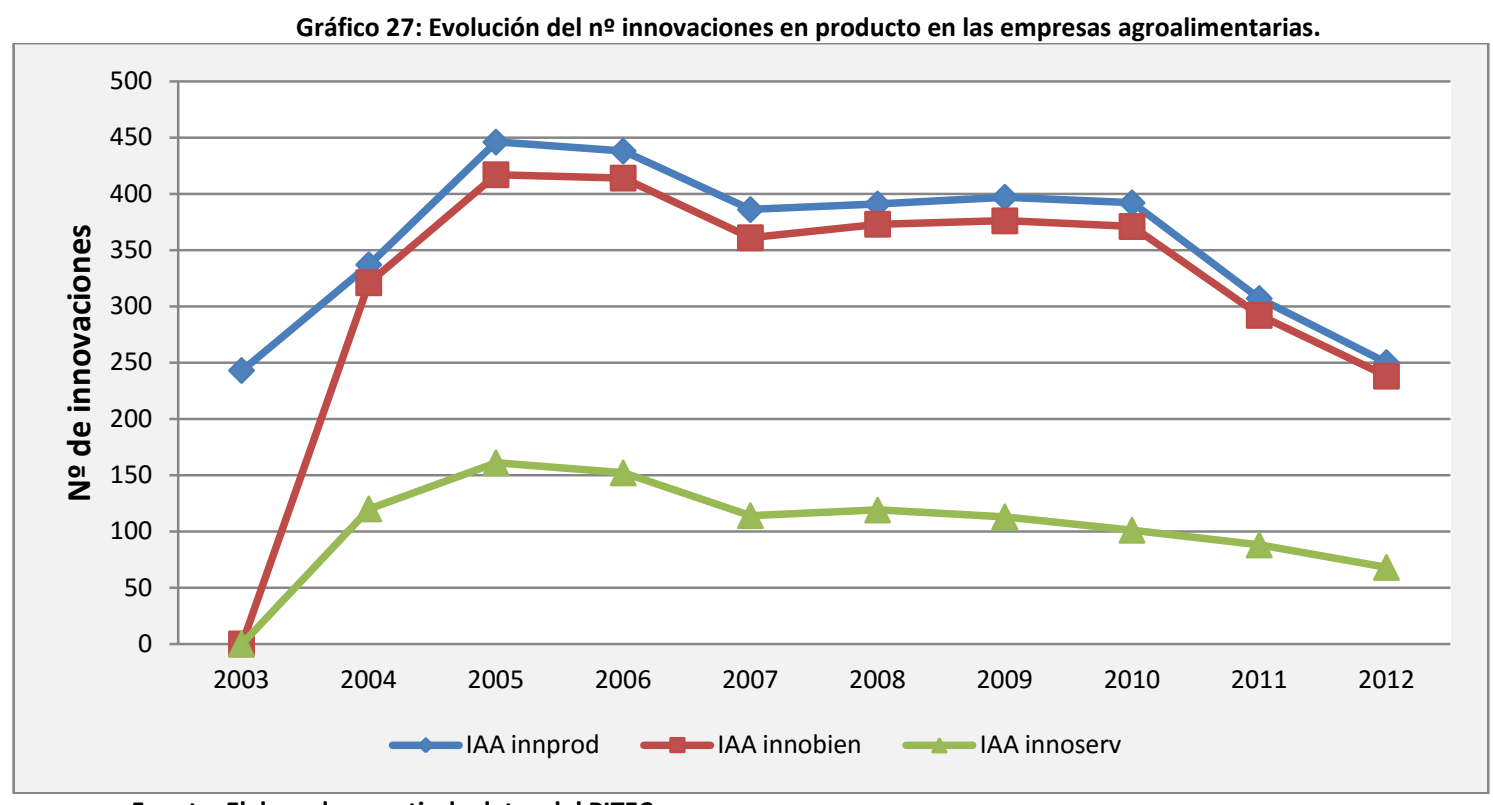

Fuente: Elaborado a partir de datos del PITEC

Ocurre lo mismo con las empresas del resto de las empresas, se producen descensos generalizados como se observa en el Gráfico 28 en las tres evoluciones representadas siendo más acusada la disminución en el caso de las innovaciones en producto.

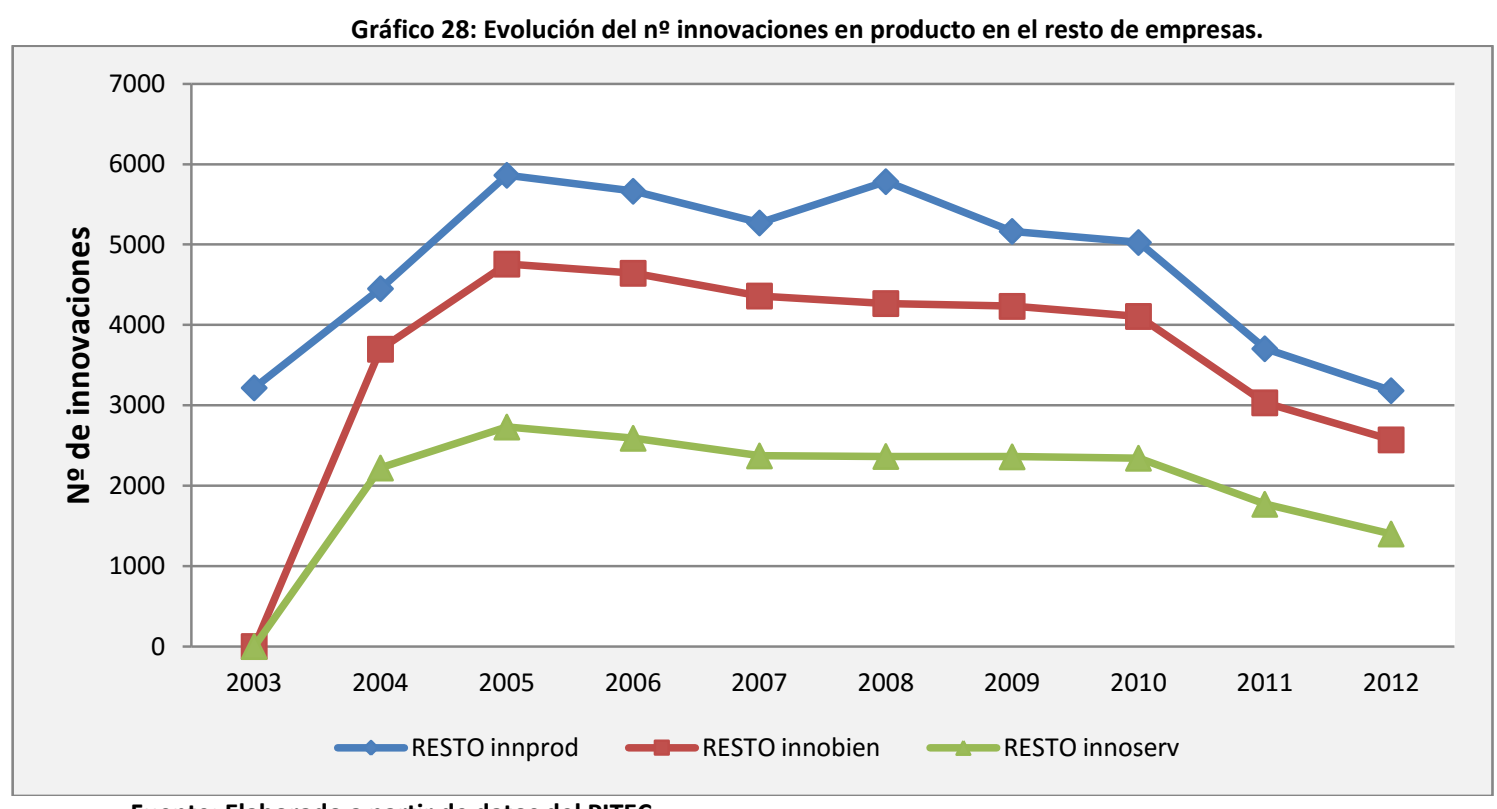

Fuente: Elaborado a partir de datos del PITEC

En cuanto a los procesos la encuesta considera que se lleva a cabo una innovación cuando se implantan procesos nuevos de producción, métodos de distribución o actividades de apoyo a sus bienes y servicios que sean nuevos o aporten una mejora significativa. La innovación debe serlo para las empresas y no necesariamente para el sector al que 
pertenece o al mercado en el que actúa. Además, al igual que ocurre con las innovaciones en producto, no es necesario que la empresa desarrolle desde su inicio la innovación y quedan excluidas las innovaciones meramente organizativas.

En el Gráfico 29 están representadas las evoluciones del número de empresas que han llevado a cabo innovaciones en producto que durante el periodo 2003-2014. Se consideran tres tipos de innovaciones en producto: innovación en métodos de fabricación o producción (innfabri), innovación en sistemas logísticos (innlogis) e innovación en apoyo para los procesos (innapoyo).

Las tendencias de las evoluciones en todos los casos considerados son descendentes como ha ocurrido a lo largo del análisis de los datos de todos los indicadores.

Por orden de utilización las innovaciones en métodos de fabricación son las más empleadas por las empresas agroalimentarias seguidas de las innovaciones en apoyo para los procesos. En último lugar, son las innovaciones en sistemas logísticos las que menos se emplean.

Gráfico 29: Evolución del no innovaciones en proceso en las empresas agroalimentarias.

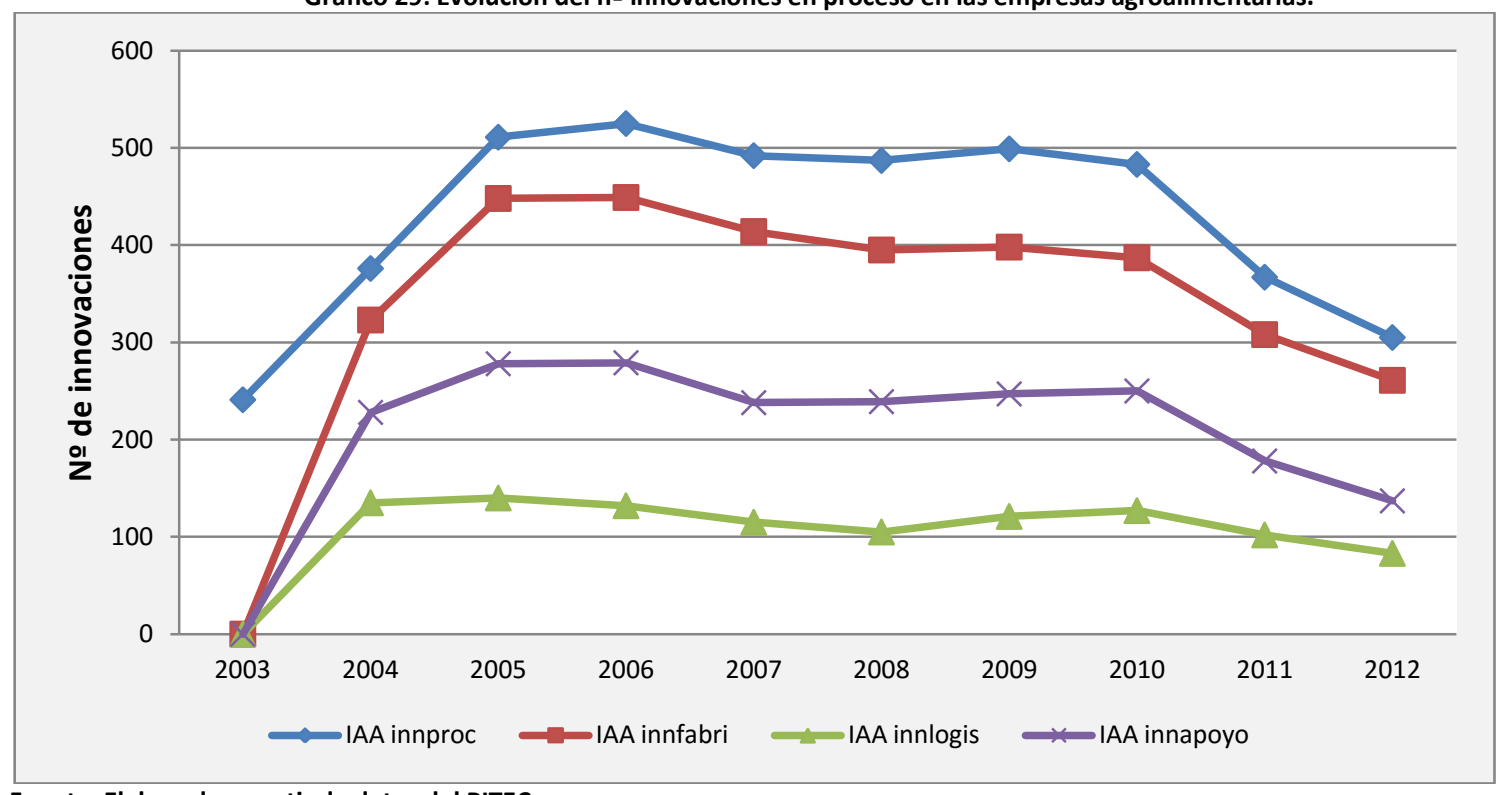

Fuente: Elaborado a partir de datos del PITEC 
En el caso de las innovaciones en proceso del resto de empresas existe un paralelismo en cuanto a las tendencias de las evoluciones. Se percibe además una menor diferencia entre las innovaciones en métodos de fabricación y de apoyo a los procesos.

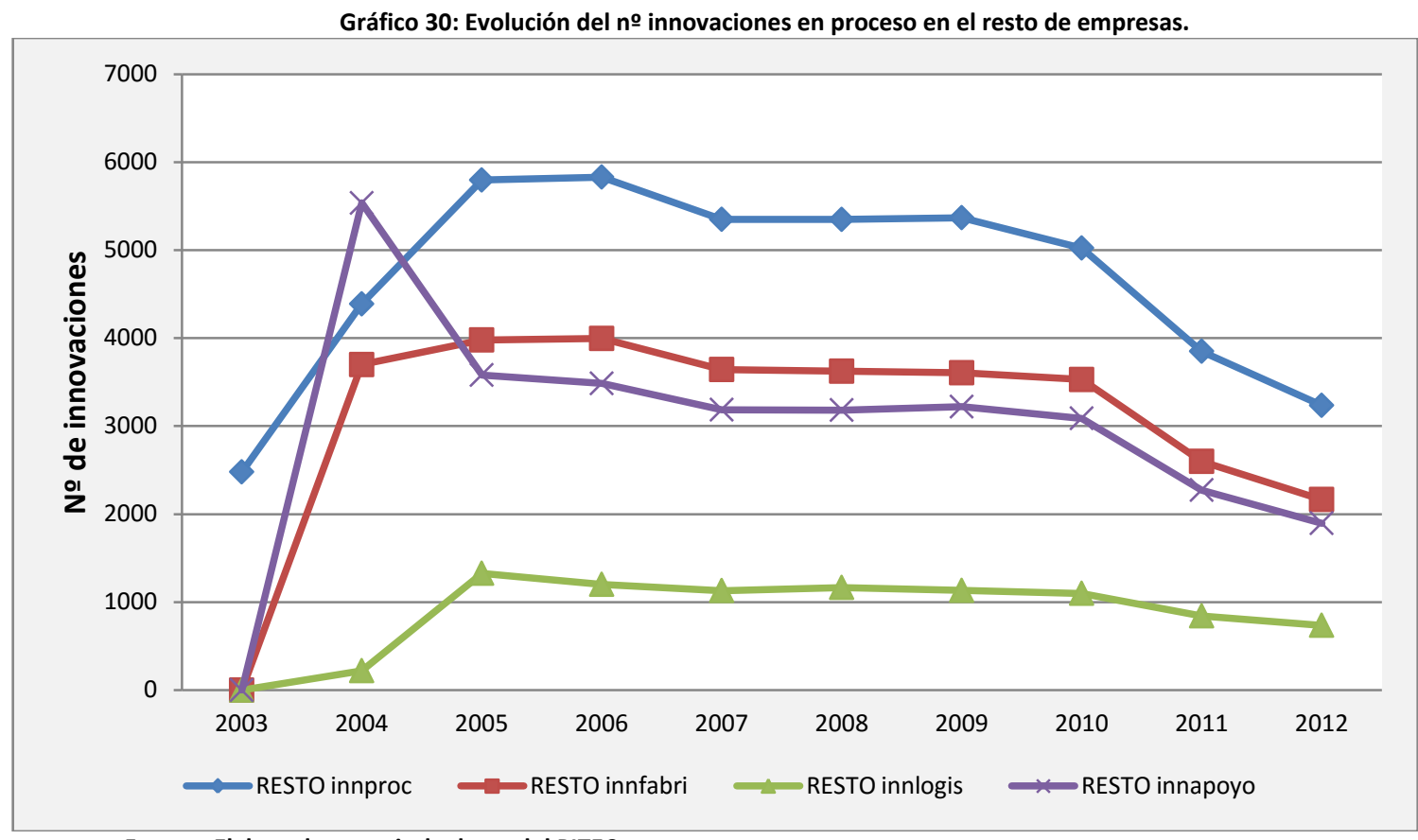

Fuente: Elaborado a partir de datos del PITEC

Finalizamos este último apartado del capítulo representando en la Gráfico 31 la evolución del número de actividades innovadoras en el curso de cada año o de actividades innovadoras no exitosas durante el periodo 2003-2012.

Representados por un lado las que pertenecen a las empresas agroalimentarias y por otro lado las del resto del sector observamos que en el caso de las primeras la evolución se representa por una línea aproximadamente paralela al eje de abscisas mientras que en el caso de las empresas del resto de empresas el descenso es bastante significativo, la tendencia es descendente a lo largo de todo el periodo. 
Gráfico 31: Evolución de las actividades innovadora en curso o no exitosas.

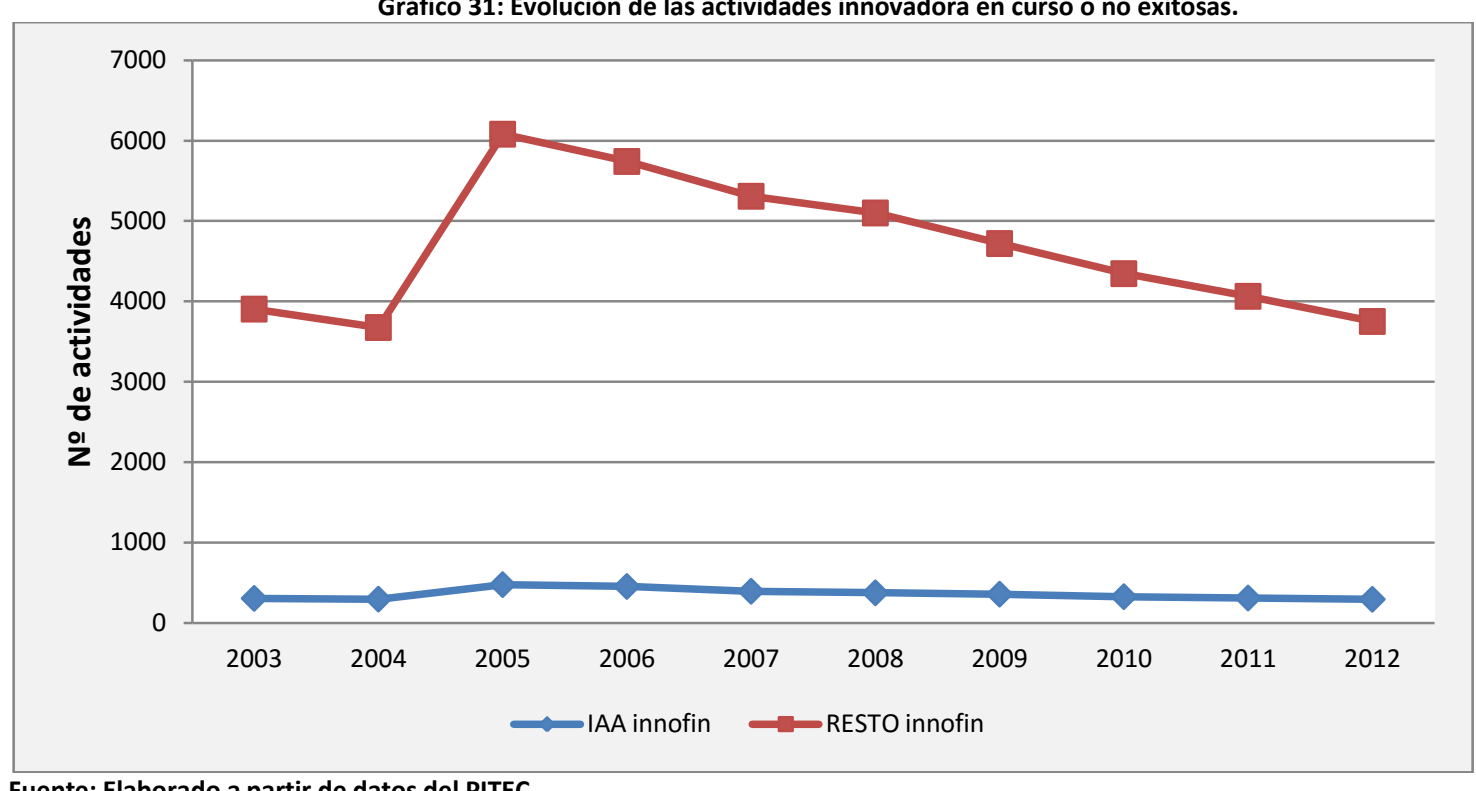

Fuente: Elaborado a partir de datos del PITEC 
Capítulo 5 Variables

$y$

Especificación del

Modelo 



\section{VARIABLES Y ESPECIFICACIÓN DEL MODELO}

Para finalizar con el planteamiento expuesto en la introducción, la propuesta metodológica se completa con la especificación de los modelos econométricos utilizados en cada uno de los tres casos empíricos planteados en la investigación.

\subsection{Planteamiento técnico del problema}

Uno de los objetivos por el cual se emplean los modelos de regresión es establecer la relación que hay entre diferentes variables explicativas con la variable explicada a través de la estimación de los coeficientes de cada una de las variables especificadas en el modelo econométrico. De esta manera, tras el análisis de la significación de los coeficientes obtenidos, se pueden determinar los factores que explican la variable explicada.

Siguiendo la Teoría de los Recursos y Capacidades se asume que la actividad innovadora de la empresa viene proporcionada por la capacidad de innovación que le proporcionan los recursos empresariales de que dispone.

En consonancia con la revisión bibliográfica, expuesta en el capítulo 2, el grado de innovación se expresa a través del uso de indicadores tales como el número de nuevos productos que se introducen en el mercado y el número de patentes que una empresa obtiene para proteger sus invenciones. De esta manera, se considera a la empresa como un conjunto de atributos que podrán o no afectar al desarrollo de proyectos innovadores.

$$
\text { indicador }=\mathrm{f}\left(\text { atributos }_{\mathrm{i}}\right) \quad \mathrm{i}=1,2, \ldots, \mathrm{n}
$$


Donde cada i representa los diferentes atributos empresariales (variables explicativas).

A la hora de escoger los atributos que mejor representan a la actividad innovadora se tiene en cuenta dos aspectos

- Su justificación en base a la teoría económica; y

- La intensidad de las correlaciones parciales de las variables explicativas con el resultado innovador.

De esta manera, el modelo general que se plantea en este trabajo para explicar los factores que explican la innovación en producto y la demanda de patentes lo expresamos de la siguiente manera:

$\mathrm{n}$ oppatentes o no innovaciones en producto $=\mathrm{f}($ actividad en $\mathrm{I}+\mathrm{D}$, Cooperación tecnológica, activos complementarios)

Donde la componente denominada activos complementarios incluye la inversión en bienes de equipo, la propensión exportadora de la empresa, activos financieros y humanos, la deuda y el tamaño de la empresa.

\subsection{Variables}

Como variable explicada se ha tomado el número de patentes (PAT) que se han registrado tanto en España (PATESP) como en el extranjero (PATEXT). Consideramos el registro de patentes como un indicador de output que valora la actividad verdaderamente innovadora. Es una variable de conteo, es decir, se corresponde con la respuesta a la pregunta de la encuesta sobre el número de patentes presentadas cada año del periodo considerado. Las empresas de la muestra realizaron 348 patentes entre 1998 y 2008, de las cuales 143 (41,1\%) fueron registradas por pymes y 205 (58,9\%) por grandes empresas. Expresado 
con otras cifras: en este sector la media de patentes por empresa y año es de 0,1489 (Tabla 1), y presentan valores medios tres veces más elevados las grandes $(0,2740)$ que las pymes $(0,0899)$. Por tanto, es evidente que las empresas grandes patentan más tanto en términos absolutos como por empresa; sin embargo muchas pymes también patentan y en conjunto aportan más del $40 \%$ del total en la muestra.

En el Gráfico 32 se representan las evoluciones durante el período analizado del número de patentes que se han presentado tanto en España como en el extranjero. En términos porcentuales y en el sector agroalimentario español, el número de patentes registradas en España durante el periodo de los once años de estudio es del $70 \%$ frente al 30 $\%$ de las que se registran en el extranjero. Tan sólo hay un año, el 2001, en el que el porcentaje de patentes registradas en el extranjero es superior al de las registradas en España. Por lo general, podemos afirmar que las tendencias son paralelas en ambos casos.

Gráfico 32: Número de patentes en España y en el extranjero
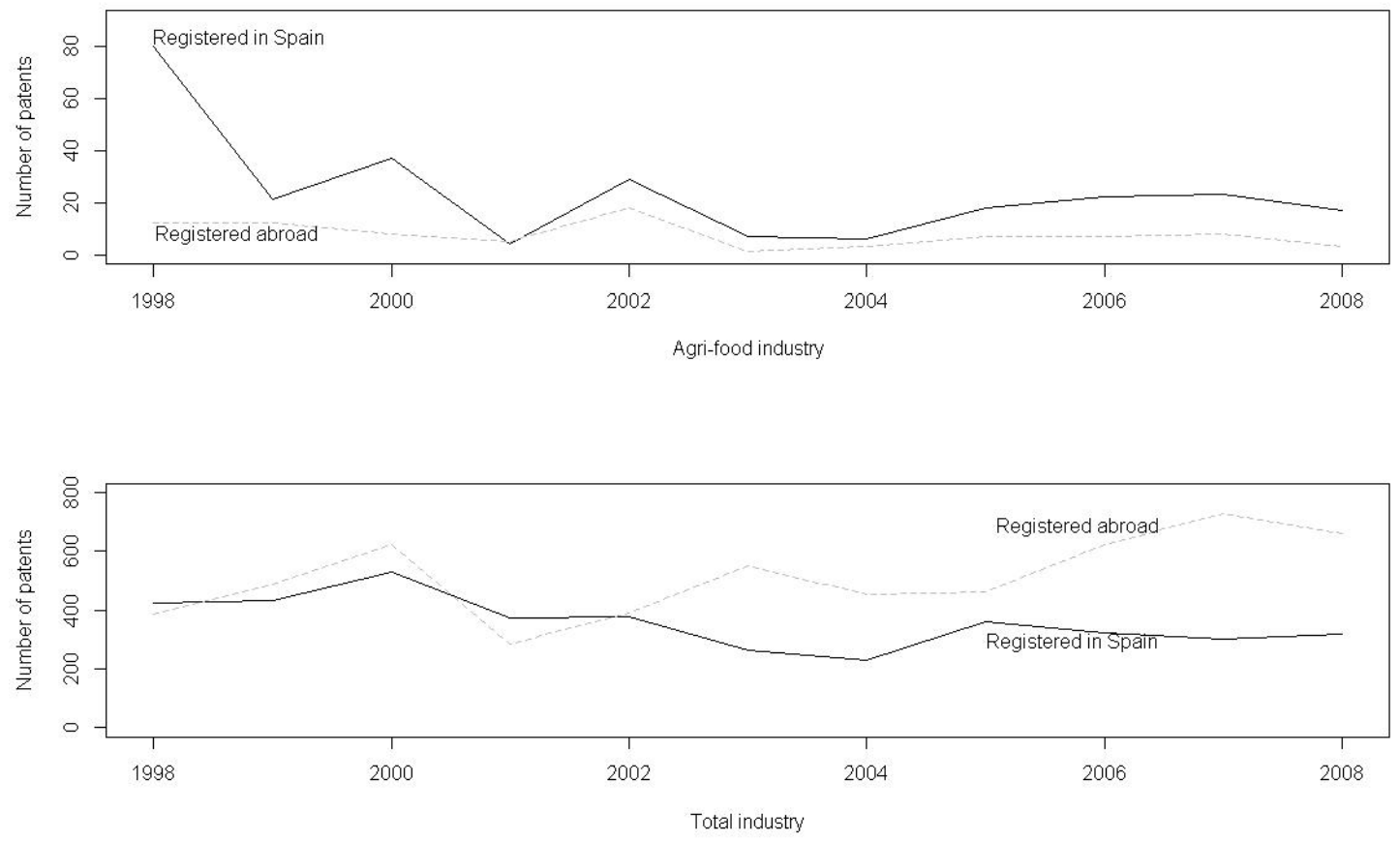

Fuente: Alarcón, S. y González Polonio, L. (2014) 
Si consideramos ahora el conjunto del sector manufacturero, podemos ver en Gráfico 32 cómo se invierten los términos y, en el caso del número de registros de patentes en España es inferior a los registrados en el extranjero a partir del año 2002. La tendencia, a la luz de los datos, es que la brecha entre ambos casos es ascendente. La media porcentual de patentes registradas en España es de $41 \%$ frente al $59 \%$ de las registradas en el extranjero.

Para aproximar los recursos tecnológicos nos hemos basado en el esfuerzo de las empresas en actividades de $I+D$, mediante gastos externos en I+D (GEID) y gastos internos en I+D (GIID). Los ratios incluidos en el análisis son los valores de estas variables divididas por el volumen de ventas:

$$
\text { GEIDV }=\frac{\text { gastos externos en } \mathrm{I}+\mathrm{D}}{\text { ventas }} \quad \text { GIIDV }=\frac{\text { gastos internos en } \mathrm{I}+\mathrm{D}}{\text { ventas }}
$$

La Gráfico 33 que es mayor el número de empresas con gastos internos en I+D que las que tienen gastos externos.

Gráfico 33: Porcentaje de empresas con I+D o cooperación tecnológica
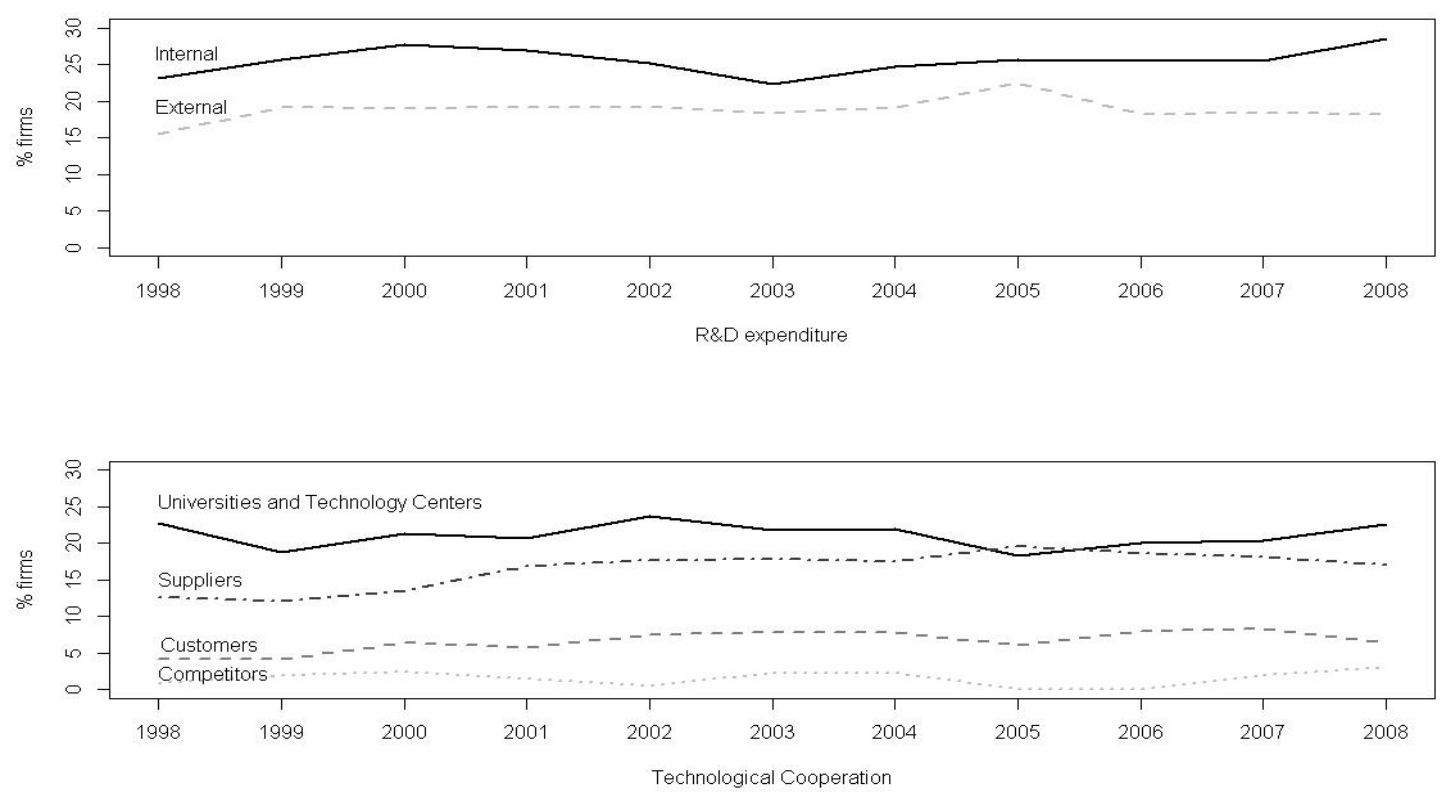

Fuente: Alarcón, S. y González Polonio, L. (2014) 
Así, la media de las empresas que llevan a cabo gastos en I+D externa es de $18,8 \%$ frente al $25,5 \%$ que realizan gastos internos en I+D. Sin embargo las diferencias por tamaños son muy grandes: muy pocas pymes acometen I+D, solamente el $12,4 \%$ compran $I+D$ externa $y$ solamente el $13,6 \%$ desarrollan I+D interna, frente a unas proporciones en grandes empresas del $58,7 \%$ y el $89,0 \%$, respectivamente.

La Cooperación Tecnológica está incluida dentro de la encuesta en el apartado de actividades tecnológicas, en la cual se contesta, entre otras si se dispuso durante el año de algún mecanismo entre los cuales se encuentran la colaboración con proveedores, con clientes, con empresas de la competencia y con Universidades y/o Centros Tecnológicos. La evolución del número de empresas que siguen las diferentes estrategias de cooperación se muestran en la Figura 4. La opción con un mayor número de empresas es la colaboración con las Universidades y los centros tecnológicos, 21,1\% (Tabla 1). Esta opción ha experimentado una subida durante los últimos tres años del periodo analizado. La segunda opción más seguida es la cooperación tecnológica con los proveedores $(16,4 \%)$. En este caso vemos que ha sufrido un descenso durante los tres últimos años del final del periodo analizado. Y por último, claramente inferiores en número, encontramos la cooperación tecnológica con clientes $(6,6 \%)$ y con empresas rivales $(1,5 \%)$. Al igual que en las actividades de $I+D$, la cooperación tecnológica es mucho menos frecuentes en pymes que en grandes. En pymes agroalimentarias solamente el $13,8 \%$ realiza algún tipo de cooperación tecnológica frente al 56,1\% en grandes.

Los recursos físicos se han se han medido mediante el ratio de las inversiones en bienes de equipo (INBE) efectuadas por la empresa sobre el activo total de la misma para cada año del período. La inversión media anual es del 4,9\% del activo. 


$$
\text { INBEA }=\frac{\text { inversiones en bienes de equipo }}{\text { Activo }}
$$

Para el tamaño de la empresa se ha utilizado como aproximación la variable Personal total medio (PTP), y dado su gran variabilidad se ha preferido tomar logaritmos.

En el caso de los recursos humanos se han aproximado mediante los costes de personal sobre producción (CPSP). Mayores valores de esta variable se interpretan como mayor calidad de los recursos humanos usados por la empresa.

$$
\text { CPSP }=\frac{\text { coste de personal }}{\text { producción }}
$$

Los recursos comerciales de la empresa se cuantifican a través de la propensión exportadora de la empresa en cada año del periodo, y en concreto se ha usado el porcentaje que las exportaciones que realiza la empresa representan sobre el total de ventas de la empresa (PX).Las empresas de la muestra exportan de media el $11,6 \%$ de sus ventas. De nuevo las diferencias por tamaños son considerables pues exportan el $41,1 \%$ de las pymes, frente a $88,1 \%$ en grandes, mientras que las ventas por exportaciones representan de media el $8,7 \%$ del total de ventas en pymes, frente a $17,6 \%$ en grandes.

Para los recursos financieros de la empresa se han tomado dos ratios. En primer lugar, un indicador de la liquidez de la empresa como es el ratio del fondo de maniobra sobre ventas. Es decir, activo corriente menos el total de fondos de ajenos a corto plazo sobre el volumen de ventas de la empresa. Por otra parte, el nivel de endeudamiento total de la empresa se ha medido como el cociente entre el pasivo (fondos ajenos) y el patrimonio neto (fondos propios). Tanto el nivel de endeudamiento como la liquidez son ligeramente superiores en pymes que en grandes. 


$$
\mathrm{FMV}=\frac{\text { activo corriente }- \text { fondos ajenos a corto plazo }}{\text { ventas }}
$$

$$
\text { DEUDA }=\frac{\text { pasivo }}{\text { patrimonio neto }}
$$

A continuación en la Tabla 22 encontramos la codificación de las variables explicativas del modelo para poder interpretar los resultados.

\begin{tabular}{|c|c|}
\hline nombre & Factor \\
\hline CTPR & Cooperación Tecnológica con proveedores \\
\hline CTCL & Cooperación Tecnológica con clientes \\
\hline CTCO & Cooperación Tecnológica con competidores \\
\hline CUCT & $\begin{array}{l}\text { Cooperación Tecnológica con Universidades } \\
\text { y Centros Tecnológicos }\end{array}$ \\
\hline GEIDV & Gastos externos I+D sobre ventas \\
\hline GIIDV & Gastos internos I+D sobre ventas \\
\hline IPR & Innovación en producto \\
\hline $\mathrm{DPI}$ & Dominio propio de Internet \\
\hline CPSP & Costes de personal sobre producción \\
\hline $\mathrm{PX}$ & Propensión exportadora \\
\hline INBEA & $\begin{array}{l}\text { Inversión en bienes de equipo sobre activos } \\
\text { totales }\end{array}$ \\
\hline FMV & Fondo de maniobra sobre ventas \\
\hline $\log (\mathrm{PTP})$ & Personal total medio \\
\hline DEUDA & Deuda \\
\hline
\end{tabular}

Tabla 22: Resumen de las variables explicativas de los modelos

Fuente: Elaboración propia 


\subsection{Especificación econométrica de los modelos}

A la hora de incorporar en la especificación econométrica las variables explicativas se han considerado dos enfoques diferentes. Estos se traducen en tres casos empíricos atendiendo al indicador de innovación considerado.

Un primer enfoque en el que se considera la inversión en I+D y la cooperación tecnológica como principales estrategias para la protección de las innovaciones (casos 1 y 3 ), y un segundo enfoque en el que se estudia la incorporación de nuevos productos al mercado (caso 2 )

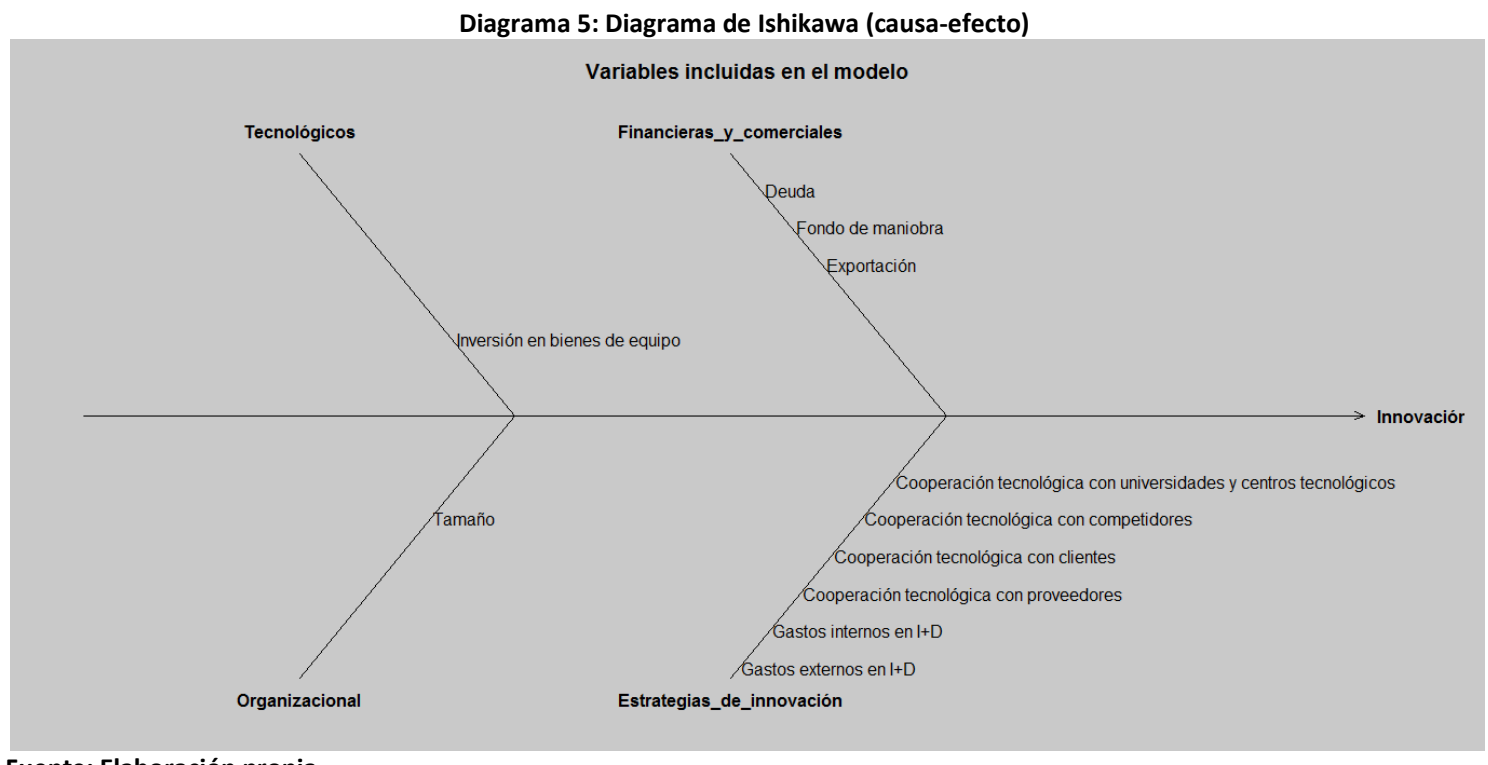

Fuente: Elaboración propia

\subsubsection{Especificación del modelo econométrico (caso empírico 1)}

La variable a explicar o dependiente, viene definida por el número de patentes dentro y fuera de España, es una variable de conteo, que toma valores enteros no negativos. Por este motivo, en lugar de estimar mediante mínimos cuadrados ordinarios, es mejor usar un modelo que tenga en cuenta que la variable dependiente se ha generado mediante 
una distribución de Poisson, que expresa la probabilidad de que ocurra un evento en un intervalo de tiempo (Greene, 2006).

La especificación que se ha empleado a la hora de realizar la aplicación empírica es la siguiente:

$$
\begin{aligned}
& \log \left(P A T_{i t}\right)=\beta_{0}+\beta_{1 A} G E I D V_{i t}+\beta_{1 B} G I I D V_{i t}+\beta_{2 \mathrm{~A}} C T P R_{i t}+\beta_{2 \mathrm{~B}} C T C L_{i t} \\
& +\beta_{2 \mathrm{C}} C \mathrm{CCO}_{i t}+\beta_{2 \mathrm{D}} \operatorname{CUCT}_{i t}+\beta_{3 \mathrm{~A}} I N B E A_{i t}+\beta_{3 \mathrm{~B}} \log P T P_{i t} \\
& +\beta_{3 \mathrm{C}} C P S P_{i t}+\beta_{3 \mathrm{D}} P X_{i t}+\beta_{3 \mathrm{E}} F M V_{i t}+\beta_{3 \mathrm{E} *} D E U D A_{i t}+E M P R E S A_{i} \\
& +A \tilde{\mathrm{N}} O_{t}
\end{aligned}
$$

El subíndice $\mathrm{i}$ denota la empresa $(\mathrm{i}=1, \ldots, \mathrm{N})$ y el subíndice $\mathrm{t}$ el año $(t=1998, \ldots, 2008)$. Los coeficientes $\beta_{1 \mathrm{~A}}$ y $\beta_{1 \mathrm{~B}}$ corresponden a las Hipótesis $\mathrm{H} 1$ relacionadas con los gastos en $I+D, \beta_{2 A}, \beta_{2 B}, \beta_{2 C}$ y $\beta_{2 D}$ contrastan las Hipótesis $\mathrm{H} 2$ de cooperación tecnológica, y $\beta_{3 \mathrm{~A}}, \beta_{3 \mathrm{~B}}, \beta_{3 \mathrm{C}}$, $\beta_{3 \mathrm{D}}, \beta_{3 \mathrm{E}}$ y $\beta_{3 \mathrm{E} *}$ establecen el papel de otros activos complementarios (Hipótesis H3).

Los modelos de regresión de Poisson asumen que su media y su varianza son iguales, y en la mayoría de los casos prácticos en econometría ocurre que la varianza es superior a la media (sobredispersión). En este trabajo se usan procedimientos robustos a sobredispersión. Por otra parte, la estructura de datos de panel permite mejorar los resultados mediante la realización de una estimación condicionada a los efectos característicos, desconocidos e invariables de cada empresa $\left(\operatorname{EMPRESA}_{\mathrm{i}}\right)$ y de cada año $\left(\mathrm{ANNO}_{\mathrm{t}}\right)$. En este trabajo se estiman modelos de efectos fijos y de efectos aleatorios, y se comparan los resultados.

Otra cuestión a tener en cuenta es la posibilidad de incluir regresores desfasados dado que parece lógico que los efectos de la I+D y de la cooperación tecnológica no sean inmediatos. Sin embargo, Hall, Griliches y Hausman (1986), en un estudio con empresas manufactureras 
estadounidenses en los 70, concluyen que los retardos de I+D no son significativos y que son las variables explicativas contemporáneas las que conducen a una mayor explicación del número de patentes que registran las empresas. Por tanto, lo primero que se va a realizar en la siguiente sección es comprobar si este comportamiento también se produce en nuestros datos de empresas agroalimentarias españolas. Siguiendo a estos autores y considerando por separado las Hipótesis H1 (efectos de la I+D) y $\mathrm{H} 2$ (efectos de la cooperación tecnológica) se han realizado estimaciones del tipo:

$$
\begin{aligned}
\log \left(P A T_{i t}\right) & =\beta_{0}+\beta_{10} G E I D V_{i t}+\beta_{1 A 1} G E I D V_{i t-1}+\cdots+\beta_{1 A s} G E I D V_{i t-s} \\
& +\beta_{1 B 0} G I I D V_{i t}+\beta_{1 B 1} G I I D V_{i t-1}+\cdots+\beta_{1 B s} G I I D V_{i t-s}+A \tilde{\mathrm{N}} O_{t}
\end{aligned}
$$

$$
\begin{aligned}
\log \left(P A T_{i t}\right) & =\beta_{0}+\beta_{2 A 0} C_{T P P R_{i t}}+\beta_{2 A 1} C T P R_{i t-1}+\cdots+\beta_{2 A s} C T P R_{i t-s} \\
& +\beta_{2 B 0} C_{T C L}+L_{i t}+\beta_{2 B 1} C T C L_{i t-1}+\cdots+\beta_{2 B s} C T C L_{i t-s}+\beta_{2 C 0} C T C O_{i t} \\
& +\beta_{2 C 1} C_{T C O} O_{i t-1}+\cdots+\beta_{2 C s} C T C O_{i t-s}+\beta_{2 D 0} C U C T_{i t}+\beta_{2 D 1} C U C T_{i t-1} \\
& +\cdots+\beta_{2 D s} C U C T_{i t-s}+A \tilde{N} O_{t}
\end{aligned}
$$

\subsubsection{Especificación del modelo econométrico (caso empírico 2)}

En este segundo caso se ha querido poner en valor el efecto de las TICs, esperando que un mayor uso de ellas aumente el porcentaje de empresas que innovan en producto. La intensidad de uso de TICs se ha modelizado con la variable que expresa la posesión de un dominio propio en Internet (DPI).

El modelo econométrico se especifica atendiendo al tipo de variable que se quiere explicar, número de innovaciones en producto, que es una variable de conteo. Esta variable presenta valores bajos y discretos con gran abundancia de ceros. Al igual que en el modelo de las patentes se recomienda usar un modelo que tenga en cuenta que la 
variable dependiente se ha generado mediante una distribución de Poisson (o similar) que expresa la probabilidad de que ocurra un evento en un intervalo de tiempo (Greene, 2006). En nuestro caso, el evento es el número de innovaciones en producto de una empresa en un año determinado, que presenta una tasa media de 1.02 innovaciones por empresa y año pero el $79.8 \%$ de las empresas no realizan ninguna innovación y por tanto la variable toma el valor cero.

La principal crítica que se ha realizado a los modelos de regresión de Poisson es que asumen que su media y su varianza son iguales, y en la mayoría de los casos prácticos ocurre que la varianza es superior a la media (sobredispersión). En este trabajo se ha contrastado la existencia de sobredispersión y, por tanto, se usa la distribución binomial negativa que es más flexible y permite que la varianza sea superior a la media (Greene, 2006; Kleiber and Zeileis (2008).

$$
\begin{aligned}
\log \left(I P_{i t}\right)= & \beta_{0}+\beta_{1} I N B E A_{i t}+\beta_{2} I P R_{i t}+\beta_{3} C T P R_{i t}+\beta_{4} C T C L_{i t}+\beta_{5} C_{C T C O} \\
& +\beta_{6} C U C T_{i t}++\beta_{7} G E I D V_{i t}+\beta_{8} G I I D V_{i t}+\beta_{9} D P I_{i t}+\beta_{10} \log P T P_{i t} \\
& +A \tilde{\mathrm{N}} O_{t}
\end{aligned}
$$

En este segundo caso se ha introducido la variable Innovación en proceso (IPR) que presenta un valor de correlación de 0,40 entre esta y la innovación en producto.

Por otro lado las variables CPSP, PX, FM Y DEUDA, se han omitido en este modelo al presentar correlaciones muy bajas e incluso negativas como en el caso de FM.

En cualquier caso, como ya se ha comentado, el interés de este modelo está centrado principalmente en el uso de las TICS y su influencia en la innovación en producto. 


\subsubsection{Especificación del modelo econométrico (caso empírico 3)}

Abordamos en este caso empírico los factores de la apropiabilidad de las invenciones. En este caso las variables dependientes son las patentes, los modelos de utilidad y las marcas de fábrica. Para estimar los efectos buscados se ha propuesto un modelo Logit atendiendo al carácter binario de las variables MARCA Y MODELO ya que ambas tienen sólo dos posibles resultados.

En consecuencia, se formula un modelo Logit para analizar cómo afectan los gastos en I+D, la inversión en bienes de equipo, la cooperación y el tamaño de las empresas en la decisión de proteger o no las innovaciones conseguidas en el proceso productivo.

Las relaciones propuestas entre las variables explicadas y las variables explicativas se exponen a continuación:

$$
\begin{gathered}
\log \left(\text { PAT }_{\text {it }}\right)=\beta_{0}+\beta_{1} \text { TAMAÑO }+\beta_{2} \text { INBEA }+\beta_{3} \text { GIIDV }+\beta_{4} \text { GEIDV }+\beta_{5} \text { COOPERA }+ \text { AÑO } \\
\log \left(\text { MARCA }_{\mathrm{tt}}\right)=\beta_{0}+\beta_{1} \text { TAMAÑO }+\beta_{2} \text { INBEA }+\beta_{3} \text { GIIDV }+\beta_{4} \text { GEIDV }+\beta_{5} \text { COOPERA }+ \text { AÑO } \\
\log \left(\text { MODELO }_{i t}\right)=\beta_{0}+\beta_{1} \text { TAMAÑO }+\beta_{2} \text { INBEA }+\beta_{3} \text { GIIDV }+\beta_{4} \text { GEIDV }+\beta_{5} \text { COOPERA }+ \text { AÑO }
\end{gathered}
$$

Llama la atención el hecho de que se hayan omitido variables en estos modelos que si estaban reflejadas en el modelo del caso empírico 1 como la propensión a la exportación y la deuda, esto es debido a que la información que suministra el PITEC no la incluye. En el caso de la variable de cooperación (COOPERA) además de que en las dos encuestas utilizadas en esta tesis disgregan de forma diferente los tipos de cooperación, problema que se podría solucionar agregando las diferentes variables para obtener las mismas que en la ESEE, hay una serie de años en los que no aparecen los datos disgregados sino como la agregación de todos en una única variable. 
Capítulo 6

Resultados 



\section{RESULTADOS}

Una vez delimitado de forma descriptiva el esfuerzo innovador y en TICs realizado por las empresas agroalimentarias españolas, se exponen los resultados del análisis de las características innovadoras del sector agroindustrial. Siguiendo la metodología propuesta se han estimado cada uno de los modelos econométricos para cada uno de los casos de estudio que se han llevado a cabo en la investigación. Los resultados obtenidos se exponen por separado en cada uno de los tres apartados siguientes.

Por tanto, y desde un punto de vista metodológico, se concluye que la investigación se lleva a cabo a través de un enfoque centrado en el análisis ex post facto de la actuación de los gestores de las empresas manufactureras y a través de métodos de regresión específicos para variables de elección discreta.

\subsection{Resultados del caso 1. Variable explicada: número de patentes}

Una primera aproximación a las correlaciones entre el número de patentes (PAT) y las variables explicativas (Tabla 23) muestra que la mayoría de ellas son positivas, a excepción de los recursos humanos y el fondo de maniobra.

También se detecta correlación positiva entre las variables de I+D y las de cooperación tecnológica, siendo el valor más alto el que existe entre Gastos internos en I+D (GIID_V) y Cooperación tecnológica con proveedores (CTPR) que alcanza un valor de 0.673. Sin embargo este tipo de coeficientes de correlación no capturan los efectos de los retardos en las variables, lo que explicaría los bajos valores que se obtienen. 


\begin{tabular}{|c|c|c|c|c|c|c|c|c|c|c|c|c|c|}
\hline & PAT & GEID & GIID & CTPR & $\mathrm{CTCL}$ & СТСO & CUCT & INBE & PTP & CPCS & $\mathrm{PX}$ & $\mathrm{FM}$ & DEUDA \\
\hline PAT & 1 & & & & & & & & & & & & \\
\hline GEID & 0.19 & 1 & & & & & & & & & & & \\
\hline GIID & 0.17 & 0.54 & 1 & & & & & & & & & & \\
\hline CTPR & 0.18 & 0.53 & 0.67 & 1 & & & & & & & & & \\
\hline CTCL & 0.17 & 0.37 & 0.42 & 0.52 & 1 & & & & & & & & \\
\hline CTCO & 0.11 & 0.20 & 0.18 & 0.24 & 0.35 & 1 & & & & & & & \\
\hline CUCT & 0.15 & 0.52 & 0.48 & 0.45 & 0.37 & 0.21 & 1 & & & & & & \\
\hline INBE & 0.05 & 0.05 & 0.05 & 0.06 & 0.04 & -0.03 & 0.04 & 1 & & & & & \\
\hline PTP & 0.11 & 0.35 & 0.49 & 0.45 & 0.25 & 0.15 & 0.39 & 0.15 & 1 & & & & \\
\hline CPCS & -0.06 & -0.21 & -0.16 & -0.17 & -0.09 & -0.04 & -0.22 & 0.02 & -0.28 & 1 & & & \\
\hline$P X$ & 0.09 & 0.28 & 0.36 & 0.29 & 0.17 & 0.09 & 0.27 & -0.02 & 0.44 & -0.42 & 1 & & \\
\hline FM & -0.03 & 0.02 & 0.06 & 0.04 & 0.01 & 0.06 & 0.01 & -0.20 & -0.06 & 0.03 & 0.04 & 1 & \\
\hline DEUDA & 0.02 & -0.04 & -0.05 & -0.06 & -0.05 & -0.03 & -0.05 & 0.01 & -0.01 & -0.08 & 0.13 & -0.50 & 1 \\
\hline
\end{tabular}

De forma más general se ha calculado que el $87,1 \%$ de las patentes se realizan en empresas que ha realizado en algún momento algún tipo de I+D. En relación con la cooperación tecnológica este porcentaje es del $86,2 \%$. Solamente el $11,7 \%$ de las patentes proceden de empresas que en ningún año han participado en actividades de I+D ni cooperación tecnológica.

A pesar de esta correlación, el análisis de multicolinealidad realizado entre los regresores (cálculo de los factores de inflación generalizados para modelos lineales generalizados) indica que no se superan los valores recomendados (Neter et al, 1989).

\section{I+D}

La Tabla 24 muestra los resultados de la estimación del modelo especificado (2) 


$$
\begin{gathered}
\log \left(P A T_{i t}\right)=\beta_{0}+\beta_{1 A 0} G E I D V_{i t}+\beta_{1 A 1} G E I D V_{i t-1}+\cdots+\beta_{1 A s} G E I D V_{i t-s} \\
+\beta_{1 B 0} G I I D V_{i t}+\beta_{1 B 1} G I I D V_{i t-1}+\cdots+\beta_{1 B s} G I I D V_{i t-s}+A \tilde{N} O_{t}
\end{gathered}
$$

que considera variables de gastos en I+D tanto externos como internos.

\begin{tabular}{|c|c|c|c|c|c|c|}
\hline & \multicolumn{3}{|l|}{ Pymes } & \multicolumn{3}{|l|}{ Grandes } \\
\hline & Estimate & SD & & Estimate & SD & \\
\hline const & $-3,09047$ & 0,374475 & $* * *$ & $-2,08763$ & 0,408153 & $* * *$ \\
\hline GEID_V & $-3,6029$ & 50,822 & & $-2,73397$ & 17,1645 & \\
\hline GEID_V_1 & $-746,771$ & 610,377 & & $-1,26447$ & 14,4545 & \\
\hline GEID_V_2 & $-106,052$ & 307,927 & & $-0,13371$ & 16,91 & \\
\hline GEID_V_3 & & & & 5,74358 & 10,8198 & \\
\hline GEID_V_4 & & & & 130,98 & 60,6541 & $* *$ \\
\hline Suma coeficientes GEIDV & $-856,426$ & 722,556 & & 132,592 & 50,6171 & $* * *$ \\
\hline GIID_V & 82,8985 & 50,1049 & $*$ & $-26,4637$ & 103,934 & \\
\hline GIID_V_1 & 145,947 & 80,5005 & $*$ & $-106,188$ & 120,783 & \\
\hline$G \| D_{-} V_{-} 2$ & $-228,343$ & 164,413 & & 94,7507 & 61,4242 & \\
\hline GIID_V_3 & & & & 11,7357 & 71,4548 & \\
\hline GIID_V_4 & & & & 114,398 & 61,6715 & $*$ \\
\hline Suma coeficientes GIIDV & 0,502219 & 151,941 & & 88,2328 & 62,1053 & \\
\hline alpha & 3,94494 & 2,30365 & $*$ & 6,54547 & 1,74005 & $* * *$ \\
\hline Criterio Akaike & 247,5687 & & & 228,6917 & & \\
\hline
\end{tabular}

Tabla 24: Resultado del modelo 2. Variables explicativas GEID y GIID. Variable explicada: PAT

En Pymes solamente se pudieron tomar 2 retardos mientras que en las grandes empresas se llegó hasta 4. Además de los habituales contrastes de significatividad cada coeficiente se realizaron test para contrastar la suma de los coeficientes de cada tipo de I+D.

Los recursos de investigación y desarrollo presentan relaciones con la propensión de las empresas a registrar patentes. En Pymes, se 
detecta cierta evidencia positiva para los gastos internos en I+D pues los coeficientes GIIDV y GIDV_1 son significativos. En las grandes empresas se percibe de forma más clara el efecto de I+D sobre el número de patentes. Así, los gastos externos son negativos en la variable contemporánea GEIDV y en los dos primeros retardos pero el tercero ya es positivo y el cuarto es positivo y significativo. Además, la suma de estos coeficientes también es positiva y significativa. Los gastos internos son positivos a partir del segundo retardo pero solamente son significativos en el cuarto. En este caso, la suma de los coeficientes no es significativa. Por tanto, se ha encontrado evidencia para la hipótesis H1A (I+D externa relacionada positivamente con las patentes) en las empresas grandes, y más débilmente para H2A (I+D interna relacionada positivamente con las patentes) tanto en Pymes como en grandes.

\section{Cooperación tecnológica}

La Tabla 25 ofrece los resultados de las regresiones del modelo (3) que incluye como regresores las variables de los diferentes tipos de cooperación tecnológica.

$$
\begin{aligned}
\log \left(P A T_{i t}\right) & =\beta_{0}+\beta_{2 A 0} C T P R_{i t}+\beta_{2 A 1} C T P R_{i t-1}+\cdots+\beta_{2 A s} C T P R_{i t-s} \\
& +\beta_{2 B 0} C T C L_{i t}+\beta_{2 B 1} C T C L_{i t-1}+\cdots+\beta_{2 B s} C T C L_{i t-s}+\beta_{2 C 0} C T C O_{i t} \\
& +\beta_{2 C 1} C_{T C O} O_{i t-1}+\cdots+\beta_{2 C s} C T C O_{i t-s}+\beta_{2 D 0} C U C T_{i t}+\beta_{2 D 1} C U C T_{i t-1} \\
& +\cdots+\beta_{2 D s} C U C T_{i t-s}+A \tilde{N} O_{t}
\end{aligned}
$$

Igual que ocurría en el modelo anterior, el número de retardos que se pudo tomar en Pymes es menor que en grandes debido a que la cantidad de datos es inferior en el primer panel. 
Tabla 25: Resultado del modelo 3. Variable explicativa: Cooperación. Variable explicada: PAT

\begin{tabular}{|c|c|c|c|c|c|c|}
\hline & \multicolumn{3}{|l|}{ Pymes } & \multicolumn{3}{|l|}{ Grandes } \\
\hline & Estimate & SD & & Estimate & SD & \\
\hline const & $-3,15757$ & 0,398903 & $* * *$ & $-6,73228$ & 2,40942 & $* * *$ \\
\hline CTPR & 1,03808 & 0,593374 & $*$ & 2,31796 & 1,39571 & $*$ \\
\hline CTPR_1 & 1,65098 & 0,882047 & $*$ & $-1,71364$ & 0,844596 & $* *$ \\
\hline CTPR_2 & 0,393958 & 1,08293 & & 0,302543 & 0,832059 & \\
\hline CTPR_3 & & & & 0,565738 & 0,699341 & \\
\hline CTPR_4 & & & & $-0,156593$ & 0,903588 & \\
\hline Suma coeficientes CTPR & 3,08301 & 0,759443 & $* * *$ & 1,31601 & 1,08049 & \\
\hline CTCL & $-39,9393$ & 0,731776 & $* * *$ & $-0,222201$ & 0,977056 & \\
\hline $\mathrm{CTCL}_{-} 1$ & 1,02995 & 0,943929 & & 0,21552 & 1,37451 & \\
\hline $\mathrm{CTCL}_{2} 2$ & $-56,9745$ & 0,454379 & $* * *$ & 1,55265 & 0,795758 & $*$ \\
\hline $\mathrm{CTCL}_{3} 3$ & & & & $-0,299549$ & 0,611419 & \\
\hline $\mathrm{CTCL}_{-} 4$ & & & & 0,814829 & 0,819335 & \\
\hline Suma coeficientes CTCL & $-95,8838$ & 1,22936 & $* * *$ & 2,06125 & 0,945478 & $* *$ \\
\hline СТСO & $-108,503$ & 1,5669 & $* * *$ & 2,12708 & 1,52691 & \\
\hline $\mathrm{CTCO}_{-} 1$ & $-51,6953$ & 1,151 & $* * *$ & $-0,537124$ & 1,83013 & \\
\hline $\mathrm{CTCO}_{-} 2$ & & & & 1,14367 & 3,19158 & \\
\hline $\mathrm{CTCO}_{-} 3$ & & & & $-1,87999$ & 2,69388 & \\
\hline $\mathrm{CTCO}_{-} 4$ & & & & $-1,901$ & 1,44977 & \\
\hline Suma coeficientes CTCO & $-160,198$ & 1,90048 & $* * *$ & $-1,04736$ & 1,029 & \\
\hline CUCT & $-0,744759$ & 0,828533 & & 1,09741 & 1,19709 & \\
\hline $\mathrm{CUCT}_{-} 1$ & $-0,873604$ & 1,8516 & & $-0,0886964$ & 0,972567 & \\
\hline $\mathrm{CUCT}_{-} 2$ & $-0,371885$ & 2,11797 & & $-0,556212$ & 0,677974 & \\
\hline $\mathrm{CUCT}_{-} 3$ & & & & 2,43139 & 1,22541 & $* *$ \\
\hline $\mathrm{CUCT}_{-} 4$ & & & & 1,67334 & 0,954666 & $*$ \\
\hline Suma coeficientes CUCT & $-1,99025$ & 0,841729 & & 4,55723 & 1,85192 & $* *$ \\
\hline alpha & 3,92278 & 2,30729 & $*$ & 4,6312 & 2,33927 & $* *$ \\
\hline Criterio Akaike & 250,3875 & & & 215,2497 & & \\
\hline
\end{tabular}


Se observan efectos positivos de la cooperación sobre el registro de patentes en el caso de que esta se lleve a cabo con los proveedores en empresas con menos de 200 empleados. Se acepta la hipótesis H2A en Pymes pues los coeficientes CTPR, CTPR_1 y la suma de estos es positiva y significativa. Sin embargo, se obtienen resultados negativos y significativos en relación con la cooperación con clientes y con competidores que son difíciles de explicar, y podrían apuntar a que estas colaboraciones han producido efectos contrarios a los esperados.

Con los clientes por el contrario son las empresas grandes las que contribuyen positivamente y de manera significativa a incrementar la probabilidad de registrar patentes. Esto implica aceptar la hipótesis H2B para las empresas grandes y a refutarla en el caso de las empresas pequeñas.

En el caso de la cooperación tecnológica con las empresas rivales se observa un efecto negativo en ambos tipos de empresas aunque solo significativo en las de menos de 200 empleados. Estos resultados rechazan la hipótesis $\mathrm{H} 2 \mathrm{C}$, y podrían apuntar a que estas colaboraciones han producido efectos contrarios a los esperados.

La cooperación con universidades y centros tecnológicos no presenta relaciones evidentes en Pymes pero sí en las empresas grandes. En estas, la suma de coeficientes CUCT es positiva y significativa y se acepta H2D. Tanto en este tipo de colaboración como en la de clientes parece que los efectos no son inmediatos. Así, las colaboraciones con clientes presentan coeficiente positivo y significativo en el segundo retardo, mientras que las colaboraciones con universidades y centros tecnológicos en el tercero y cuarto.

\section{I+D, cooperación tecnológica y otros activos complementarios}

La Tabla 26 (efectos fijos) y la Tabla 27 (efectos aleatorios) recogen los resultados del modelo (1) 


$$
\begin{aligned}
& \log \left(P A T_{i t}\right)=\beta_{0}+\beta_{1 A} G E I D V_{i t}+\beta_{1 B} G I I V_{i t}+\beta_{2 \mathrm{~A}} C T P R_{i t}+\beta_{2 \mathrm{~B}} C T C L_{i t} \\
& +\beta_{2 \mathrm{C}} C \mathrm{CCO}_{i t}+\beta_{2 \mathrm{D}} \operatorname{CUCT}_{i t}+\beta_{3 \mathrm{~A}} I N B E A_{i t}+\beta_{3 \mathrm{~B}} \log P T P_{i t} \\
& +\beta_{3 \mathrm{C}} C P S P_{i t}+\beta_{3 \mathrm{D}} P X_{i t}+\beta_{3 \mathrm{E}} F M V_{i t}+\beta_{3 \mathrm{E} *} D E U D A_{i t}+E M P R E S A_{i} \\
& +A \tilde{\mathrm{N}} O_{t}
\end{aligned}
$$

Que han sido estimados mediante regresión de quasipoisson de

\begin{tabular}{|c|c|c|c|c|}
\hline & \multicolumn{2}{|r|}{ PYMES } & \multicolumn{2}{|r|}{ GRANDES } \\
\hline & Coeficiente & SD & Coeficiente & SD \\
\hline Intercepto & -1.06 & 13740.000 & -53.20 & 15330.00 \\
\hline
\end{tabular}
efectos fijos y aleatorios, respectivamente. En este caso se consideran conjuntamente variables de I+D, cooperación tecnológica y otros activos complementarios, y se prescinde de las estructuras de retardos.

Actividades de I+D

\begin{tabular}{|l|l|l|l|l|l|l|}
\hline GEID & 69.54 & 86.39 & & 260.50 & 65.81 & $* * *$ \\
\hline GIID & 54.79 & 25.28 & $* *$ & 24.34 & 18.58 \\
\hline
\end{tabular}

\begin{tabular}{|c|c|c|c|c|c|c|}
\hline \multicolumn{7}{|c|}{ Cooperación tecnológica } \\
\hline CTPR & -3.24 & 1.69 & $*$ & -0.15 & 0.43 \\
\hline CTCL & -0.87 & 0.96 & & 0.90 & 0.47 & $*$ \\
\hline CTCO & 1.96 & 0.74 & $* * *$ & 1.97 & 0.80 & $* *$ \\
\hline CUCT & -1.01 & 0.39 & $* * *$ & 0.03 & 0.49 & \\
\hline
\end{tabular}

\begin{tabular}{c|c|c|c|c|c|c}
\hline \multicolumn{7}{|c|}{ Partidas complementarias } \\
\hline INBE & -3.32 & 2.29 & & -4.76 & 2.70 & $*$ \\
\hline Log(PTP) & -4.45 & 1.20 & $* * *$ & 3.44 & 1.04 & $* * *$ \\
\hline CPSP & -0.04 & 0.06 & & 0.17 & 0.09 & $*$ \\
\hline PX & -0.02 & 0.03 & & 0.08 & 0.03 & $* *$ \\
\hline FMV & 0.54 & 0.41 & & 1.55 & 1.51 & \\
\hline DEUDA & 0.19 & 0.07 & $* * *$ & 0.39 & 0.24 & \\
\hline
\end{tabular}

Código: significativo al $10 \%(*)$, al $5 \%(* *)$ y al $1 \%(* * *)$ 


\begin{tabular}{|c|c|c|c|c|c|c|}
\hline & \multicolumn{3}{|c|}{ PYMES } & \multicolumn{3}{|c|}{ GRANDES } \\
\hline & Coeficiente & SD & & Coeficiente & SD & \\
\hline Intercepto & -5.76 & 3.85 & & -23.95 & 4.67 & $* * *$ \\
\hline \multicolumn{7}{|c|}{ Actividades de I+D } \\
\hline GEID & 7.87 & 79.05 & & 111.50 & 37.89 & $* * *$ \\
\hline GIID & 57.18 & 27.58 & $* *$ & 5.70 & 15.38 & \\
\hline \multicolumn{7}{|c|}{ Cooperación tecnológica } \\
\hline CTPR & -1.59 & 1.20 & & 0.11 & 0.38 & \\
\hline CTCL & -0.11 & 1.01 & & 1.14 & 0.41 & $* * *$ \\
\hline CTCO & 1.80 & 0.93 & $*$ & 0.61 & 0.61 & \\
\hline CUCT & -0.52 & 0.45 & & 0.23 & 0.42 & \\
\hline \multicolumn{7}{|c|}{ Partidas complementarias } \\
\hline INBE & -0.29 & 2.77 & & -3.53 & 2.42 & \\
\hline $\log (P T P)$ & -0.45 & 0.95 & & 2.15 & 0.71 & $* * *$ \\
\hline CPSP & -0.10 & 0.06 & & 0.04 & 0.07 & \\
\hline $\mathrm{PX}$ & 0.01 & 0.03 & & 0.06 & 0.02 & $* *$ \\
\hline FMV & 0.17 & 0.48 & & 1.52 & 1.09 & \\
\hline DEUDA & 0.01 & 0.05 & & 0.03 & 0.03 & \\
\hline
\end{tabular}

Código: significativo al $10 \%(*)$, al $5 \%(* *)$ y al $1 \%(* * *)$

En relación con las Hipótesis $\mathrm{H} 1$, se confirman los resultados obtenidos anteriormente. Tanto el modelo de efectos fijos como el de efectos aleatorios muestran que la I+D externa en grandes empresas y la I+D interna en Pymes son positivas y significativas, incluso después de controlar los factores intrínsecos de cada empresa. Este resultado parece, por tanto, bastante robusto, y está en consonancia con otros trabajos realizados sobre patentes (Hall, Griliches y Hausman, 1986; Cincera, 1997; entre otros). En el sector que nos ocupa, Gopinath y 
Vasavada (1999) en un panel de 32 empresas agroalimentarias norteamericanas en el periodo 1970-1985 concluyen que sus resultados muestran una asociación positiva entre patente e I+D, y cuantifican, además, los efectos spillovers de la I+D del conjunto de la industria; Cabral y Traill (2001) en una muestra con 242 empresas brasileñas (1994-96) también encuentran que la probabilidad de realizar innovaciones no protegidas está relacionada positivamente con los gastos en I+D; sin embargo, Batterink et al. (2006) usan 328 empresas agroalimentarias holandesas de 2001, y no hallan ninguna relación con los gastos en I+D. La aportación de este trabajo es que se han podido diferenciar por tipo de $I+D$, externa e interna, $y$ en diferentes tamaños de empresas. Esto permite subrayar el papel de la I+D interna en los procesos de innovación de las Pymes agroalimentarias españolas, en contraposición con otros trabajos que apuntan a la mayor capacidad de innovación de las grandes empresas agroalimentarias europeas (Huiban y Bouhsina, 1998; Traill y Muelenber, 2002). Nuestros resultados están más en la línea de Alfranca et al. (2004) que, en un grupo de multinacionales de alimentación y bebidas, hallan que las empresas que más patenten no suelen ser las de mayor tamaño sino más bien las que innovan persistentemente.

En la cooperación tecnológica se encuentran, sin embargo, resultados algo diferentes. El tipo de modelo econométrico que se use afecta al signo y significatividad de la cooperación tecnológica. Esto hace que la evidencia encontrada en relación con la cooperación tecnológica sea más débil que la correspondiente a la I+D. Con la especificación del modelo (1), se rechaza la hipótesis de cooperación con proveedores (H2A); se acepta la de cooperación con clientes (H2B) en grandes empresas; la cooperación con competidores (H2C) se acepta en Pymes (en ambas estimaciones, efectos fijos y aleatorios, es positiva y significativa) y, en menor medida, en grandes empresas; se rechaza la hipótesis de relación positiva de patentes agroalimentarias con 
cooperación con universidades y centros tecnológicos (H2D).Aunque este tipo de colaboraciones se hacen siempre para mejorar la posición innovadora de la empresa, no siempre están claros los resultados que se obtienen, como muestra Batterink et al. (2006) que trabaja también con estos cuatro tipos de colaboraciones tecnológicas y no encuentra ninguna asociación. En este trabajo, el haber detectado un efecto positivo de la colaboración con competidores en Pymes es de gran valor pues confirma que los esfuerzos de las políticas públicas en este tipo de acciones están teniendo efectos positivos. Sin embargo, la integración vertical con proveedores y clientes no presenta unos efectos tan claros sobre la innovación como Karantininis et al (2.010) en su estudio sobre la industria agroalimentaria danesa. La cooperación con universidades y centro tecnológicos, por su parte, deja de ser relevante cuando se controlan otros activos de innovación, complementarios y efectos específicos de cada empresa.

En cuanto a los activos complementarios: en Pymes solamente se aceptaría el efecto (negativo) del tamaño (H3B) y la relación positiva con el endeudamiento (H3E) en la estimación condicionada a efectos fijos, si bien en el modelo de efectos aleatorios no se obtiene ningún coeficiente significativo; en las grandes empresas se constatan las relaciones positivas con tamaño (H3B) y recursos comerciales (H3D), y de forma más débil con recursos humanos (H3C). Estos resultados apuntarían a que las grandes empresas tienen más recursos financieros y humanos para resistir los riesgos y costes asociados a la innovación (Karantininis et al., 2.010).

Al contrario de lo que indica Rama (1996) para el periodo 1969 1988 sobre el papel que juegan los suministradores de equipos en la innovación de la industria agroalimentaria, en este trabajo no se ha encontrado evidencia de este tipo y se rechaza Hipótesis H3A. Otros estudios señalan la importancia de este factor en innovaciones en producto no protegidas (García y Burns, 1999) o incluso en los 
resultados de la empresa (Alarcón y Sánchez, 2013) pero en el momento actual no parece que las inversiones en bienes de equipo sean una condición suficiente para que las empresas agroalimentarias aumenten sus innovaciones protegidas.

\subsection{Resultados del caso 2. Var. explicada: $n \circ$ de innovaciones en producto.}

Las variables explicativas son las que se han comentado en el capítulo 6, y se agrupan en 5 categorías: inversiones de capital e innovación de procesos (1), cooperación tecnológica (2), gastos en I+D sobre ventas (3), TICs (dominio propio en internet) (4) y el tamaño (logaritmo del número medio de empleados) como variable de control (5). Además se han incluido variables yearly dummy bajo la sospecha de su contribución a la reducción de la suma de cuadrados de los errores, proporcionando unas estimaciones más precisas y que recogen efectos temporales comunes a todas las empresas. Sus resultados, significativos, se omiten en esta parte de la Tesis incluyéndose en el apéndice. Este modelo ha sido aplicado al conjunto de las empresas agroalimentarias (TODAS), así como a las pequeñas y medianas empresas (PYMES) y a las grandes empresas (GRANDES) (Tabla28).

Atendiendo a los resultados obtenidos, era de esperar, en consonancia con la literatura consultada al respecto, un efecto positivo y significativo de la innovación en proceso sobre el número de innovaciones en producto (Braun 1986; Brewin et al., 2009), tanto en las PYMES como en las grandes. En las tres regresiones realizadas la innovación en proceso es la variable más significativa y con mayor capacidad para explicar la variable dependiente. Asimismo, la variable Inversión en bienes de equipo es positiva en ambas regresiones pero solamente significativa en las PYMES. En las regresiones de los subsectores (Tabla29), la innovación en proceso es siempre altamente 
significativa, mientras que inversión en bienes de equipo no lo es en Industria cárnica y sí en las otras dos, especialmente en Bebidas. En relación con estos resultados García y Burns (1999) resaltan la gran importancia de los proveedores de equipos y maquinaria en la innovación tecnológica de la industria agroalimentaria española. Por tanto, se constata la fuerte conexión entre innovación en proceso e innovación en producto.

\begin{tabular}{|c|c|c|c|c|c|c|c|c|c|}
\hline & \multicolumn{3}{|c|}{ Todas } & \multicolumn{3}{|c|}{ PYMES } & \multicolumn{3}{|c|}{ Grandes } \\
\hline & Coef. & SD & & Coef. & SD & & Coef. & SD & \\
\hline Intercepto & -3.66 & 0.32 & $* *$ & -4.17 & 0.56 & $* *$ & -4.35 & 0.87 & $* *$ \\
\hline \multicolumn{10}{|c|}{ Inversión de capital y procesos de innovación } \\
\hline Inversión equipos & 2.74 & 1.00 & $* * *$ & 3.65 & 1.34 & $* *$ & 1.41 & 1.93 & \\
\hline Inn. en proceso & 1.56 & 0.15 & $* *$ & 1.68 & 0.24 & $* *$ & 1.63 & 0.19 & $* *$ \\
\hline \multicolumn{10}{|c|}{ Cooperación tecnológica } \\
\hline Proveedores & 0.44 & 0.21 & $*$ & 0.18 & 0.52 & & 0.91 & 0.20 & $* *$ \\
\hline Clientes & 0.15 & 0.27 & & 1.01 & 0.68 & & -0.41 & 0.26 & \\
\hline Competencia & -0.56 & 0.50 & & -38.73 & 1432.0 & & -0.06 & 0.45 & \\
\hline Instituciones & -0.29 & 0.18 & & -0.92 & 0.35 & $* *$ & 0.08 & 0.20 & \\
\hline \multicolumn{10}{|c|}{ Estrategias de $I+D$} \\
\hline$I+D$ externa & 3.88 & 10.92 & & 28.94 & 15.36 & $*$ & 2.47 & 15.28 & \\
\hline$I+D$ interna & 68.05 & 11.70 & $* *$ & 102.90 & 19.64 & $* *$ & 14.24 & 15.19 & \\
\hline \multicolumn{10}{|c|}{ Estrategia TIC } \\
\hline Dominio propio & 0.67 & 0.17 & $* *$ & 1.56 & 0.27 & $* *$ & -0.43 & 0.24 & $*$ \\
\hline \multicolumn{10}{|c|}{ Complementarias } \\
\hline tamaño & 0.46 & 0.06 & $* *$ & 0.55 & 0.14 & $* *$ & 0.67 & 0.14 & ** \\
\hline pseudo $R^{2}$ & 0.2275 & & & 0.1250 & & & 0.0918 & & \\
\hline
\end{tabular}

Código: significativo al $10 \%(*)$, al $5 \%(* *)$ y al $1 \%(* * *)$ 
Además en muchas empresas agroalimentarias (PYMES de Bebidas y Productos alimenticios y tabaco) las inversiones en bienes de equipo siguen teniendo una estrecha relación con las innovaciones de producto.

En cuanto a la cooperación tecnológica, solamente la cooperación tecnológica con proveedores es positiva y significativa para las grandes empresas. Se rechaza por tanto que la cooperación tecnológica esté contribuyendo de forma decisiva sobre los procesos de innovación de las PYMES, al menos sobre la obtención de más innovaciones en producto. Una posibilidad que se ha manejado en la literatura para mejorar esta situación pasa por la integración vertical con proveedores y con clientes como una vía para mejorar la oferta de productos y acercarse a las demandas de los consumidores finales, especialmente en las empresas con menor capacidad para acometer gastos de I+D (Cabral y Traill, 2001).

En relación con las estrategias $I+D$, sorprende que tanto la externa como la interna son positivas y significativas en las PYMES y no en las grandes empresas. Además los gastos internos presentan un efecto positivo y significativo mayor que los externos. La I+D externa presenta un efecto positivo y significativo en la industria cárnica, mientras que la interna lo hace en Productos alimenticios y tabaco. Aunque existen referencias en la literatura sobre la ausencia de conexión entre I+D e innovación en producto (Batternik et al., 2006, para un conjunto de empresas agroalimentarias holandesas) son más los trabajos que señalan una relación clara (Cabral y Traill, 2001; Traill y Muelenber, 2002).

Respecto a las variables que miden la e-innovación las estrategias TICs también se revelan de mayor importancia en las PYMES. La variable Dominio propio en internet es positiva y altamente significativa, indicando una estrecha conexión entre dominio propio en internet e 
innovaciones de producto. No así en las grandes empresas donde la relación es negativa, lo que probablemente sea debido a un amplio uso de TICs en ellas.

La Tabla29 nos muestra la estimación por subsectores donde la significatividad de las TICs es mayor en Industria cárnica y Productos alimenticios y tabaco que en Bebidas.

\begin{tabular}{|c|c|c|c|c|c|c|c|c|c|}
\hline & \multicolumn{3}{|c|}{ Cárnicas } & \multicolumn{3}{|c|}{ Alimentación y tabaco } & \multicolumn{3}{|c|}{ Bebidas } \\
\hline & Coef. & SD & & Coef. & SD & & Coef. & SD & \\
\hline Intercepto & -4.5931 & 0.79 & $* * *$ & -3.69 & 0.38 & $* * *$ & -4.45 & 0.87 & $* * *$ \\
\hline \multicolumn{10}{|c|}{ Inversión de capital y procesos de innovación } \\
\hline Inversión equipos & -0.44 & 2.44 & & 2.10 & 1.18 & & 9.17 & 3.54 & $* *$ \\
\hline Inn. en proceso & 1.45 & 0.33 & $* * *$ & 1.60 & 0.18 & $* * *$ & 1.86 & 0.35 & $* * *$ \\
\hline \multicolumn{10}{|c|}{ Cooperación tecnológica } \\
\hline Proveedores & 0.75 & 0.49 & & 0.42 & 0.26 & & 0.48 & 0.38 & \\
\hline Clientes & -0.13 & 0.76 & & -0.21 & 0.32 & & 0.38 & 0.62 & \\
\hline Competencia & 0.51 & 1.65 & & -0.88 & 0.59 & & 1.4 & 0.89 & \\
\hline Instituciones & -0.43 & 0.43 & & -0.15 & 0.21 & & -1.06 & 0.41 & $* *$ \\
\hline \multicolumn{10}{|c|}{ Estrategias de I+D } \\
\hline$I+D$ externa & 162.92 & 85.04 & . & 3.93 & 11.87 & & 4.22 & 29.93 & \\
\hline$I+D$ interna & -39.85 & 40.77 & & 97.66 & 17.82 & $* * *$ & -30.86 & 19.17 & \\
\hline \multicolumn{10}{|c|}{ Estrategia TIC } \\
\hline Dominio propio & 1.36 & 0.42 & $* *$ & 0.66 & 0.20 & $* *$ & 0.07 & 0.51 & \\
\hline \multicolumn{10}{|c|}{ Complementarias } \\
\hline tamaño & 0.69 & 0.13 & $* * *$ & 0.44 & 0.06 & $* * *$ & 0.58 & 0.13 & $* * *$ \\
\hline pseudo $R^{2}$ & 0.2773 & & & 0.2206 & & & 0.3131 & & \\
\hline
\end{tabular}

Código: significativo al $10 \%(*)$, al $5 \%(* *)$ y al $1 \%(* * *)$ 
Se han usado otras variables de -uso de internet como compras a proveedores o ventas (a empresas B2B, a consumidores B2C) y los resultados como podemos observar en la Tabla30 son muy similares a los obtenidos en el modelo mostrado en la Tabla29

Tabla30: Estimación de la regresión binomial negativa. Variable explicada: $n$ o de innovaciones en product (IP) (B2B) Por subsectores.

\begin{tabular}{|c|c|c|c|c|c|c|c|c|c|}
\hline & \multicolumn{3}{|c|}{ Cárnicas } & \multicolumn{3}{|c|}{ Alimentación y tabaco } & \multicolumn{3}{|c|}{ Bebidas } \\
\hline & Coef. & SD & & Coef. & SD & & Coef. & SD & \\
\hline Intercepto & -3.28 & 0.83 & $* * *$ & -3.02 & 0.42 & $* * *$ & -4.37 & 0.9 & $* * *$ \\
\hline
\end{tabular}

Inversión de capital y procesos de innovación

\begin{tabular}{|c|c|c|c|c|c|c|c|c|c|}
\hline Inversión equipos & -0.44 & 2.44 & & 2.09 & 1.18 & . & 9.17 & 3.54 & $* *$ \\
\hline Inn. en proceso & 1.45 & 0.3 .3 & $* * *$ & 1.61 & 0.18 & $* * *$ & 1.86 & 0.35 & $* * *$ \\
\hline
\end{tabular}

Cooperación tecnológica

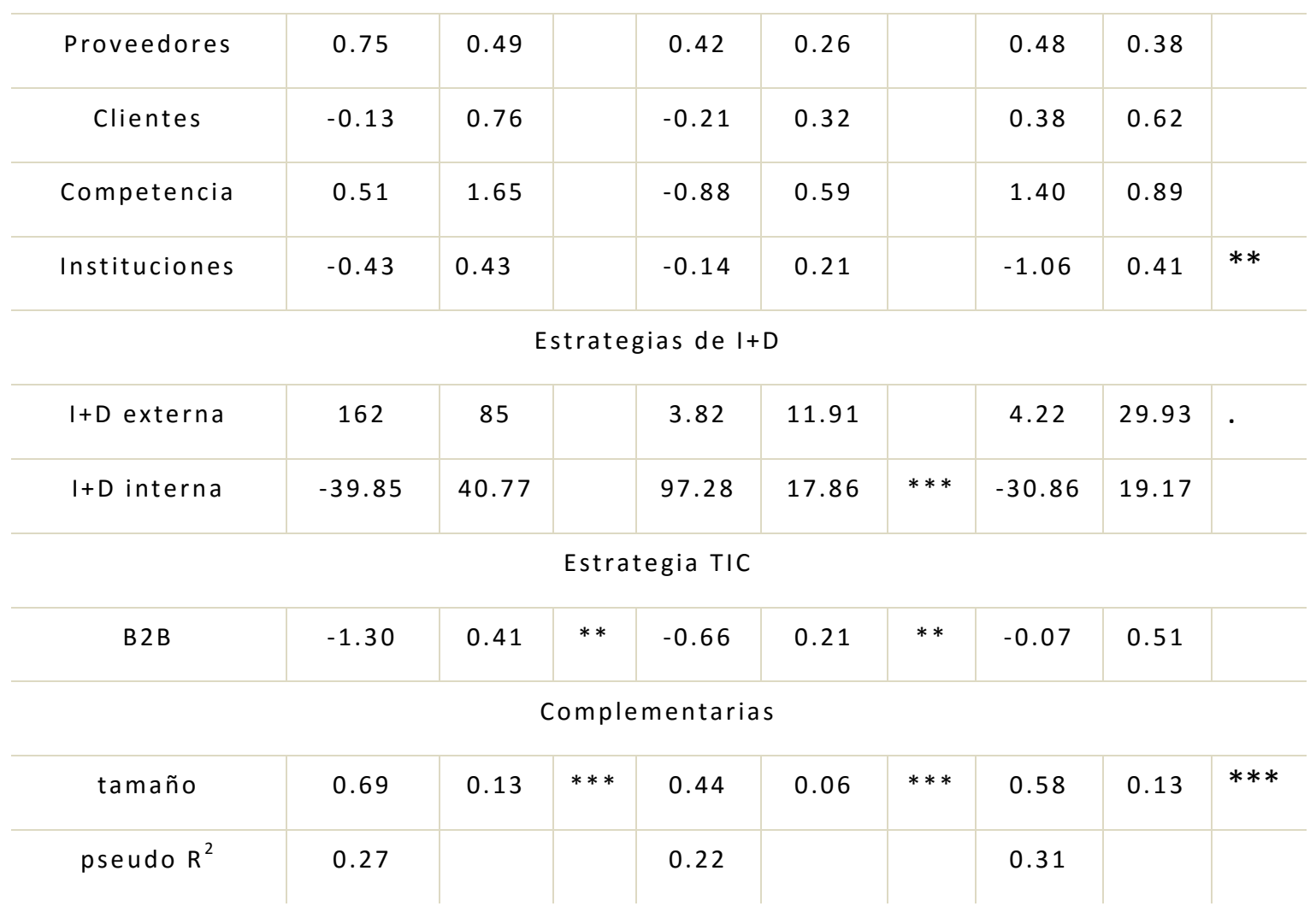

Código: significativo al $10 \%\left({ }^{*}\right)$, al $5 \%\left(*^{*}\right)$ y al $1 \%(* * *)$ 


\subsection{Resultados del caso 3: variable explicada: número de patentes, modelos de utilidad y marcas de fábrica}

El problema que se presenta en este tercer caso empírico es el carácter binario de la variable respuesta. La solución que se ha adoptado para el análisis de dichas variables es el uso de modelos binarios que han sido utilizados ampliamente en ámbitos económicos.

En concreto el modelo econométrico empleado en este estudio ha sido ajustado empleando un modelo lineal generalizado (MLG) con una familia de distribución de errores de tipo binomial con una función de enlace para la transformación de las variables tipo Logit, a través de la aplicación a la variables explicadas de logaritmos. Información sobre este modelo de regresión se puede encontrar en cualquier manual de econometría a los que ya se han hecho referencia en este trabajo.

La variable respuesta contiene unos y ceros representando estos el hecho de que la empresa proteja sus invenciones en alguna de las tres versiones que se consideran en este trabajo, patentes, modelos de uso o marcas de fábrica, o no lo haga respectivamente.

La bondad de ajuste del modelo que nos permite determinar si el modelo se ajusta a los datos se ha realizado a partir de McFadden (1974). El método está basado en el paralelismo entre los modelos lineales y los generalizados obteniendo de esta manera el pseudo- ${ }^{2}$ que se construye a partir de la verosimilitud del modelo nulo (sin variables independientes) y la verosimilitud del modelo completo (con variables independientes)

$$
\text { pseudo } R^{2}=1-\frac{\log (\text { verosimilitud mod. } \text { nulo })}{\log (\text { verosimilitud mod.completo })}
$$


En este caso no es posible realizar estimaciones de los modelos atendiendo a los diferentes subsectores puesto que el panel de datos empleado no nos ofrece la disgregación como si hacía la encuesta ESEE.

De igual forma tampoco nos permite realizar las distinción entre PYMES y grandes como la ESEE a partir de los 200 empleados sino que el criterio que toma para diferenciar por número de empleados es a partir de 250 empleados.

Las hipótesis planteadas en el capítulo 2 que atendiendo a los datos ofrecidos por el panel podemos confirmar o no serían las siguientes:

- H1A relacionada con la inversión interna en I+D.

- H1B relacionada con la inversión externa en I+D.

- H2 relacionada con la cooperación

- H3A relacionada con la inversión en bienes de equipo

- H3B relacionada con el tamaño de la empresa.

\begin{tabular}{|c|c|c|c|c|c|c|c|c|}
\hline & PAT & $\begin{array}{c}\text { Uso } \\
\text { model }\end{array}$ & $\begin{array}{c}\text { Uso } \\
\text { marca }\end{array}$ & GEID & GIID & COOPERA & INBEA & TAMAÑ 0 \\
\hline PAT & 1 & & & & & & & \\
\hline usomodel & 0.24 & 1 & & & & & & \\
\hline usomarca & 0.25 & 0.41 & 1 & & & & & \\
\hline GEID & 0.05 & 0.06 & 0.05 & 1 & & & & \\
\hline GIID & 0.12 & 0.16 & 0.06 & -0.05 & 1 & & & \\
\hline COOPERA & 0.17 & 0.12 & 0.08 & 0.21 & 0.26 & 1 & & \\
\hline INBEA & 0.07 & 0.05 & 0.04 & 0.001 & 0.001 & 0.102 & 1 & \\
\hline TAM AÑO & 0.11 & 0.04 & 0.07 & -0.01 & 0.01 & 0.128 & 0.49 & 1 \\
\hline
\end{tabular}

Fuente: Elaboración propia a partir del PITEC 
A la vista de los datos de la tabla de correlaciones entre las variables, salvo los coeficientes de correlación entre los gastos internos y los externos en I+D y estos últimos y el tamaño, el resto muestra correlaciones positivas. Se puede apreciar en los matrices de correlación (Diagrama 6), la correlación negativa que indica como el aumento del gasto externo en $I+D$ conlleva una disminución en el interno propio y se corresponde con empresas de menor tamaño.

Por otro lado se observa que los valores de correlación de las variables son valores bajos no superando el 0,2 en ninguno de los casos salvo la inversión en bienes de equipo (INBEA) con 0,49 que es la más elevada y las establecidas entre las variables explicadas que se sitúan entre el 0,24 y el 0,45 . 
Diagrama 6: Diagramas de correlación entre las variables
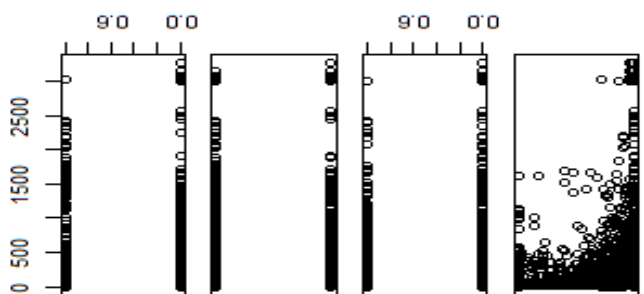

08 ot 0
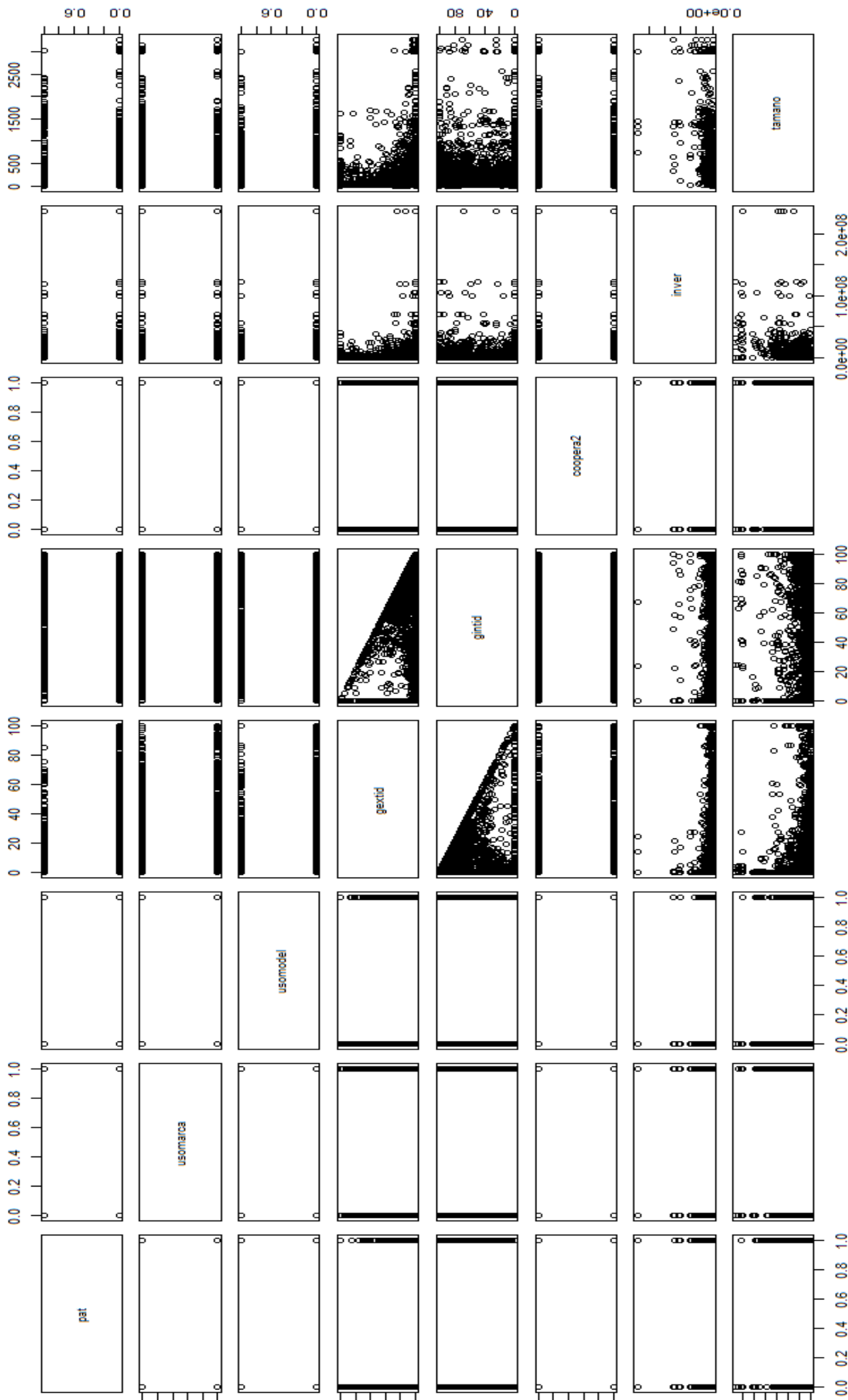

9000
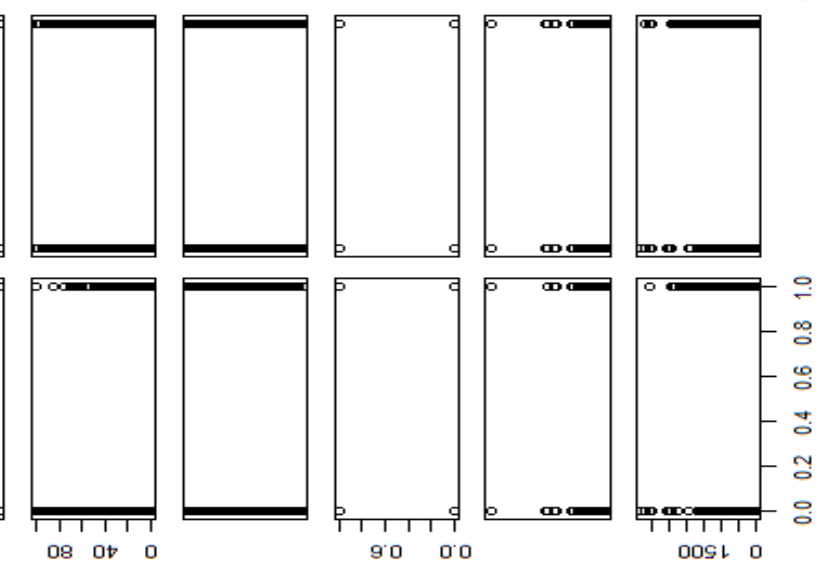

Fuente: elaborado a partir de los datos del PITEC 
En la Tabla 32 y la Tabla 33 se presentan los resultados obtenidos tras el ajuste de los modelos de regresión que contemplan como variable dependiente la solicitud de patentes, el modelo de utilidad y la marca de fábrica para todas las empresas del sector agroalimentario.

La variable Tamaño toma en los tres casos valores positivos y significativos, indicando que es necesario controlar este factor porque se produce un efecto tamaño con respecto a los tres tipos de innovación protegida. Las inversiones necesarias para realizar este tipo de actividades son considerables y el acceso a este tipo de innovación viene condicionado porque las empresas tengan cierto tamaño. Se acepta por tanto la hipótesis H3B. Así mismo, cabe resaltar que el efecto significativo y positivo que presentan es mayor en el caso de las marcas de fábrica cuando la estimación está condicionada a efectos aleatorios al ser este tipo de protección más fácil de llevar a cabo por las empresas.

En cuanto a la Inversión en Bienes y Equipos (H3A), se encuentra relación con los modelos de utilidad y las marcas de fábrica y no con las patentes. Este último está en consonancia con los resultados en el caso empírico 1 en el que tampoco se encontraba evidencias en este aspecto.

La hipótesis $\mathrm{H} 2$, relacionada con la cooperación, se acepta en el caso de las patentes y los modelos de utilidad, es decir, se encuentra evidencia de que las empresas que realizan algún tipo de cooperación tecnológica solicitan más patentes y modelos de utilidad. Lo que indica que tener socios implica garantía de éxito.

Por último, la I+D interna presenta coeficientes positivos y significativos en el modelo de efectos fijos. Cuando se controlan los factores intrínsecos de las empresas el grado de significatividad es menor en todos los casos. Este resultado, en cierta manera, indica la dificultad de las empresas para afrontar esfuerzos individuales de I+D. 
Tabla 32: Resultado de la estimación del modelo binomial (Logit) Efectos fijos (TODAS)

\begin{tabular}{l|l|l|l|l|l|l|l|l|} 
& \multicolumn{3}{|c|}{ Patentes } & \multicolumn{2}{c|}{ Modelo de utilidad } & \multicolumn{2}{c}{ Marcas de fábrica } \\
\hline & Coef. & SD & & Coef. & SD & Coef. SD \\
\hline Intercepto & -2.85 & 0.259 & $* * *$ & -2.12 & 0.229 & $* * *$ & -0.23 & 0.165 \\
\hline
\end{tabular}

Inversión de capital y procesos de innovación

\begin{tabular}{|c|c|c|c|c|c|c|c|c|c|}
\hline Inversión equipos & 0.03 & 0.067 & & 0.19 & 0.058 & $* *$ & 0.20 & 0.044 & $* * *$ \\
\hline Cooperación & 0.64 & 0.108 & $* * *$ & 0.118 & 0.100 & & 0.08 & 0.066 & \\
\hline$I+D$ externa & 0.12 & 0.041 & $* *$ & 0.14 & 0.04 & $* * *$ & 0.08 & 0.027 & $* *$ \\
\hline$I+D$ interna & 0.27 & 0.035 & $* * *$ & 0.07 & 0.030 & $*$ & 0.14 & 0.020 & $* * *$ \\
\hline
\end{tabular}

Complementarias

\begin{tabular}{|l|l|l|l|l|l|l|l|l|}
\hline tamaño & 0.29 & 0.039 & $* * *$ & 0.24 & 0.035 & $* * *$ & 0.13 & 0.023 \\
\hline pseudo R2 & 0.154 & & & 0.143 & & 0.187 \\
\hline
\end{tabular}

Código: significativo al $10 \%(*)$, al $5 \%(* *)$ y al $1 \%(* * *)$

Tabla 33: Resultado de la estimación del modelo binomial (Logit) Efectos aleatorios (TODAS)

\begin{tabular}{|l|l|l|l|l|l|l|l|l|}
\hline & \multicolumn{3}{|c|}{ Patentes } & \multicolumn{2}{c}{ Modelo de utilidad } & \multicolumn{2}{c}{ Marcas de fábrica } \\
\hline & Coef. & SD & & Coef. & SD & Coef. & SD \\
\hline Intercepto & -2.79 & 0.476 & $* * *$ & -2.46 & 0.431 & $* * *$ & -0.29 & 0.33 \\
\hline
\end{tabular}

Inversión de capital y procesos de innovación

\begin{tabular}{|c|c|c|c|c|c|c|c|c|}
\hline Inversión equipos & 0.13 & 0.099 & 0.25 & 0.087 & $* *$ & 0.26 & 0.067 & $* * *$ \\
\hline
\end{tabular}

Cooperación tecnológica

\begin{tabular}{|l|l|l|l|l|l|l|l|l|}
\hline Cooperación & 0.770 & 0.178 & $* * *$ & 0.37 & 0.160 & $*$ & 0.13 & 0.110 \\
\hline
\end{tabular}

Estrategias de I+D

\begin{tabular}{l|l|l|l|l|l|l|l|l|}
\hline I+D externa & 0.07 & 0.068 & & 0.14 & 0.062 & $*$ & 0.10 & 0.044 \\
\hline I+D interna & 0.22 & 0.053 & $* * *$ & 0.06 & 0.047 & 0.23 & 0.020 \\
\hline
\end{tabular}

Complementarias

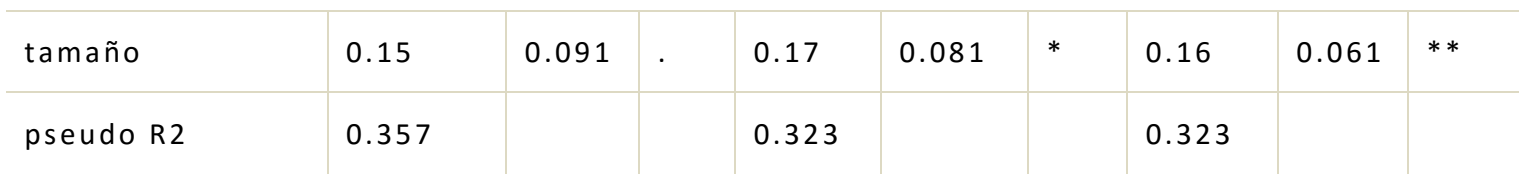

Código: significativo al $10 \%(*)$, al $5 \%(* *)$ y al $1 \%(* * *)$ 

Capítulo 7

CONCLUSIONES 



\section{CONCLUSIONES}

\section{Caso empírico 1}

Con este caso empírico, se ha pretendido analizar el papel de los recursos empresariales sobre la propensión de las empresas agroalimentarias al registro de patentes como producto de su actividad innovadora. La falta de trabajos empíricos que analicen está cuestión considerando diferentes tamaños de empresas, así como varios tipos de I+D y de cooperación tecnológica, es uno de los principales puntos fuertes de esta investigación. Así, los resultados sugieren comportamientos diferentes según el tamaño de la empresa de que se trate.

Los datos usados, ESEE, son representativos de la población de empresas industriales del sector agroalimentario. El periodo de análisis, 1998-2008, también se considera como una etapa de crecimiento y estabilidad que puede ser representativa de una situación frecuente en la que se realiza la actividad empresarial. Una primera aproximación a los datos revela que casi el $90 \%$ de las patentes agroalimentarias proceden de empresas que han realizado algún tipo de actividad de I+D o cooperación tecnológica.

Los modelos econométricos con datos de panel y de conteo consideran como variable dependiente el registro de patentes tanto nacionales como extranjeras, y las variables explicativas se agrupan en torno a tres tipos de recursos: I+D, cooperación tecnológica y recursos complementarios. Además, se han controlado efectos temporales y efectos individuales propios de cada empresa. También se han considerado estructuras de retardo para las variables de I+D y cooperación tecnológica. 
Los esfuerzos en I+D que realizan las empresas agroalimentarias inciden en aspectos como son la innovación en producto o en proceso o la mejora de resultados (productividad y rentabilidad). Este trabajo constata, además, que es la vía más importante y directa para patentar. Las estimaciones muestran que los gastos en I+D tienen una clara relación positiva y significativa con la innovación mediante patentes. En las Pymes la I+D interna presenta mayor efectividad y en las grandes la I+D externa. Los modelos estimados con retardos indican que estos efectos no son inmediatos sino que se manifiestan en el medio plazo (entre 2 y 4 años). Dado que hay todavía un porcentaje elevado de empresas (aproximadamente el $50 \%$ ) que no realizan ningún tipo de I+D, esta podría ser una posibilidad para establecer ventajas competitivas en muchas de ellas. Probablemente no todas tengan esta oportunidad porque estas actividades son caras, pero lo que nuestro análisis revela es que no es algo restringido a las grandes empresas. Por el contrario, las Pymes también patentan y su I+D interna contribuye a ello.

Entre cooperación tecnológica y patentes no se revelan relaciones tan fuertes como en el caso de la I+D. La evidencia es más débil pero no se descarta. La colaboración vertical de la industria con sus proveedores y clientes presenta su potencial innovador en que es la forma de desarrollar nuevos productos adecuando las posibilidades técnicas de la oferta a las necesidades de los consumidores. Este desarrollo de nuevos productos acaba frecuentemente en patentes. Este trabajo muestra en Pymes efectos positivos de cooperación con proveedores y en grandes con clientes. Asimismo, la integración horizontal con competidores se ha revelado como positiva y significativa en Pymes y grandes, una vez que se controlan otros factores. Este tipo de cooperación tecnológica, que es el menos usado por las empresas pero que constituye una forma de que participen en proyectos de $I+D$ que individualmente no podrían realizar, se perfila como una vía adicional o alternativa para que las empresas patenten y ganen competitividad. La colaboración con 
instituciones (universidades y centros tecnológicos) también juega un papel importante aunque los resultados apuntan a que solamente son visibles en las grandes empresas.

En cuanto a los activos complementarios, en Pymes no se ha encontrado ninguna influencia sobre la propensión a patentar, pero en grandes los recursos humanos, comerciales y financieros sí contribuyen considerablemente. Por tanto, el tamaño sí parece un factor importante que favorece que las empresas organicen más eficiente sus recursos complementarios para que sean aprovechados conjuntamente con los activos de innovación para conseguir patentes.

Entre las limitaciones del trabajo, hay que señalar que hubiera sido deseable contar con mejores variables para caracterizar los recursos humanos y comerciales de las empresas. Para los primeros, si en vez de usar el ratio de coste salarial total sobre producción se hubiera podido contar con el coste de personal dedicado a actividades de I+D o de titulados superiores quizá se hubiera conseguido una más apropiada caracterización de este factor. Y de la misma forma se puede decir para los recursos comerciales: las empresas no solamente se diferencian por si exportan o no. Existe una gama más amplia de mercados donde pueden vender sus productos: mercados regionales, nacionales, UE y fuera de ella. En este sentido la base de datos PITEC quizá ofrezca la posibilidad de una mejor caracterización de las empresas en cuanto a activos de innovación y activos complementarios, aunque presenta la desventaja de que no tiene la representatividad de la ESEE. 


\section{Caso empírico 2}

El objetivo de este caso empírico es caracterizar a la industria agroalimentaria española en cuanto a recursos y estrategias empresariales relacionadas con la innovación y las nuevas tecnologías, así como estudiar la evolución en el periodo 2000-2008, y establecer conexiones entre estos activos y el número de innovaciones que realizan estas empresas. La fuente de datos utilizada ha sido ESEE (Survey of Business Strategies) que está diseñada para investigar las decisiones que toman las empresas para mejorar su competitividad.

No se detecta que la industria agroalimentaria española realice menos innovaciones en producto que otros tipos de industrias. Sí se percibe una menor tasa en la Industria cárnica que en Productos alimenticios y tabaco y que en Bebidas. Pero sobre todo lo que llama la atención es que la proporción de empresas que innovan dentro de las grandes es más de 3 veces de la proporción de innovadoras dentro de las PYMES.

Algo similar ocurre con la innovación en proceso, aunque con una brecha menor y una tendencia creciente en los últimos años. Las inversiones en bienes de equipos también es algo común a todas las empresas pero en este caso con tendencia a la baja. Los resultados del modelo econométrico permiten evidenciar la fuerte conexión entre innovación en proceso e innovación en producto. Además en muchas empresas agroalimentarias (PYMES de Bebidas y Productos alimenticios y tabacol las inversiones en bienes de equipo siguen teniendo una estrecha relación con las innovaciones de producto.

La cooperación tecnológica con otras empresas y/o instituciones es la asignatura pendiente de las PYMES pues presentan valores muy bajos en relación con las grandes. Por ejemplo, el $43.8 \%$ de las grandes realizan colaboraciones con proveedores frente a $4.6 \%$ en las pequeñas. La estimación econométrica indica que esta variable aumenta 
significativamente el número de innovaciones que realizan las grandes empresas agroalimentarias. Es por tanto una buena alternativa para mejorar la capacidad de innovación en productos, que apenas han usado todavía las PYMES.

Se han detectado unos niveles muy bajos de gastos en $I+D$ en la industria agroalimentaria, tanto en PYMES como en grandes, en relación con otros tipos de industrias manufactureras. Solamente Bebidas presenta una tendencia creciente en los últimos años. A pesar de estos bajos gastos en investigación y desarrollo los resultados del modelo indican que ambos tipos de $I+D$ contribuyen positivamente de forma significativa sobre la capacidad de innovación de las PYMES, especialmente la interna.

Por otro lado, en cuanto a e-innovación la industria agroalimentaria española ha realizado esfuerzos importantes en los últimos años para adoptar TICs. En cuanto a empresas con dominio en internet las agroalimentarias presentan tasas similares a las de otros sectores industriales. Las diferencias entre grandes y PYMES son notables pues la proporción de las que tienen dominio en internet está por encima del $90 \%$ en las primeras mientras que en las segundas se sitúan entre 60 y $80 \%$. Sin embargo el esfuerzo realizado por las PYMES, entre 2000 y 2008, por adquirir dominio en internet ha sido muy importante. En cuanto a compras a proveedores por internet las PYMES están en el entorno del $25 \%$ y las grandes por encima del $40 \%$. El uso de internet para vender no es tan elevado como para realizar compras. Sin embargo la brecha entre PYMES y grandes es menor. Por ejemplo, en 2008 , en Productos alimenticios y tabaco el $11.5 \%$ de las empresas vendían a consumidores finales dentro de PYMES y $15.9 \%$ en grandes. Estas variables también están relacionadas positivamente con la capacidad de innovación de las empresas agroalimentarias, y se revelan como especialmente importantes en las PYMES. 


\section{Caso empírico 3}

Las empresas agroalimentarias han disminuido las solicitudes de patentes, marcas de utilidad y marcas de fábrica en los últimos años. Acometer gastos de I+D, interno o externo, o cooperar tecnológicamente con otros socios es necesario para desarrollar nuevos productos y procesos, y ganar competitividad. Pero estos esfuerzos no son siempre garantía de éxito, como muestra la aplicación empírica de este trabajo. En este sentido, fomentar la innovación a través de la cooperación tecnológica con otras empresas o con universidades y centros de investigación es una medida que puede incrementar los resultados de innovación de las empresas agroalimentarias.

\subsection{Limitaciones de la investigación}

Una limitación con la que nos encontramos en este estudio es la que se deriva de los datos de la encuesta. No es posible realizar un estudio regionalizado de la innovación. Esta cuestión, entre otras, se considera importante para poder establecer realmente una relación entre las causas y los efectos. Es por ello que en este trabajo no se ha tenido como objetivo analizar las causas.

\subsection{Sugerencias para futuras investigaciones}

El sector agroalimentario debiera recibir en el futuro un mayor nivel de estudio en relación a sus estrategias de innovación. Considerado de forma clásica como un sector de baja tecnología llowtech) puede pasar a incorporarse como de alta tecnología (high-tech) de la mano de los importantes nuevos avances en biotecnología (Filipalos et al., 2009). Además están surgiendo con éxito nuevas propuestas de abordar la innovación de forma colaborativa, bajo el paradigma del paso 
de una innovación cerrada (closed innovation) a una innovación abierta (open innovation). Estas opciones de gestión empresarial pueden permitir la obtención de buenos resultados en sectores, como el agroalimentario, caracterizado por la presencia de una proporción muy elevada de PYMES, con sus limitaciones de recursos y capacidades. Por otro lado, las opciones que surjan alrededor de la e-innovación pueden permitir nuevas opciones de relaciones entre los agentes de la cadena alimentaria que cambien su estructura. Por otro lado, el crecimiento de la internacionalización de los negocios provocará también un cambio en el panorama innovador de las empresas agroalimentarias.

En relación a futuras investigaciones, el propósito es continuar aplicando métodos econométricos que tengan en cuenta la heterogeneidad de las empresas. La aplicación de un modelo mixto es el apropiado teniendo en cuenta que los datos que tenemos están en forma de panel y nos permite ajustar mejor el modelo. Además, una mayor disgregación en el tamaño de las empresas nos podrá dar un resultado más útil para la aplicación de políticas de innovación. 

Bibliografía 

BIBLIOGRAFÍA

ACS, Z.J. Y AUDRETSCH, D.B. (1987). Innovation, market structure, and firm size. . The Review of Economics and Statistics, LXIX (4), 567 574.

Abramson, M., Littman, D. (2002): Innovation. Rowman and Littlefield Publisers. Maryland. USA.

Alarcón, S., González-Polonio, L.; (2014) Patents, research \& development and technological cooperation in the Spanish agri-food industry. New Medit, Mediterranean Journal of Economics, Agriculture and Environement. Vol. XIII, no $3 / 2014$

Alarcón, S., Sánchez, M., (2013). External and internal R\&D, capital investment and business performance in the Spanish agri-food industry. Journal of Agricultural Economics, 64(3): 654-675.

Alfranca, O., Rama, R., Von Tunzelmann, N. (2004). Innovation spells in the multinational agri-food sector. Technovation 24(8), 599614.

Archibugi, D., Pianta, M. (1996). Measuring technological change through patents and innovation surveys. Technovation, 16 (9), 451-468.

Arundel, A. y Kabla, I. (1998), What percentage of innovations are patented? Empirical estimates for European firms. Research Policy, vol.27, 127-141.

Avermaete, T., Viaene, J., Morgan, E.J. (2004). Determinants of product and process innovation in small food manufacturing firms. Trends in Food Science \& Technology 15 (2004) 474-483. 
Barge-Gil, A. (2010). Open, Semi-Open and Closed Innovators. Towards an explanation of degree of openness. Technovation, 30, 195206.

Barney, J.B. (1991). Firm Resources and Sustained Competitive Advantage. Journal of Management, 17(1), 99-120.

Baltagi, B.H. (2001) Econometrics Analysis of Panel Data $2^{\text {nd }}$ Edition. John Wiley \& Sons, LTD.

Batterink, M.H., M. Wubben, E.F., Omta, S.W.F. (2006). Factors related to innovative output in the Dutch agrifood industry. Journal on Chain and Network Science, 6(1), 31-44.

Bello, L. (1992), "La innovación y el marketing en el desarrollo economic regional". Lección inaugural, Universidad de León.

Beurskens, F. (2003). The Economics of Dot.coms and E-Commerce in the Agrifood sector. Review of Agricultural Economics, 25 (1), 22-28.

Braun, E. (1986). Tecnología rebelde. Fundesco-Tecnos. Madrid.

Brewin, D.G., Monchuk, D.C., Partridge, M.D. (2009). Examining the Adoption of Product and Process Innovations in the Canadian Food Processing. Canadian Journal of Agricultural Economics 57(1), 75-97.

Briz, J.; De Felipe, I. y Briz, T. (2012): "Las redes de cadenzas de valor como instrument de análisis del sistema alimentario"; en CEA (Cuadernos de estudios agroalimentarios); Noviembre, pp. 13-27.

Cabral, J.E.O., Traill, W.B. (2001). Determinants of a firm's likelihood to innovate and intensity of innovation in the Brazilian food industry. Journal on Chain and Network Science, 1 (1), 33-48. 
Caldentey, P. (1998). Nueva Economía Agroalimentaria. Ed. Agrícola Española, S.A.

Capitanio, F., Coppola, A., Pascucci, S. (2009). Indications for drivers of innovation in the food sector. British Food Journal, 111 (8), 820-838.

Carnegie, r., y butlin, M. (1993). Managing the innovative enterprise: Australian Companies Competing against the Worlds Best, Business Council of Australia, Melbourne.

Chisenga, J. (2008). The e-agriculture initiative: achieving the MDGS through sharing of innovative experiences. Paper presented at 18th SCECSAL Conference Location. Lusaka, Zambia. July.

Cho, S.E., Park, H.W. (2012). Government organizations' innovative use of the Internet: the case of Twitter activity of South Korea's Ministry for Food, Agriculture, Forestry and Fisheries. Scientometrics, 90, 9-23.

Christensen, J.F. (1995). Asset profiles for technological innovation. Research Policy, 24(5), 727-745.

Comisión Europea (1993): Libro blanco: Crecimiento, Competitividad y Empleo. Retos y pistas para entrar en el siglo XXI, Bruselas.

Comisión Europea (1995). Libro Verde de la Innovación. Bruselas, http://www.cordis.lu/innovation/src/grnpap1.htm.

Crawford, M. (1994). New products management. R.D. Irwin, 4a Ed. 
Cruz-Cázares, C., C. Bayona-Sáez, T. García-Marco (2010). R\&D Strategies And Firm Innovative Performance: A Panel Data Analysis. International Journal of Innovation Management, 14 (6), 1013-1045.

Cuello de Oro, D.J. y López-Cózar, C. (2005), Las patentes como mecanismo de apropiación de rentas económicas. Un estudio empírico en el sector farmacéutico español. Revista Europea de Dirección y Economía de la Empresa, vol. 16, núm.1, 11-28.

Díaz, M.C., (1997). Factores determinantes de la innovación para las empresas pequeñas. Servicio de publicaciones UCM, Madrid. Cuadernos de estudios empresariales (6).

Drucker, P. (1998). The coming of the new organization, Harvard Business Review on Knowledge Management, Harvard Business School Press, Boston.

\section{EUROSTAT}

http://ec.europa.eu/eurostat/tgm/refreshTableAction.do?tab=table\&plu gin=0\&p code $=t 2020 \_20 \&$ language $=e n$

Filippaios, F. Papanastasiou, M., Pearce, M., Rama, R. (2009). New forms of organization and R\&D internlisation among the world's 100 largest food and beverage multinationals. Research Policy, 34, 1032-1043.

FIAB. Federación Española de Industrias Agroalimentarias y Bebidas. (Food and Beverages Spanish Federation) www.fiab.es.

De Jong, J.P.J, Vermeulen, P.A. (2006). Determinants of product innovations in Small firms. A comparison across industries. International Small Business Journal, 24 (6), 587-609. 
Furtan, W.H., Sauer, J. (2008). Determinants of food industry performance: survey data and regressions for Denmark. Journal of Agricultural Economics, 59 (3), 555-573.

Galende, J. y Suárez, I. (1999). A resource-based analydis of the factors determining a firm's R \& D activities. Research Policy, 28, 891905.

Galende, J., De la Fuente, J.M., (2003). Internal factors determininga firm's innovative behaviour. Research Policy (32), 715 736

Gambardella, A. (1992): "Competitive advantages from in-house scientific research: the U.S. pharmaceutical industry in the 1980s", Research Policy, vol. 21, pp. 391-407.

García Martinez, M. and J. Burns (1999). Sources of Technological Development in the Spanish Food \& Drink Industry. A 'SupplierDominated' Industry". Agribusiness, 15 (4), 431-448.

Gómez, J.L., Calvo, A., (2010). La innovación: factor clave del éxito empresarial. Ed. Ra-Ma Editorial S.A.

Gopinath, M., Vasadava, U. (1999). Patents, R\&D, and market structure in the U.S. food processing industry. Journal of Agricultural and Resource Economics, 24 (1), 127-139.

Greene, W.H. (2006). Econometric Analysis. Academic Internet Publishers, 5th Edition.

Hall, B., Z.Griliches and J. Hausman 1986. Patents and R\&D: Is there a lag? International Economic Review 27 (2): 265-83. 
Hartl, J., Herrmann, R. (2006). The Role of Business Expectations for New Product Introductions: A Panel Analysis for the German Food Industry. Journal of Food Distribution Research, 37(2), 12-22.

Heijs, J., Buesa M. y Baumert T. (2007). Sistemas nacionales de innovación: conceptos, perspectivas y desafíos, en: Heijs, J. y Buesa, M. (coord.), Sistemas regionales de innovación: nuevas formas de análisis y medición. Madrid: Fundación de las Cajas de Ahorros.

Heijs, J. (2012). Fallos sistémicos y de Mercado en el sistema español de innovación. ICE. Innovación y competitividad no 869 pp. 4363.

Huiban, J.P., Bouhsina, Z. (1998). Innovation and the Quality of Labour Factor: An empirical investigation in the French food industry. Small Business Economics, 10(4), 389-400.

Informe PITEC 2010: La financiación de la innovación de las empresas, (2012). Fundación española para la Ciencia y la Tecnología, FECYT.

Karantininis, K., Sauer, J., Hartley, W. (2010). Innovation and integration in the agri-food industry. Food Policy, 35 (2), 112-120.

Koellinger, P. (2008). The relationship between technology, innovation, and firm performance-Empirical evidence from e-business in Europe. Research Policy, 37, 1317-1328.

Kuczmarski, T.D. (1996). What is innovation?. The art of welcoming risk. Journal of Consumer Marketing, 13 (5), pp. 7-11.

Livingstone, L., Palich., y Carini, G. (1998). Viewing strategic innovation through the logic of contradiction. Competitiveness Review, $8,(1), 46-54$. 
Méndez, R. (2002): "Innovación y desarrollo territorial: algunos debates teóricos recientes». Revista EURE, XXVIII, no 84, pp. 63-83.

West, M. y Farr, J., (1990). Innovation and Creativity at Work: Psychological and Organizational Strategies, Chichester, John Wiley \& Sons Inc. pp. 3-13.

Miotti, L. and Sachwald, F., (2003). Co-operative R\&D: why and with whom? An integrated framework of analysis. Research Policy, 32(8), 1481-1499.

Munuera, J.L. y Rodríguez, A.I. (2002). Estrategias de marketing. Teoría de Casos.

Nystrom, H. (1990), Technological and Market Innovation: Strategies for Product and Company Development, John Willey \& Sons, London.

OCDE (1997). Oslo Manual: The Measurement of Scientific and Technological Activities. Proposed Guidelines for Collecting and Interpreting Technological Innovation Data. 2nd Edition. OECD Publications, Paris.

OCDE (2005). Oslo Manual: The Measurement of Scientific and Technological Activities. Guidelines for Collecting and Interpreting Innovation. 3rd Edition. OECD Publications, Paris.

Pavitt, K. (1984). Sectoral pattern of technological change: towards a taxonomy and theory. Research Theory 13(6), 343-373.

Penrose, E.T. (1959). The Theory of the Growth of the Firm. John Wiley and Sons, New York 
R Development Core Team (2010). R: A language and environment for statistical computing. R Foundation for Statistical Computing, Vienna, Austria. ISBN 3-900051-07-0, URL http://www.R-project.org/.

Real Academia Española. (2001). Diccionario de la lengua española (22.aed.). Consultado en http://www.rae.es/rae.html

Rama, R. (1996). Empirical study on sources of innovation in international food and beverages industry. Agribusiness, 12 (2), 123 134.

Röder, C., R. Herrmann and J. M. Connor. 2000. Determinants of new product introductions in the US food industry: A panel-model approach. Applied Economics Letters 7 (11): 743-48.

Rogers, E.M. (1990), Diffusión of innovations. 4a Ed., Free Press, Nueva York.

Romer P.M. (1990). The Problem of Development: A Conference of the Institute for the Study of Free Enterprise Systems. The Journal of Political Economy, Vol. 98, No. 5, Part 2, pp. S71-S102.

Sala-i-Martín, X. (1994) Apuntes de crecimiento económico. Antoni Bosch Editor. Octubre.

Salinas-Rodríguez, A., Manrique-Espinoza, M., Sosa-Rubí, S. (2009) Análisis estadístico para datos de conteo: aplicaciones para el uso de los servicios de salud. Salud pública de México. Vol.51 $\mathrm{n}$ 5, septiembreoctubre.

Sánchez Pérez, M., Galera, M.C., Segovia, C., Marín, G.M., (2007). Estrategias y acciones de innovación en las empresas agrarias. Ed. Universidad de Almería, Fundación Tecnova. 
Schumpeter, J.A., (1934). The theory of economic development. Harvard University Press, Cambridge, MA.

Smith, A. (1776). Investigación sobre la naturaleza y causas de la riqueza de las naciones ("La riqueza de las naciones»).

Scherer, F.M., (1965). Firm size, market structure, opportunity and the output of patented invection. The American Economic Rewiew. Vol. 55 núm. 5

Solow, R.M., (1957). Technical Change and the Aggregate Production Function. Review of Economics and Statistics (39), 312-20.

Surroca, J. y Santamaría, L. (2007). La cooperación tecnológica como determinante de los resultados empresariales. Cuadernos de Economía y Dirección de Empresas.(33), 031-062.

Szabolcs, B. Y Escribano, A., (2010). Knowledge spillovers in US patents: A dynamic patent intensity model with secret common innovation factors Journal of Econometrics Volumen: 159 Núm. 1, 14-32.

Teece, D.J., (1986). Profiting from technological innovation: Implications for integration, collaboration, licensing and public policy. Research Policy, 15 (6), 285-305.

Teece, D.J. (2006). Profiting Reflections on" Profiting from innovation". Research Policy, 35 (8), 1131-1146.

Traill, W.B., Meulenberg, M. (2002). Innovation in the food industry. Agribusiness, 18 (1), 1-21.

Weiss, C. R., Wittkopp, A. (2005). Retailer concentration and product innovation in food manufacturing. European Review of Agricultural Economics, 32(2), 219-244. 
Wernerfelt, B. (1984). The Resource-Based View of the Firm. Strategic Management Journal, 5, (2), 171-180.

West, M. y Farr, J., (1990). Innovation and Creativity at Work: Psychological and Organizational Strategies, Chichester, John Wiley \& Sons Inc., , pp. 3-13.

Xuemei, L., Jian, Z., Yuning, Z. (2010). Research on the Innovation of Strategic Business model in Green Agriculture products based on Internet of Things (IOT). Paper presented at e-Business and Information System Security (EBISS), 2nd International Conference, Wuhan (China) 22-23 May. 
APÉNDICES 



\section{APÉNDICE 1: Estrategia española de ciencia y tecnología y de innovación 2013-2020}

Esta estrategia responde a la apuesta por parte del Gobierno de fomentar la Investigación, el Desarrollo y la Innovación.

La Estrategia Española de Ciencia y Tecnología y de Innovación se encuadra dentro del Programa Marco de la Unión Europea "Horizonte 2020" con el que se pretende incentivar la participación activa de los agentes del Sistema Español de Ciencia y Tecnología e innovación en el espacio europeo. El periodo de vigencia de la estrategia es desde el 2013 hasta el 2020 y en él se establecen los 4 objetivos generales que están relacionados con la educación, la formación en investigación, formación empresarial y un último objetivo dedicado a los retos de la sociedad (sostenibilidad del sistema).

La política española de Investigación, Desarrollo e Innovación promueve activamente la contribución del conjunto de políticas públicas y todos los actores tanto públicos como privados a conseguir un desarrollo y un crecimiento económico ordenado y sostenible en el tiempo.

Los objetivos generales contribuyen a un progreso hacia una ordenación de la estructura empresarial principalmente desde tres ámbitos de actuación. El primero es el educativo, directamente relacionado con el factor de Recursos Humanos dedicados a la investigación. Con el segundo objetivo se promueve la generación de conocimiento incrementando el liderazgo científico del país. El tercer objetivo pretende aumentar la competitividad empresarial con un aumento de la actividad en I+D. y por último el cuarto objetivo que consiste en la estimulación del potencial científico e innovador hacía los problemas que existen en la sociedad y precisan un importante desarrollo en I+D. 
Los objetivos generales y específicos de la Estrategia quedan establecidos como sigue:

Tabla 34: Objetivos generales y específicos de la estrategia española de ciencia tecnología y de innovación

Fomento y promoción del talento y sus empleabilidad

Formación y capacitación en $\mathrm{I}+\mathrm{D}+\mathrm{i}$

Movilidad y desarrollo de la carrera investigadora

Incorporación de recursos humanos en $\mathrm{I}+\mathrm{D}+\mathrm{i}$

Fomento de la investigación científica y técnica de excelencia

Generación de conocimiento de frontera

Desarrollo de tecnologías emergentes

Fortalecimiento institucional

Consolidación y usos de infraestructuras científicas y técnicas singulares

Potenciar el liderazgo empresarial en $I+D+i$

Impulso a las actividades empresariales de $I+D+i$

Tecnologías facilitadoras esenciales

$1+D+i$ colaborativa orientada al tejido productivo

Investigación orientada a los retos de la sociedad.

Fuente: Ministerio de de Economía y competitividad. 


\section{APÉNDICE 2: Definiciones}

Empresa

Estrategia

Innovación

tecnológica

Innovación

organizativa

$1+D$

Marca de fábrica
Toda unidad jurídica que constituye una unidad organizativa de producción de bienes y servicios y que disfruta de una cierta autonomía de decisión, principalmente a la hora de emplear los recursos corrientes de que dispone

Decisiones que las empresas adoptan sobre aquellas variables que constituyen sus instrumentos de competencia

Bien o servicio (producto) nuevo o sensiblemente mejorado introducido en el mercado o un proceso nuevo o sensiblemente mejorado introducido en el empresa.

Implementación de métodos de funcionamiento interno de la empresa, de organización del área de trabajo y de relaciones externas.

Investigación y desarrollo. Comprende el trabajo creativo llevado a cabo de forma sistemática para incrementar el volumen de conocimientos que pueden derivar en nuevas aplicaciones.

La marca y el nombre comercial son signos distintivos que se protegen mediante títulos otorgados por el Estado y que confieren a su titular el derecho exclusivo de utilizarlos en el 
tráfico económico, e impedir a otros la utilización en España de los signos distintivos protegidos $u$ otros idénticos o similares aplicados a productos o servicios idénticos o semejantes.

Título otorgado por el Estado para proteger las invenciones que, siendo nuevas e implicando una actividad inventiva, consisten en dar a un

Modelo de utilidad objeto una configuración, estructura o constitución de la que resulte alguna ventaja prácticamente apreciable para su uso o fabricación.

Título otorgado por el Estado que da a su titular el derecho de impedir temporalmente a otros la fabricación, venta o utilización comercial en España de la invención protegida. Son patentables las invenciones nuevas, que Patente impliquen actividad inventiva y sean susceptibles de aplicación industrial, aun cuando tengan por objeto un producto que esté compuesto o que contenga materia biológica, o un procedimiento mediante el cual se produzca, transforme o utilice materia biológica.

Sector Agroindustrial Rama industrial que añade valor a la producción primaria procedente del sector agrario.

Se da cuando un país o una organización Ventaja comparativa produce, en comparación con otro, mejor y con menor costo. 
Ventaja competitiva
Es aquella ventaja que goza un país o estado sobre otro, en cuanto al costo de producir algún producto. Por lo general, es una ventaja natural del país, es decir, no ha hecho nada en extraordinario para obtener esta ventaja. 



\section{APÉNDICE 3: Análisis estadístico (ESEE)}

\begin{tabular}{|c|c|c|c|}
\hline & I.A.A. & resto Ind. & total \\
\hline 1998 & 253 & 1523 & 1776 \\
\hline 1999 & 232 & 1522 & 1754 \\
\hline 2000 & 254 & 1616 & 1870 \\
\hline 2001 & 221 & 1503 & 1724 \\
\hline 2002 & 228 & 1480 & 1708 \\
\hline 2003 & 186 & 1194 & 1380 \\
\hline 2004 & 186 & 1188 & 1374 \\
\hline 2005 & 262 & 1649 & 1911 \\
\hline 2006 & 284 & 1739 & 2023 \\
\hline 2007 & 300 & 1713 & 2013 \\
\hline 2008 & 304 & 1705 & 2009 \\
\hline
\end{tabular}

\begin{tabular}{|c|c|c|c|}
\cline { 2 - 4 } \multicolumn{1}{c|}{} & $\begin{array}{c}\text { no empresas } \\
\text { con GEID }\end{array}$ & GEID & GEID/no empresas \\
\hline 1998 & 40 & 10229460,30 & 255736,51 \\
\hline 1999 & 46 & 9559013,10 & 207804,63 \\
\hline 2000 & 46 & 12399378,40 & 269551,70 \\
\hline 2001 & 40 & 20516558,00 & 512913,95 \\
\hline 2002 & 42 & 15861213,00 & 377647,93 \\
\hline 2003 & 35 & 13239838,00 & 378281,09 \\
\hline 2004 & 36 & 13526795,00 & 375744,31 \\
\hline 2005 & 61 & 41348231,00 & 677839,85 \\
\hline 2006 & 51 & 13135931,00 & 257567,27 \\
\hline 2007 & 57 & 24495422,00 & 429744,25 \\
\hline 2008 & 54 & 15612881,00 & 289127,43 \\
\hline
\end{tabular}

Fuente: ESEE 
Tabla 37: Gastos internos en I+D en la IAA

\begin{tabular}{|c|c|c|c|}
\cline { 2 - 4 } \multicolumn{1}{c|}{} & $\begin{array}{c}\text { no empresas } \\
\text { con GIID }\end{array}$ & GIID & $\begin{array}{c}\text { GIID/no } \\
\text { empresas }\end{array}$ \\
\hline 1998 & 59 & 27262702,40 & 462079,70 \\
\hline 1999 & 59 & 26000715,30 & 440690,09 \\
\hline 2000 & 76 & 34908057,30 & 459316,54 \\
\hline 2001 & 58 & 35021444,20 & 603818,00 \\
\hline 2002 & 56 & 30731645,00 & 548779,38 \\
\hline 2003 & 40 & 25946094,00 & 648652,35 \\
\hline 2004 & 44 & 27272988,00 & 619840,64 \\
\hline 2005 & 75 & 36361245,00 & 484816,60 \\
\hline 2006 & 73 & 114110577,00 & 1563158,59 \\
\hline 2007 & 76 & 73434308,00 & 966240,89 \\
\hline 2008 & 85 & 58735966,00 & 691011,36 \\
\hline
\end{tabular}

Fuente: ESEE

Tabla 38: Número de empresas que innovan en producto (IP) y en proceso (IPR) en la IAA

\begin{tabular}{|c|c|c|}
\cline { 2 - 3 } \multicolumn{1}{c|}{} & IP & IPR \\
\hline 1998 & 57 & 86 \\
\hline 1999 & 61 & 58 \\
\hline 2000 & 75 & 85 \\
\hline 2001 & 44 & 69 \\
\hline 2002 & 52 & 63 \\
\hline 2003 & 33 & 56 \\
\hline 2004 & 43 & 58 \\
\hline 205 & 62 & 87 \\
\hline 2006 & 58 & 97 \\
\hline 2007 & 53 & 123 \\
\hline 2008 & 55 & 131 \\
\hline
\end{tabular}

Fuente: ESEE 
APÉNDICE 4: Análisis estadístico (PITEC)

\begin{tabular}{|c|c|c|c|}
\hline \multicolumn{4}{|c|}{ Tabla 39: Número de empresas del Panel } \\
\hline & AGRO & IAA & RESTO \\
\hline 2003 & 80 & 445 & 6759 \\
\hline 2004 & 109 & 651 & 9563 \\
\hline 2005 & 157 & 796 & 11850 \\
\hline 2006 & 172 & 780 & 11851 \\
\hline 2007 & 171 & 758 & 11879 \\
\hline 2008 & 142 & 743 & 11928 \\
\hline 2009 & 137 & 731 & 11949 \\
\hline 2010 & 130 & 715 & 11976 \\
\hline 2011 & 133 & 698 & 11977 \\
\hline 2012 & 131 & 669 & 12038 \\
\hline MEDIA & 136,2 & 698,6 & 11177 \\
\hline
\end{tabular}

Fuente: PITEC

Tabla 40: Número de empresas totales del Panel

\begin{tabular}{|c|c|}
\cline { 2 - 2 } \multicolumn{1}{c|}{} & No de empresas \\
\hline 2003 & 7284 \\
\hline 2004 & 10323 \\
\hline 2005 & 12803 \\
\hline 2006 & 12803 \\
\hline 2007 & 12808 \\
\hline 2008 & 12813 \\
\hline 2009 & 12817 \\
\hline 2010 & 12821 \\
\hline 2011 & 12808 \\
\hline 2012 & 12838 \\
\hline
\end{tabular}


Tabla 41: Número de empresas con gastos internos en I+D y Media de los gastos en I+D

\begin{tabular}{|c|c|c|c|c|}
\cline { 2 - 5 } \multicolumn{1}{c|}{} & \multicolumn{5}{c|}{ Tabla 41: Número de empresas con gastos internos en I+D y Media de los gastos en I+D } \\
\cline { 2 - 5 } \multicolumn{1}{c|}{} & \multicolumn{5}{c|}{ AGRO } \\
\hline $\mathbf{2 0 0 3}$ & 80 & GINTID & IDEX & GEXTID \\
\hline $\mathbf{2 0 0 4}$ & 103 & 83,683 & 35 & 11,062 \\
\hline $\mathbf{2 0 0 5}$ & 119 & 77,198 & 48 & 9,447 \\
\hline $\mathbf{2 0 0 6}$ & 114 & 65,095 & 65 & 9,838 \\
\hline $\mathbf{2 0 0 7}$ & 100 & 53,563 & 64 & 9,971 \\
\hline $\mathbf{2 0 0 8}$ & 78 & 46,888 & 50 & 8,201 \\
\hline $\mathbf{2 0 0 9}$ & 71 & 42,188 & 45 & 9,166 \\
\hline $\mathbf{2 0 1 0}$ & 66 & 40,091 & 45 & 11,154 \\
\hline $\mathbf{2 0 1 1}$ & 61 & 40,801 & 49 & 11,837 \\
\hline $\mathbf{2 0 1 2}$ & 58 & 36,606 & 42 & 12,215 \\
\hline MEDIA & 85 & 35,939 & 33 & 7,423 \\
\hline
\end{tabular}

Fuente: PITEC

IDIN Gastos internos en I+D (1, 0, Blanco)

GINTID Cifra de gastos internos en I+D (\%)
IDEX Gastos externo en I+D (1, 0, Blanco)

GEXTID Cifra de gastos internos en I+D (\%)

Leyenda tabla 42,43 y 44

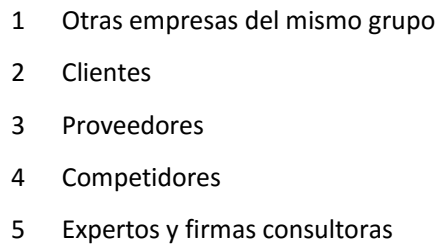

6 Laboratorios comerciales/empresas de I+D

7 Universidades

8 Opi's

9 Centros tecnológicos

Tabla 42: Cooperación en IAA

\begin{tabular}{|c|c|c|c|c|c|c|c|c|c|c|}
\cline { 2 - 13 } \multicolumn{1}{c|}{} & \multicolumn{10}{c|}{} \\
\cline { 2 - 13 } \multicolumn{1}{c|}{} & Coopera & 1 & 2 & 3 & 4 & 5 & 6 & 7 & 8 & 9 \\
\hline 2003 & 199 & 27 & 12 & 56 & 12 & 37 & 24 & 88 & 47 & 50 \\
\hline 2004 & 202 & 51 & 117 & 42 & 26 & 77 & 99 & 47 & 63 & 0 \\
\hline 2005 & 257 & 67 & 139 & 51 & 27 & 82 & 118 & 53 & 76 & 0 \\
\hline 2006 & 258 & 70 & 147 & 57 & 28 & 99 & 108 & 51 & 91 & 0 \\
\hline 2007 & 215 & 65 & 135 & 42 & 25 & 84 & 99 & 50 & 78 & 0 \\
\hline 2008 & 215 & 77 & 131 & 57 & 25 & 79 & 101 & 60 & 87 & 0 \\
\hline 2009 & 200 & 77 & 139 & 66 & 35 & 80 & 106 & 63 & 96 & 0 \\
\hline 2010 & 213 & 80 & 145 & 75 & 41 & 87 & 109 & 76 & 96 & 0 \\
\hline 2011 & 188 & 94 & 136 & 80 & 46 & 90 & 97 & 73 & 93 & 0 \\
\hline 2012 & 186 & 0 & 0 & 0 & 0 & 0 & 0 & 0 & 0 & 0 \\
\hline MEDIA & 213,3 & 60,8 & 110,1 & 52,6 & 26,5 & 71,5 & 86,1 & 56,1 & 72,7 & 5 \\
\hline
\end{tabular}


Tabla 43: Cooperación en RESTO de empresas

\begin{tabular}{|c|c|c|c|c|c|c|c|c|c|c|}
\multicolumn{10}{c|}{ Tabla 43: Cooperación en RESTO de empresas } \\
\cline { 2 - 13 } \multicolumn{1}{c|}{} & \multicolumn{10}{c|}{ RESTO } \\
\cline { 2 - 13 } \multicolumn{1}{c|}{ Coopera } & 1 & 2 & 3 & 4 & 5 & 6 & 7 & 8 & 9 \\
\hline 2003 & 2192 & 368 & 410 & 614 & 294 & 403 & 262 & 968 & 422 & 640 \\
\hline 2004 & 2540 & 803 & 1335 & 1057 & 695 & 894 & 1283 & 638 & 1063 & 0 \\
\hline 2005 & 3172 & 927 & 1582 & 1205 & 843 & 1021 & 1486 & 762 & 1201 & 0 \\
\hline 2006 & 3040 & 926 & 1594 & 1272 & 822 & 1034 & 1492 & 780 & 1226 & 0 \\
\hline 2007 & 2735 & 879 & 1425 & 1162 & 825 & 998 & 1501 & 738 & 1173 & 0 \\
\hline 2008 & 2710 & 920 & 1476 & 1244 & 808 & 1006 & 1500 & 793 & 1194 & 0 \\
\hline 2009 & 2613 & 891 & 1440 & 1281 & 796 & 987 & 1445 & 778 & 1221 & 0 \\
\hline 2010 & 2535 & 914 & 1449 & 1302 & 821 & 1056 & 1474 & 810 & 1255 & 0 \\
\hline 2011 & 2252 & 908 & 1324 & 1210 & 778 & 995 & 1321 & 763 & 1190 & 0 \\
\hline 2012 & 2243 & 0 & 0 & 0 & 0 & 0 & 0 & 0 & 0 & 0 \\
\hline MEDIA & 2603,2 & 753,6 & 1203,5 & 1034,7 & 668,2 & 839,4 & 1176,4 & 703 & 994,5 & 64 \\
\hline
\end{tabular}

Tabla 44: Cooperacion en sector agrario

\begin{tabular}{|c|c|c|c|c|c|c|c|c|c|c|}
\multicolumn{1}{c|}{} & \multicolumn{10}{c|}{ AGRO } \\
\cline { 2 - 13 } \multicolumn{1}{c|}{} & Coopera & 1 & 2 & 3 & 4 & 5 & 6 & 7 & 8 & 9 \\
\hline 2003 & 53 & 3 & 3 & 3 & 9 & 5 & 7 & 31 & 25 & 9 \\
\hline 2004 & 49 & 12 & 12 & 17 & 16 & 14 & 45 & 36 & 22 & 0 \\
\hline 2005 & 67 & 20 & 28 & 22 & 12 & 16 & 45 & 41 & 22 & 0 \\
\hline 2006 & 66 & 19 & 24 & 13 & 18 & 15 & 44 & 27 & 27 & 0 \\
\hline 2007 & 71 & 19 & 25 & 15 & 13 & 15 & 46 & 40 & 26 & 0 \\
\hline 2008 & 9 & 9 & 14 & 7 & 11 & 11 & 39 & 26 & 21 & 0 \\
\hline 2009 & 57 & 9 & 15 & 9 & 13 & 13 & 42 & 29 & 22 & 0 \\
\hline 2010 & 49 & 7 & 14 & 11 & 18 & 15 & 40 & 27 & 14 & 0 \\
\hline 2011 & 40 & 11 & 7 & 1 & 11 & 15 & 28 & 18 & 16 & 0 \\
\hline 2012 & 38 & 0 & 0 & 0 & 0 & 0 & 0 & 0 & 0 & 0 \\
\hline MEDIA & 49,9 & 10,9 & 14,2 & 9,8 & 12,1 & 11,9 & 33,6 & 27,5 & 19,5 & 0,9 \\
\hline
\end{tabular}


Leyenda tabla 45,46 y 47

\begin{tabular}{ll|} 
innprod & Innovación en productos de $(\mathrm{t}-2)$ a t \\
innobien & Innovación bienes de $(\mathrm{t}-2)$ a t \\
innoserv & Innovación servicios de $(\mathrm{t}-2)$ a t \\
desaprod & Quien desarrolla la innovación en producto
\end{tabular}

innprodm Inn de producto desarrollada por empresa o grupo innprods Inn. En producto desarrollada en cooperación otras empresas o instituciones

novedad Introducción de productos nuevos para mercado

novedemp Introducción de productos nuevos sólo para empresa

Tabla 45: Tabla de datos de innovación en producto en IAA

\begin{tabular}{|c|c|c|c|c|c|c|c|c|c|}
\hline & \multicolumn{9}{|c|}{ IAA } \\
\hline & innprod & innobien & innoserv & desaprod & innprodm & innprodc & innprodt & novedad & novedemp \\
\hline 2003 & 243 & 0 & 0 & 0 & 223 & 42 & 4 & 121 & 0 \\
\hline 2004 & 337 & 321 & 120 & 412 & 0 & 0 & 0 & 201 & 266 \\
\hline 2005 & 446 & 417 & 161 & 552 & 0 & 0 & 0 & 246 & 357 \\
\hline 2006 & 438 & 414 & 152 & 539 & 0 & 0 & 0 & 247 & 348 \\
\hline 2007 & 386 & 361 & 114 & 474 & 0 & 0 & 0 & 220 & 315 \\
\hline 2008 & 391 & 373 & 119 & 478 & 0 & 0 & 0 & 219 & 326 \\
\hline 2009 & 397 & 376 & 113 & 486 & 0 & 0 & 0 & 221 & 323 \\
\hline 2010 & 392 & 371 & 101 & 479 & 0 & 0 & 0 & 221 & 309 \\
\hline 2011 & 307 & 292 & 88 & 359 & 0 & 0 & 0 & 173 & 245 \\
\hline 2012 & 250 & 238 & 68 & 0 & 0 & 0 & 0 & 147 & 203 \\
\hline MEDIA & & & & & & & & & \\
\hline
\end{tabular}

Fuente: PITEC

Tabla 46: Tabla de datos de innovación en producto en RESTO de empresas

\begin{tabular}{|c|c|c|c|c|c|c|c|c|c|}
\hline & \multicolumn{9}{|c|}{ RESTO } \\
\hline & innprod & innobien & innoserv & desaprod & innprodm & innprodc & innprodt & novedad & novedemp \\
\hline 2003 & 3218 & 0 & 0 & 0 & 2763 & 623 & 81 & 1581 & 0 \\
\hline 2004 & 4452 & 3699 & 2221 & 5536 & 0 & 0 & 0 & 2652 & 3402 \\
\hline 2005 & 5863 & 4758 & 2731 & 7320 & 0 & 0 & 0 & 3323 & 4502 \\
\hline 2006 & 5664 & 4644 & 2591 & 685 & 0 & 0 & 0 & 3239 & 4239 \\
\hline 2007 & 5270 & 4361 & 2372 & 6465 & 0 & 0 & 0 & 3127 & 3951 \\
\hline 2008 & 5784 & 4267 & 2365 & 6364 & 0 & 0 & 0 & 3150 & 3954 \\
\hline 2009 & 5165 & 4232 & 2360 & 6366 & 0 & 0 & 0 & 3032 & 3902 \\
\hline 2010 & 5027 & 4107 & 2343 & 6196 & 0 & 0 & 0 & 2899 & 3843 \\
\hline 2011 & 3705 & 3032 & 1770 & 4536 & 0 & 0 & 0 & 2190 & 2824 \\
\hline 2012 & 3183 & 2571 & 1400 & 0 & 0 & 0 & 0 & 1844 & 2407 \\
\hline
\end{tabular}


Tabla 47: Tabla de datos de innovación en producto en Agricultura

\begin{tabular}{|c|c|c|c|c|c|c|c|c|c|}
\hline & \multicolumn{9}{|c|}{ AGRO } \\
\hline & innprod & innobien & innoserv & desaprod & innprodm & improdc & improdt & novedad & novedemp \\
\hline 2003 & 41 & 0 & 0 & 0 & 36 & 10 & 1 & 19 & 0 \\
\hline 2004 & 57 & 53 & 23 & 73 & 0 & 0 & 0 & 35 & 39 \\
\hline 2005 & 68 & 65 & 25 & 83 & 0 & 0 & 0 & 41 & 45 \\
\hline 2006 & 75 & 69 & 25 & 98 & 0 & 0 & 0 & 47 & 48 \\
\hline 2007 & 71 & 65 & 18 & 95 & 0 & 0 & 0 & 47 & 43 \\
\hline 2008 & 63 & 57 & 24 & 84 & 0 & 0 & 0 & 40 & 37 \\
\hline 2009 & 67 & 59 & 24 & 89 & 0 & 0 & 0 & 40 & 43 \\
\hline 2010 & 62 & 53 & 23 & 77 & 0 & 0 & 0 & 3 & 42 \\
\hline 2011 & 40 & 32 & 15 & 52 & 0 & 0 & 0 & 21 & 31 \\
\hline 2012 & 33 & 25 & 13 & 0 & 0 & 0 & 0 & 17 & 24 \\
\hline
\end{tabular}

Leyenda tabla 48,49 y 50
Innproc Innovación en proceso de (t-2) a t
Innfabri Innovación en proceso de (t-2) a t: métodos de fabricación o producción
Innlogis Innovación en proceso de (t-2) a t: Logísticos
Innapoyo Innovación en proceso de (t-2) a t: actividades de apoyo para sus procesos
Innprocm Innovación de proceso desarrollada por empresa o grupo
Innprocc Inn. En proceso desarrollada en cooperación otras empresas o instituciones
Innproct Inn. En proceso desarrollada por otras empresas o instituciones
innofin Actividad innovadora en curso o no exitosa

\begin{tabular}{|c|c|c|c|c|c|c|c|c|}
\hline & \multicolumn{8}{|c|}{ IAA } \\
\hline & innproc & innfabri & innlogis & innapoyo & improcc & innproct & & innofin \\
\hline 2003 & 241 & 0 & 0 & 0 & 80 & 13 & 2003 & 306 \\
\hline 2004 & 376 & 323 & 135 & 228 & 0 & 0 & 2004 & 296 \\
\hline 2005 & 511 & 448 & 140 & 278 & 0 & 0 & 2005 & 477 \\
\hline 2006 & 525 & 449 & 132 & 279 & 0 & 0 & 2006 & 454 \\
\hline 2007 & 492 & 414 & 115 & 238 & 0 & 0 & 2007 & 394 \\
\hline 2008 & 487 & 395 & 105 & 239 & 0 & 0 & 2008 & 375 \\
\hline 2009 & 499 & 398 & 121 & 247 & 0 & 0 & 2009 & 358 \\
\hline 2010 & 483 & 387 & 127 & 250 & 0 & 0 & 2010 & 327 \\
\hline 2011 & 367 & 308 & 102 & 178 & 0 & 0 & 2011 & 310 \\
\hline 2012 & 305 & 261 & 83 & 137 & 0 & 0 & 2012 & 294 \\
\hline
\end{tabular}

Fuente: PITEC 


\begin{tabular}{|c|c|c|c|c|c|c|c|c|c|}
\hline & \multicolumn{9}{|c|}{ RESTO } \\
\hline & innproc & innfabri & innlogis & innapoyo & innprocm & improcc & innproct & & innofin \\
\hline 2003 & 2480 & 0 & 0 & 0 & 1880 & 546 & 175 & 2003 & 3905 \\
\hline 2004 & 4389 & 3699 & 221 & 5536 & 0 & 0 & 0 & 2004 & 3676 \\
\hline 2005 & 5797 & 3979 & 1328 & 3581 & 0 & 0 & 0 & 2005 & 6081 \\
\hline 2006 & 5831 & 3996 & 1202 & 3486 & 0 & 0 & 0 & 2006 & 5742 \\
\hline 2007 & 5350 & 3643 & 1131 & 3187 & 0 & 0 & 0 & 2007 & 5309 \\
\hline 2008 & 5349 & 3624 & 1167 & 3183 & 0 & 0 & 0 & 2008 & 5101 \\
\hline 2009 & 5369 & 3606 & 1133 & 3221 & 0 & 0 & 0 & 2009 & 4721 \\
\hline 2010 & 5024 & 3529 & 1100 & 3089 & 0 & 0 & 0 & 2010 & 4346 \\
\hline 2011 & 3851 & 2599 & 844 & 2274 & 0 & 0 & 0 & 2011 & 4064 \\
\hline 2012 & 3236 & 2166 & 737 & 1897 & 0 & 0 & 0 & 2012 & 3751 \\
\hline
\end{tabular}

\begin{tabular}{|c|c|c|c|c|c|c|c|c|c|}
\hline & \multicolumn{9}{|c|}{ AGRO } \\
\hline & innproc & innfabri & innlogis & innapoyo & innprocm & improcc & innproct & & innofin \\
\hline 2003 & 35 & 0 & 0 & 0 & 27 & 8 & 2 & 2003 & 75 \\
\hline 2004 & 59 & 54 & 18 & 30 & 0 & 0 & 0 & 2004 & 69 \\
\hline 2005 & 80 & 70 & 14 & 33 & 0 & 0 & 0 & 2005 & 93 \\
\hline 2006 & 99 & 83 & 14 & 48 & 0 & 0 & 0 & 2006 & 109 \\
\hline 2007 & 95 & 81 & 15 & 28 & 0 & 0 & 0 & 2007 & 102 \\
\hline 2008 & 83 & 66 & 18 & 30 & 0 & 0 & 0 & 2008 & 74 \\
\hline 2009 & 83 & 68 & 18 & 24 & 0 & 0 & 0 & 2009 & 71 \\
\hline 2010 & 81 & 66 & 14 & 25 & 0 & 0 & 0 & 2010 & 69 \\
\hline 2011 & 58 & 46 & 10 & 24 & 0 & 0 & 0 & 2011 & 65 \\
\hline 2012 & 44 & 33 & 10 & 16 & 0 & 0 & 0 & 2012 & 53 \\
\hline
\end{tabular}




\begin{tabular}{|c|c|c|c|c|c|c|c|c|c|c|}
\hline & \multicolumn{4}{|c|}{ IAA } & & \multicolumn{5}{|c|}{ IAA } \\
\hline & pat & usomodel & usomarca & usoautor & & patnum & patoepm & patepo & patuspto & patpct \\
\hline 2003 & 31 & 0 & 0 & 0 & 2003 & 71 & 44 & 24 & 4 & 9 \\
\hline 2004 & 79 & 81 & 226 & 5 & 2004 & 0 & 0 & 0 & 0 & 0 \\
\hline 2005 & 66 & 91 & 273 & 11 & 2005 & 183 & 144 & 22 & 13 & 21 \\
\hline 2006 & 58 & 82 & 250 & 9 & 2006 & 155 & 109 & 31 & 10 & 21 \\
\hline 2007 & 53 & 71 & 213 & 10 & 2007 & 117 & 98 & 13 & 9 & 9 \\
\hline 2008 & 45 & 63 & 181 & 4 & 2008 & 96 & 71 & 14 & 5 & 17 \\
\hline 2009 & 40 & 51 & 182 & 6 & 2009 & 104 & 55 & 30 & 10 & 20 \\
\hline 2010 & 43 & 47 & 150 & 2 & 2010 & 88 & 51 & 24 & 9 & 10 \\
\hline 2011 & 41 & 43 & 147 & 0 & 2011 & 106 & 48 & 28 & 10 & 31 \\
\hline 2012 & 33 & 31 & 123 & 1 & 2012 & 108 & 46 & 35 & 20 & 28 \\
\hline
\end{tabular}

\begin{tabular}{|c|c|c|c|c|c|c|c|c|c|c|}
\hline & \multicolumn{4}{|c|}{ RESTO } & & \multicolumn{5}{|c|}{ RESTO } \\
\hline & pat & usomodel & usomarca & usoautor & & patnum & patoepm & patepo & patuspto & patpct \\
\hline 2003 & 929 & 0 & 0 & 0 & 2003 & 3975 & 2552 & 944 & 355 & 645 \\
\hline 2004 & 1452 & 973 & 1861 & 246 & 2004 & 0 & 0 & 0 & 0 & 0 \\
\hline 2005 & 1365 & 1052 & 2255 & 244 & 2005 & 5142 & 3146 & 1350 & 640 & 824 \\
\hline 2006 & 1233 & 936 & 2006 & 218 & 2006 & 4767 & 2950 & 1224 & 531 & 778 \\
\hline 2007 & 1124 & 817 & 1778 & 154 & 2007 & 5453 & 3365 & 1497 & 677 & 971 \\
\hline 2008 & 1058 & 672 & 1637 & 160 & 2008 & 6412 & 4031 & 1514 & 654 & 1097 \\
\hline 2009 & 970 & 632 & 1486 & 144 & 5098 & 5098 & 2827 & 1490 & 591 & 1146 \\
\hline 2010 & 905 & 592 & 1407 & 122 & 2010 & 4993 & 2814 & 1408 & 586 & 1157 \\
\hline 2011 & 834 & 529 & 1241 & 128 & 2011 & 4412 & 2441 & 1237 & 504 & 895 \\
\hline 2012 & 778 & 383 & 1029 & 106 & 2012 & 4227 & 2393 & 1371 & 517 & 747 \\
\hline
\end{tabular}

\begin{tabular}{|c|c|c|c|c|c|c|c|c|c|c|}
\hline & \multicolumn{4}{|c|}{ AGRO } & & \multicolumn{5}{|c|}{ AGRO } \\
\hline & pat & usomodel & usomarca & usoautor & & patnum & patoepm & patepo & patuspto & patpct \\
\hline 2003 & 8 & 0 & 0 & 0 & 2003 & 10 & 10 & 1 & 1 & 0 \\
\hline 2004 & 20 & 8 & 25 & 3 & 2004 & 0 & 0 & 0 & 0 & 0 \\
\hline 2005 & 13 & 12 & 29 & 4 & 2005 & 60 & 17 & 40 & 3 & 0 \\
\hline 2006 & 11 & 10 & 34 & 3 & 2006 & 24 & 22 & 3 & 0 & 0 \\
\hline 2007 & 16 & 6 & 33 & 1 & 2007 & 64 & 19 & 45 & 0 & 0 \\
\hline 2008 & 12 & 4 & 25 & 3 & 2008 & 24 & 17 & 7 & 0 & 0 \\
\hline 2009 & 11 & 3 & 17 & 3 & 2009 & 53 & 11 & 42 & 0 & 0 \\
\hline 2010 & 13 & 2 & 14 & 4 & 2010 & 70 & 25 & 45 & 0 & 0 \\
\hline 2011 & 9 & 2 & 15 & 1 & 2011 & 49 & 20 & 29 & 0 & 0 \\
\hline 2012 & 8 & 2 & 10 & 3 & 2012 & 49 & 10 & 39 & 0 & 0 \\
\hline
\end{tabular}

Fuente: PITEC 
APÉNDICE 5: Salidas del programa estadístico R. Caso empírico 2

\section{Regresión binomial negativa. Todas las empresas agroalimentarias}

Call:

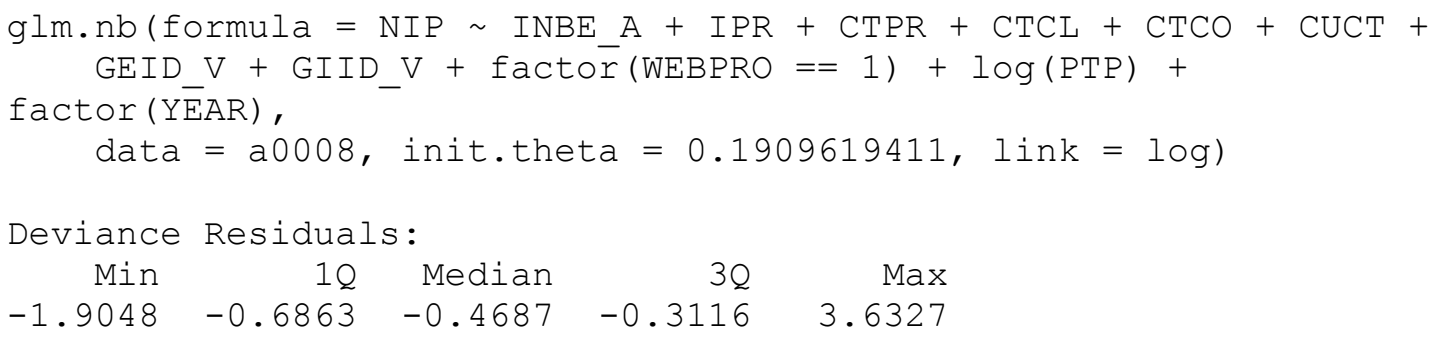

Coefficients:

\begin{tabular}{|c|c|c|c|c|c|}
\hline (Intercept) & $\begin{array}{l}\text { Estimate } \\
-3.66026\end{array}$ & $\begin{array}{r}\text { Std. Error } \\
0.31584\end{array}$ & $\begin{array}{l}\text { z value } \\
-11.589\end{array}$ & $\begin{array}{l}\operatorname{Pr}(>x z x) \\
<2 e-16\end{array}$ & $\star \star \star$ \\
\hline INBE_A & 2.73735 & 0.99692 & 2.746 & 0.006036 & $\star \star$ \\
\hline IPR & 1.55620 & 0.14815 & 10.504 & $<2 e-16$ & $\star \star$ \\
\hline TPR & 0.44238 & 0.20541 & 2.154 & 0.031270 & * \\
\hline TCL & 0.14872 & 0.27269 & 0.545 & 0.585498 & \\
\hline $\mathrm{TCO}$ & -0.55838 & 0.49750 & $-1 \cdot 122$ & 0.261711 & \\
\hline CUCT & -0.28816 & 0.17875 & -1.612 & 0.106950 & \\
\hline GEID_V & 3.8801 & 10.91595 & 0.355 & 0.722245 & \\
\hline GIID_V & 68.04729 & 11.70081 & 5.816 & $6.04 e-09$ & $\star \star$ \\
\hline factor (WEBPRO == 1) TRUE & $0.665^{7}$ & 0.17347 & 3.838 & 0.000124 & $\star \star$ \\
\hline $\log (\mathrm{PTP})$ & 0.460 & 0.05551 & 8.304 & $<2 e-16$ & $\star \star$ \\
\hline factor (YEAR) 2001 & -0.397 & 0.28425 & $-1 \cdot 398$ & 0.162057 & \\
\hline factor (YEAR) 2002 & -0.206 & 0.28523 & -0.723 & 0.469779 & \\
\hline factor (YEAR) 2003 & -0.669 & 0.30 & -2.199 & 0.027850 & * \\
\hline factor (YEAR) 2004 & -0.351 & 0.25 & -1.184 & 0.25 & \\
\hline factor (YEAR) 2005 & -0.146 & 0.29826 & -0.492 & 0.622930 & \\
\hline factor (YEAR) 2006 & -0.3 & 0 . & $-1 \cdot 1$ & 0.2 & \\
\hline factor (YEAR) 2007 & $-1 \cdot 2$ & 0 . & -4.2 & $1.86 e-05$ & $\star \star$ \\
\hline factor (YEAR) 2008 & -0.7 & 0.2 & -2.8 & 0.004460 & $\star \star$ \\
\hline
\end{tabular}

(Dispersion parameter for Negative Binomial(0.191) family taken to be 1)

Null deviance: 1442.78 on 1891 degrees of freedom Residual deviance: 913.48 on 1873 degrees of freedom

(25982 observations deleted due to missingness) AIC: 3433.7

Number of Fisher Scoring iterations: 1

Theta: 0.1910

Std. Err.: 0.0143

$2 \times$ log-likelihood: $\quad-3393.6670$

[1] 0.2275137 
Analysis of Deviance Table

Model: Negative Binomial(0.191), link: log

Response: NIP

Terms added sequentially (first to last)

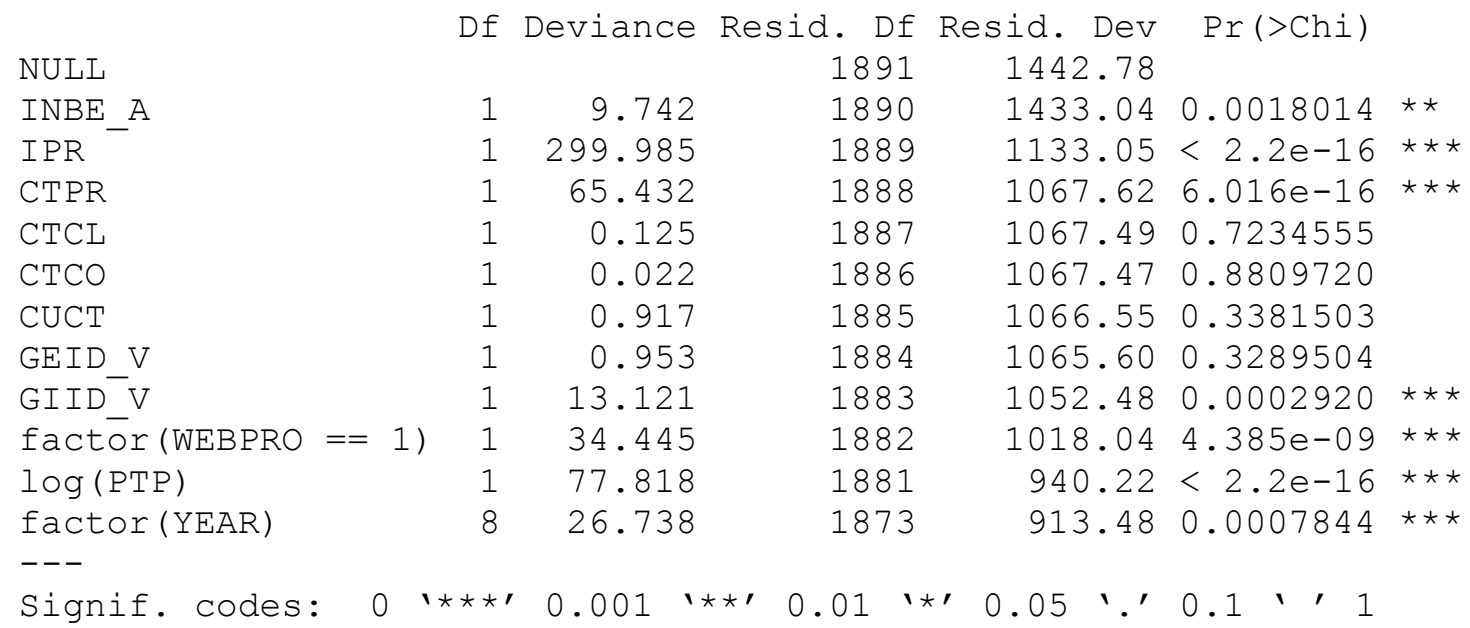




\section{Regresión binomial negativa. PYMES agroalimentarias}

Call:

glm.nb formula $=\mathrm{NIP} \sim \mathrm{INBE} A+\mathrm{IPR}+\mathrm{CTPR}+\mathrm{CTCL}+\mathrm{CTCO}+\mathrm{CUCT}+$ GEID_V + GIID_V + factor $(2$ - WEBPRO) + log(PTP) + factor(YEAR), data $=$ a0008, subset $=$ a0008\$PTP $<=200$, init. theta $=$ 0.125808764 ,

link = log)

Deviance Residuals:

$\begin{array}{rrrrr}\text { Min } & 1 Q & \text { Median } & 3 Q & \text { Max } \\ -1.3741 & -0.5499 & -0.3530 & -0.2256 & 2.8996\end{array}$

Coefficients:

\begin{tabular}{|c|c|c|c|c|c|}
\hline (Intercept) & $\begin{array}{r}\text { Estimate } \\
-4.166 e+00\end{array}$ & $\begin{array}{r}\text { Std. Error } \\
5.629 e-01\end{array}$ & $\begin{array}{r}\text { z value } \\
-7.402\end{array}$ & $\begin{array}{l}\operatorname{Pr}(>x z x) \\
1.34 e-13\end{array}$ & $\star \star \star$ \\
\hline INBE_A & $3.651 e+00$ & $1.340 e+00$ & 2.725 & 0.00643 & $\star \star$ \\
\hline IPR & $1.681 e+00$ & $2.437 e-01$ & 6.900 & $5.18 e-12$ & $\star \star \star$ \\
\hline CTPR & $1.760 e-01$ & $5.189 e-01$ & 0.339 & 0.73439 & \\
\hline CTCL & $1.005 e+00$ & $6.765 e-01$ & 1.485 & 0.13749 & \\
\hline $\mathrm{CTCO}$ & $-3.873 e+01$ & $1.432 e+07$ & 0.000 & 1.00000 & \\
\hline CUCT & $-9.190 e-01$ & $3.516 e-01$ & -2.613 & 0.00897 & $\star \star$ \\
\hline GEID_V & $2.894 e+01$ & $1.536 e+01$ & 1.884 & 0.05954 & . \\
\hline GIID_V & $1.029 e+02$ & $1.964 e+01$ & 5.238 & $1.62 e-07$ & $\star \star \star$ \\
\hline factor $(2-$ WEBPRO $) 1$ & $1.559 e+00$ & $2.724 e-01$ & 5.725 & $1.04 e-08$ & $\star \star \star$ \\
\hline $\log (\mathrm{PTP})$ & $5.474 e-01$ & $1.392 e-01$ & 3.931 & $8.44 e-05$ & $\star \star \star$ \\
\hline factor (YEAR) 2001 & $-1.084 e+00$ & $4.688 e-01$ & -2.312 & 0.02075 & $\star$ \\
\hline factor (YEAR) 2002 & $-5.940 e-01$ & $4.451 e-01$ & -1.334 & 0.18205 & \\
\hline factor (YEAR) 2003 & $-9.144 e-01$ & $4.759 e-01$ & $-1 \cdot 922$ & 0.05467 & . \\
\hline factor (YEAR) 2004 & $-6.216 e-01$ & $4.620 e-01$ & -1.345 & 0.17852 & \\
\hline factor (YEAR) 2005 & $-3.046 e-01$ & $4.512 e-01$ & -0.675 & 0.49971 & \\
\hline factor (YEAR) 2006 & $-9.012 e-01$ & $4.353 e-01$ & -2.070 & 0.03846 & $\star$ \\
\hline factor (YEAR) 2007 & $-2.362 e+00$ & $4.732 e-01$ & -4.991 & $6.01 e-07$ & $\star \star \star$ \\
\hline $\begin{array}{l}\text { factor (YEAR) } 2008 \\
---\end{array}$ & $-1.683 e+00$ & $4.323 e-01$ & -3.893 & $9.90 e-05$ & $\star \star \star$ \\
\hline
\end{tabular}

(Dispersion parameter for Negative Binomial(0.1258) family taken to be 1)

Null deviance: 626.57 on 1279 degrees of freedom Residual deviance: 394.44 on 1261 degrees of freedom

(25944 observations deleted due to missingness)

AIC : 1452

Number of Fisher Scoring iterations: 1

Theta: 0.1258

Std. Err.: 0.0151

Warning while fitting theta: alternation limit reached

$2 \times$ log-likelihood: $\quad-1411.9630$

[1] 0.1250329

Analysis of Deviance Table 
Model: Negative Binomial(0.1258), link: log

Response: NIP

Terms added sequentially (first to last)

\begin{tabular}{|c|c|c|c|c|c|c|}
\hline NULL & Df & Deviance & $\begin{array}{r}\text { Resid. Df } \\
1279\end{array}$ & $\begin{array}{r}\text { Resid. Dev } \\
626.57\end{array}$ & $\operatorname{Pr}(>\operatorname{Ch} i)$ & \\
\hline INBE_A & 1 & 19.286 & 1278 & 607.29 & $1.125 e-05$ & $\star \star \star$ \\
\hline IPR & 1 & 72.769 & 1277 & 534.52 & $<2.2 e-16$ & $\star \star \star$ \\
\hline CTPR & 1 & 16.935 & 1276 & 517.58 & $3.869 e-05$ & $\star \star \star$ \\
\hline CTCL & 1 & 1.676 & 1275 & 515.91 & 0.195478 & \\
\hline СTCO & 1 & 3.717 & 1274 & 512.19 & 0.053870 & . \\
\hline CUCT & 1 & 0.303 & 1273 & 511.89 & 0.582167 & \\
\hline GEID_V & 1 & 7.584 & 1272 & 504.31 & 0.005890 & $\star \star$ \\
\hline GIID_V & 1 & 7.328 & 1271 & 496.98 & 0.006788 & $\star \star$ \\
\hline factor (2 - WEBPRO) & 1 & 47.592 & 1270 & 449.39 & $5.248 e-12$ & $\star \star \star$ \\
\hline $\log (\mathrm{PTP})$ & 1 & 20.423 & 1269 & 428.96 & $6.207 e-06$ & $\star \star \star$ \\
\hline $\begin{array}{l}\text { factor (YEAR) } \\
---\end{array}$ & 8 & 34.523 & 1261 & 394.44 & $3.266 e-05$ & $\star \star \star$ \\
\hline
\end{tabular}




\section{Regresión binomial negativa. GRANDES agroalimentarias}

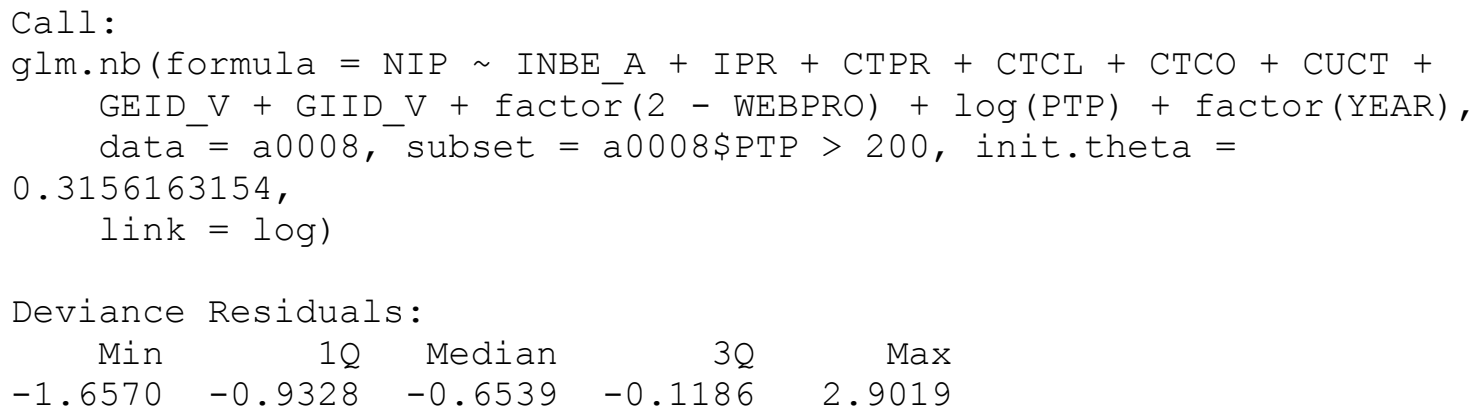

Coefficients:

\begin{tabular}{|c|c|c|c|c|c|}
\hline (Intercept) & $\begin{array}{l}\text { Estimate } \\
-4.34580\end{array}$ & $\begin{array}{r}\text { Std. Error } \\
0.86514\end{array}$ & $\begin{array}{l}\text { z value } \\
-5.023\end{array}$ & $\begin{array}{l}\operatorname{Pr}(>x z x) \\
5.08 e-07\end{array}$ & $\star \star \star$ \\
\hline INBE_A & 1.40542 & 1.93485 & 0.726 & 0.467613 & \\
\hline IPR & 1.63039 & 0.18625 & 8.754 & $<2 e-16$ & $\star \star \star$ \\
\hline TPR & 0.91306 & 0.20235 & 4.512 & $6.41 e-06$ & $\star \star \star$ \\
\hline CTCL & -0.41413 & 0.26287 & -1.575 & 0.115170 & \\
\hline $\mathrm{TCO}$ & -0.06261 & 0.45493 & -0.138 & 0.890540 & \\
\hline CUCT & 0.07685 & 0.19659 & 0.391 & 0.695855 & \\
\hline EID_V & 2.47063 & 15.28036 & 0.162 & 0.871552 & \\
\hline $\mathrm{IID}_{-}^{-} \mathrm{V}$ & 14.24039 & 15.18710 & 0.938 & 0.348417 & \\
\hline $\operatorname{actor}(2-$ WEBPRO $) 1$ & -0.42906 & 0.24071 & -1.782 & 0.074669 & . \\
\hline og ( PTP) & 0.67475 & 0.13597 & 4.963 & $6.96 e-07$ & $\star \star \star$ \\
\hline actor (YEAR) 2001 & -0.36734 & 0.34451 & -1.066 & 0.286303 & \\
\hline actor (YEAR) 2002 & -0.44169 & 0.35894 & -1.231 & 0.218493 & \\
\hline actor (YEAR) 2003 & -1.19906 & 0.38407 & -3.122 & 0.001796 & $\star \star$ \\
\hline factor (YEAR) 2004 & -0.79395 & 0.37089 & -2.141 & 0.032303 & * \\
\hline actor (YEAR) 2005 & -1.35071 & 0.40187 & -3.361 & 0.000776 & $\star \star \star$ \\
\hline factor (YEAR) 2006 & -0.40359 & 0.35357 & -1.141 & 0.253670 & \\
\hline $\operatorname{actor}(\mathrm{YEAR}) 2007$ & -0.71424 & 0.34 & -2.047 & 0.040702 & * \\
\hline $\begin{array}{l}\text { factor (YEAR) } 2008 \\
---\end{array}$ & -0.38908 & 0.33990 & -1.145 & 0.252348 & \\
\hline
\end{tabular}

(Dispersion parameter for Negative Binomial(0.3156) family taken to be 1$)$

Null deviance: 659.87 on 611 degrees of freedom Residual deviance: 473.78 on 593 degrees of freedom (25938 observations deleted due to missingness) AIC : 1911.6

Number of Fisher Scoring iterations: 1

Theta: 0.3156

Std. Err.: 0.0305

Warning while fitting theta: alternation limit reached

$2 \times$ log-likelihood: $\quad-1871.5530$

[1] 0.09184589 
Analysis of Deviance Table

Model: Negative Binomial(0.3156), link: log

Response: NIP

Terms added sequentially (first to last)

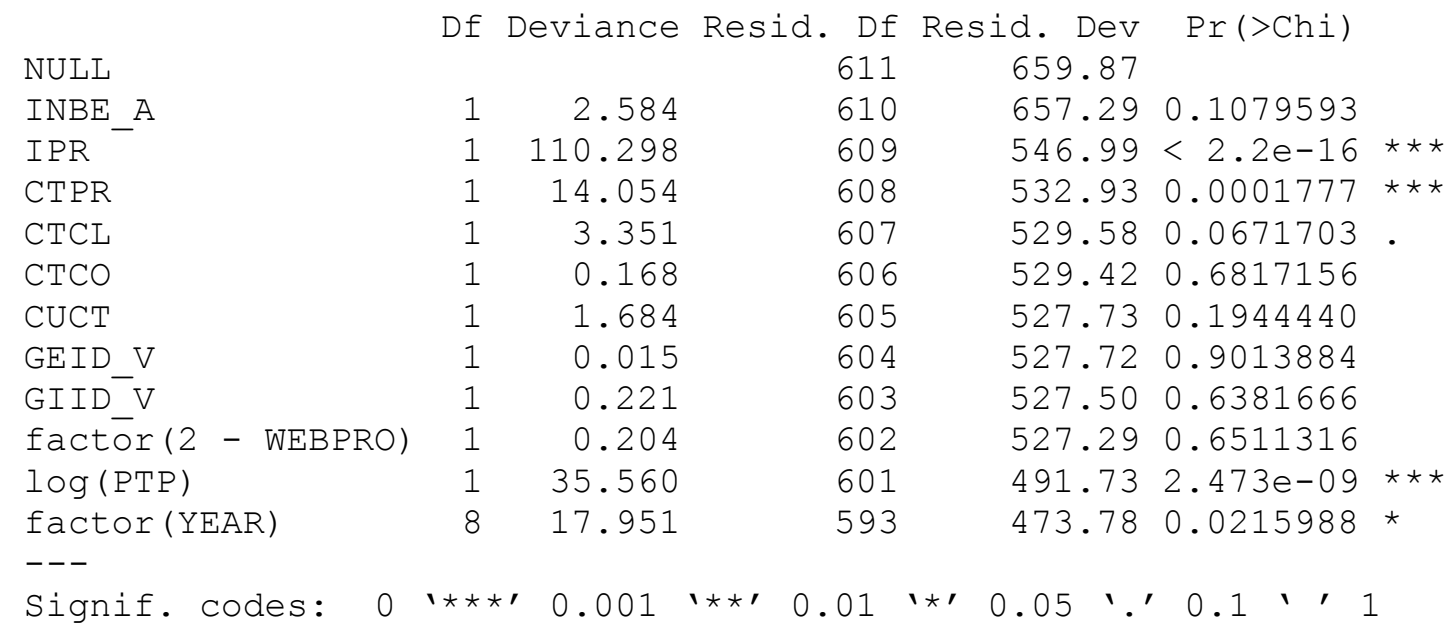




\section{Regresión Hurdle. TODAS agroalimentarias}

\section{Call:}

hurdle formula $=$ NIP $\sim$ IPR $+\log (P T P) \times I N B E \_A+I P R+$ CTPR + CTCL $+$

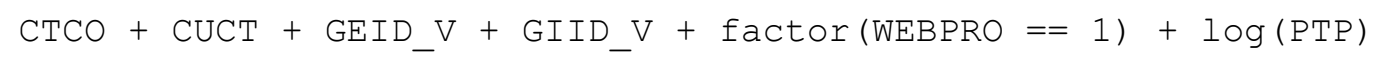

Count model coefficients (truncated negbin with log link): Estimate std. Error z value Pr(>xzx)

\begin{tabular}{|c|c|c|c|c|c|}
\hline (Intercept) & -0.55272 & 0.35745 & -1.546 & 22034 & \\
\hline IPR & 0.38248 & 0.1898 & & 3931 & * \\
\hline P) & & & & $\pi$ & $\star \star \star$ \\
\hline (theta) & -1 & 0 . & -3 & & \\
\hline
\end{tabular}

Zero hurdle model coefficients (binomial with probit link):

\begin{tabular}{|c|c|c|c|c|c|}
\hline (Intercept) & $\begin{array}{l}\text { Estimate } \\
-2.09924\end{array}$ & $\begin{array}{r}\text { Std. Error } \\
0.17613\end{array}$ & $\begin{array}{l}\text { z value } \\
-11.918\end{array}$ & $\begin{array}{r}\operatorname{Pr}(>x z x) \\
<2 e-16\end{array}$ & $\star \star \star$ \\
\hline INBE_A & 1.45553 & 0.58006 & 2.509 & 0.012098 & * \\
\hline IPR & 0.92182 & 0.08248 & 11.177 & $<2 e-16$ & $\star \star \star$ \\
\hline CTPR & 0.62914 & 0.11137 & 5.649 & $1.61 e-08$ & $\star \star \star$ \\
\hline CTCL & 0.10608 & 0.14942 & 0.710 & 0.477725 & \\
\hline $\mathrm{CTCO}$ & -0.35392 & 0.26350 & -1.343 & 0.179228 & \\
\hline CUCT & 0.11388 & 0.09668 & 1.178 & 0.238844 & \\
\hline GEID V & 3.1355 & 6.13101 & 0.511 & 0.609056 & \\
\hline GIID_V & 23.21943 & 6.45673 & 3.596 & 0.000323 & $\star \star \star$ \\
\hline factor (WEBPRO == 1) TRUE & 0.2950 & 0.10067 & 2.931 & 0.003382 & $\star \star$ \\
\hline $\log (\mathrm{PTP})$ & 0.16021 & 0.03166 & 5.060 & $4.18 e-07$ & $\star \star \star$ \\
\hline factor (YEAR) 2001 & -0.4046 & 0.15979 & -2.532 & 0.011326 & * \\
\hline factor (YEAR) 2002 & -0.2688 & 0.16027 & -1.678 & 0.093400 & . \\
\hline factor (YEAR) 2003 & -0.581 & 0.17477 & -3.328 & 0.000875 & $\star \star \star$ \\
\hline factor (YEAR) 2004 & -0.2913 & 0.16553 & -1.760 & 0.078380 & • \\
\hline factor (YEAR) 2005 & -0.4300 & 0.17138 & -2.509 & 0.012107 & * \\
\hline factor (YEAR) 2006 & -0.52982 & 0.16107 & -3.289 & 0.001004 & $\star \star$ \\
\hline factor (YEAR) 2007 & -0.7406 & 0.15841 & -4.676 & $2.93 e-06$ & $\star \star \star$ \\
\hline factor (YEAR) 2008 & -0.56700 & 0.15234 & -3.722 & 0.000198 & $\star \star \star$ \\
\hline 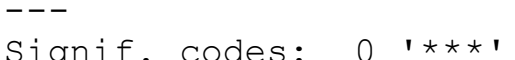 & & & & & \\
\hline
\end{tabular}

Theta: count $=0.3233$

Number of iterations in BFGS optimization: 19 Log-likelihood: -1595 on 23 Df

[1] 0.2730279 


\section{Regresión Hurdle. PYMES agroalimentarias}

Call:

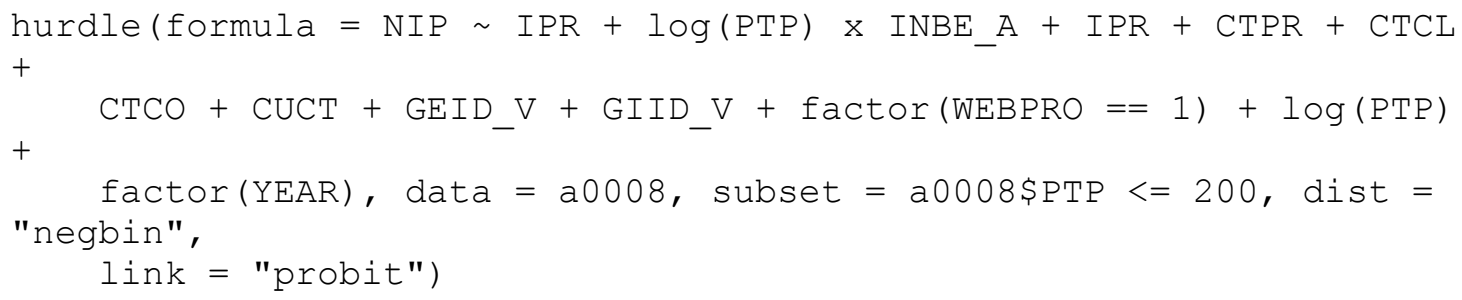

Count model coefficients (truncated negbin with log link): Estimate Std. Error z value Pr(>xzx)

$\begin{array}{lrrrr}\text { (Intercept) } & 0.53006 & 0.65414 & 0.810 & 0.4178 \\ \text { IPR } & -0.24753 & 0.26500 & -0.934 & 0.3503 \\ \text { Iog (PTP) } & 0.08855 & 0.13802 & 0.642 & 0.5211 \\ \text { Log (theta) } & -0.89863 & 0.49258 & -1.824 & 0.0681 .\end{array}$

Zero hurdle model coefficients (binomial with probit link):

\begin{tabular}{|c|c|c|c|c|c|}
\hline (Intercept) & $\begin{array}{l}\text { Estimate } \\
-2.42312\end{array}$ & $\begin{array}{r}\text { Std. Error } \\
0.27680\end{array}$ & $\begin{array}{r}\text { z value } \\
-8.754\end{array}$ & $\begin{array}{l}\operatorname{Pr}(>x z x) \\
<2 e-16\end{array}$ & $\star \star \star$ \\
\hline INBE_A & 0.85358 & 0.68929 & 1.238 & 0.215586 & \\
\hline IPR & 1.09892 & 0.11700 & 9.392 & $<2 e-16$ & $\star \star \star$ \\
\hline CTPR & 0.80573 & 0.23942 & 3.365 & 0.000765 & $\star \star \star$ \\
\hline CTCL & 0.05118 & 0.31214 & 0.164 & 0.869757 & \\
\hline $\mathrm{CTCO}$ & -6.69904 & 189.11535 & -0.035 & 0.971742 & \\
\hline CUCT & -0.09531 & 0.15891 & -0.600 & 0.548645 & \\
\hline GEID_V & 2.64682 & 10.09865 & 0.262 & 0.793247 & \\
\hline GIID_V & 40.69410 & 10.23294 & 3.977 & $6.99 e-05$ & $\star \star \star$ \\
\hline factor (WEBPRO == 1) TRUE & 0.41610 & 0.13718 & 3.033 & 0.002419 & $\star \star$ \\
\hline $\log (\mathrm{PTP})$ & 0.22322 & 0.06885 & 3.242 & 0.001186 & $\star \star$ \\
\hline factor (YEAR) 2001 & -0.41776 & 0.22975 & -1.818 & 0.069015 & - \\
\hline factor (YEAR) 2002 & -0.30973 & 0.22212 & -1.394 & 0.163194 & \\
\hline factor (YEAR) 2003 & -0.38555 & 0.23841 & -1.617 & 0.105840 & \\
\hline factor (YEAR) 2004 & -0.24316 & 0.22930 & -1.060 & 0.288954 & \\
\hline factor (YEAR) 2005 & -0.17633 & 0.22462 & -0.785 & 0.432447 & \\
\hline factor (YEAR) 2006 & -0.53432 & 0.22283 & -2.398 & 0.016492 & * \\
\hline factor (YEAR) 2007 & -0.95844 & 0.22884 & -4.188 & $2.81 e-05$ & $\star \star \star$ \\
\hline $\begin{array}{l}\text { factor (YEAR) } 2008 \\
---\end{array}$ & -0.68959 & 0.21024 & -3.280 & 0.001038 & $\star \star$ \\
\hline
\end{tabular}

Theta: count $=0.4071$

Number of iterations in BFGS optimization: 29 Log-likelihood: -655.1 on 23 Df

[1] 0.1889608 


\section{Regresión Hurdle. GRANDES agroalimentarias}

Call:

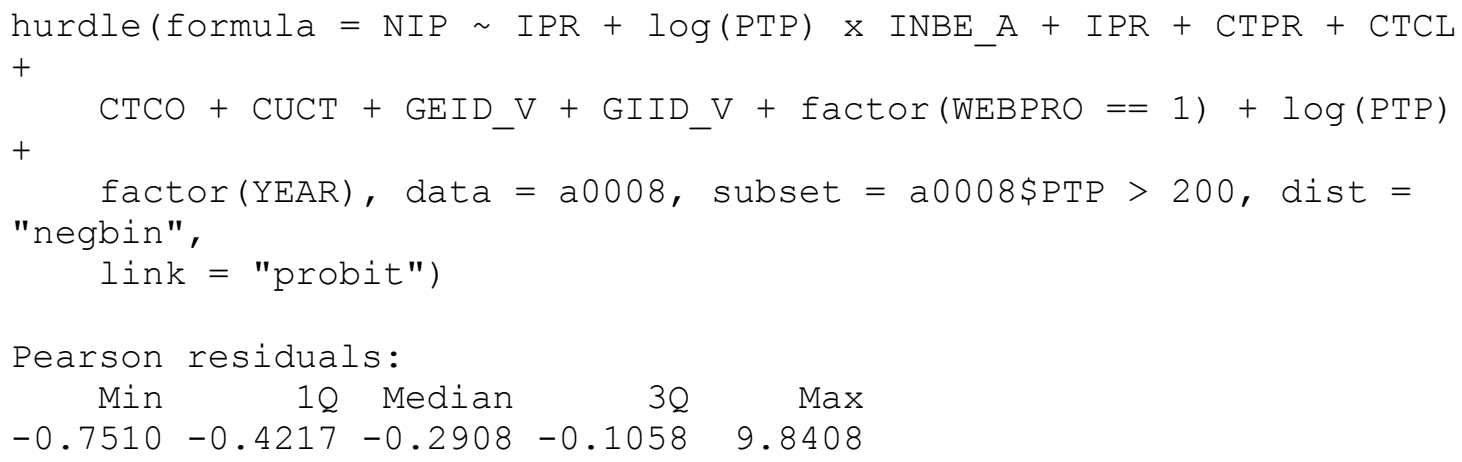

Count model coefficients (truncated negbin with log link): Estimate Std. Error z value Pr(>xzx)

$\begin{array}{lrrrr}\text { (Intercept) } & -2.7362 & 0.8859 & -3.089 & 0.002011 \\ \text { IPR } & 1.0309 & 0.2367 & 4.356 & 1.33 e-05 \\ \text { Iog (PTP) } & 0.4793 & 0.1303 & 3.677 & 0.000236 \\ \text { Log (theta) } & -0.9095 & 0.3142 & -2.895 & 0.003796\end{array}$

Zero hurdle model coefficients (binomial with probit link):

\begin{tabular}{|c|c|c|c|c|c|}
\hline (Intercept) & $\begin{array}{l}\text { Estimate } \\
-2.18078\end{array}$ & $\begin{array}{r}\text { Std. Error } \\
0.59335\end{array}$ & $\begin{array}{r}\text { z value } \\
-3.675\end{array}$ & $\begin{array}{l}\operatorname{Pr}(>x z x) \\
0.000237\end{array}$ & $\star \star \star$ \\
\hline INBE_A & 2.21355 & 1.32969 & 1.665 & 0.095970 & . \\
\hline IPR & 0.76628 & 0.12171 & 6.296 & $3.05 e-10$ & $\star \star \star$ \\
\hline CTPR & 0.67856 & 0.13417 & 5.057 & $4.25 e-07$ & $\star \star \star$ \\
\hline CTCL & 0.06067 & 0.17656 & 0.344 & 0.731119 & \\
\hline СTCO & -0.09095 & 0.30752 & -0.296 & 0.767423 & \\
\hline CUCT & 0.19936 & 0.12919 & 1.543 & 0.122805 & \\
\hline GEID_V & 9.12544 & 8.52187 & 1.071 & 0.284248 & \\
\hline GIID_V & 9.27911 & 10.28246 & 0.902 & 0.366833 & \\
\hline factor (WEBPRO == 1) TRUE & 0.03445 & 0.16319 & 0.211 & 0.832810 & \\
\hline $\log (\mathrm{PTP})$ & 0.21542 & 0.09380 & 2.297 & 0.021645 & * \\
\hline factor (YEAR) 2001 & -0.46104 & 0.23544 & -1.958 & 0.050208 & . \\
\hline factor (YEAR) 2002 & -0.27064 & 0.24472 & -1.106 & 0.268755 & \\
\hline factor (YEAR) 2003 & -0.80408 & 0.26006 & -3.092 & 0.001989 & $\star \star$ \\
\hline factor (YEAR) 2004 & -0.36270 & 0.24860 & -1.459 & 0.144575 & \\
\hline factor (YEAR) 2005 & -0.78799 & 0.26757 & -2.945 & 0.003229 & $\star \star$ \\
\hline factor (YEAR) 2006 & -0.56613 & 0.24255 & -2.334 & 0.019594 & * \\
\hline factor (YEAR) 2007 & -0.63189 & 0.23985 & -2.635 & 0.008425 & $\star \star$ \\
\hline factor (YEAR) 2008 & -0.48599 & 0.23496 & -2.068 & 0.038606 & * \\
\hline
\end{tabular}

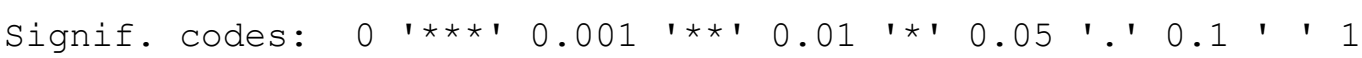

Theta: count $=0.4027$

Number of iterations in BFGS optimization: 16 Log-likelihood: -913.3 on 23 Df

[1] 0.1136178 


\section{APÉNDICE 6: Salidas del programa estadístico R. Caso empírico 3.}

\section{Regresión Logit. TODAS agroalimentarias: patentes}

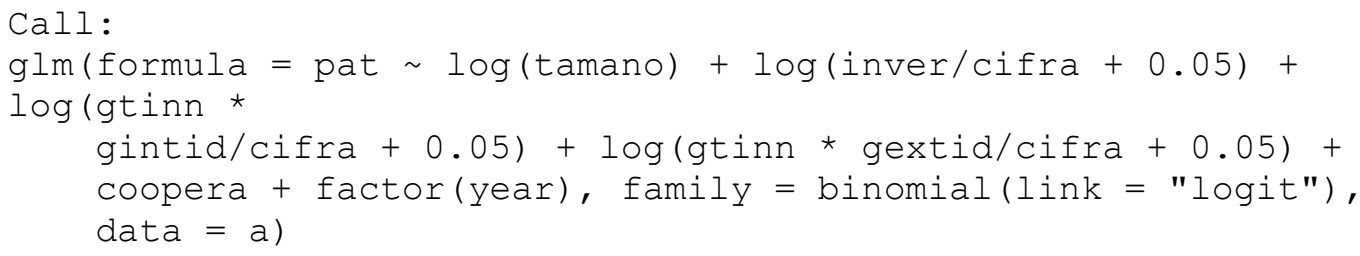

Coefficients:

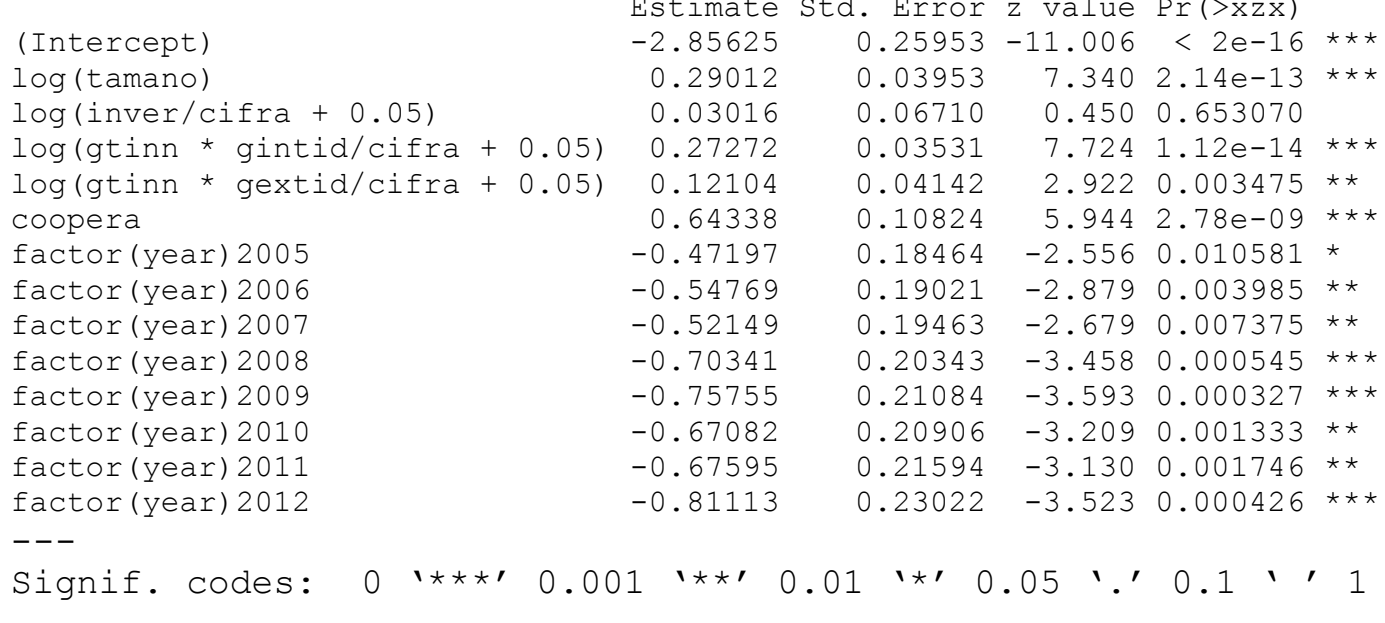

(Dispersion parameter for binomial family taken to be 1)

Null deviance: 3051.4 on 5139 degrees of freedom Residual deviance: 2804.5 on 5126 degrees of freedom

(1382 observations deleted due to missingness)

AIC: 2832.5

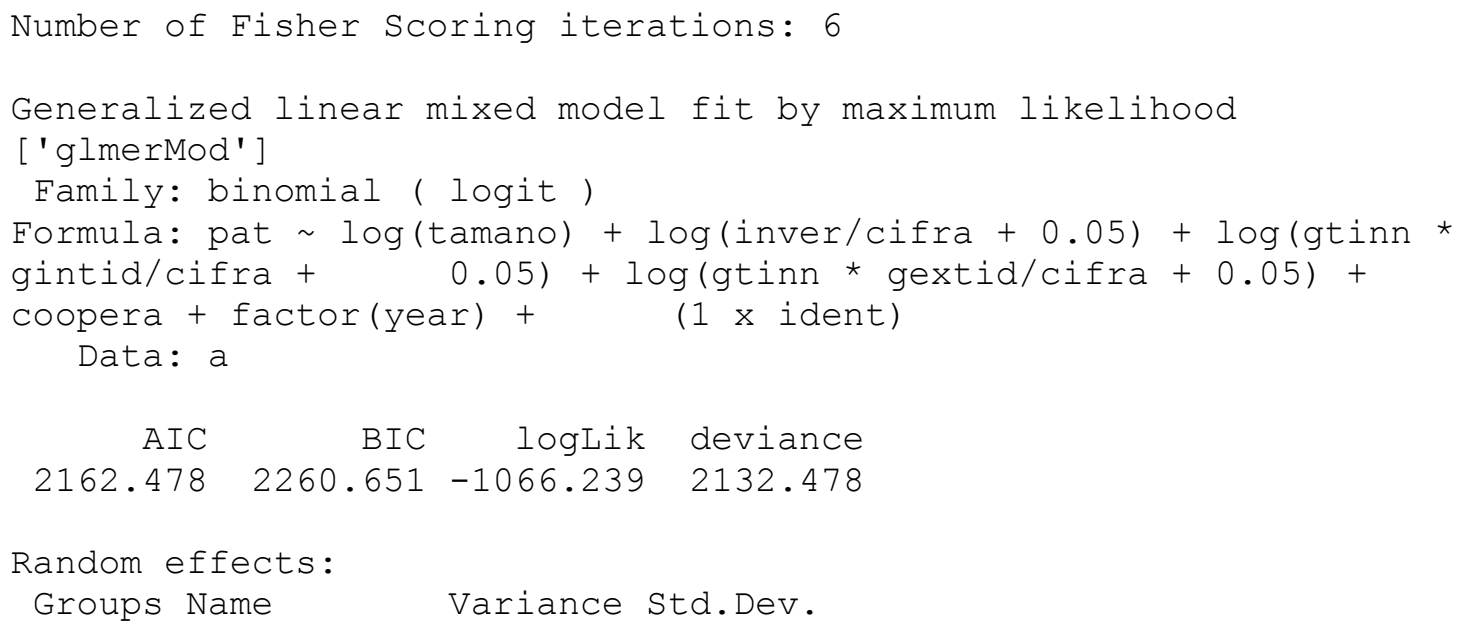


ident (Intercept) $6.953 \quad 2.637$

Number of obs: 5140, groups: ident, 797

Fixed effects:

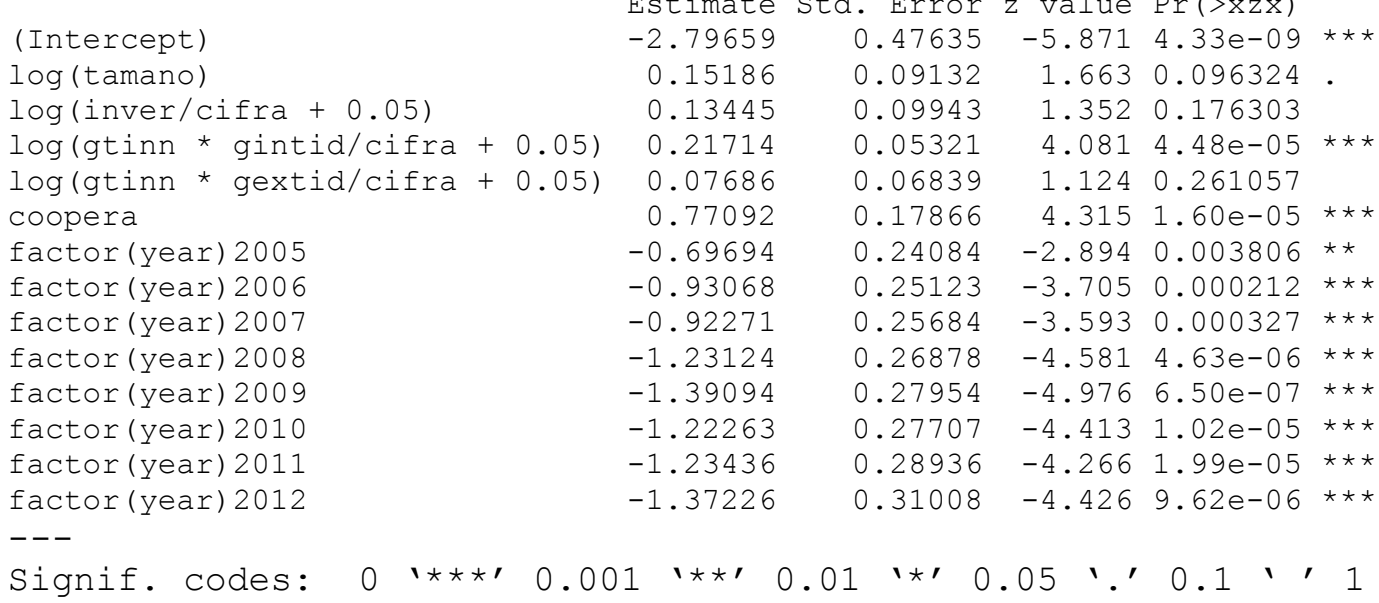

Correlation of Fixed Effects:

(Intr) $\lg (\mathrm{tm}) \quad l(/+0 . \lg (* g n /+0.05) \quad \lg (* g x /+0.05)$ cooper $f() 2005$

$\log ($ tamano $) \quad-0.715$

$\lg (\mathrm{n} /+0.05) \quad 0.370 \quad 0.075$

$\lg (* g n /+0.05)-0.2520 .165-0.240$

$\lg (* g x /+0.05) \quad 0.212 \quad 0.104 \quad-0.052-0.231$

coopera $\quad-0.134-0.123-0.016-0.060$

$\begin{array}{llllll}\text { fctr }(y) 2005 & -0.261 & 0.008 & -0.041 & -0.015\end{array}$

fctr $(y) 2006 \quad-0.226 \quad 0.004 \quad 0.015 \quad 0.040$

$\begin{array}{lllll}\text { fetr }(y) 2007 & -0.216 & -0.006 & 0.004 & 0.041\end{array}$

$\begin{array}{lllll}f \operatorname{ctr}(\mathrm{y}) 2008 & -0.187 & -0.014 & 0.028 & 0.019\end{array}$

fctr(y)2009 $-0.171-0.001 \quad 0.064 \quad 0.048$

$\begin{array}{lllll}\text { fctr }(y) 2010 & -0.171 & 0.005 & 0.077 & 0.057\end{array}$

fctr $(\mathrm{y}) 2011 \quad-0.152 \quad-0.006 \quad 0.082 \quad 0.049$

fctr $(y) 2012$

$\begin{array}{llll}-0.134 & -0.014 & 0.073 & 0.056\end{array}$

$-0.172$

0.021

$-0.023$

0.010

0.001

$-0.005$

0.000

$-0.001$

0.007

$f() 2006 f() 2007$ f() 2008 f() 2009 f() 2010 f() 2011

$\begin{array}{rr}-0.019 & \\ -0.040 & 0.483 \\ 0.009 & 0.470 \\ -0.014 & 0.448 \\ -0.026 & 0.429 \\ -0.028 & 0.432 \\ -0.033 & 0.413 \\ -0.028 & 0.384\end{array}$

$\log ($ tamano $)$

$\lg (\mathrm{n} /+0.05)$

$\lg (* g n /+0.05)$

$\lg (* g x /+0.05)$

coopera

fetr (y) 2005

fetr (y) 2006

fetr (y) 2007

fetr (y) 2008

fctr (y) 2009

fetr (y) 2010

fetr (y) 2011

0.463

0.442

0.429

0.433

0.415

0.441

fetr(y) 2012

0.426

0.429

0.411

0.419

0.386

$\begin{array}{ll}0.383 & 0.377\end{array}$

0.420

0.403

$\begin{array}{ll}0.377 & 0.387\end{array}$

0.380

[1] 0.1542496

[1] 0.3569152 
Regresión Logit. TODAS agroalimentarias: modelos de utilidad

Call:

glm(formula $=$ usomodel $\log ($ tamano $)+\log ($ inver/cifra +0.05$)+$ $\log ($ gtinn * gintid/cifra + 0.05) + log(gtinn * gextid/cifra + $0.05)+$ coopera + factor(year), family = binomial (link = "logit"), data $=$ a)

Deviance Residuals:

$\begin{array}{rrrrr}\text { Min } & 1 Q & \text { Median } & 3 Q & \text { Max } \\ -1.7983 & -0.5050 & -0.4226 & -0.3435 & 2.7032\end{array}$

Coefficients:

\begin{tabular}{|c|c|c|c|c|c|}
\hline \multirow[b]{2}{*}{ (Intercept) } & \\
\hline & -2.11156 & 0.22988 & -9.186 & $<2 e-16$ & $\star \star \star$ \\
\hline $\log ($ tamano) & 0.23811 & 0.03522 & 6.760 & $1.38 e-11$ & $\star \star \star *$ \\
\hline $\log ($ inver/cifra +0.05$)$ & 0.19261 & 0.05867 & 3.283 & 0.001026 & $\star \star$ \\
\hline $\log ($ gtinn * gintid/cifra +0.05$)$ & 0.07088 & 0.03082 & 2.300 & 0.021455 & * \\
\hline $\log ($ gtinn $*$ gextid/cifra +0.05$)$ & 0.13694 & 0.03977 & 3.443 & 0.000574 & $\star \star \star$ \\
\hline coopera & 0.11814 & 0.10025 & 1.179 & 0.238590 & \\
\hline actor (year) 2005 & -0.08068 & 0.17208 & -0.469 & 0.639185 & \\
\hline actor (year) 2006 & -0.14993 & 17578 & -0.853 & 0.393686 & \\
\hline factor (year) 2007 & -0.25728 & 18181 & -1.415 & 0.157035 & \\
\hline factor (year) 2008 & $-0.38 \varepsilon$ & 0.18805 & -2.063 & 0.039079 & * \\
\hline factor (year) 2009 & -0.59950 & 0.20076 & $-2 \cdot 986$ & 0.002825 & $\star \star$ \\
\hline factor (year) 2010 & -0.63990 & 0.20650 & -3.099 & 0.001943 & *夫 \\
\hline factor (year) 2011 & -0.52605 & 0.20885 & -2.519 & 0.011774 & * \\
\hline factor (year) 2012 & -0.83592 & 0.23507 & -3.556 & 0.000376 & $\star \star \star$ \\
\hline
\end{tabular}

(Dispersion parameter for binomial family taken to be 1)

Null deviance: 3389.9 on 5139 degrees of freedom Residual deviance: 3270.6 on 5126 degrees of freedom

(1382 observations deleted due to missingness)

AIC: 3298.6

Number of Fisher Scoring iterations: 5

Generalized linear mixed model fit by maximum likelihood ['glmerMod']

Family: binomial ( logit)

Formula: usomodel log (tamano) + log (inver/cifra + 0.05) + $\log (g \operatorname{tinn} * \quad$ gintid/cifra +0.05$)+\log (g t i n n$ * gextid/cifra + $0.05)+$ coopera + factor (year $)+(1 \mathrm{x}$ ident $)$

Data: a

AIC BIC logLik deviance

$2612.575 \quad 2710.747-1291.288 \quad 2582.575$

Random effects:

Groups Name Variance Std.Dev.

ident (Intercept) $6.131 \quad 2.476$

Number of obs: 5140, groups: ident, 797

Fixed effects:

(Intercept)

$\log ($ tamano)

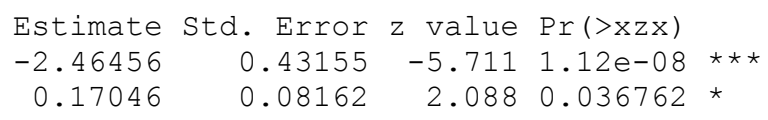


Apéndices

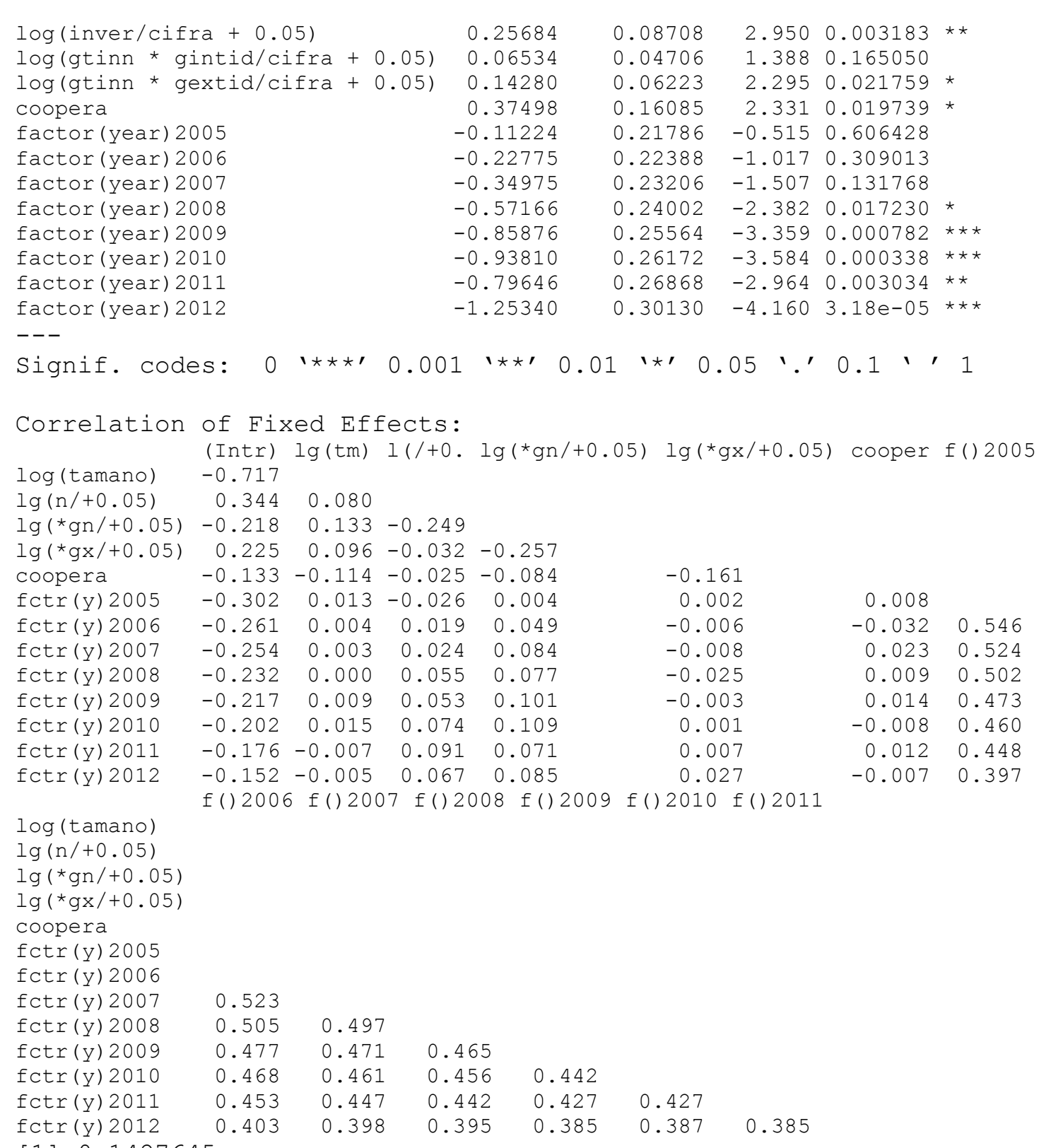

[1] 0.1427645

[1] 0.3231084 


\section{Regresión Logit. TODAS agroalimentarias marcas de fábrica}

Call:

glm(formula = usomarca $\sim \log ($ tamano $)+\log ($ inver/cifra +0.05$)+$ log(gtinn * gintid/cifra + 0.05) + log(gtinn * gextid/cifra + $0.05)+$ coopera + factor(year), family = binomial (link = "logit"), data $=$ a)

Deviance Residuals:

Min $\quad 10$ Median $\quad 3 Q \quad$ Max

$\begin{array}{lllll}-1.7813 & -0.8856 & -0.7272 & 1.3141 & 2.0408\end{array}$

Coefficients:

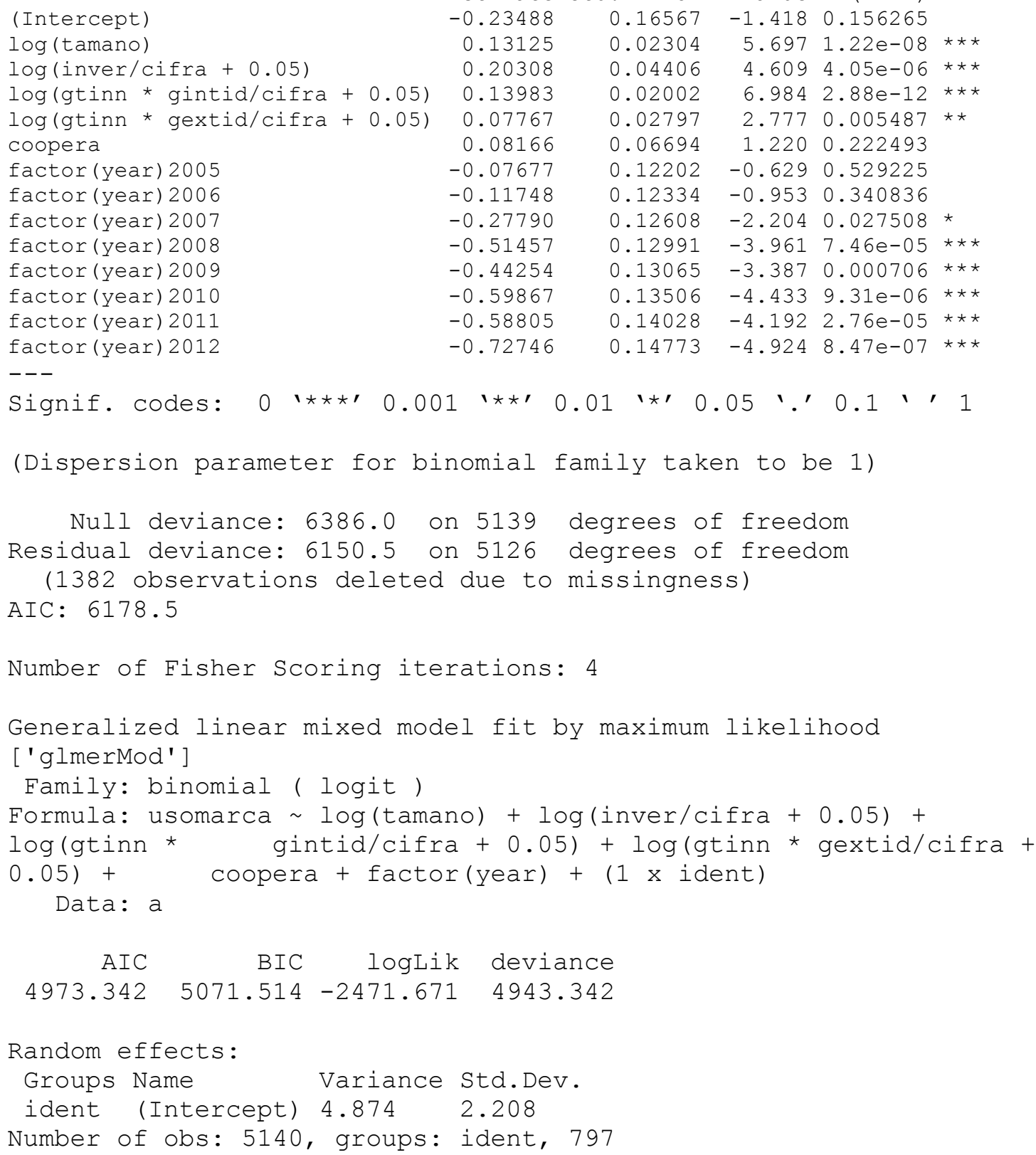

Fixed effects: 


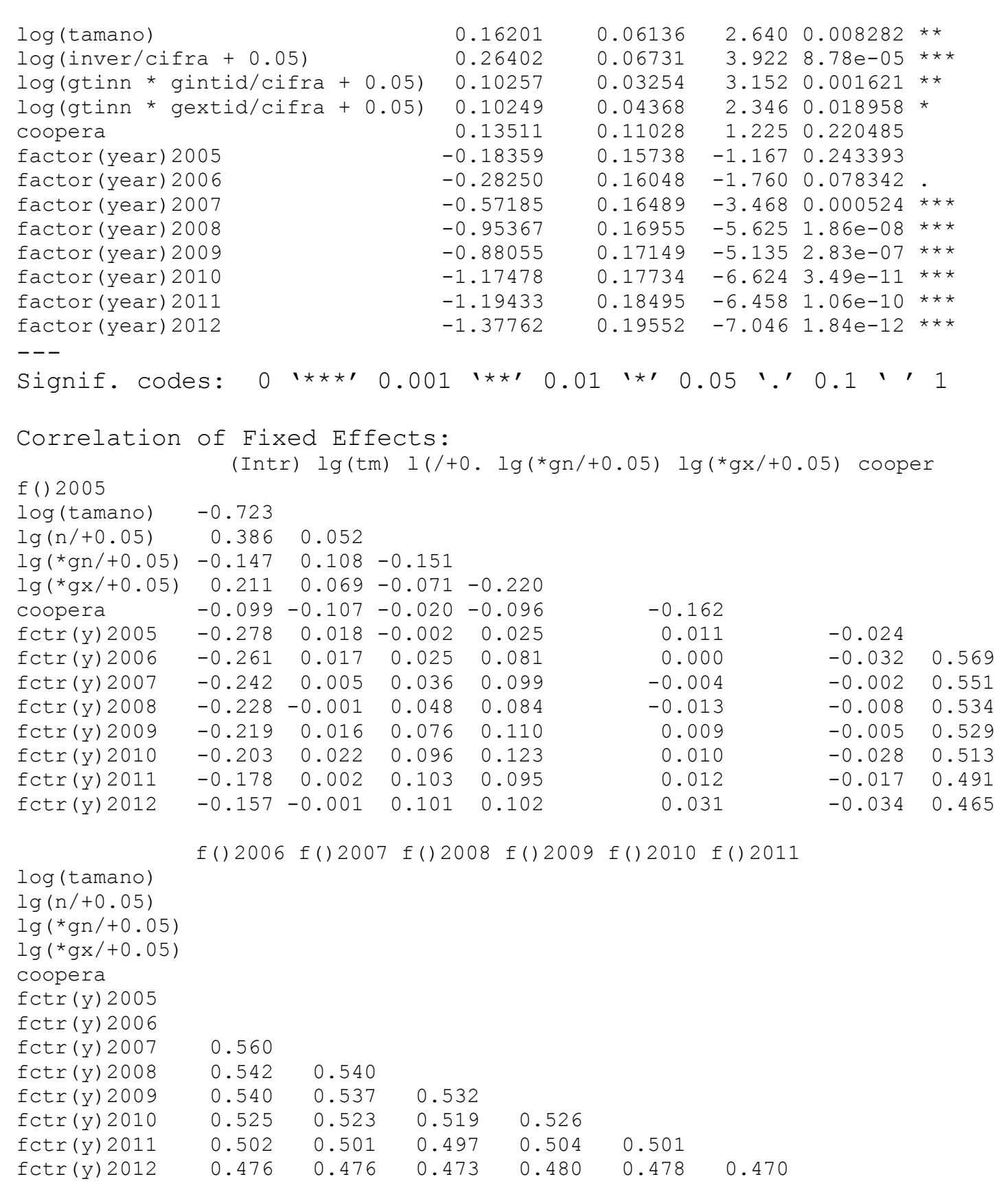

$\begin{array}{ll}\text { [1] } & 0.1879617 \\ \text { [1] } & 0.3473366\end{array}$ 


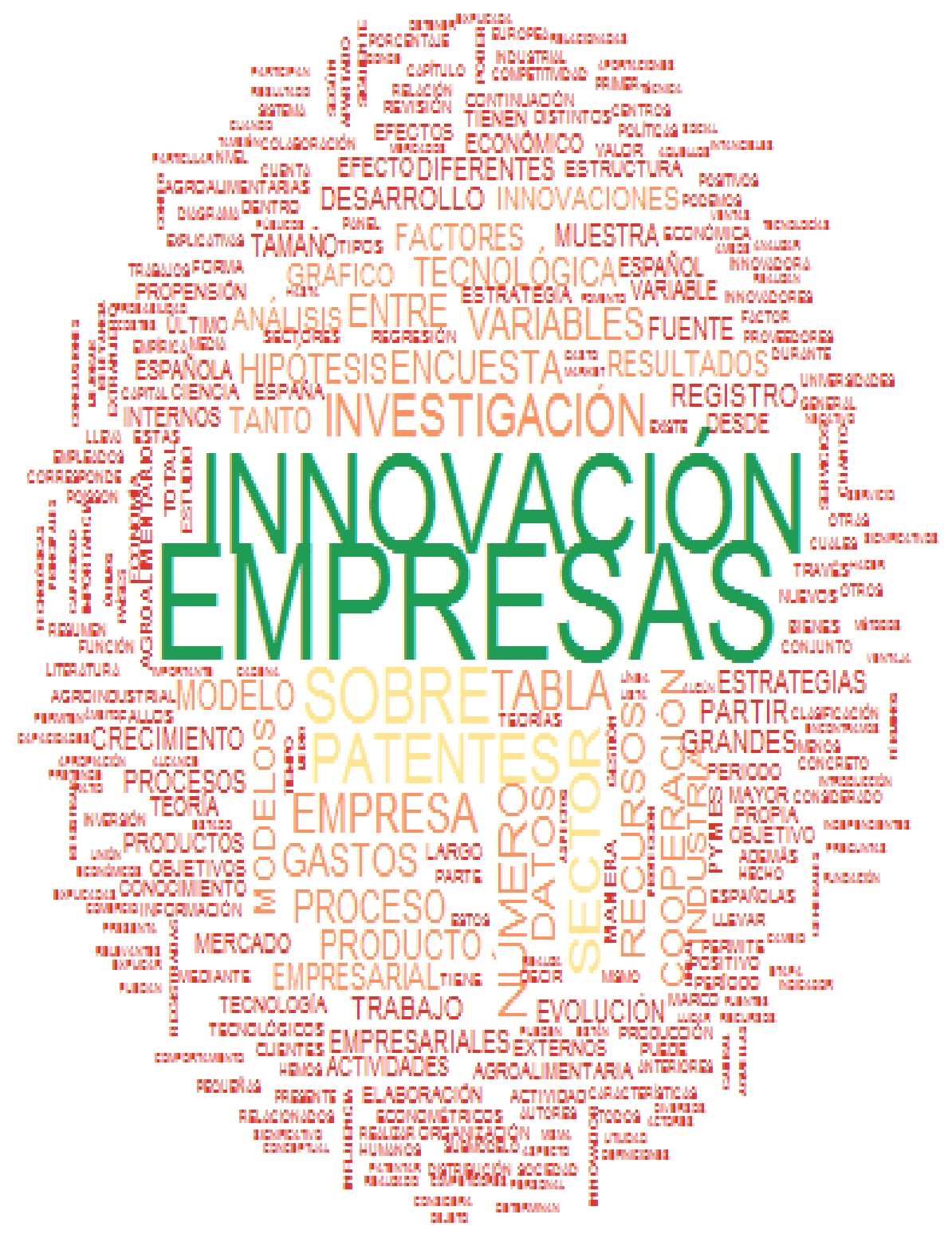

